\title{
CONTROLE GLICÊMICO INTENSIVO VERSUS CONTROLE GLICÊMICO CONVENCIONAL EM \\ PACIENTES PORTADORES DE DIABETES \\ MELITO TIPO II: REVISÃO SISTEMÁTICA E META-ANÁLISE DE ENSAIOS CLÍNICOS \\ RANDOMIZADOS
}

Tese apresentada ao Programa de PósGraduação em Fisiologia e Biofísica do Instituto de Ciências Biomédicas da Universidade de São Paulo, para obtenção do Título de Doutor em Ciências. 


\section{CONTROLE GLICÊMICO INTENSIVO VERSUS \\ CONTROLE GLICÊMICO CONVENCIONAL EM \\ PACIENTES PORTADORES DE DIABETES \\ MELITO TIPO II: REVISÃO SISTEMÁTICA E \\ META-ANÁLISE DE ENSAIOS CLÍNICOS \\ RANDOMIZADOS}

Tese apresentada ao Programa de PósGraduação em Fisiologia e Biofísica do Instituto de Ciências Biomédicas da Universidade de São Paulo, para obtenção do Título de Doutor em Ciências.

Área de concentração: Endocrinologia.

Orientador: Prof. Dr. Silvana Auxiliadora Bordin 
DADOS DE CATALOGAÇÃO NA PUBLICAÇÃO (CIP)

Serviço de Biblioteca e Informação Biomédica do

Instituto de Ciências Biomédicas da Universidade de São Paulo

reprodução não autorizada pelo autor

\section{Buehler, Anna Maria.}

Efeito do controle intensivo de glicemia versus controle convencional em pacientes com Diabetes Mellitus tipo II: uma revisão sistemática com meta-análise de ensaios clínicos randomizados I Anna Maria Buehler. -- São Paulo, 2010.

Orientador: Silvana Auxiliadora Bordin da Silva.

Tese (Doutorado) - Universidade de São Paulo. Instituto de Ciências Biomédicas. Departamento de Fisiologia e Biofísica. Área de concentração: Fisiologia Humana. Linha de pesquisa: Diabetes Melito

Versão do título para o inglês: Effect of intensive glycaemic control versus conventional control in patients with Diabetes Mellitus type II: a systematic review with meta-analysis of randomized controlled trials.

Descritores: 1. Diabetes Mellitus 2. Glicemia (controle) 3. Diabetes Melittus não insulino dependente I. Silva, Silvana Auxiliadora Bordin da II. Universidade de São Paulo. Instituto de Ciências Biomédicas. Programa de Pós-Graduação em Fisiologia e Biofísica. III. Título. 
Candidato(a):

Título da Tese:

Orientador(a):
Anna Maria Buehler.

Controle glicêmico intensivo versus controle glicêmico convencional em pacientes portadores de Diabetes Melito tipo II: revisão sistemática e meta-análise de ensaios clínicos randomizados.

A Comissão Julgadora dos trabalhos de Defesa da Tese de Doutorado, em sessão pública realizada a .... considerou

\section{$\begin{array}{ll}\text { ( ) Aprovado(a) ( ) Reprovado(a) } & \text { (a) }\end{array}$}

\begin{tabular}{|c|c|}
\hline Examinador(a): & $\begin{array}{l}\text { Assinatura: } \\
\text { Nome: ......... } \\
\text { Instituição: . }\end{array}$ \\
\hline Examinador(a): & $\begin{array}{l}\text { Assinatura: } \\
\text { Nome: ......... } \\
\text { Instituição: . }\end{array}$ \\
\hline Examinador(a): & $\begin{array}{l}\text { Assinatura: } \\
\text { Nome: ......... } \\
\text { Instituição: . }\end{array}$ \\
\hline Examinador(a): & $\begin{array}{l}\text { Assinatura: } \\
\text { Nome: ......... } \\
\text { Instituição: . }\end{array}$ \\
\hline Presidente: & $\begin{array}{l}\text { Assinatura: } \\
\text { Nome: ......... } \\
\text { Instituição: . }\end{array}$ \\
\hline
\end{tabular}


Dedico a minha mãe, Hermínia Aparecida Occaso, por nunca abrir mão de tentar me tornar uma pessoa cada dia melhor e fazer questão que eu seja a pessoa mais feliz deste mundo! 


\section{AGRADECIMENTOS}

Agradeço ao meu amado marido, Allan Vila Espejo, pelo amor, compreensão e inesgotável apoio em todas as esferas da minha vida, permitindo que eu tivesse tranqüilidade e concentração necessárias à dedicação ao meu projeto;

Ao meu filho, Allan Vila Buehler, que durante a fase de condução do projeto estava dentro de minha barriga e se comportou exemplarmente, me dando força e incentivo constantes para seguir em frente;

Ao meu chefe, Dr. Otávio Berwanger, pela oportunidade de poder conciliar a obtenção do meu título com as demandas profissionais; e com quem eu aprendi e aprendo muito diariamente.

Ao Dr. Alexandre Biasi Cavalcanti, que foi incansável em me apoiar, orientar e criticar construtivamente meu projeto em todas as etapas; e com quem eu aprendi e aprendo muito diariamente.

A minha orientadora, Prof. Dr. Silvana Bordin, pela compreensão e originalidade em aceitar um projeto que não está diretamente ligado com sua metodologia de pesquisa.

A minha amiga Andrea Divanna, pela surpresa de amizade fiel, que se iniciou na época da condução deste projeto e prosseguirá para sempre.

A minha amiga Lígia Reis que, apesar de mais distante neste momento de minha vida, tenho certeza que estará comigo sempre que eu precisar.

Ao meu pai e irmãos porque simplesmente eu os amo.

A todas as demais pessoas que fazem parte da minha vida e que são diretamente responsáveis por eu me sentir totalmente feliz! 
"Viver é a coisa mais rara do mundo.

A maioria das pessoas apenas existe."

Oscar Wilde 


\section{RESUMO}

Buehler AM. Efeito do controle intensivo de glicemia versus controle convencional em pacientes com Diabetes Mellitus tipo II: uma revisão sistemática com meta-análise de ensaios clínicos randomizados. [tese (Doutorado em Fisiologia e Biofísica)]. São Paulo: Instituto de Ciências Biomédicas da Universidade de São Paulo; 2010.

Dados de ensaios clínicos randomizados que incluíram grande número de pacientes ja demostraram que o controle mais intensivo do diabetes diminui o risco de eventos microvasculares em pacientes com diabetes melito tipo 1 e tipo 2 diabetes. No entanto, o quanto o controle intensivo da glicose reduz eventos cardiovasculares e mortalidade total é incerto. Nós sumarizamos os efeitos clínicos do controle intensivo da glicemia versus controle convencinal em pacientes com diabetes tipo 2. Pesquisamos sistematicamente as principais bases de dados eletrônicos Medline, Embase, Cochrane Library e ISI do Knowledge, sem utilizar limites de linguagem e sem limitar por período. Dois revisores independentes triaram os artigos por título e resumos e textos completos para inclusão de ensaios clínicos randomizados que incluiram pacientes com diabetes tipo 2 e que visavam dois níveis de intensidade da glicemia bem definidos por um período de seguimento de, pelo menos, um ano. Nós investigamos os eventos microvasculares (retinopatia, deteriorização visual, neuropatias, nefropatias), eventos cardiovasculares (mortalidade cardiocascular, infarto do miocárdio (IAM) não-fatal, acidente vascular cerebral não fatal e amputação de membros), todas as causas de mortalidade e de episódios de hipoglicemia. Utilizamos o modelo de efeitos aleatórios de meta-análise para obter o risco relativo (RR) como estimativa de efeito e avaliados heterogeneidade estatística entre os ensaios utilizando a estatística $\mathrm{I}^{2}$. Foram incluídos sete estudos envolvendo 27.814 pacientes. Em relação aos eventos cardiovasculares, o controle intensivo da glicemia reduziu o risco relativo de IAM não-fatais em 17\% [RR 0,83 IC95\% (0,71-0,97)] e amputação do membro em 36\% [RR 0,64 IC95\% (0,430,96)]. Para eventos microvasculares, o controle intensivo da glicemia reduziu o risco relativo de progressão da retinopatia em $20 \%$ [RR 0,80 IC 95\% $(0,71-0,91)]$, a incidência de neuropatia periférica em $6 \%$ [RR 0,94 IC 95\% $(0,89-0,99)$ ], a incidência de nefropatia em 35\% [RR 0,65 $95 \%$ IC $(0,43-0,98)$ ], a progressão da nefropatia em 
45\% [RR $0.5595 \%$ IC $(0,37-0,80)$ ] e a incidência de em $22 \%$ [microalbuminúria RR 0,78 IC 95\% (0,65- 0,92)]. Em relação aos eventos hipoglicêmicos, o controle intensivo da glicemia aumentou o risco de episódios severos de hipoglicemia em 97\% [RR 1,97 IC 95\% (1,33-2,92)]. Não houve diferenças entre o controle glicêmico intensivo e convencional em relação à mortalidade total, mortalidade cardiovascular e outros resultados. Conclui-se que controle intensivo da glicose reduziu o risco de alguns eventos micro e macrovasculares, sem redução na mortalidade geral e mortalidade cardiovascular, porém as custas do dobro da incidência de episódios severos de hipoglicemia

Palavras-chave: Diabetes melito tipo II. Doenças cardiovasculares. Glicemia. Revisão sistemática. Meta-análise. 


\begin{abstract}
Buehler AM. Effect of intensive glycaemic control versus conventional control in patients with Diabetes Mellitus type II: A systematic review with meta-analysis of randomized controlled trials [Ph.D. thesis (Physiology and Biophysics)]. São Paulo: Instituto de Ciências Biomédicas da Universidade de São Paulo; 2010.
\end{abstract}

Data of larger clinical trials have showed more intensive diabetes control prevents microvascular events with both type 1 and type 2 diabetes. However whether intensive control of glucose reduces cardiovascular events and total mortality is conflicting. We summarize clinical effects of intensive versus conventional glucose control in patients with type 2 diabetes. So, we systematically searched the main electronic data bases Medline, Embase, Cochrane Library and ISI of Knowledge with no limits of language and time. Two independents reviewers screened title and abstracts and full-text articles to include randomized controlled trials with type 2 diabetes patients which aimed two levels of intensity glycemic and a follow-up period for at least one year. We investigated microvascular events (retinopathies, visual deteriorization, neuropathies, and nephropathies), cardiovascular events (cardiocascular mortality, non-fatal myocardial infarction (MI), non-fatal stroke and limb amputation), all-cause mortality and hypoglycemic episodes. We used a random-effects meta-analysis to obtain a relative risk (RR) effects estimates and assessed statistical heterogeneity across trials using $\mathrm{I}^{2}$ statistics. We included 7 trials involving 27,814 patients. For cardiovascular events, intensive glucose control reduced the relative risk for non-fatal MI in $17 \%$ [RR $0.8395 \%$ CI (0.71-0.97)] and limb amputation in 36\% [RR $0.6495 \%$ CI (0.43-0.96)]. For microvascular events, intensive glucose control reduced the risk progression of retinopathy [RR $0.8095 \%$ IC (0.71-0.91)], incidence of peripheral neuropathy [RR 0.94 95\% IC (0.89-0.99)], incidence of nephropathy [RR 0.65 95\% CI (0.43-0.98)], progression of nephropathy [RR $0.55 \quad 95 \%$ IC $\quad(0.37-0.80)]$ and incidence of microalbuminuria [RR 0.78 95\% IC (0.65-0.92)]. Related to hypoglycemic events, intensive glucose control rises the risk of major hypoglycemic episodes up to $97 \%$ [RR 1,97 95\% IC (1.33-2.92)]. There were no differences between intensive and conventional glucose control regarding all causes of mortality, cardiovascular mortality and others 
outcomes. We have concluded that Intensive glucose control reduced the risk for some macrovascular and microvascular events, without reduction on all-cause mortality and cardiovascular mortality. Also, it increases the risk for major hypoglycemic episodes.

Key Words: Diabetes mellitus type II. Cardiovascular diseases. Glycemia. Systematic review. Meta-analysis. 


\section{LISTA DE ABREVIATURAS}

$\%$

AAS

AVC

CV

DAC

DAG

DAP

DCV

DE

DM

DMII

ECR

GLUT4

IAM

IC

ICC

IECA

IMC

Kg

LDL

mmHg

NNT

NO

NOs

OMS

OR

PAI-1

PICO

PKC

RAR

RR

RRR
Percentual

Ácido Acetilsalicílico

Acidente Vascular Cerebral

Cardiovascular

Doença Arterial Coronariana

Diacilglicerol

Doença Arterial Periférica

Doenças Cardiovasculares

Disfunção endotelial

Diabetes melito

Diabetes melito tipo II

Ensaios Clínicos Randomizados

Glucose transporter type 4

Infarto Agudo do Miocárdio

Intervalo de Confiança

Insuficiência Cardíaca congestiva

Inibidores da Enzima conversora de angiotensina

Índice de massa corporal

Kilogramas

Low density lipoprotein

Milímetros de mercúrio

Número necessário para tratar

Óxido nítrico

Óxido nítrico sintetase

Organização Mundial da Saúde

Odds ratio

Inibidor do ativador de plasminogênio

Paciente, intervenção, controle, desfecho

Proteína cinase $\mathrm{C}$

Redução do risco absoluto

Risco relativo

Redução do risco relativo 


\section{LISTA DE FIGURAS}

Figura 1 - Fluxo de seleção dos artigos incluídos.

Figura 2 - Controle intensivo da glicemia versus convencional no risco de mortalidade total em pacientes com DM I

Figura 3 - Controle intensivo versus convencional da glicemia no risco de mortalidade cardiovascular em pacientes com DM.

Figura 4 - Controle intensivo versus convencional de glicemia sobre Infarto Agudo do Miocárdio não-fatal em pacientes com DMII.

Figura 5 - Controle intensivo versus convencional da glicemia sobre Acidente Vascular Cerebral não-fatal em pacientes com DMII.

Figura 6 - Controle intensivo versus convencional da glicemia sobre amputação de membros em pacientes com DMII

Figura 7 - Controle intensivo versus convencional de glicemia sobre desfecho combinado macrovascular em pacientes com DMII.

Figura 8 - Controle intensivo versus convencional de glicemia sobre retinopatias em pacientes com DMII

Figura 9 - Controle intensivo versus convencional da glicemia sobre retinopatias em pacientes com DMII.

Figura 10 - Controle intensivo versus convencional da glicemia sobre desfechos combinados de retinopatias em pacientes com DMII.

Figura 11 - Controle intensivo versus convencional da glicemia sobre deterioração visual em pacientes com DMII. 60

Figura 12 - Controle intensivo versus convencional da glicemia sobre neuropatias em pacientes com DMII 63

Figura 13 - Controle intensivo versus convencional da glicemia sobre nefropatias em pacientes com DMII

Figura 14 - Controle intensivo versus convencional da glicemia sobre desfecho combinado microvascular em pacientes com DMII.

Figura 15 - Controle intensivo versus convencional da glicemia sobre hipoglicemia em pacientes com DMII 70 


\section{LISTA DE QUADRO}

Quadro 1 - Duplas de revisores e estudos para extração de dados. 34 


\section{LISTA DE TABELAS}

Tabela 1 - Características de base dos pacientes nos estudos. ............................... 36

Tabela 2 - Pacientes randomizados e perdas de seguimento. ....................................... 37

Tabela 3 - Controle de glicemia de base: ........................................................................ 39

Tabela 4 - Controle de glicemia após seguimento:.................................................. 39

Tabela 5 - Alvos e parâmetros glicêmicos de controle intensivo e convencional: .. 41

Tabela 6 - Intervenções no grupo controle intensivo e controle convencional nos

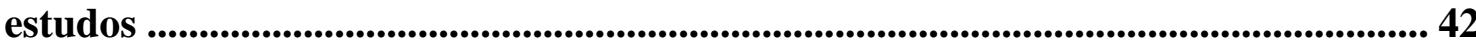

Continua: Tabela 6 - Intervenções no grupo controle intensivo e controle convencional nos estudos ....................................................................................... 43

Tabela 7 - Características metodológicas dos estudos incluídos: ............................... 45

Tabela 8- Qualidade da evidência - Análises no GRADEprofiler ............................ 75 


\section{SUMÁRIO}

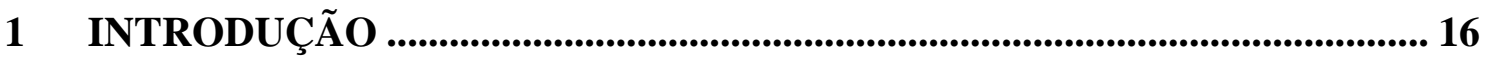

1.1 Diabetes melito tipo II: prevalência e incidência ......................................... 16

1.2 Revisão de literatura ....................................................................................................... 17

1.2.1 Fisiopatologia do diabetes melito tipo II ............................................. 17

1.2.2 Diabetes melito Tipo II e doenças cardiovasculares ................................. 20

1.3 Justificativa da revisão sistemática ..................................................... 23

2 OBJETIVOS ................................................................................................................... 25

3 METODOLOGIA................................................................................................... 26

3.1 Definições dos critérios de elegibilidade ........................................................ 26

3.2 Bases eletrônicas de dados pesquisadas....................................................... 27

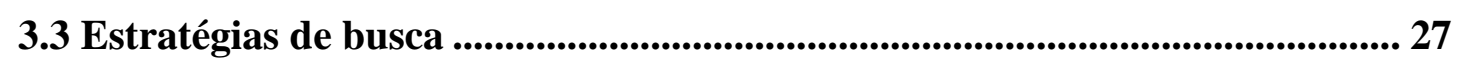

3.4 Avaliação de artigos duplicados na base ................................................................ 27

3.5 Avaliação da elegibilidade ........................................................................ 28

3.6 Avaliação de artigos com textos completos (FULL TEXT) ............................ 28

3.7 Extração de dados................................................................................................... 29

3.8 Plano de análises estatísticas da revisão sistemática ...................................... 29

3.9 Avaliação da qualidade da evidência gerada pela meta-análise ....................... 30

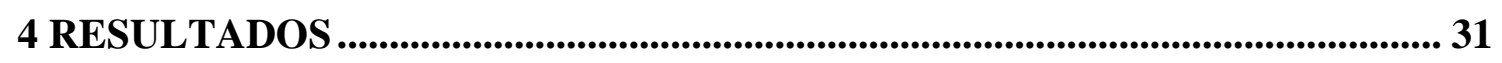

4.1 Resultado da estratégia de busca ...................................................................... 31

4.2 Avaliação da elegibilidade ................................................................................ 31

4.2.1 Artigos em língua não inglesa.............................................................33

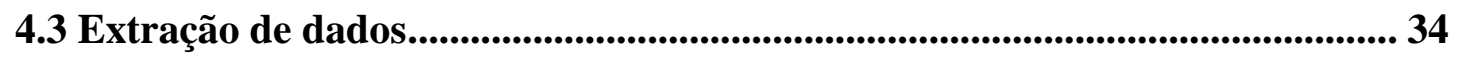

4.4 Resultados da meta-análise................................................................................ 34

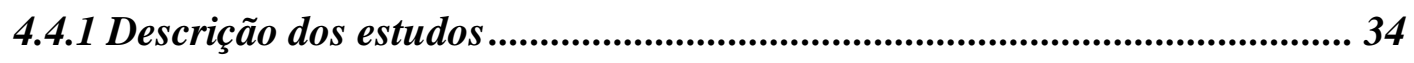

4.4.1.1 Características de Base dos Pacientes nos Estudos ............................... 34

4.4.1.2 Tempo de seguimento, número de pacientes randomizados nos estudos e

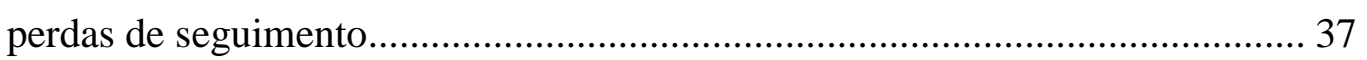

4.4.1.3 Controle glicêmico de base e pós-intervenção ....................................... 38

4.4.1.4 Alvos Glicêmicos e Definições de Intervenção, controle e desfechos

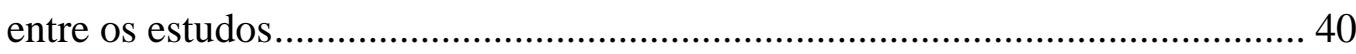


4.4.2 Risco de Vieses nos Estudos Incluídos ............................................................. 44

4.4.3 Avaliação dos Desfechos Macrovasculares .................................................. 46

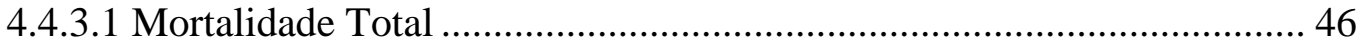

4.4.3.2 Mortalidade Cardiovascular .................................................................. 46

4.4.3.3 Infarto Agudo do Miocárdio (IAM) Não Fatal....................................... 48

4.4.3.4 Acidente Vascular Cerebral (AVC) Não Fatal ...................................... 48

4.4.3.5 Amputação de Membros....................................................................... 50

4.4.3.6 Desfechos Combinados Macrovasculares ............................................ 50

4.4.4 Desfechos Microvasculares ......................................................................5 53

4.4.4.1 Retinopatias .................................................................................................... 53

4.4.4.1.1 Incidência e progressão................................................................. 53

4.4.4.1.2 Progressão para maculopatia, retinopatia proliferativa, fotocoagulação retinal, hemorragia vítrea e extração de catarata ................ 56

4.4.4.1.3 Desfechos combinados de retinopatia ........................................... 58

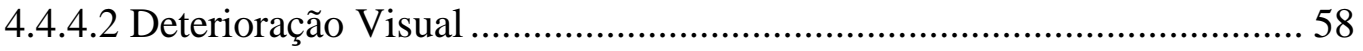

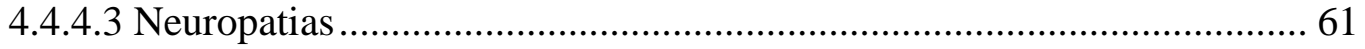

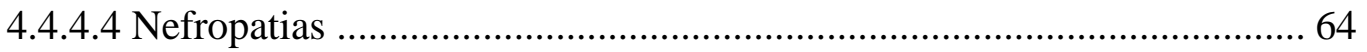

4.4.4.5 Desfecho Combinado Microvascular ...................................................... 67

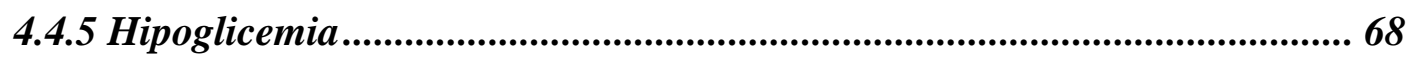

4.4.6 Análises de Sensibilidade ............................................................................ 71

4.4.7 Qualidade da Evidência..................................................................................... 73

5 DISCUSSÃO

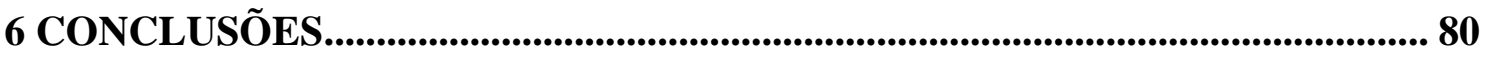

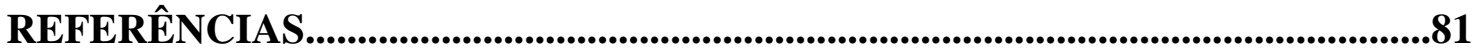

APÊNDICE A - METODOLOGIA DAS REVISÕES SISTEMÁTICAS E META-

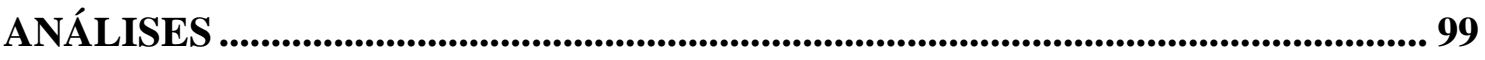

1.0 Definição......................................................................................................................... 99

1.1 Diferenças entre revisões sistemáticas e revisões narrativas ............................. 99

1.2 Princípios e Procedimentos para Revisões Sistemáticas ................................ 100

1.2.1 Elaboração da Questão de Revisão........................................................... 100

1.2.2 Definição dos Critérios de Elegibilidade ................................................ 100

1.2.3 Base de dados para busca e identificação dos potenciais estudos incluídos 
1.2.4 Seleção dos estudos, acesso a qualidade metodológica e extração de dados 102

1.2.5 Padronização das medidas de desfecho e apresentação dos resultados .. 105

1.2.6 Heterogeneidade entre os resultados dos estudos...................................... 107

1.2.7 Métodos para estimar o efeito combinado dos estudos elegíveis ............. 108

1.2.8 Avaliação da qualidade da Evidência ...................................................... 109

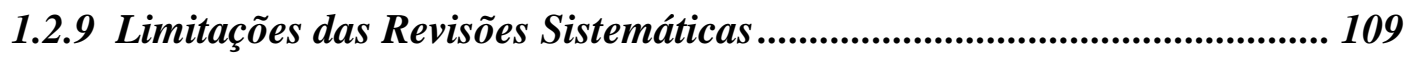

APÊNDICE B - ESTRATÉGIA DETALHADA DE BUSCA ................................... 111

APÊNDICE C - FORMULÁRIO DE AVALIAÇÃO DE ELEGIBILIDADE..... 117

APÊNDICE D - FORMULÁRIO DE EXTRAÇÃO DE DADOS ............................ 119

Results: (absolute number of events/total of participants in the group) ............... 140

APÊNDICE E - PLANILHA DE CONTROLE DE REFERÊNCIAS E

AVALIAÇÃO DA ELEGIBILIDADE ................................................................. 144

ANEXO A - CORRESPONDÊNCIAS COM AUTORES DOS ENSAIOS

CLÍNICOS RANDOMIZADOS. 168 


\section{INTRODUÇÃO}

\subsection{Diabetes melito tipo II: prevalência e incidência}

O Diabetes melito tipo II é uma das doenças crônico-degenerativas de maior prevalência (1). Além disto, o número de pessoas com diabetes está aumentando devido ao crescimento populacional, maior expectativa de vida, urbanização, aumento na prevalência de obesidade e inatividade física (2).

Segundo a Organização Mundial da Saúde, em 2000, havia 171 milhões de pessoas em todo o mundo com Diabetes. Destas, mais de $90 \%$ são portadoras de Diabetes melito tipo II. A projeção é que o número de pessoas com diabetes irá mais do que dobrar nos próximos 25 anos, alcançando o total de 366 milhões em 2030 (1). A maioria desta população é proveniente de países em desenvolvimento e esta projeção pode estar subestimada, dado o aumento na prevalência da obesidade nestes países.

Nos Estados Unidos da América 23.6 milhões de pessoas são portadoras de diabetes melito e apenas em 2005 a prevalência aumentou 13,5\% (3). Em 2007 ocorreram 1.6 milhões de novos casos em pessoas com idade superior a 20 anos.

O Brasil ocupa o $8^{\circ}$ lugar nos países com maior número de pessoas com diabetes melito, com 4,6 milhões de pessoas portadoras (dados de 2000) (4,5).

O diabetes melito aumenta a incidência e acelera o curso de inúmeras doenças cardiovasculares. O risco de desenvolver doença arterial coronariana em diabéticos é duas a quatro vezes o risco de não-diabéticos (6). Dados de um estudo de coorte (7) demonstram que a incidência de infarto do miocárdio em sete anos foi de $20 \%$ entre diabéticos, comparado com 3,5\% em não diabéticos e que os pacientes portadores de diabetes sem infarto prévio tinham o mesmo risco de um evento coronariano agudo subsequiente que os pacientes não diabéticos com história de infarto prévio.

No Registro OASIS (8), um estudo de 6 nações sobre angina instável e infarto do miocárdio sem onda $\mathrm{Q}$, o diabetes aumentou independentemente o risco de morte em 57\%. Ainda, a mortalidade em 5 anos após infarto do miocárdio foi de $50 \%$ em pacientes diabéticos, mais que o dobro do que em pacientes não-diabéticos (9).

Evidências epidemiológicas confirmam a associação entre diabetes e aumento da prevalência de doença arterial periférica (DAP). Indivíduos com diabetes têm risco aumentado de 2 a 4 vezes para DAP (10) e índices anormais tornozelo-braquial 
variando 17até $16,0 \%$ (valores normais 0,91 a 1,30) (11). A duração e severidade da diabetes correlacionam com a incidência e extensão da DAP (12). Ainda, pacientes com diabetes mais comumente desenvolvem formas sintomáticas de DAP, claudicação intermitente e amputação (13). Na coorte de Framingham (14), a presença de diabetes aumentou o risco para claudicação em 3,5 vezes em homens e 8,6 vezes em mulheres.

Diabetes afeta adversamente a circulação arterial cerebrovascular, similarmente aos efeitos na vasculatura coronária e periférica. O risco de acidente vascular cerebral (AVC) aumenta $150 \%$ a $400 \%$ em pacientes com diabetes $(15,16)$ e um controle não adequado de glicemia está diretamente relacionado com o aumento do risco para AVC. No estudo MRFIT (17) que incluiu 347.978 homens, os que tomavam medicações para diabetes tiveram 3 vezes mais chance de desenvolverem AVC $(p=0,01)$. O diabetes também afeta o prognóstico do AVC. Aumenta o risco de demência em mais de 3 vezes (18), dobra o risco de recorrência de AVC (19) e aumenta a letalidade (20).

\subsection{Revisão de literatura}

\subsubsection{Fisiopatologia do diabetes melito tipo II}

O diabetes melito tipo II é uma doença crônico-degenerativa, multifatorial. Comumente, é caracterizada pela combinação de resistência insulínica, hiperglicemia e falência das células beta-pancreáticas, responsáveis pela produção e secreção de insulina (21).

Resistência insulínica é definida como uma diminuição de resposta da célula alvo às concentrações de insulina que são expostas (22). É mais comumente evidenciada em musculatura esquelética, tecido adiposo e fígado. O prejuízo da sensibilidade insulínica compromete sua atividade de maneira distinta em cada órgão ou tecido. Na musculatura esquelética acarreta diminuição da captação da glicose circulante por estas células pela diminuição da translocação do transportador de glicose GLUT4 para a membrana celular. Esta translocação é realizada mediante ativação da via de sinalização da insulina nestas células, que está comprometida com a resistência (23). No fígado, a insulina diminui a liberação de glicose, por inibir a glicogenólise e a expressão de enzimaschaves da gliconeogênese. Na resistência à insulina, ocorre, portanto, uma constante liberação de glicose do fígado para a circulação, decorrente desta quebra de glicogênio 
hepático (24), que contribui para a hiperglicemia no diabético. No tecido adiposo, a insulina inibe a lipólise diminuindo a atividade do lipase hormônio sensível. Com a resistência à insulina, aumenta a liberação de ácidos graxos livres na circulação, levando à perda de homeostase lipídica, disfunção de produção e secreção de inúmeros hormônios e adipocinas, que contribui para um estado inflamatório sistêmico (25).

As causas da resistência insulínica podem ser genéticas e/ou adquiridas. As causas genéticas ou predisposições são pouco compreendidas, mas ilustradas por alguns achados. Evidências apontam para um metabolismo glicêmico não-oxidativo reduzido em musculatura esquelética, associados com uma redução de formação de glicogênio muscular, em filhos de pais diabéticos (26). Também pode haver o comprometimento genético de proteínas importantes na cascata de sinalização da insulina, prejudicando a ação da insulina nos tecidos (27). Mesmo assim, qualquer componente genético deve interagir com fatores ambientais para que o desenvolvimento da resistência insulínica possa evoluir para a condição patológica. Em sociedades ocidentais, os fatores de risco mais comuns de diabetes melito tipo II são a obesidade, sedentarismo e idade, todas estas geralmente associadas entre si (28).

A disfunção do sistema adiposo ocasionada pela obesidade parece ser a gênese da resistência insulínica. A obesidade é um processo crônico, acarretado pelo constante balanço energético positivo, caracterizado pela ingestão excessiva de nutrientes e/ou pouco gasto energético. Indivíduos obesos são caracterizados por um maior fluxo de quebra de triglicérides e liberação, de ácidos graxos livres, e estes são importantes mediadores da resistência insulínica (29). A perda de peso diminui este fluxo de ácidos graxos e melhora a sensibilidade à insulina (30).

O processo de aquisição de peso acontece paralelamente à hiper-funcionalidade das células beta-pancreáticas, que respondem ao excesso de nutrientes circulantes com um aumento na liberação de insulina. Em um primeiro momento, esta resposta compensatória de liberação exacerbada de insulina consegue manter os níveis de glicose em seu patamar normal. Entretanto, dada a constância do estímulo, este mecanismo compensatório não consegue se sustentar, pois os tecidos se tornam resistentes à ação da insulina, mesmo em concentrações anormalmente elevadas (31). O estímulo constante e a maior produção e liberação de insulina, alteram o padrão secretório das células betapancreáticas, levando à sua falência, estabelecendo a intolerância à glicose, e consequiente progressão para o diabetes (32). A hiperglicemia, por si só, já é tóxica para 
as células beta pancreáticas, levando à sua morte por estresse oxidativo (33). Entretanto, é necessário considerar que evidências experimentais (34) sugerem que ratos homozigóticos para o gene db desenvolvem diabetes com severo dano nas $\beta$ - células. Ainda, a proporção de $\beta$ - células diminui com a idade neste genótipo, mas não em ratos não diabéticos $\mathrm{db} / \mathrm{m}$ e $\mathrm{m} / \mathrm{m}$. O conteúdo de insulina nas ilhotas é menor, mas o conteúdo de triglicérides foi maior nos db/db que nos demais genótipos. A expressão do perfil do gene específico da célula de ilhota, analisado por micro dissecção e achados morfológicos, sugerem um aumento de apoptose nas $\beta$ - células, estresse oxidativo e estresse de retículo em ratos $\mathrm{db} / \mathrm{db}$. Adicionalmente, houve um aumento na expressão genética de insulina I e II, fator bcl-2 anti-apoptótico e ERK-1 em ratos db/m, sugerindo que heterozigotos para $\mathrm{db}$, mas não homozigotos, adquirem um mecanismo compensatório supressor de apoptose de células $\beta$ - pancreáticas, aumentando a capacidade da função destas células (34).

Com o aumento do fluxo de ácidos graxos livres circulantes, a musculatura esquelética e fígado não conseguem metabolizar por completo a excessiva quantidade de ácidos graxos captados por estas células. Isto leva a acumulação intracelular de intermediários metabólicos destes ácidos graxos (DAG, ceramidas, acilcarnitinas), que se acumulam na musculatura esquelética e fígado e regulam negativamente a ação da insulina, por ativarem inúmeras serina cinases, incluindo JNK1, IKK $\beta$ e PKC- $\theta$ (35). A ativação destas serinas cinases é significante porque estas representam a ligação potencial entre obesidade, inflamação e regulação negativa da ação da insulina (36).

O excesso de ácidos graxos circulantes e conseqüente hiperplasia das células adiposas levam à morte dos adipócitos, via comprometimento da oxigenação (hipóxia) e estresse de retículo $(37,38)$. Um possível mecanismo seria via ativação da via JNK1 e IKK/NF- $\kappa \beta$, ativado pela hipóxia, que aumentam a expressão de genes envolvidos na inflamação e estresse de retículo endoplasmático. A ativação destas vias leva a liberação de quimiocinas e subseqüente recrutamento e ativação dos macrófagos circulantes (ação parácrina). Via ciclo de retroalimentação, estes macrófagos promovem o recrutamento e infiltração de macrófagos adicionais da medula no tecido adiposo, com maior liberação de citocinas inflamatórias e uma resposta mais efetiva, terminando com morte das células adiposas. Estes efeitos parecem ser mais pronunciados no tecido adiposo visceral do que no tecido adiposo subcutâneo e compromete a sensibilidade dos tecidos à insulina (39). 
A resistência insulínica sistêmica é um processo complexo, que reflete a interação de múltiplos órgãos e sistemas e uma variedade de sobreposições, mas mecanisticamente distintas, de vias de sinalização e metabolismo. Também se deve dar atenção aos fatores genéticos, mencionados anteriormente, e do papel do sistema nervoso central coordenando todos os sistemas. A resistência insulínica é o maior preditor do desenvolvimento da diabetes tipo II e este processo precede a hiperglicemia.

\subsubsection{Diabetes melito Tipo II e doenças cardiovasculares}

O estado metabólico anormal que acompanha o diabetes melito causa disfunção arterial. Anormalidades relevantes incluem hiperglicemia crônica, dislipidemia e resistência insulínica. Estes fatores tornam as artérias susceptíveis à aterosclerose. $\mathrm{O}$ diabetes altera a função de múltiplos tipos de células, incluindo o endotélio, células musculares lisas e plaquetas, indicando a extensão da disfunção vascular nesta doença (40).

Uma única camada de células endoteliais recobre a camada interna de todos os vasos sanguíneos, promovendo uma interface metabolicamente ativa entre o sangue e tecido que modula o fluxo sanguíneo, absorção de nutrientes, coagulação e trombose e a diapedése leucocitária (41) Além disso, sintetiza importantes substâncias bioativas, incluindo óxido nítrico e outras espécies reativas do oxigênio, prostaglandinas, endotelina e angiotensina II, que regulam as funções dos vasos sanguíneos e sua estrutura. Todas estas propriedades inibem o processo aterosclerótico e protegem os vasos sanguíneos de sofrerem as lesões características desta doença.

A relação entre diabetes melito e doenças micro e macrovasculares tem sido atribuída à associação entre hiperglicemia, inflamação crônica e disfunção endotelial (DE) (42) O diabetes melito (DM) acarreta disfunção endotelial por prejudicar, por vários mecanismos, o sistema de vasodilatação endotélio-dependente mediado por óxido nítrico (NO), antes da formação do ateroma (43).

Em condições normais, o NO é produzido pela óxido nítrico-sintase endotelial (eNOS), que é uma NOS constitutiva e produz NO em endotélio vascular sob condições basais. O óxido nítrico é um potente vasodilatador e é o principal mediador endotelial do relaxamento vascular (44). Ainda, ele inibe a ativação plaquetária (adesão e agregação), limita a resposta inflamatória, por reduzir a migração e adesão leucocitária no endotélio, inibe a síntese de DNA, mitogênese e a proliferação de células da 
musculatura lisa vascular (45), além de ser responsável pela regulação da pressão sangüínea e contratilidade do músculo cardíaco (46).

A hiperglicemia crônica aumenta a expressão da eNOS e a liberação de NO (47). Contudo, ocorre aumento concomitante do radical superóxido, um potente oxidante. Estes ânions inativam o NO e levam à produção de peroxinitrito (ONOO-) que apresenta ação citotóxica, oxidando o cofator para produção de NO, tetrahidrobiopterina e promovendo também a produção de superóxido, em vez de NO. A oxidação da tetrahidrobiopterina leva ao desacoplamento da eNOS. O desacoplamento é uma situação em que a transferência de elétrons na cadeia oxidativa não se completa adequadamente. Os elétrons se desprendem de suas camadas energéticas e são captados pelo oxigênio molecular, gerando mais radicais livres. O desacoplamento da eNOS é, portanto, um importante mecanismo inicial de DE(48,49).

A produção de óxido nítrico prejudicada pela formação de espécies reativas do oxigênio também é atribuída ao aumento no fluxo de ácidos graxos do tecido adiposo decorrente da resistência insulínica neste tecido. Estes ácidos graxos ativam a enzima sinalizadora proteína cinase $\mathrm{C}$, que por sua vez induz a síntese da enzima NADPH oxidase, que também contribui para produção de superóxido. Também inibem a PI-3 cinase, que é uma importante enzima da via eNOS (50).

Ainda, o estado diabético aumenta a produção de vasoconstritores, principalmente a endotelina-1, que ativa os receptores de endotelina-A na musculatura lisa, induzindo vasoconstrição, além de induzir a hipertrofia da musculatura lisa vascular e aumentar a retenção renal de sal e água, estimulando o sistema renina-angiotensina (51), com o consequiente aumento do vasoconstritor angiotensina II (52). Vale ressaltar que a própria disfunção do tecido adiposo culmina com a maior produção de angiotensinogênio, angiotensina II e renina, além do aumento da atividade da enzima conversora de angiotensina II, que aumenta a pressão arterial (53). A angiotensina II parece prejudicar a sinalização intracelular da insulina similarmente ao TNF- $\alpha$ e aos ácidos graxos livres levando a redução na captação de glicose e contribuindo para o estado hiperglicêmico (54).

A hiperglicemia gera glicação de inúmeras substâncias, que ativam receptores celulares e aumentam a ativação do fator nuclear de transcrição $\beta$ e proteína 1 ativada. Estes fatores regulam a expressão de genes codificadores de inúmeros mediadores de aterosclerose, como, por exemplo, moléculas de adesão da superfície endotelial para 
células leucocitárias, quimiocinas recrutantes de leucócitos para a parede vascular e mediadores pro inflamatórios encontrados no ateroma, incluindo IL-1 e TNF- $\alpha .(55,56)$. Anormalidade lipídicas comumente encontradas em diabéticos e o excesso de ácidos graxos livres na circulação também aumentam o fator nuclear de transcrição $\beta$, com a subseqüente expressão de citocinas e moléculas de adesão celular (57).

O colágeno confere estabilidade mecânica às placas fibrosas formadas. Algumas destas citocinas prejudicam a síntese de novo de colágeno pelas células musculares lisas vasculares, podendo levar a uma ruptura precoce destas placas, desencadeando a formação de trombos (58).

Lesões ateroscleróticas avançadas em pacientes diabéticos possuem menor quantidade de células de musculatura lisa vascular quando comparadas com os controles (59). Em parte, esta deficiência pode ser atribuída ao diabetes, já que a hiperglicemia glica resíduos no LDL- colesterol, que induz apoptose nestas células musculares lisas (60).

O potencial trombótico ocasionado pelo diabetes melito envolve uma série de mecanismos. As plaquetas estão diretamente envolvidas na formação do trombo. A concentração de glicose em seu interior reflete a concentração sanguínea, uma vez que a entrada de glicose nas mesmas não depende da insulina (61). Nas plaquetas, assim como nas células endoteliais, níveis elevados de glicose ativam a proteína cinase $\mathrm{C}$, diminuem a produção de óxido nítrico derivado de plaquetas e aumentam a formação de espécies reativas do oxigênio (62). A produção do peroxinitrito também diminui a síntese da prostaciclina, um prostanóide vasodilatador e antiplaquetário, que contribui para a formação dos trombos (63).

A capacidade fibrinolítica também está prejudicada, devido aos elevados níveis dos inibidores do ativador de plasminogênio tipo I em lesões ateroscleróticas (64). O estado diabético (hiperglicemia e hiperinsulinemia) aumenta a expressão de fator tecidual, um potente pro coagulante, e fatores de coagulação plasmáticos como fator VII e diminuição dos níveis de anticoagulantes endógenos, como antitrombina III e proteína C funcional $(65,66)$.

Agindo em conjunto, as anormalidades decorrentes do estado diabético produzem em um estado pró-trombótico persistente (67). 
Todas estas alterações associadas ao longo do tempo (cronicidade dos estímulos), sem uma mudança de estilo de vida ou tratamento clínico para compensar tais efeitos, propiciam a ocorrência de eventos cardiovasculares.

\subsection{Justificativa da revisão sistemática}

Os dados prévios dos estudos que avaliaram o controle intensivo de glicemia na incidência de desfechos clínicos micro e macrovasculares são divergentes em relação aos resultados encontrados. Em relação aos desfechos macrovasculares, o estudo UKPDS $(68,69)$, por exemplo, não encontrou diferenças estatisticamente significantes entre o tratamento intensivo e convencional nos desfechos mortalidade total $\mathrm{e}$ mortalidade cardiovascular. Entretanto, demonstrou uma redução de risco relativo de 19\% na incidência de infarto agudo do miocárdio (IAM) não-fatal. Já o estudo ACCORD (70) foi interrompido precocemente por uma maior incidência de mortalidade total e cardiovascular no grupo do tratamento intensivo, apesar de também ter encontrado uma RRR de $21 \%$ para IAM não-fatal. O estudo ADVANCE (71), que randomizou 11.140 pacientes, não encontrou diferenças entre o tratamento intensivo e convencional em relação a nenhum desfecho macrovascular avaliado. Para os eventos microvasculares, os estudos também são divergentes. Assim, o estudo UKPDS $(72,73)$ demonstrou uma RRR de $17 \%$ na progressão de retinopatia e uma RRR de $33 \%$ na incidência de nefropatia. Já o estudo VADT (74) não encontrou diferenças entre o tratamento intensivo e convencional para estes desfechos.

Ainda, estes estudos têm seus níveis intensivos de glicemia alcançados por protocolos clínicos muito diferentes em relação ao número e classe de hipoglicemiantes utilizados, bem como as dosagens utilizadas. O estudo Kumamoto (75), por exemplo, só utilizou insulina nos pacientes, sem o uso de nenhum outro agente hipoglicemiante. $\mathrm{O}$ próprio estudo ACCORD (76) teve 59,1\% dos pacientes alocados para o tratamento intensivo utilizando 3 classes de agentes hipoglicemiantes que não a insulina.

Evidências provindas de revisões sistemáticas e meta-análise não estavam disponíveis até o ano de 2009, quando foram publicadas, sequencialmente, as duas revisões sistemáticas sobre a análise de eventos cardiovasculares, uma em Maio e outra em Setembro $(77,78)$. Entretanto, ambos os trabalho diferiram em relação ao número e 
estudos incluídos. Também avaliaram apenas eventos macrovasculares, excluindo as análises de eventos microvasculares.

A continuidade da presente revisão sistemática se justifica por contemplar análises complementares às revisões sistemáticas prévias, como as analises dos desfechos microvasculares nos estudos que os reportam, além da avaliação da qualidade da evidência para os principais desfechos 


\section{OBJETIVOS}

A presente revisão sistemática com meta-análise tem como objetivo avaliar a incidência de eventos microvasculares, macrovasculares, mortalidade total e episódios de hipoglicemia em pacientes diabéticos tipo II, tratados com esquema intensivo de controle glicêmico em comparação aos tratados com esquema convencional de controle glicêmico.

Os eventos macrovasculares avaliados foram:

1) Mortalidade cardiovascular: qualquer óbito decorrente de complicações cardiovasculares. Alguns estudos referiram-se como mortalidade relacionada à diabetes melito, que foi considerado como sinônimo na revisão;

2) Mortalidade total: incidência de óbitos por quaisquer motivos;

3) Infarto Agudo do Miocárdio (IAM) Não-fatal: foi aceito a definição descrita nos artigos incluídos;

4) Acidente Vascular Cerebral (AVC) Não-fatal: foi aceito a definição descrita nos artigos incluídos;

5) Desfechos combinados macrovasculares, quando reportados pelos estudos;

Os eventos microvasculares foram:

1) Retinopatias: incidência, progressão, desfecho combinado de incidência ou progressão, progressão para maculopatia, progressão para retinopatia proliferativa, desfecho combinado de progressão para maculopatia ou retinopatia proliferativa, fotocoagulação retinal, hemorragia vítrea e extração de catarata;

2) Deteriorização Visual: cegueira e piora na deteriorização visual;

3) Neuropatias: autonômica, periférica e desfecho combinado de incidência ou piora;

4) Nefropatias: incidência, progressão, microalbuminúria e diálise;

5) Desfechos combinados microvasculares, quando reportados pelos estudos;

Os episódios de hipoglicemia foram classificados como menores, maiores ou desfechos combinados de menores ou maiores, quando reportados.

Para os desfechos mais relevantes, será realizada a avaliação da qualidade da evidência da meta-análise, considerando as características metodológicas e resultados dos estudos individuais que preencheram os critérios de elegibilidade para serem incluídos nas análises. 


\section{METODOLOGIA}

\subsection{Definições dos critérios de elegibilidade}

Incluiu-se exclusivamente pacientes adultos, portadores de diabetes melito tipo II (Diabetes melito não insulino-dependente). Estudos com pacientes portadores de diabetes melito tipo I (Diabetes melito insulino-dependente), pacientes pediátricos ou menores de 18 anos não foram incluídos.

Entendeu-se por controle glicêmico intensivo um controle efetuado por um protocolo de tratamento clínico que almejou obter uma glicemia de jejum ou um percentual de hemoglobina glicada menor que um valor alvo conservador, geralmente próximo aos valores de normalidade para não diabéticos. O protocolo clínico e os valores de glicemia ou hemoglobina glicada podiam variar entre os estudos elegíveis. $\mathrm{O}$ tratamento clínico intensivo podia ter uma ou mais intervenções medicamentosas ou de alterações de estilo de vida.

O controle convencional de glicemia foi um controle efetuado por um protocolo de tratamento clínico sugerido pelo estudo ou que respeitava as diretrizes institucionais ou locais do país que conduziu o estudo. Teve como alvo um controle de glicemia de jejum ou percentual de hemoglobina glicada menos restrito que o controle intensivo. $\mathrm{O}$ protocolo clínico e os valores de glicemia ou hemoglobina glicada podiam variar entre os estudos elegíveis. O tratamento clínico convencional também podia ter uma ou mais intervenções medicamentosas ou de alterações de estilo de vida.

É importante notar que estes diferentes níveis de intensidade deviam estar bem definidos nos métodos de cada estudo incluído, como parte dos critérios de inclusão da presente revisão.

Avaliaram-se os eventos macro e microvasculares e episódios de hipoglicemia. Em relação ao período de seguimento dos estudos, como desfechos crônicos estavam sendo avaliados, estipulou-se um período mínimo de 12 meses de seguimento para inclusão do estudo na revisão sistemática. 


\subsection{Bases eletrônicas de dados pesquisadas}

A estratégia de busca incluiu bases primárias e secundárias de dados. Como bases primárias de dados, foram pesquisados o PUBMED/MEDLINE, o EMBASE e o ISI of Knowledge; e como base secundária de dados, a Cochrane Central Register of Controlled Trials.

\subsection{Estratégias de busca}

A estratégia de busca foi realizada por blocos. Cada bloco continha palavras estratégicas para caracterizar seu conteúdo. O bloco 1 compreendeu palavras relacionadas ao tipo do paciente, patologia e desfechos. O segundo e o terceiro blocos referiram-se a palavras relacionadas à intervenção (tratamento clínico e palavras de texto Word -adjetivos- que caracterizassem "tratamento intensivo", respectivamente) e o quarto bloco restringiu a busca a ensaios clínicos randomizados exclusivamente realizados em humanos.

As estratégias foram montadas buscando as publicações disponíveis por cada termo individual dentro do bloco e depois somando estes resultados, utilizando o operador booleano de soma OR. Quando finalizada as buscas dos blocos, os mesmos eram combinados de forma a obtermos a intersecção dos blocos através do operador booleano AND, tornando, assim, a busca mais específica.

Para busca de ensaios clínicos randomizados realizados exclusivamente em humanos, utilizamos estratégias prontas já validadas (79).

A estratégia de busca detalhada da revisão encontra-se no Apêndice B

\subsection{Avaliação de artigos duplicados na base}

Inicialmente, os artigos selecionados pela busca estratégica nas bases de dados foram avaliados através do título e resumo, utilizando o Reference Manager versão 11 como ferramenta.

Excluíram-se os artigos que estavam em duplicata na base do Reference Manager de forma automática e de forma manual, já que a exclusão automática não se 
demonstrou totalmente eficaz. Foi necessária, pelo menos, a leitura de todos os títulos e autores dos artigos, para que possíveis publicações repetidas pudessem ser eliminadas da base, já que muitas vezes são publicadas em nome de diferentes autores ou em diferentes revistas.

\subsection{Avaliação da elegibilidade}

A triagem dos artigos para inclusão ou exclusão, baseada nos critérios de elegibilidade pré-definidos, foi realizada por dois revisores independentes. Cada dupla realizou a leitura do título e resumo (quando disponível). Quando um artigo não apresentava resumo, mas o título era sugestivo de elegibilidade, ele passada para a próxima etapa de obtenção de texto completo.

Nesta etapa de triagem, cada revisor da dupla interpretava o título e resumo e os resultados eram comparados. Se ao menos um considerasse elegível, mesmo havendo discordância, o artigo era selecionado para a próxima fase de avaliação de textos completos.

\subsection{Avaliação de artigos com textos completos (FULL TEXT)}

Todos os artigos que foram julgados elegíveis pela leitura de título e resumo tinham sua elegibilidade confirmada através da coleta dos critérios de elegibilidade em uma ficha clínica padronizada. A ficha clínica utilizada na avaliação da elegibilidade, que encontra-se no Apêndice $\mathrm{C}$, constava dos quatro critérios estabelecidos para inclusão dos estudos na revisão, a saber:

1- Ensaio Clínico Randomizado (como desenho exclusivo de estudo);

2- Somente pacientes portadores de Diabetes melito tipo II;

3- Pelo menos dois níveis de intensidade controle glicêmico objetivados;

4- Período de seguimento superior a 12 meses;

Nestes artigos em texto completo, também foram avaliadas outras questões não abordadas na ficha clínica, mas importantes para classificação na revisão, como os desfechos, por exemplo. Como não havia restrição de linguagem na busca estratégica, 
artigos em outros idiomas não dominados pela equipe foram encaminhados para tradução.

Nesta etapa de avaliação do texto completo, havendo divergências, estas foram resolvidas por consenso.

\subsection{Extração de dados}

Os artigos elegíveis forneceram os dados para as análises dos desfechos de interesse da revisão. Todas as informações relevantes para as análises foram coletadas em fichas clínicas padronizadas previamente elaboradas.

A ficha clínica de extração de dados encontra-se no Apêndice D.

Dados faltantes ou dúvidas de interpretação de resultados tentaram ser resolvidos mediante contato com o autor do estudo. Em alguns casos não se obteve respostas e as interpretações foram discutidas entre os revisores para consenso.

\subsection{Plano de análises estatísticas da revisão sistemática}

A análise estatística foi realizada em duas etapas. Na primeira etapa procedeu-se a análise descritiva das características de base dos pacientes, definições de desfecho, intervenções utilizadas e alvos glicêmicos.

Os desfechos binários foram apresentados considerando o número de eventos em cada grupo.

A meta-análise foi realizada posteriormente para combinar os resultados. Como ferramenta para o cálculo da meta-análise, utilizou-se o programa Review Manager [(RevMan) - Computer program - Version 5.0 - Copenhagen: The Nordic Cochrane Centre. The Cochrane Collaboration 2008] $(80,81)$.

Para os desfechos binários as estimativas foram geradas por um modelo de efeitos aleatórios considerando a estatística de Mantel-Haenzel como ponderador, e magnitude de efeito o risco relativo (RR) com seu respectivo intervalo de confiança de $95 \%$ (IC $95 \%)$

Para quantificação da consistência entre os resultados de cada estudo, utilizou-se o teste de inconsistência $\mathrm{I}^{2}$ de Higgins e col. (82). 


\subsection{Avaliação da qualidade da evidência gerada pela meta-análise}

Utilizamos como ferramenta para avaliação da qualidade da evidência o programa GRADEprofiler versão 3.2.2.

A seleção dos desfechos a terem suas estimativas de efeito qualificadas foi definida após os resultados principais, para a seleção dos achados mais relevantes. 


\section{RESULTADOS}

\subsection{Resultado da estratégia de busca}

A soma de todas as referências das bases eletrônicas pesquisadas totalizou 7.225 artigos. Destes, foram excluídos 2.453 artigos em duplicatas, totalizando 4772 artigos para avaliação da elegibilidade.

\subsection{Avaliação da elegibilidade}

Para avaliação da elegibilidade, contou-se com a participação de 5 duplas de revisores $[(\mathrm{AB})-(\mathrm{ES}) ;(\mathrm{AC})-(\mathrm{AO}) ;(\mathrm{HP})-(\mathrm{BK}) ;(\mathrm{AB})-(\mathrm{DG}) ;(\mathrm{LN})-(\mathrm{AZ})]$, todos eles envolvidos em pesquisa clínica e qualificados para tal avaliação. Cada dupla ficou, em média, com 954 artigos.

Dos 4772 artigos triados pelas duplas, 127 artigos precisaram ser adquiridos na forma de texto completo, quer porque foram classificados como elegíveis pela dupla, quer porque o título era sugestivo de inclusão, mas faltavam critérios explicitados no resumo ou mesmo porque não o apresentavam. Nesta etapa, a maioria dos artigos foi adquirida via porta Capes da USP, entretanto, uma grande parte teve que ser buscada na BIREME. Quando não disponível nos arquivos da BIREME, foi solicitado sua compra no mesmo local. A planilha de controle das referências e avaliação da elegibilidade encontra-se no Anexo E. Setenta e quatro artigos foram excluídos nesta etapa, onde foi possível confirmar os critérios que não estavam claros e ter acesso aos resumos dos trabalhos que não os tinham disponíveis.

Quarenta e oito artigos finais foram elegíveis. Entretanto, todos estes se referem a apenas sete estudos, já que os estudos principais publicam também outros artigos, descrevendo sub-estudos, comentários e outros derivados, em mais de uma revista.

A figura 1 apresenta o fluxo de obtenção dos artigos que foram considerados elegíveis para a revisão sistemática. 


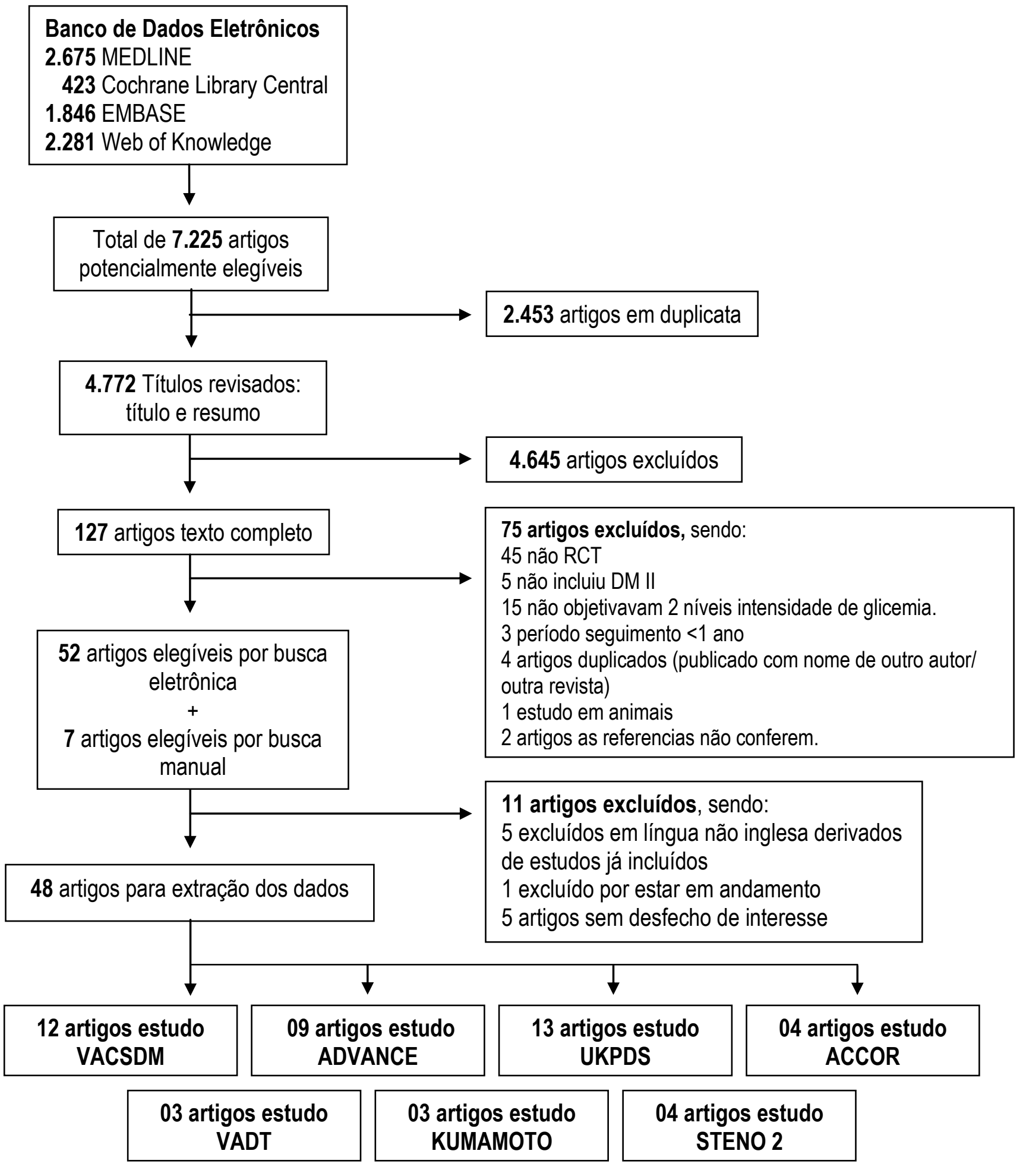

Figura 1 - Fluxo de seleção dos artigos incluídos. 


\subsubsection{Artigos em língua não inglesa}

Oito artigos estavam em língua não inglesa. Embora em idioma não dominado pela equipe, possuíam resumos em inglês, o que permitiu a classificação da elegibilidade. Apenas um elegível pelo resumo precisou ser traduzido, do russo para português. Abaixo, segue a descrição deste processo:

1 Húngaro (83): Tratava-se de um artigo derivado de um estudo já incluído na extração de dados (ADVANCE). Como não tiveram dados faltantes que justificassem uma nova fonte de informação, não foi realizada a tradução deste trabalho.

2 Tcheco (84): Tratava-se de um artigo derivado de um estudo já incluído na extração de dados (UKPDS). Como não tiveram dados faltantes que justificassem uma nova fonte de informação, não foi realizada a tradução deste trabalho.

3 Japonês (85): Tratava-se de um artigo que não objetivava dois níveis de intensidade de controle glicêmico. Objetivava a determinação de um limiar glicêmico para prevenção ou regressão de microangiopatias diabéticas e regime de administração de insulina para estabelecer o controle glicêmico em pacientes diabéticos tipo II.

4 Chinês (86): Não avaliava desfechos de nosso interesse. Entretanto, como possuía todos os demais critérios, foi feita uma comunicação via e-mail com o autor principal, a fim de obter dados sobre nossos desfechos de interesse, que poderiam estar coletados e não estarem publicados. $\mathrm{O}$ autor respondeu que a pesquisa estava em andamento e os resultados sobre desfechos clínicos ainda não estavam à disposição. A cópia do e-mail encontra-se no anexo 6, junto com outros contatos com autores.

5 Francês $(87,88)$ : Tratava-se de dois artigos derivados de estudos já incluídos na extração de dados (ADVANCE e Steno-2, respectivamente). Como não tiveram dados faltantes que justificassem uma nova fonte de informação, não foi realizada a tradução deste trabalho.

6 Dinamarquês (89): Tratava-se de um artigo derivado de um estudo já incluído na extração de dados (Steno-2). Como não tiveram dados faltantes que justificassem uma nova fonte de informação, não foi realizada a tradução deste trabalho.

7 Russo (90): O resumo em inglês do artigo caracterizou-o como elegível para a nossa revisão, de modo que foi necessária a contratação de uma tradutora de língua russa para extração dos dados. Este serviço foi realizado, mas o artigo não permaneceu elegível, pois, após tradução, constatou-se que o estudo não havia encontrado diferença 
estatisticamente significante entre os grupos intensivo e controle nos valores de hemoglobina glicada (HbA1c), o que fez com que o autor refizesse as análises de modo retrospectivo, estratificando os pacientes em 3 grupos, por diferenças nos níveis de HbA1c alcançados: grupo 1: $\mathrm{HbA1c} \geq 1 \%$; grupo 2 : $\mathrm{HbA} 1 \mathrm{c}<1 \%$ e grupo 3 : aumentaram os níveis de HbA1c. Desta forma, o artigo não permaneceu elegível pelos nossos critérios de elegibilidade.

\subsection{Extração de dados}

Os sete estudos incluídos na revisão, bem como todas as publicações derivadas que foram encontradas, são: ACCORD (91-94); ADVANCE (95-103), UKPDS (104116), VACSDM (117-128), VADT (129-131), STENO-2 (132-135), KUMAMOTO (136-138).

Para extração dos dados destes estudos, contamos com 4 duplas de revisores, conforme o quadro 1:

Quadro 1 - Duplas de revisores e estudos para extração de dados.

\begin{tabular}{|c|l|l|}
\hline DUPLAS & \multicolumn{1}{|c|}{ NOMES } & \multicolumn{1}{c|}{ ESTUDOS } \\
\hline 1 & $(\mathrm{AB})-(\mathrm{LN})$ & ACCORD, ADVANCE, Steno-2 \\
\hline 2 & $(\mathrm{AB})-(\mathrm{AZ})$ & Kumamoto \\
\hline 3 & $(\mathrm{AB})-(\mathrm{GS})$ & UKPDS \\
\hline 4 & $(\mathrm{AC})-(\mathrm{AZ})$ & VADT, VACSDM \\
\hline
\end{tabular}

\subsection{Resultados da meta-análise}

\subsubsection{Descrição dos estudos}

4.4.1.1 Características de Base dos Pacientes nos Estudos 
A tabela 1 apresenta as características de base das populações envolvidas em cada estudo.

Foram coletados dados considerados importantes para avaliação dos resultados, entretanto, nem todos os estudos reportaram todas estas características avaliadas.

Quatro estudos (ACCORD, ADVANCE, VADT e VACSDM) avaliaram população idosa e 3 estudos avaliaram adultos com média de 53 anos (Steno-2, UKPDS e Kumamoto). Em todos os estudos, a grande maioria era do sexo masculino. À exceção do estudo UKPDS, que incluiu pacientes recém diagnosticados com diabetes melito, os demais contavam com pacientes com, no mínimo, 5 anos de diagnóstico.

O único estudo que incluiu pacientes com IMC normal foi o Kumamoto. Os demais incluíram média de pacientes com sobrepeso e obesidade grau 1.

Quanto ao perfil lipídico dos pacientes incluídos, avaliados pelo valor do LDL colesterol, os estudos incluíram pacientes com médias de níveis desejáveis à limítrofes desta fração.

À exceção do estudo Kumamoto, a média de pressão arterial sistólica de todos os estudos incluídos em ambos os braços foi >130 mmHg.

Vale ressaltar que as características de base dos pacientes entre os dois braços nos estudos individuais são bastante semelhantes, o que sugere que a randomização foi realizada adequadamente. 
Tabela 1 - Características de base dos pacientes nos estudos.

\begin{tabular}{|c|c|c|c|c|c|c|}
\hline & \multicolumn{2}{|c|}{ ACCORD } & \multicolumn{2}{|c|}{ ADVANCE } & \multicolumn{2}{|c|}{ Steno-2 } \\
\hline & Intensivo & Convencional & Intensivo & Convencional & Intensivo & Convencional \\
\hline Pacientes randomizados & 5128 & 5123 & 5571 & 5569 & 80 & 80 \\
\hline Idade 1 & 62,2 & 62,2 & 66,0 & 66,0 & 54,9 & 55,5 \\
\hline Homem & $3143(61 \%)$ & $3156(62 \%)$ & $3198(57 \%)$ & $3213(58 \%)$ & $63(79 \%)$ & $56(70 \%)$ \\
\hline Tempo de diagnostico DMII (anos) ${ }^{1}$ & $10,0^{2}$ & $10,0^{2}$ & 7,9 & 8,0 & 5,5 & 6,0 \\
\hline Doença cardiovascular previa & $1826(36 \%)$ & $1783(35 \%)$ & $1794(32 \%)$ & $1796(32 \%)$ & $18(22 \%)$ & $21(26 \%)$ \\
\hline Tabagistas & $733(14 \%)$ & $702(14 \%)$ & $793(14 \%)$ & $757(123 \%)$ & $32(40 \%)$ & $27(34 \%)$ \\
\hline Pressão arterial sistólica media $(\mathrm{mmHg})^{1}$ & 136,2 & 136,5 & 145,0 & 145,0 & 146,0 & 149 \\
\hline LDLcolesterol (mg/dL)1 & 104,9 & 104,9 & 120,6 & 120,3 & 127,6 & 131,5 \\
\hline IMC $\left(\mathrm{Kg} / \mathrm{m}^{2}\right)^{1}$ & 32,2 & 32,2 & 28,0 & 28,0 & 29,7 & 29,9 \\
\hline
\end{tabular}

\begin{tabular}{|c|c|c|c|c|c|c|c|c|}
\hline & \multicolumn{2}{|c|}{ VADT } & \multicolumn{2}{|c|}{ VACSDM } & \multicolumn{2}{|c|}{ UKPDS } & \multicolumn{2}{|c|}{ Kumamoto } \\
\hline & Intensivo & convencional & intensivo & convencional & intensivo & convencional & intensivo & convencional \\
\hline Pacientes randomizados & 892 & 899 & 75 & 78 & 3071 & 1138 & 55 & 55 \\
\hline Idade 1 & 60,5 & 60,3 & 60,4 & 59,9 & 53,2 & 53,4 & 48,0 & 51,0 \\
\hline Homem & $866(97 \%)$ & $873(97 \%)$ & $75(100 \%)$ & $78(100 \%)$ & $806(26 \%)$ & $705(62 \%)$ & $28(51 \%)$ & $26(47 \%)$ \\
\hline Tempo de diagnostico DMII (anos) ${ }^{1}$ & 11,5 & 11,5 & 8,0 & 7,7 & NR & NR & 8,6 & 8,5 \\
\hline Doença cardiovascular previa & $355(40 \%)$ & $368(41 \%)$ & $31(41 \%)$ & $27(35 \%)$ & NR & NR & NR & NR \\
\hline Tabagistas & $154(17 \%)$ & $145(16 \%)$ & $17(23 \%)$ & $10(13 \%)$ & $844(27 \%)$ & $353(31 \%)$ & NR & NR \\
\hline $\begin{array}{l}\text { Pressão arterial sistólica media } \\
(\mathrm{mmHg})^{1}\end{array}$ & 131,0 & 132,0 & 136,1 & 134,5 & 135,6 & 135,6 & 120,5 & 122,0 \\
\hline LDL colesterol (mg/dL)1 & 107,0 & 108,0 & 136 & 141 & 136,1 & 136,1 & NR & NR \\
\hline IMC $\left(\mathrm{Kg} / \mathrm{m}^{2}\right)^{1}$ & 31,3 & 31,2 & 30,7 & 31,3 & 28,0 & 28,2 & 20,6 & 20,4 \\
\hline
\end{tabular}

NOTAS: ${ }^{1}$ Os dados são apresentados em media $;{ }^{2}$ dados em mediana

Para converter LDL colesterol de $\mathrm{mg} / \mathrm{dL}$ para mmol/L, multiplicar por 0,02586 
4.4.1.2 Tempo de seguimento, número de pacientes randomizados nos estudos e perdas de seguimento

Os tamanhos das amostras variaram bastante entre os estudos, bem como o percentual de perdas de seguimento. A tabela 2 resume estes dados.

Para a presente revisão, adotamos a definição de perda de seguimento como sendo todos os pacientes que não foram avaliados na visita final do estudo ou que não se conhece o desfecho, embora a maioria dos estudos defina apenas como pacientes que retiraram o consentimento ou mudaram para outra cidade/estado. Neste sentido, em alguns casos, nosso número de perdas de seguimentos diferiu das perdas relatadas dos textos dos artigos e serão levados em conta nas análises de sensibilidade dos resultados encontrados, para podermos afirmar se estas perdas foram relevantes ou não para as conclusões dos estudos.

Tabela 2 - Pacientes randomizados e perdas de seguimento.

\begin{tabular}{c|c|c|c|c|c|c}
\hline Estudo & \multirow{2}{*}{$\begin{array}{l}\text { Tempo de } \\
\text { seguimento } \\
\text { (anos) }\end{array}$} & \multirow{2}{*}{$\begin{array}{c}\text { Total de } \\
\text { pacientes } \\
\text { randomizados }\end{array}$} & \multicolumn{2}{|c|}{$\begin{array}{c}\text { Total de pacientes } \\
\text { randomizados nos grupos }\end{array}$} & \multicolumn{2}{|c}{$\begin{array}{c}\text { Perda de seguimento nos } \\
\text { grupos }\end{array}$} \\
\cline { 4 - 7 } & intensivo & convencional & Intensivo & Convencional \\
\hline ACCORD & $3,5^{1}$ e $3,4^{2}$ & 10.251 & 5128 & 5123 & $110(2 \%)$ & $102(2 \%)$ \\
\hline ADVANCE & $5,0^{2}$ & 11.140 & 5571 & 5569 & $245(4 \%)$ & $295(5 \%)$ \\
\hline Steno 2 & $7,8^{2}$ & 160 & 80 & 80 & $1(1 \%)$ & $2(2 \%)$ \\
\hline VADT & $5,6^{2}$ & 1.791 & 892 & 899 & $120(13 \%)$ & $139(15 \%)$ \\
\hline VACSDM & $2,25^{2}$ & 153 & 75 & 78 & $2(2 \%)$ & $0(0 \%)$ \\
\hline UKPDS & $10,0^{2}$ & 4.209 & 3071 & 1138 & $122(4 \%)$ & $45(4 \%)$ \\
\hline Kumamoto & $8,0^{2}$ & 110 & 55 & 55 & $2(4 \%)$ & $2(4 \%)$ \\
\hline
\end{tabular}

NOTAS: ${ }^{1}$ Dados em media; ${ }^{2}$ Dados em mediana 


\subsubsection{Controle glicêmico de base e pós-intervenção}

A diferença de intensidade entre a intervenção (tratamento intensivo) e o controle (tratamento convencional) foi confirmada nos estudos através da medida glicemia de jejum ou hemoglobina glicada. Uma medida de base foi efetuada nos pacientes antes do início do estudo e acompanhada nos tempos de seguimentos dos estudos, que diferem entre si. As tabelas 3 e 4 descrevem estes valores. 
Tabela 3 - Controle de glicemia de base.

\begin{tabular}{|c|c|c|c|c|}
\hline \multirow{2}{*}{ Estudos } & \multicolumn{2}{|c|}{ HbA1c (\%) de base } & \multicolumn{2}{|l|}{ Glicemia de jejum (mg/dL) de base } \\
\hline & intensivo & convencional & intensivo & convencional \\
\hline ACCORD & $8,3^{1-8,1^{2}}$ & $8,3^{1-8,1^{2}}$ & $174,9(56,0)^{1}$ & $175,7(56,5)^{1}$ \\
\hline ADVANCE & $7,511-7,2^{2}$ & $7,52^{1-7,2^{2}}$ & $153,3(50,1)^{1} 142,3(118,9-174,7)^{2}$ & $152,8(49,7)^{1} 142,3(118,9-174,7)^{2}$ \\
\hline Steno 2 & 8,41 & $8,8^{1}$ & $181,9(55,8)^{1}$ & $189,1(50,0)^{1}$ \\
\hline VADT & $9,4^{1}$ & $9,4^{1}$ & NR & NR \\
\hline VACSDM & 9,31 & 9,51 & 206 & 227 \\
\hline Kumamoto & 9,41 & 8,91 & NR & NR \\
\hline UKPDS & 7,091 & $7,05^{1}$ & $145,9(127,90-176,54)$ & $144,12(127,9-172,94)$ \\
\hline
\end{tabular}

NOTAS: ${ }^{1}$ Dados apresentados em média; ${ }^{2}$ Dados apresentados em mediana

Tabela 4 - Controle de glicemia após seguimento.

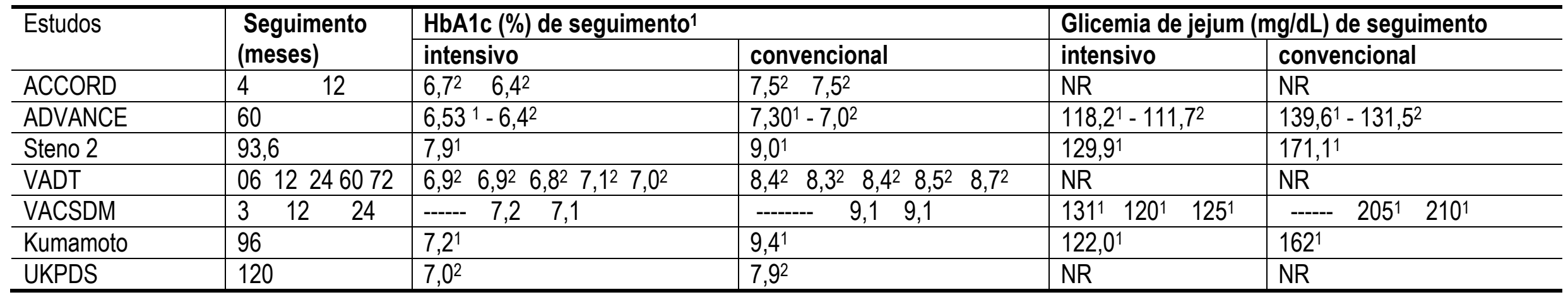

NOTAS: ${ }^{1}$ Dados apresentados em media; ${ }^{2}$ Dados em mediana 
Nos valores dos parâmetros glicêmicos de base, o estudo ADVANCE contou com pacientes que tiveram as menores médias de hemoglobina glicada. Os estudos VADT e VACSDM incluíram pacientes com as maiores médias desta variável.

No monitoramento de seguimento, todos os estudos incluídos atingiram significância estatística na diferença do parâmetro glicêmico avaliado entre os braços intensivo e controle, porém a diferença absoluta diferiu entre os estudos. O estudo Kumamoto teve a maior média de diferença absoluta no valor da hemoglobina glicada: 2,2\% (grupo intensivo 7,2\% e grupo convencional 9,4\%) e o UKPDS a menor diferença absoluta no valor da hemoglobina glicada: 0.9\% (grupo intensivo 7,0\% e grupo convencional $7,9 \%)$.

4.4.1.4 Alvos Glicêmicos e Definições de Intervenção, controle e desfechos entre os estudos

Os estudos diferiram em relação aos alvos glicêmicos, estratégias de tratamento e desfechos avaliados.

$\mathrm{Na}$ presente revisão, o importante foi a definição da diferença de nível entre os braços tratamento intensivo e tratamento convencional e que esta diferença fosse estatisticamente significante, independente do parâmetro e alvos adotados para cada braço.

A maioria dos estudos definiu a medida de hemoglobina glicada (HbA1c) como parâmetro para avaliar o nível de intensidade do controle glicêmico. O estudo UKPDS foi o único que utilizou apenas a glicemia de jejum como parâmetro.

A tabela 5 descreve os alvos e parâmetros glicêmicos dos níveis de controle da glicemia nos estudos. 
Tabela 5 - Alvos e parâmetros glicêmicos de controle intensivo e convencional.

\begin{tabular}{|c|c|c|}
\hline \multirow{2}{*}{ Estudo } & \multicolumn{2}{|c|}{ Alvo glicêmico } \\
\hline & intensivo & Convencional \\
\hline ACCORD & $\mathrm{HbA1c}<6.0 \%$ & HbA1c entre $7,0 \%$ e $7,9 \%$ \\
\hline ADVANCE & $\mathrm{HbA} 1 \mathrm{c}<6,5 \%$ & $\begin{array}{l}\text { Níveis de HbA1c definido de acordo com } \\
\text { diretrizes locais }\end{array}$ \\
\hline Steno-2 & HbA1c $<6,5 \%$ & $\mathrm{HbA1c}<7,5 \%$ \\
\hline VADT & $\mathrm{HbA} 1 \mathrm{C} \leq 6,0 \%$ & $\begin{array}{l}\text { HbA1c entre } 8 \% \text { e } 9 \% \text { e manutenção de bem } \\
\text { estar, com prevenção de glicosúria, } \\
\text { hipoglicemia ou cetonúria }\end{array}$ \\
\hline VACSDM & $\begin{array}{l}\text { HbA1c } 5,1 \%+-1 \% ; \text { FPG } 4.44- \\
6.38 \text { mmol/L }(80-115 \mathrm{mg} / \mathrm{dL}) \\
\text { ou qualquer outra medida pré } \\
\text { prandial }<7.22 \mathrm{mmol} / \mathrm{L}(130 \\
\mathrm{mg} / \mathrm{dL})\end{array}$ & $\begin{array}{l}\text { Manter a média de HbAlc de } 9,1 \% \text {, a fim de } \\
\text { evitar sintomas diabéticos, glicosúria } \\
\text { excessiva ou hipoglicemia }\end{array}$ \\
\hline UKPDS & Glicemia de jejum $<6 \mathrm{mmol} / \mathrm{L}$ & $\begin{array}{l}\text { Glicemia de jejum }>6 \mathrm{mmol} / \mathrm{L} \mathrm{e}<15 \\
\mathrm{mmol} / \mathrm{L} \text {. }\end{array}$ \\
\hline Kumamoto & $\begin{array}{l}\text { Glicemia de jejum <140 mg/dl, } \\
\text { glicemia pós-prandial de } 2-\mathrm{h}< \\
200 \mathrm{mg} / \mathrm{dl} \text {, um nível de } \mathrm{HbA} 1 \mathrm{c} \\
<7.0 \% \text { e uma média de } \\
\text { amplitude glicêmica (MAGE) } \\
<100 \mathrm{mg} / \mathrm{dl}\end{array}$ & $\begin{array}{l}\text { Não apresentar sintomas de hiper ou } \\
\text { hipoglicemia e ter a glicemia de jejum }<140 \\
\text { mg/dl. }\end{array}$ \\
\hline
\end{tabular}

Em relação ao protocolo clínico utilizado para o alcance do alvo glicêmico, estes também diferiram bastante entre os estudos. A maioria dos estudos tinha um esquema de tratamento principal e um alternativo, no caso de não se alcançar o alvo glicêmico proposto.

Para os estudos que propunham um mesmo esquema de tratamento para os dois braços do estudo, a variante era a dose de cada medicação, sendo, geralmente, a dose máxima de cada classe no grupo intervenção e uma dose menor no grupo controle.

A tabela 6 descreve os protocolos clínicos utilizados nos estudos.

Nem todos os estudos avaliaram todos os desfechos de interesse. Ainda, para um mesmo desfecho, diferentes definições foram encontradas. 
Estudo

Intervenção

\begin{tabular}{|c|c|c|}
\hline & intensivo & convencional \\
\hline ACCORD & $\begin{array}{l}\text { Combinação de uma ou mais classes de medicamentos, } \\
\text { podendo ser metformina, glimepirida, repaglinida, } \\
\text { rosiglitazona, inibidor da alfa glucosidase, exenatida ou } \\
\text { insulina }\end{array}$ & $\begin{array}{l}\text { Combinação de uma ou mais classes de medicamentos, } \\
\text { podendo ser metformina, glimepirida, repaglinida, } \\
\text { rosiglitazona, inibidor da alfa glucosidase, exenatida ou } \\
\text { insulina }\end{array}$ \\
\hline ADVANCE & $\begin{array}{l}\text { Perindopril e indapamida ou placebo }+ \text { glicazida de liberação } \\
\text { modificada (se o alvo não era alcançado, introduzia-se } \\
\text { metformina, tiazolidinedionas, acarbose ou insulina) }\end{array}$ & $\begin{array}{l}\text { De acordo com o medico assistente, não podendo utilizar } \\
\text { glicazida }\end{array}$ \\
\hline STENO-2 & $\begin{array}{l}\text { Dieta (total gordura diária }<30 \% \text { do total de energia/dia e } \\
\text { ingestao de gordura saturada }<10 \% \text { ), atividade física }(30 \\
\text { minutos, } 3-5 \text { vezes/ semana, leve a moderada), } \\
\text { hipoglicemiantes orais: sobrepeso e obesos metformina + } \\
\text { glicazida, se necessário; normopesos: Glicazida + metformina, } \\
\text { se necessário. No caso de ineficiência, introduziu-se insulina na } \\
\text { hora de dormir e suspendeu-se os } 2 \text { hipoglicemiantes orais }\end{array}$ & $\begin{array}{l}\text { Tratamento de acordo com o Danish Medical Association de } \\
1988 \text { (revisão de 2000) }\end{array}$ \\
\hline VADT & $\begin{array}{l}\text { Início do tratamento: Se IMC } \geq 27: \text { Metformina } 500 \text { a 2000mg e } \\
\text { rosiglitazona em dose máxima, } \\
\text { Se IMC<27: glimepirida } 8 \mathrm{mg} \text { e rosiglitazona em dose máxima } \\
\text { Insulina ação longa ou intermediária à noite } \\
\text { Insulina matinal com ou sem inibidor da alfa-glucosidase } \\
\text { Várias doses diárias de insulina e mantendo medicamentos } \\
\text { orais } \\
\text { Qualquer combinação necessária }\end{array}$ & $\begin{array}{l}\text { Início do tratamento: Se IMC } \geq 27: \text { Metformina } 500 \text { a } 1000 \mathrm{mg} \text { e } \\
\text { rosiglitazona } 4 \mathrm{mg} \text {, } \\
\text { Se IMC<27 :glimepirida } 2 \mathrm{mg} \text { e rosiglitazona } 4 \mathrm{mg} \\
\text { Se HbA1C continuava } \geq 9 \% \text { : Insulina ação longa ou } \\
\text { intermediária à noite } \\
\text { Aumentar metformina para } 1000 \mathrm{mg} \\
\text { Aumentar rosiglitazona para } 8 \mathrm{mg} / \mathrm{dia} \\
\text { Aumentar dose de insulia com ou sem inibidor da alfa- } \\
\text { glucosidase } \\
\text { Qualquer combinação necessária }\end{array}$ \\
\hline
\end{tabular}


Tabela 6 - Intervenções no grupo controle intensivo e controle convencional nos estudos.

\begin{tabular}{|c|c|c|}
\hline \multirow[t]{2}{*}{ Estudo } & \multicolumn{2}{|c|}{ Intervenção } \\
\hline & Intensivo & Convencional \\
\hline VACSDM & $\begin{array}{l}\text { Um modelo de } 4 \text { passos foi seguido } \\
\text { 1-Uma injeção de insulina de ação de longa ou intermediária } \\
\text { antes de dormir; } \\
\text { 2-A mesma dose de insulina pela manhã associado à glipizida; } \\
\text { 3-Duas injeções de insulina por dia sem glipizida; } \\
\text { 4-Várias injeções de insulina por dia }\end{array}$ & $\begin{array}{l}\text { Tratados com no máximo } 2 \text { injeções de insulina ao dia com } \\
\text { avaliação trimestral para coleta dos dados e tratamento } \\
\text { médico. }\end{array}$ \\
\hline UKPDS & $\begin{array}{l}\text { Terapia intensiva com sulfoniluréia (clorpropamida, } \\
\text { glibenclamida ou glipizida) ou insulina. Pacientes obesos } \\
\text { também foram randomizados para receberem metformina. } \\
\text { Esses pacientes também continuaram recebendo dieta. As doses } \\
\text { diárias usadas de sulfoniluréia foram: clorpropamida } 100-500 \\
\text { mg; glibenclamida } 2.5-30 \mathrm{mg} \text {; glipizida } 2.5-40 \mathrm{mg} \text {. Pacientes } \\
\text { alocados para insulina usavam } 1 \text { dose diariamente de insulina } \\
\text { ultralente ou "isofána". A dose diária máxima era } 14 \mathrm{U} \text {. Se os } \\
\text { pacientes apresentassem hiperglicemia acentuada, para os } \\
\text { pacientes alocados para sulfoniluréia, metformina era } \\
\text { adicionada (dose máxima } 2550 \mathrm{mg} \text { ); mas se a hiperglicemia } \\
\text { fosse recorrente, os pacientes eram mudados para insulina. }\end{array}$ & $\begin{array}{l}\text { Controle convencional foi somente dieta (rica em } \\
\text { carboidratos e fibras e pobre em gorduras saturadas). } \\
\text { Drogas foram adicionadas somente se os pacientes } \\
\text { tivessem sintomas de hiperglicemia ou FPG > } 15 \mathrm{mmol} / \mathrm{L} \text {. } \\
\text { Pacientes eram então randomizados para tratamento com } \\
\text { sulfoniluréia ou insulina, com a opção adicional de } \\
\text { metformina nos pacientes obesos. Se houve hiperglicemia } \\
\text { recorrente, metformina foi adicionada junto à sulfoniluréia, } \\
\text { e naqueles alocados para metformina, glibenclamida foi } \\
\text { adicionada. Pacientes com marcada hiperglicemia foram } \\
\text { em ambos os agentes foram mudados para insulina. }\end{array}$ \\
\hline КUМАМОТО & $\begin{array}{l}\text { Insulina de ação curta em cada refeição e insulina de ação } \\
\text { intermediária na hora de dormir. }\end{array}$ & $\begin{array}{l}\text { Uma ou duas injeções diárias de insulina de ação } \\
\text { intermediária }\end{array}$ \\
\hline
\end{tabular}




\subsubsection{Risco de Vieses nos Estudos Incluídos}

As características metodológicas dos ensaios clínicos randomizados incluídos foram avaliadas individualmente.

Avaliou-se a metodologia adequada de randomização, a descrição do sigilo da lista de alocação, se existiu algum nível de cegamento e se as análises seguiram o princípio de intenção de tratar.

A tabela 7 resume os achados. De uma maneira geral, os estudos incluídos descrevem as características metodológicas utilizadas e não há limitações sérias entre os estudos. O estudo Kumamoto é o que reporta com menos detalhes estas características, não deixando clara a avaliação de metade delas. 
Tabela 7 - Características metodológicas dos estudos incluídos.

\begin{tabular}{|c|c|c|c|c|c|c|c|}
\hline & ACCORD & ADVANCE & Steno-2 & VADT & VACSDM & UKPDS & Kumamoto \\
\hline Randomização & Adequado & Adequado & $\begin{array}{l}\text { Não está claro. } \\
\text { (envelopes selados) }\end{array}$ & Adequado & Não está claro & Adequado & Não está claro \\
\hline Alocação Sigilosa & Adequado & Adequado & Adequado & Adequado & Adequado & Adequado & Não está claro \\
\hline $\begin{array}{l}\text { Cegamento dos } \\
\text { Investigadores }\end{array}$ & Não & Não & Não & Não & Não & Não & Não \\
\hline $\begin{array}{l}\text { Cegamento dos } \\
\text { participantes }\end{array}$ & Não & Não & Não & Não & Não & Não & Não \\
\hline $\begin{array}{l}\text { Comissão } \\
\text { adjudicadora }\end{array}$ & Sim & Sim & Sim & Sim & Sim & Sim & Sim \\
\hline $\begin{array}{l}\text { Cegamento de } \\
\text { dados }\end{array}$ & Sim & Sim & Não está claro & Não está claro & Não está claro & Sim & Não está claro \\
\hline Intenção de tratar & Sim & Sim & Sim & Sim & Sim & Sim & Sim \\
\hline
\end{tabular}




\subsubsection{Avaliação dos Desfechos Macrovasculares}

\subsubsection{Mortalidade Total}

Todos os sete estudos incluídos na revisão reportaram dados para este desfecho.

Os resultados dos estudos individuais variaram bastante, sendo que a maioria não demonstrou diferença estatisticamente significante entre o tratamento intensivo e o tratamento convencional. A exceção é o estudo ACCORD (139), que encontrou um aumento estatisticamente significante de mortalidade total para o grupo de tratamento intensivo. Aliás, este estudo foi interrompido precocemente por conta deste achado e dos achados de mortalidade por causa cardiovascular.

O resultado da meta-análise aponta que não há diferença estatisticamente significante nos dois braços de tratamento do estudo para o desfecho mortalidade total [RR 1,02 IC 95\% (0,90-1,15)] (Figura 2). Ainda, o intervalo de confiança foi bastante estreito, ou seja, a medida de efeito é precisa.

A heterogeneidade entre os estudos foi moderada $\left(\mathrm{I}^{2}=42 \%\right)$.

\subsubsection{Mortalidade Cardiovascular}

Os sete estudos incluídos na revisão reportaram dados para este desfecho.

Nenhum dos estudos individuais alcançou significância estatística entre os tratamentos intensivo e convencional em relação a este desfecho e a magnitude dos efeitos também foi bastante variável. A única exceção também foi o estudo ACCORD (140), que encontrou um aumento estatisticamente significante de mortalidade por causas cardiovasculares para o grupo de tratamento intensivo.

O resultado da meta-análise aponta que não há diferença estatisticamente significante nos dois braços de tratamento do estudo para o desfecho mortalidade cardiovascular [RR 1,05 IC 95\%(0,85-1,290] (Figura 3).

A heterogeneidade entre os estudos foi um pouco mais alta em relação ao evento anterior de mortalidade total, com o $\mathrm{I}^{2}=55 \%$. 
Intensivo Comencional Risk Ratio

Risk Ratio

\begin{tabular}{|c|c|c|c|c|c|c|c|}
\hline & & & & & & & \\
\hline Kumamoto 1995 & 1 & 55 & 3 & 55 & $0.3 \%$ & $0.33[0.04,3.11]$ & 1995 \\
\hline VACSDM 1995 & 5 & 75 & 5 & 78 & $1.1 \%$ & $1.04[0.31,3.45]$ & 1995 \\
\hline UKPDS 1998 & 539 & 3071 & 213 & 1138 & $27.3 \%$ & $0.94[0.81,1.08]$ & 1998 \\
\hline Steno-2 2003 & 12 & 80 & 15 & 80 & $3.0 \%$ & $0.80[0.40,1.60]$ & 2003 \\
\hline ACCORD 2008 & 257 & 5128 & 203 & 5123 & $22.6 \%$ & $1.26[1.06,1.51]$ & 2008 \\
\hline ADVANCE 2008 & 498 & 5571 & 533 & 5569 & $31.1 \%$ & $0.93[0.83,1.05]$ & 2008 \\
\hline VADT 2009 & 102 & 892 & 95 & 899 & $14.7 \%$ & $1.08[0.83,1.41]$ & 2009 \\
\hline Total (95\% Cl) & & 14872 & & 12942 & $100.0 \%$ & $1.02[0.90,1.15]$ & \\
\hline Total events & 1414 & & 1067 & & & & \\
\hline
\end{tabular}

Heterogeneity: Tau $^{2}=0.01 ; \mathrm{Chi}^{2}=10.33, \mathrm{df}=6(\mathrm{P}=0.11) ; \mathrm{I}^{2}=42 \%$

Test for overall effect: $Z=0.25(P=0.80)$

M-H, Random, 95\% CI

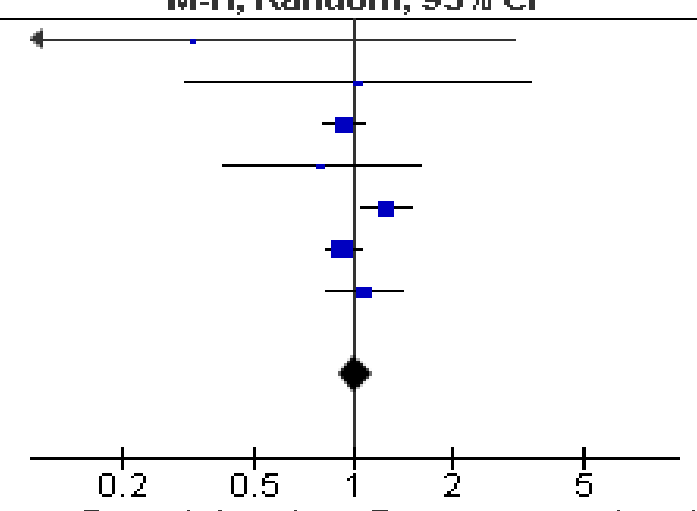

Figura 2 - Controle intensivo da glicemia versus convencional no risco de mortalidade total em pacientes com DMII.

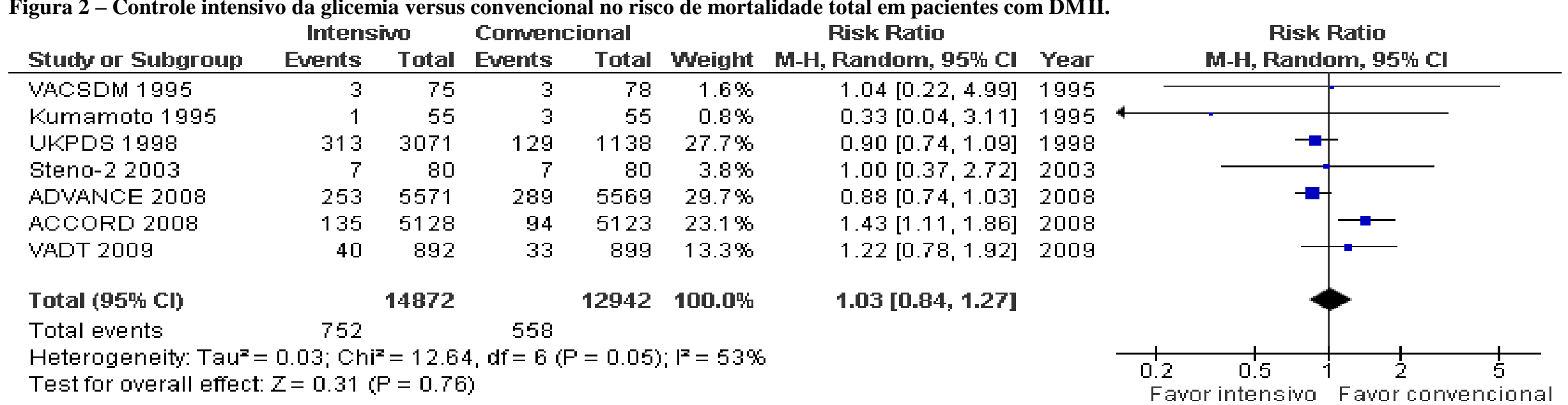

Figura 3 - Controle intensivo versus convencional da glicemia no risco de mortalidade cardiovascular em pacientes com DMII. 


\subsubsection{Infarto Agudo do Miocárdio (IAM) Não Fatal}

Seis estudos reportaram dados para o desfecho infarto agudo do miocárdio não fatal.

O estudo Kumamoto não apresentou dados para este desfecho, não sendo possível incluí-lo na meta-análise.

Três estudos demonstraram significantemente que o tratamento intensivo reduz a incidência de IAM não fatal, com as respectivas reduções de risco relativos (RRR) e riscos relativos $(\mathrm{RR})$ :

ACCORD(141) : RRR 21\% - RR 0,79 IC95\% $(0,65-0,95)$

Steno -2(142) : RRR 71\% - RR 0,29 IC95\% (0,11-0,76)

UKPDS(143): RRR 19\% - RR 0,81 IC 95\% (0,65-1,02)

Três estudos (ADVANCE, VACSDM E VADT) não encontraram significância estatística entre os tratamentos intensivo e convencional.

O resultado da meta-análise demonstra uma redução de risco relativo (RRR) de $17 \%$ de IAM não fatal para o tratamento intensivo [RR 0,83 IC 95\% $(0,71-0,97)$ ], com significância estatística. (Figura 4).

A heterogeneidade entre os estudos foi moderada $\left(\mathrm{I}^{2}=34 \%\right)$.

\subsubsection{Acidente Vascular Cerebral (AVC) Não Fatal}

Seis estudos reportaram dados para o desfecho AVC não fatal.

O estudo Kumamoto não apresentou dados dos desfechos individuais, não sendo possível incluí-lo na meta-análise.

Nenhum estudo individual alcançou significância estatística para este evento.

O resultado da meta-análise aponta que não há diferença estatisticamente significante nos dois braços de tratamento do estudo para o desfecho AVC não fatal [RR 0,92 IC95\%(0,69-1,23)] (Figura 5).

A heterogeneidade entre os estudos foi moderada $\left(\mathrm{I}^{2}=61 \%\right)$. 
Intensivo Comencional

Risk Ratio

Study or Subgroup

Events

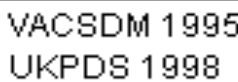

Steno-2 2003

ACCORD 2008

ADVANCE 2008

VADT 2009

Total (95\% Cl)

Total events

Heterogeneity: $\operatorname{Tau}^{2}=0.01 ; \mathrm{Chi}^{2}=7.55, \mathrm{df}=5(\mathrm{P}=0.18) ; \mathrm{I}^{2}=34 \%$

Test for overall effect: $Z=2.36(P=0.02)$

$153 \quad 5571 \quad 156 \quad 5569 \quad 25.5 \%$
Risk Ratio

M-H, Random, 95\% Cl

$\begin{array}{lllllll}221 & 3071 & 101 & 1138 & 24.8 \% & 0.81[0.65,1.02] & 1998\end{array}$

$\begin{array}{lllllll}5 & 80 & 17 & 80 & 2.5 \% & 0.29[0.11,0.76] & 2003\end{array}$

$0.79[0.65,0.95] 2008$

$0.98[0.79,1.22] 2008$

$0.83[0.60,1.14] 2009$

\section{$0.83[0.71,0.97]$}

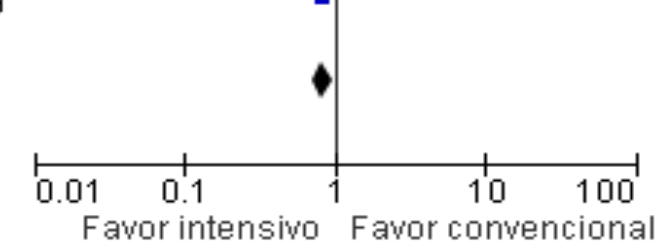

Figura 4 - Controle intensivo versus convencional de glicemia sobre Infarto Agudo do Miocárdio não-fatal em pacientes com DMII.

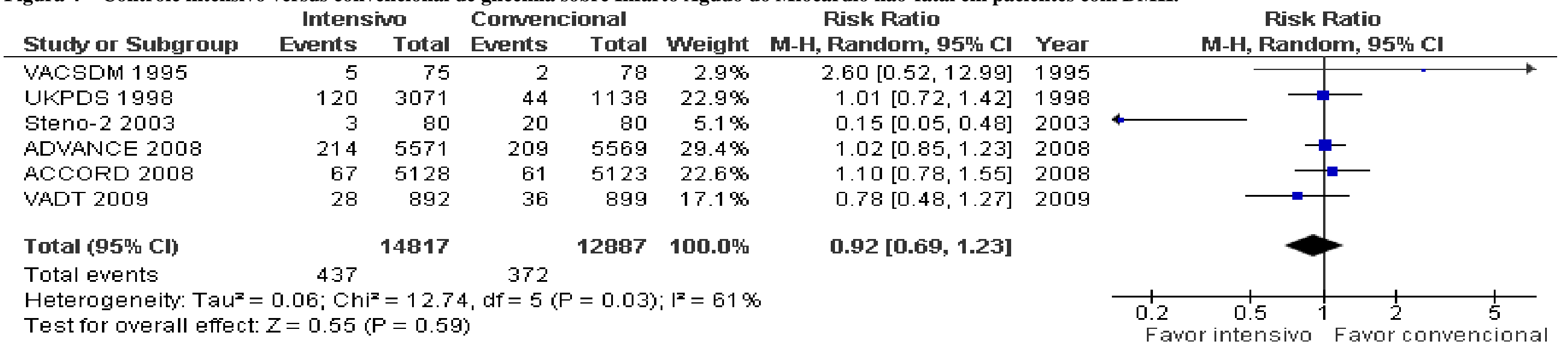

Figura 5 - Controle intensivo versus convencional da glicemia sobre Acidente Vascular Cerebral não-fatal em pacientes com DMII. 


\subsubsection{Amputação de Membros}

Somente quatro estudos reportaram dados sobre amputação de membros: VACSDM, UKPDS, Steno-2 e VADT.

Nenhum estudo apresentou diferença estatisticamente significante entre os tratamentos intensivo e convencional na incidência de amputação de membros, porém, todos tenderam a favorecer o tratamento intensivo. A exceção foi o estudo VACSDM, que tendeu a demonstrar menor incidência no grupo do tratamento convencional.

Entretanto, a meta-análise demonstrou de forma estatisticamente significante uma menor incidência de amputação de membros no braço do tratamento intensivo que o convencional [RR 0,64 IC95\%(0,43-0,96)] (Figura 5).

A RRR para o desfecho foi de $36 \%$ e os resultados foram considerados homogêneos pelo teste estatístico $\left(\mathrm{I}^{2}=0 \%\right)$.

\subsubsection{Desfechos Combinados Macrovasculares}

Para o desfecho combinado de eventos macrovasculares só foi possível realizar a meta-análise dos estudos ACCORD e ADVANCE, que combinavam os mesmos desfechos clínicos. Para os demais estudos que reportaram desfechos combinados macrovasculares, não foi possível a realização da meta-análise devido a diferenças de definições, conseguimos, apenas, visualizar as medidas de efeito dos estudos individuais.

Os desfechos combinados dos estudos que reportaram foram definidos conforme:

ACCORD: desfecho combinado de IAM não fatal ou AVC não fatal ou morte cardiovascular

ADVANCE: desfecho combinado de IAM não fatal, AVC não fatal e mortalidade cardiovascular,

Steno-2: desfecho combinado de IAM não-fatal, mortalidade cardiovascular, AVC nãofatal, uso de marcapasso, intervenção coronariana percutânea periférica, amputação resultante de isquemia ou cirurgia vascular por doença arterial periférica aterosclerótica. UKPDS: desfecho combinado de qualquer evento relacionado ao DM: morte súbita, morte por hiperglicemia ou hipoglicemia, infarto fatal ou não fatal, angina, insuficiência 
cardíaca, AVC, insuficiência renal, amputação (pelo menos 1 dedo), hemorragia vítrea, retinopatia que requeira fotocoagulação, cegamento em 1 olho ou extração da catarata.

O estudo ACCORD e o estudo ADVANCE não encontraram diferenças entre o controle intensivo e controle convencional de glicemia, apesar do estudo ACCORD ter sido interrompido precocemente por aumento de mortalidade cardiovascular no grupo de tratamento intensivo, que é um desfecho individual que compõe o desfecho combinado deste estudo (Figura 7).

Por outro lado, os estudos Steno-2 e o UKPDS demonstraram uma redução de risco relativo (RRR) de, respectivamente, $46 \%$ e 10\%, estatisticamente significantes. Ainda, o intervalo de confiança do estudo Steno-2 é largo, por causa do tamanho pequeno da amostra. Já no UKPDS, que incluiu uma amostra maior (total=4209), a RRR foi mais modesta, mas o intervalo de confiança foi bem mais estreito. (Figura 6) 


\begin{tabular}{|c|c|c|c|c|c|c|c|c|c|c|}
\hline Stucły or Subgroup & $\begin{array}{l}\text { Intens } \\
\text { Events }\end{array}$ & $\begin{array}{l}\text { ino } \\
\text { Total }\end{array}$ & $\begin{array}{l}\text { Comven } \\
\text { Events }\end{array}$ & $\begin{array}{l}\text { onal } \\
\text { Total }\end{array}$ & \multicolumn{3}{|c|}{ Risk Ratio } & \multicolumn{3}{|c|}{$\begin{array}{c}\text { Risk Ratio } \\
\text { M-H, Random, 95\% Cl }\end{array}$} \\
\hline VACSDM 1995 & 1 & 75 & 0 & 78 & $1.6 \%$ & $3.12[0.13,75.37]$ & 1995 & & & \\
\hline UKPDS 1998 & 33 & 3071 & 18 & 1138 & $48.7 \%$ & $0.68[0.38,1.20]$ & 1998 & & & \\
\hline Steno-2 2003 & 7 & 80 & 14 & 80 & $21.8 \%$ & $0.50[0.21,1.17]$ & 2003 & & & \\
\hline VADT 2009 & 11 & 892 & 17 & 899 & $28.0 \%$ & $0.65[0.31,1.38]$ & 2009 & & & \\
\hline Total (95\% Cl) & & 4118 & & 2195 & $100.0 \%$ & $0.64[0.43,0.96]$ & & & & \\
\hline Total events & 52 & & 49 & & & & & & & \\
\hline $\begin{array}{l}\text { Heterogeneity: Tau } \\
\text { Test for overall effec }\end{array}$ & $\begin{array}{l}0.00 ; \text { Chi } \\
Z=2.17(\end{array}$ & $\begin{array}{l}\mathrm{i}^{2}=1.32 \\
\mathrm{P}=0.0\end{array}$ & 2, $d f=3($ & $=0.73)$ & $;\left.\right|^{2}=0 \%$ & & & $\begin{array}{cc}0.2 & 0.5 \\
\text { Favor intensivo }\end{array}$ & $\frac{2}{2}$ & 5 \\
\hline
\end{tabular}

Figura 6 - Controle intensivo versus convencional da glicemia sobre amputação de membros em pacientes com DMII.

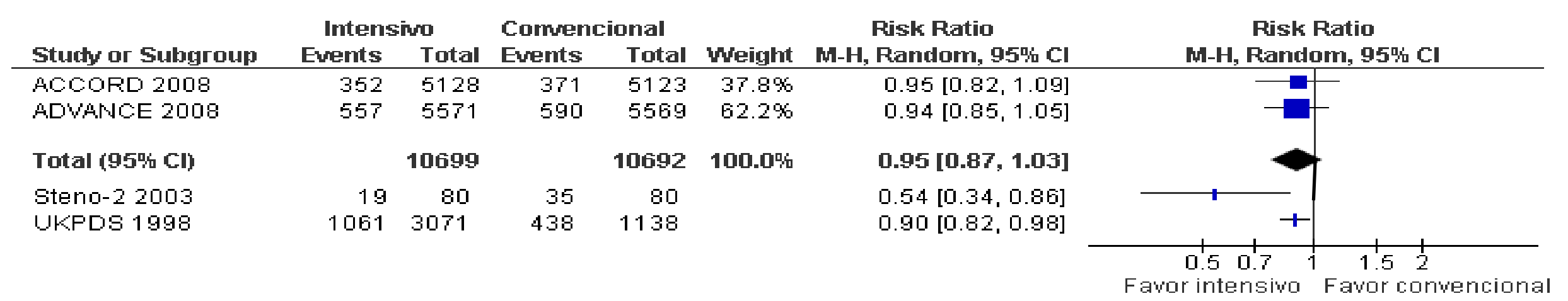

Figura 7 - Controle intensivo versus convencional de glicemia sobre desfecho combinado macrovascular em pacientes com DMII. 


\subsubsection{Desfechos Microvasculares}

\subsubsection{Retinopatias}

As retinopatias englobam uma série de situações clínicas com definições distintas. Nem todos os estudos reportaram dados para todas as definições.

A meta-análise foi realizada quando dois ou mais estudos reportavam dados para a mesma classificação.

Assim, os dados foram analisados conforme descrições abaixo:

\subsection{Incidência e progressão}

Quatro estudos apresentaram dados para incidência e cinco estudos reportaram dados para progressão. À exceção do estudo Steno-2, que utilizou a escala de 6 niveis da European Community-funded Concerted Action Programme para definição de incidência e o VACSDM, que definiu incidência como a presença de pelo menos 3 microaneurisma na soma dos 2 olhos, todos os demais utilizaram a escala ETDRS (Early Treatment of Diabetic Retinopathy Study) para incidência e progressão, porém modificadas em relação ao número de níveis na escala. A incidência definida como elevação de mais de um nível a partir do nível 1 e progressão variando como elevação de $\geq 2$ ou $\geq 3$ níveis, entre os estudos.

Para incidência de retinopatia, somente o estudo Kumamoto encontrou dados estatisticamente significantes a favor do tratamento intensivo.

A meta-análise demonstrou não haver diferença entre os tratamentos intensivo e convencional na incidência de retinopatia [RR 0,76 IC95\%(0,52-1,11)] (figura 8) e o teste para heterogeneidade foi moderado $\mathrm{I}^{2}=51 \%$.

$\mathrm{Na}$ avaliação da progressão de retinopatia, o resultado da meta-análise demonstrou uma redução de risco relativo (RRR) de $20 \%$ no grupo intensivo [RR 0,80 IC95\%(0,71-0,91)] (figura 8). Este dado foi estatisticamente significante. A homogeneidade entre os estudos foi inexistente $\mathrm{I}^{2}=0 \%$. 
Embora as meta-análises não tenham mostrado efeito benéfico estatisticamente significativo para as diversas formas como retinopatia foi definida, as estimativas de feito são todas consistentes com benefícios nos pacientes tratados de forma intensiva. 
Intensing Compencional

Stuchy or Subgroup Events Total Events Incidência de retinopatia

Kumamoto 1995

Steno-2 2003

VACSDW 1995

VADT 2009

Total events

Heterogeneity: $\operatorname{Tau}^{2}=0.07 ; \mathrm{Chi}^{2}=6.12, \mathrm{df}=3(\mathrm{P}=0.11) ; \mathrm{I}^{2}=51 \%$

Test for overall effect: $Z=1.43(\mathrm{P}=0.15$ )

\section{progressão da retinopatia}

Kumamoto 1995

UKPDS 1998

VACSDM 1995

VADT 2009

Subtotal (95\% Cl)

Total events

$\begin{array}{rrr}6 & 27 & 16 \\ 363 & 1171 & 172 \\ 13 & 36 & 17 \\ 69 & 406 & 88 \\ & \mathbf{1 6 4 0} & \end{array}$

Heterogeneity: Tau $^{2}=0.01 ; \mathrm{Chi}^{2}=3.75, \mathrm{df}=3(\mathrm{P}=0.29) ; \mathrm{I}^{2}=20 \%$

Test for overall effect: $Z=2.73(\mathrm{P}=0.006)$

428

$27 \quad 80$

827

$54 \quad 128$

263

93

Risk Ratio

Total Weight M-H, Random, 95\% CI

$0.30[0.11,0.80]$

$0.71[0.48,1.04]$

$1.48[0.56,3.93]$

$0.86[0.66,1.13]$

$0.76[0.52,1.11]$

$$
122
$$

$135 \quad 524 \%$

267100.0 吆

\section{$28 \quad 6.7 \%$}

$51.3 \%$

$42 \quad 11.5 \%$

$39930.6 \%$

$928100.0^{\text {吹 }}$

$451 \quad 293$

$0.39[0.18,0.84]$

$0.83[0.71,0.96]$

$0.89[0.51,1.58]$

$0.77[0.58,1.02]$

0.79 [0.66, 0.94]

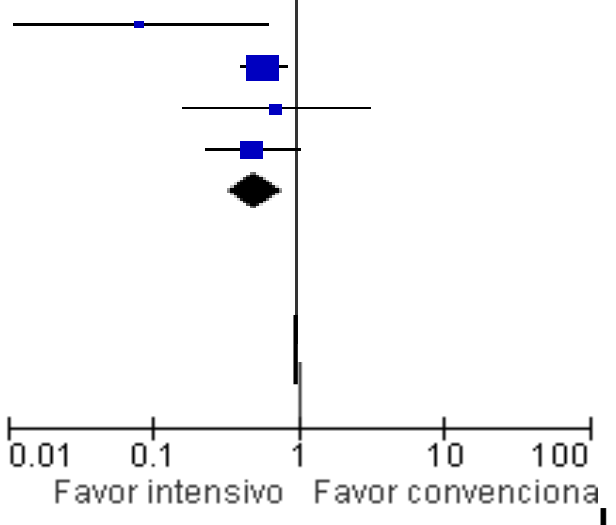

Figura 8 - Controle intensivo versus convencional de glicemia sobre retinopatias em pacientes com DMII. 
4.4.4.1.2 Progressão para maculopatia, retinopatia proliferativa, fotocoagulação retinal, hemorragia vítrea e extração de catarata

Poucos estudos reportaram retinopatias mais graves, como maculopatia e retinopatia proliferativa.

Para avaliação da progressão para maculopatia, três estudos reportaram dados para o desfecho: ADVANCE, VACSDM e VADT. A meta-análise não demonstrou diferenças entre os tratamentos [RR 0,68 IC95\% (0,46-1,02)]. O teste para heterogeneidade foi 0\%. (Figura 9).

Já em relação à progressão para retinopatia proliferativa, apenas dois estudos reportaram dados para este desfecho: VACSDM e VADT. A meta-análise não demonstrou diferenças entre os tratamentos [RR 1,39 IC95\% (0,76-2,56)], porém tendeu a um aumento na incidência no grupo tratamento intensivo. $O$ teste para heterogeneidade foi 0\%. (Figura 9).

Retinopatias requerendo fotocoagulação retinal, apenas dois estudos reportaram dados: UKPDS e VADT. A meta-análise não demonstrou diferenças entre os tratamentos [RR 0,84 IC 95\% $(0,62-1,14)] \mathrm{O}$ teste para heterogeneidade foi alto $\left(\mathrm{I}^{2}=73 \%\right)$. (Figura 9).

Dados para hemorragia vítrea foram reportados pelo estudo UKPDS e VADT. A meta-análise não demonstrou diferenças entre os tratamentos [RR 0,98 IC 95\% (0,661,44)]. A heterogeneidade foi 0\% (Figura 9)

Para o desfecho extração de catarata, três estudos apresentaram dados: ACCORD, UKPDS e VADT. A meta-análise não demonstrou diferenças entre os tratamentos [RR 0,91 IC 95\% (0,78-1,05)]. A heterogeneidade foi moderada $\left(\mathrm{I}^{2}=41 \%\right)$. (Figura 9). 
Intensivo Comencional

Risk Ratio

Risk Ratio

Study or Subgroup Events Total Events Total Weight M-H, Random, 95\% CI

\begin{tabular}{|c|c|c|c|c|c|}
\hline \multicolumn{6}{|l|}{ progress } \\
\hline ADVANCE 2008 & 24 & 791 & 33 & 811 & 57. \\
\hline VACSDM 1995 & 3 & 75 & 8 & 78 & 10. \\
\hline $\begin{array}{l}\text { VADT } 2009 \\
\text { Subtotal (95\% Cl) }\end{array}$ & 12 & $\begin{array}{r}371 \\
1237\end{array}$ & 17 & $\begin{array}{r}361 \\
1250\end{array}$ & $\begin{array}{r}31.7 \\
100.0\end{array}$ \\
\hline Total events & 39 & & 58 & & \\
\hline
\end{tabular}

Heterogeneity: $\operatorname{Tau}^{2}=0.00 ; \mathrm{Ch}^{2}=0.84, \mathrm{df}=2(\mathrm{P}=0.66) ; \mathrm{I}^{2}=0 \%_{0}$ Test for overall effect: $Z=1.87(\mathrm{P}=0.06)$

$\begin{array}{lrrrrr}\text { progressão retinopatia proliferatina } & & & \\ \text { VACSDM } 1995 & 1 & 75 & 1 & 78 & 5.4 \% \\ \text { VADT 2009 } & 23 & 406 & 16 & 399 & 94.6 \% \\ \text { Subtotal (95\% Cl) } & & \mathbf{4 8 1} & & \mathbf{4 7 7} & \mathbf{1 0 0 . 0 \%}\end{array}$

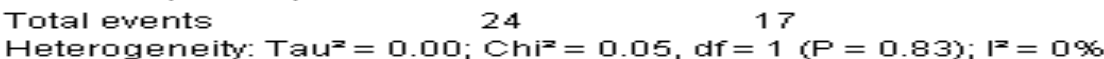

Test for Overall

\begin{tabular}{|c|c|c|c|c|c|}
\hline & & & & & \\
\hline UKPDS 1998 & 229 & 3071 & 117 & 1138 & $52.3 \%$ \\
\hline $\begin{array}{l}\text { VADT } 2009 \\
\text { Subtotal (95\% Cl) }\end{array}$ & 119 & $\begin{array}{r}769 \\
\mathbf{3 8 4 0}\end{array}$ & 121 & 1972 & $\begin{array}{r}47.7 \% \\
100.0 \%\end{array}$ \\
\hline Total events & 348 & & 238 & & \\
\hline
\end{tabular}

Heterogeneity: $\mathrm{Tau}^{2}=0.03 ; \mathrm{Chi}^{2}=3.69, \mathrm{df}=1(\mathrm{P}=0.05) ; \mathrm{I}^{2}=73 \%$ Test for overall effect: $Z=1.11(\mathrm{P}=0.27)$

$\begin{array}{llllll}\quad \text { hemorragia vítrea } & & & & & \\ \text { UKPDS 1998 } & 21 & 3071 & 10 & 1138 & 29.6 \% \\ \text { VADT2009 } & 36 & 769 & 34 & 772 & 70.4 \% \\ \text { Subtotal (95\% Cl) } & & \mathbf{3 8 4 0} & & \mathbf{1 9 1 0} & \mathbf{1 0 0 . 0 \%} \\ \text { Total events } & 57 & & 44 & & \end{array}$

Total events 57.44

$100.4 \%$

烈

Test for overall effect: $z=0.12(\mathrm{P}=0.91)$

\section{extração catarata}

\begin{tabular}{|c|c|c|c|c|c|}
\hline ACCORD 2008 & 447 & 4886 & 495 & 4910 & 45 \\
\hline UKPDS 1998 & 163 & 3071 & 80 & 1138 & \\
\hline $\begin{array}{l}\text { VADT } 2009 \\
\text { Subtotal (95\% Cl) }\end{array}$ & 144 & $\begin{array}{r}769 \\
8726\end{array}$ & 139 & $\begin{array}{r}772 \\
6820\end{array}$ & $\begin{array}{r}30.5 \\
100.0\end{array}$ \\
\hline
\end{tabular}

Heterogeneity: $\operatorname{Tau}^{2}=0.01 ; \mathrm{Chi}^{2}=3.55, \mathrm{df}=2(\mathrm{P}=0.17): \mathrm{I}^{2}=449$

Test for overall effect: $Z=1.33(\mathrm{P}=0.1 \mathrm{~B})$

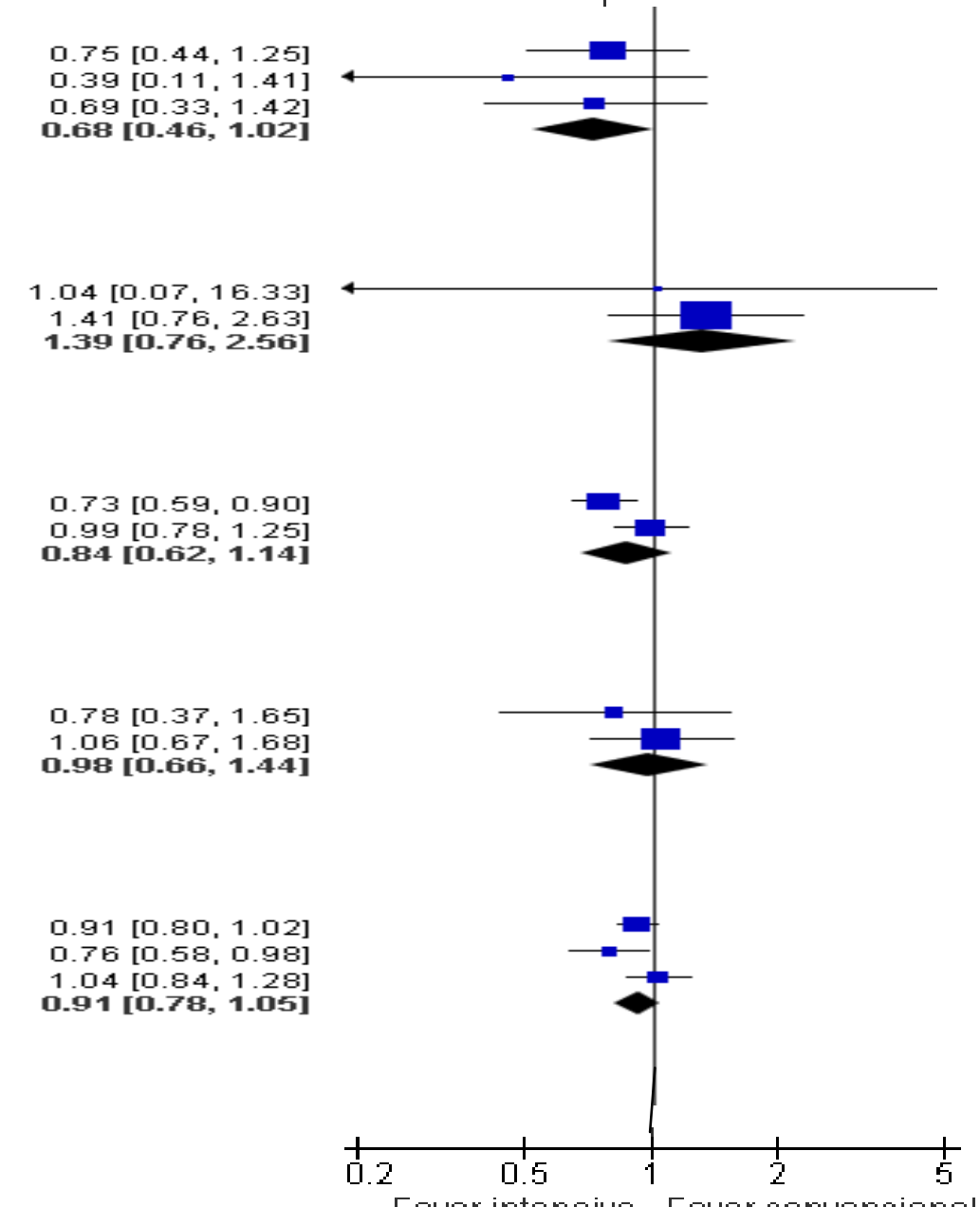

Favor intensivo Favor convencional

Figura 9 - Controle intensivo versus convencional da glicemia sobre retinopatias em pacientes com DMII. 


\subsection{Desfechos combinados de retinopatia}

Quatro estudos reportaram dados para o desfecho combinado de incidência ou progressão: ADVANCE, Kumamoto, Steno-2 e VACSDM. A meta-análise não demonstrou diferenças entre os tratamentos intensivo e convencional para este desfecho [RR 0,76 IC 95\% (0,55-1,06)]. A heterogeneidade foi alta $\left(\mathrm{I}^{2}=74 \%\right)$. (Figura 10).

Para o desfecho combinado de maculopatia ou retinopatia proliferativa, apenas o estudo Steno-2 apresentou dados para este desfecho, de modo que não foi possível realizar a meta-análise. De qualquer forma, o cálculo do risco relativo (RR) para este desfecho não demonstrou haver diferenças entre os tratamentos intensivo e convencional [RR 0,78 IC 95\% (0,30-1,99)].(Figura 10).

Para o desfecho combinado de progressão de retinopatia ou retinopatia proliferativa ou vitrectomia, apenas o estudo ACCORD reportou dados para este desfecho e a meta-análise não foi realizada. O RR calculado para este desfecho não foi estatisticamente significante para este evento e, portanto, não demonstrou diferenças entre os tratamentos. (Figura 10).

\subsubsection{Deterioração Visual}

Três estudos reportaram dados para piora na acuidade visual. A meta-análise para este desfecho demonstrou não haver diferenças estatisticamente significantes entre os tratamentos [RR 0,95 IC 95\%(0,83-1,08)] A heterogeneidade foi moderada $\left(\mathrm{I}^{2}=57 \%\right)$. (Figura 11).

Em relação à cegueira, dois estudos reportaram o desfecho (UKPDS e Steno-2), não havendo diferenças estatisticamente significantes entre os tratamentos no resultado da meta-análise [RR 0,47 IC 95\% (0,0,9-2,59)] (Figura 11). O resultado é bastante impreciso e heterogêneo $\left(\mathrm{I}^{2}=66 \%\right)$. 


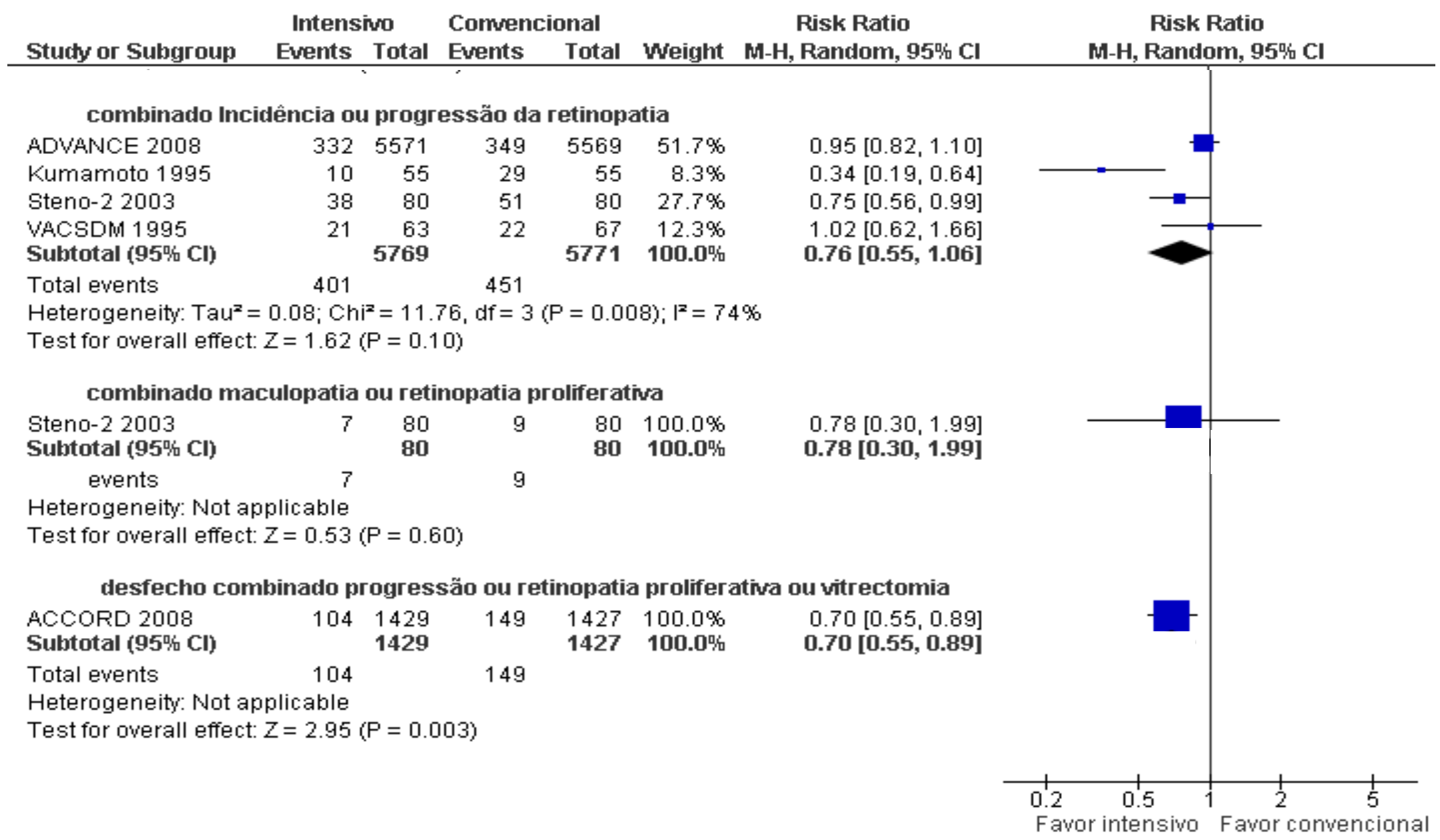

Figura 10 - Controle intensivo versus convencional da glicemia sobre desfechos combinados de retinopatias em pacientes com DMII. 
Intensivo Comencional

Risk Ratio

Risk Ratio

Study or Subgroup Events Total Events Total weight M-H, Random, 95\% Cl Year cegueira

UKPDS 1998

Steno-2 2003

Subtotal (95\% Cl)

$\begin{array}{rrrrr}90 & 3071 & 38 & 1138 & 96.1 \% \\ 1 & 80 & 7 & 80 & 3.9 \% \\ & \mathbf{3 1 5 1} & & \mathbf{1 2 1 8} & \mathbf{1 0 0 . 0 \%}\end{array}$

$0.88[0.60,1.27] 1998$

Total events

91

45

Heterogeneity: $\operatorname{Tau}^{2}=1.10 ; \mathrm{Chi}^{2}=2.90, \mathrm{df}=1(\mathrm{P}=0.09) ; \mathrm{I}^{2}=66 \%$

Test for overall effect: $Z=0.86(P=0.39$ )

\section{deteriorização visual}

\begin{tabular}{|c|c|c|c|c|c|}
\hline VACSDM 1995 & 5 & 75 & 7 & 78 & $1.8 \%$ \\
\hline ADVANCE 2008 & 3033 & 5571 & 3015 & 5569 & $57.7 \%$ \\
\hline $\begin{array}{l}\text { ACCORD } 2008 \\
\text { Subtotal (95\% Cl) }\end{array}$ & 360 & $\begin{array}{r}4450 \\
10096\end{array}$ & 417 & $\begin{array}{r}4483 \\
10130\end{array}$ & $\begin{array}{r}40.5 \% \\
100.0 \%\end{array}$ \\
\hline $\begin{array}{l}\text { Total events } \\
\text { Heterogeneity: } \\
\text { Test for overall }\end{array}$ & $\begin{array}{r}3398 \\
01 ; \mathrm{Ch} \\
=0.81\end{array}$ & & $\begin{array}{l}3439 \\
f=2(P\end{array}$ & & \\
\hline
\end{tabular}

$1.01[0.97,1.04] 2008$

$0.87[0.76,1.00] 2008$

$0.95[0.83,1.08]$

M-H, Random, 95\% CI

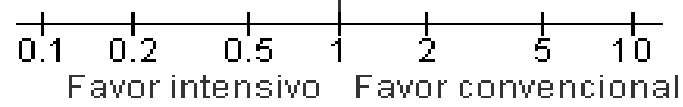

Figura 11 - Controle intensivo versus convencional da glicemia sobre deterioração visual em pacientes com DMII. 


\subsubsection{Neuropatias}

Apenas o estudo ADVANCE reporta desfecho combinado de incidência ou progressão de neuropatia, sem discriminar entre autonômica ou periférica. Assim, não foi possível realizar a meta-análise deste desfecho, embora a estimativa do efeito seja bastante precisa e aponta para a não diferença entre os tratamentos intensivo e convencional para o desfecho. (RR 1,02 IC 95\%(0,97-1,06) (Figura 12).

Os estudos que especificaram o tipo de neuropatia como autonômica ou periférica foram os estudos UKPDS, Steno-2 e VADT, e o Kumamoto. Entretanto, apesar do estudo UKPDS apresentar a definição de neuropatia autonômica, ele não reporta os dados para este desfecho. Ainda, os dados de neuropatia do estudo Kumamoto não podem ser extraídos como números de pacientes que desenvolveram ou progrediram da neuropatia periférica ou autonômicas, já que eles apresentam os dados de desfechos substitutos, com variações numéricas das medidas que caracterizaram cada tipo de neuropatia, como a média da velocidade de condução do nervo para neuropatia periférica e coeficiente de variação dos intervalos R-R do ECG e hipotensão ortostática para neuropatia autonômica, sem definir o limiar que caracterizou incidência ou progressão.

O estudo ACCORD apenas deixa claro que a neuropatia periférica foi medida pelo MNSI (Michigan neurophathy screening instrument) > 2.0, apesar de apresentar dados para quatro desfechos de neuropatia, não discernindo se os outros três se tratavam de medidas para avaliarem neuropatias autonômicas ou periféricas.

Assim, as definições de neuropatias para os demais estudos que reportaram dados são:

UKPDS: neuropatia periférica: perda do reflexo de joelho e tornozelo ou média da leitura do biotesiometro dos dois dedos $>25 \mathrm{~V}$; autonômica: intervalo RR menor que o valor normal ajustado para a idade, medido no ECG durante respiração compassada em 5 ciclos.

Steno-2: neuropatia periférica: medida por biotensiometro; autonômica: medida do intervalo RR do ECG durante respiração compassada e teste de hipotensão ortostática.

VADT: Neuropatia periférica: definido como radiculoneuropatia, polineuropatia, amiopatia diabética ou úlcera neuropática; autonômica: sintomas de hipotensão ortostática, gastroparesia, bexiga neurogênica ou diarréia diabética. 
Não foi realizada a meta-análise para o desfecho neuropatia autonômica, já que os dois estudos que reportaram dados para este desfecho apresentaram tendências de medida de efeito totalmente opostas.

Para o desfecho neuropatia periférica, a meta-análise demonstrou uma redução de risco relativo (RRR) na incidência de 6\%. A heterogeneidade foi nula. [RR 0,94 IC 95\% $(0,97$ - 1,06)] (Figura 12). 
Intensivo Comencional

Risk Ratio

Risk Ratio

Stucty or Subgroup

Events Total Events

Total Weight M-H, Random, 95\% Cl Year

M-H, Random, 95鸣 Cl

Steno-2 2003

VADT 2009

$\begin{array}{lll}24 & 80 & 43\end{array}$

$38 \quad 464 \quad 26$

$80 \quad 59.1 \%$

$498 \quad 40.9 \%$

\begin{tabular}{|c|c|c|c|c|c|}
\hline UKPDS 1998 & 354 & 1521 & 168 & 607 & 23.9 \\
\hline Steno-2 2003 & 40 & 80 & 40 & 80 & 9. \\
\hline ACCORD 2008 & 1277 & 2815 & 1338 & 2791 & 42 \\
\hline $\begin{array}{l}\text { VADT } 2009 \\
\text { Subtotal (95\% Cl) }\end{array}$ & 178 & $\begin{array}{r}464 \\
4880\end{array}$ & 199 & $\begin{array}{r}498 \\
3976\end{array}$ & $\begin{array}{r}23 . \\
100 .\end{array}$ \\
\hline $\begin{array}{l}\text { Total events } \\
\text { Heterogeneity: Ta } \\
\text { Test for overall eff }\end{array}$ & $\begin{array}{r}1849 \\
00 ; \mathrm{Ch} \\
=2.54\end{array}$ & & $\begin{array}{r}1745 \\
\text { df }=3\end{array}$ & & \\
\hline
\end{tabular}

Test for overall effect: $Z=2.54(P=0.01)$

nowo evento ou piora neuropatia

ADVANCE 2008

23535571

$2311 \quad 5569 \quad 100.0 \%$

$0.56[0.38,0.83] 2003$

$1.57[0.97,2.54] 2009$

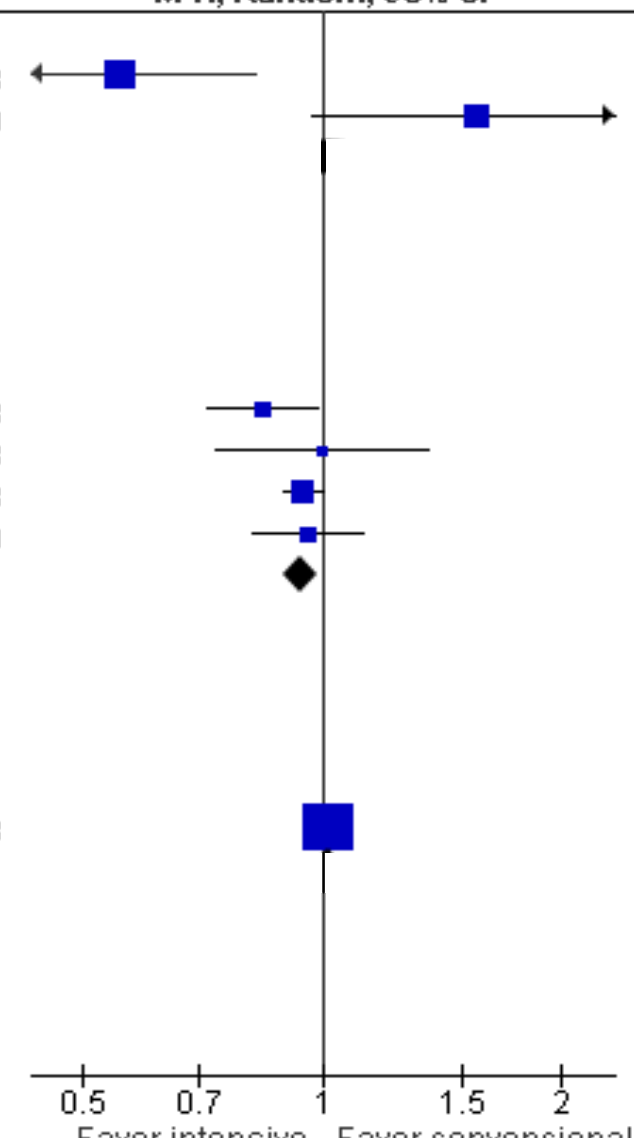

$0.84[0.72,0.98] 1998$

$1.00[0.73,1.36] 2003$

$0.95[0.89,1.00] 2008$

$0.96[0.82,1.12] 2009$

Favor intensivo Favor convencional
$0.94[0.89,0.99]$

Total events

2353

2311

Heterogeneity: Not applicable

Test for overall effect: $Z=0.79(P=0.43)$ 


\subsubsection{Nefropatias}

Para lesões renais diabéticas, avaliamos 4 desfechos clínicos e um desfecho combinado.

Os estudos que reportaram dados para nefropatia adotaram as seguintes definições:

Kumamoto: os pacientes foram divididos em 3 estágios dependendo da excreção de albumina: normoalbuminuria ( $<30 \mathrm{mg} / 24 \mathrm{~h}$ ), microalbuminuria $(30-300 \mathrm{mg} / 24 \mathrm{~h})$, ou albuminuria (>300 mg/24 h). A progressão foi definida como a elevação de qualquer nível.

UKPDS: falência renal não fatal: evolução para diálise ou creatinina plasmática $>250$ $\mu \mathrm{mol} / \mathrm{L}$; microalbuminuria: concentração de albumina urinaria $>50 \mathrm{mg} / \mathrm{L}$; proteinuria: concentração albumina urinaria> $300 \mathrm{mg} / \mathrm{L}$ (considerado como incidência).

Steno-2: incidência: razão excreção albumina > 300mg em urina $24 \mathrm{~h}$

VADT: nefropatia severa: níveis de creatinina $>3 \mathrm{mg} / \mathrm{dL}(265 \mu \mathrm{mol} / \mathrm{L})$; progressão da albuminuria definida como aumento da albuminuria por pelo menos 2 visitas sucessivas anuais sem melhora do nível anterior.

VACSDM: microalbuminuria definido como excreção de razão albumina:creatinina entre 0,03 - 0,30 (ambas em mg/100 mL); nefropatia clínica como albumina urinária > $300 \mathrm{mg} / 24 \mathrm{~h}$ ou uma razão albumina creatinina > 0,2. Estágio final de doença renal como creatinina sérica $>265,2 \mu \mathrm{M}$ e/ou necessidade de diálise ou transplante.

ADVANCE: desfecho combinado de novo evento ou piora, sendo o desenvolvimento de macroalbuminuria, definido como razão albuminia:creatinina urinaria maior que 300 $\mu \mathrm{g}$ de albumina por $\mathrm{mg}$ de creatinina - 33,9 mg/mmol, ou o dobro dos níveis de creatinina para pelo menos $200 \mu \mathrm{mol} / \mathrm{L}=2,26 \mathrm{mg} / \mathrm{dL}-$, necessidade de terapia de reposição renal ou morte por doença renal; microalbuminuria: razão de albumina:creatinina urinaria 30 a $300 \mu \mathrm{g} / \mathrm{mg}-0,34$ a $33,9 \mathrm{mg} / \mathrm{mmol}$.

ACCORD: desfecho combinado de macroalbuminuria, definido pela razão albumina:creatinina $\geq 33.9 \mathrm{mg} / \mathrm{mmol}$ ou desenvolvimento de falência renal (diálise ou ESRD (end stage renal disease) ou transplante renal, ou aumento de creatinina sérica > $291,72 \mu \mathrm{mol} / \mathrm{L}$ na ausência de qualquer causa aguda) ou dobro de creatinina de base ou 
mais uma diminuição de $20 \mathrm{~mL} / \mathrm{min}$ por $1,73 \mathrm{~m} 2$ na razão de filtração glomerular (RFG); microalbuminuria: razão albumina:creatinina $\geq 3,4 \mathrm{mg} / \mathrm{mmol}$.

Dos resultados avaliados para os desfechos clínicos individuais, a meta-análise não demonstrou diferença entre os tratamentos para o desfecho "diálise" [RR 0,60 IC $95 \%(0,20-1,78)]$, com heterogeneidade baixa $\left(I^{2}=13 \%\right)$; e para o desfecho combinado comum entre os estudos ACCORD e ADVANCE [RR 0,90 IC 95\% (0,70-1,16)], com heterogeneidade alta $\left(\mathrm{I}^{2}=88 \%\right)$. (Figura 13).

Tanto a incidência quanto a progressão de nefropatia e incidência de microalbuminuria tiveram suas meta-análises com resultados estatisticamente significantes favorecendo o tratamento intensivo, com diferenças nos estudos que reportaram dados para estes desfechos.

Assim, os 4 estudos (Kumamoto, UKPDS, Steno-2 e VADT) que reportaram dados para incidência de nefropatia, apontaram uma redução de risco relativo (RRR) de $35 \%$ no evento no grupo intensivo [RR 0,65 IC 95\% (0,43-0,98)] (Figura 12). Entretanto, deve-se considerar que a heterogeneidade foi alta entre os estudos $\left(\mathrm{I}^{2}=71 \%\right)$. A incidência de microalbuminuria segue o mesmo padrão do desfecho anterior, sendo que os 5 estudos que reportaram dados para este desfecho (VACSDM, UKPDS, VADT, ADVANCE e ACCORD) resultaram em uma meta-análise que demonstra uma RRR de $22 \%$ no grupo tratado intensivamente [RR 0,78 IC 95\% $(0,65-0,92)$ (Figura 12). A heterogeneidade foi alta $\left(\mathrm{I}^{2}=79 \%\right)$.

O resultado mais relevante para nefropatias foi em relação à progressão da nefropatia. $\mathrm{O}$ grupo de tratamento intensivo demonstrou uma redução de risco relativo de $45 \%$ para este evento [RR 0,55 IC 95\% (0,37 - 0,80) (Figura 13). E ainda, os resultados foram homogêneos entre os estudos $\left(\mathrm{I}^{2}=0 \%\right)$. 
Intensino

Commencional

Risk Ratio

Risk Ratio

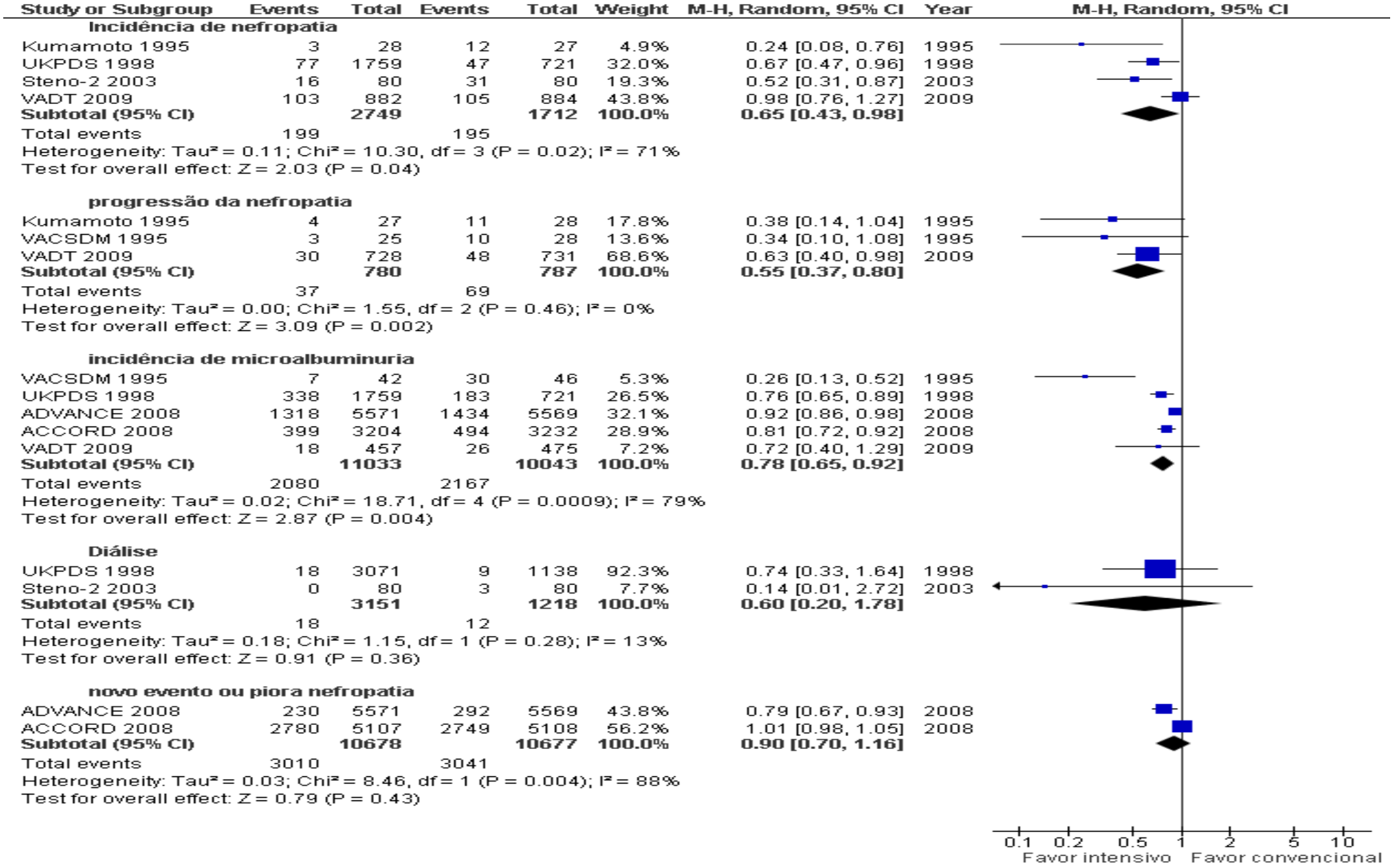

Figura 13 - Controle intensivo versus convencional da glicemia sobre nefropatias em pacientes com DMII. 


\subsubsection{Desfecho Combinado Microvascular}

A meta-análise para desfechos combinados de eventos microvasculares só foi possível ser calculada para os dados reportados nos estudos UKPDS e ACCORD, que incluíram os mesmos eventos. Ainda, o estudo ACCORD reportou dados para um outro desfecho microvascular, que incluiu as neuropatias. Tanto para este, quanto para o desfecho combinado reportado pelo estudo ADVANCE, não se realizou a meta-análise e a estimativa de efeito é apresentada para os estudos individuais (Figura 14). Abaixo, seguem as definições nos estudos que reportaram desfechos combinados microvascular:

UKPDS: retinopatia requerendo fotocoagulação, hemorragia vítrea e falência renal fatal e não fatal

ACCORD: desfecho combinado 1: Desenvolvimento de falência renal (iniciação de diálise ou ESDR, transplante renal ou aumento de creatinina sérica > 291,72 $\mu \mathrm{mol} / \mathrm{L}$ ) ou potocoagulação retinal ou vitrectomia para tratar retinopatia; desfecho combinado 2 : desfecho combinado 1 ou Score MNSI > 2.0.

ADVANCE: novo evento ou piora de nefropatia (desenvolvimento de macroalbuminuria, definido como razão albuminia:creatinina urinaria maior que $300 \mu \mathrm{g}$ de albumina por $\mathrm{mg}$ de creatinina $-33,9 \mathrm{mg} / \mathrm{mmol}$, ou o dobro dos níveis de creatinina para pelo menos $200 \mu \mathrm{mol} / \mathrm{L}=2,26 \mathrm{mg} / \mathrm{dL}$-, necessidade de terapia de reposição renal ou morte por doença renal) ou retinopatia (desenvolvimento de retinopatia proliferativa, edema macular ou cegueira de causas diabéticas ou uso de terapia de fotocoagulação retinal).

A meta-análise não demonstrou diferença entre os tratamentos para o desfecho combinado microvascular [RR 0,88 IC 95\%(0,68-1,15)].

Para a estimativa de efeito dos estudos individuais, o estudo ADVANCE demonstrou um benefício do tratamento intensivo em seu desfecho combinado microvascular [RR 0,87 IC95\%(0,78-0,97)] e para o segundo desfecho combinado do estudo ACCORD não houve diferenças entre os tratamentos [RR0,96 IC 95\%(0,91$1,02)]$ 


\subsubsection{Hipoglicemia}

Todos os estudos reportaram algum dado para eventos de hipoglicemia. Entretanto, a maneira de apresentar estes dados no estudo Kumamoto ( $\mathrm{n}^{\circ}$ eventos/100 pacientes-ano) impossibilitou obtermos dados absolutos de incidência.

Episódios menores eram definidos, de maneira geral, como os que apresentavam algum sintoma (sudorese, confusão, tremedeira), porém não necessitavam de ajuda de uma segunda pessoa ou que causavam perda consciência. Nestes casos, o episódio de hipoglicemia era classificado como maior.

Assim, apenas dois estudos reportaram dados para episódios menores de hipoglicemia: Steno -2 e ACCORD. A meta-análise é inconclusiva, com alta heterogeneidade entre os estudos e intervalo de confiança amplo, mas com uma tendência de maior incidência no grupo intensivo.

Seis estudos reportaram dados para eventos maiores de hipoglicemia. Neste caso a meta-análise foi estatisticamente significante e apresenta risco 1.97 maior de ocorrer um evento nos pacientes tratados intensivamente [RR 1,97 IC 95\%(1,33 - 2,92)] (Figura 15). Apesar da alta heterogeneidade, o intervalo de confiança não foi muito largo.

Três estudos reportaram dados gerais de hipoglicemia (UKPDS, Steno-2 e ACCORD). A meta- análise não demonstrou diferenças entre os tratamentos [RR 1,63 IC $95 \%(0,77-3,43)]$, mas manteve a tendência a um aumento no grupo tratamento intensivo. (Figura 15). 


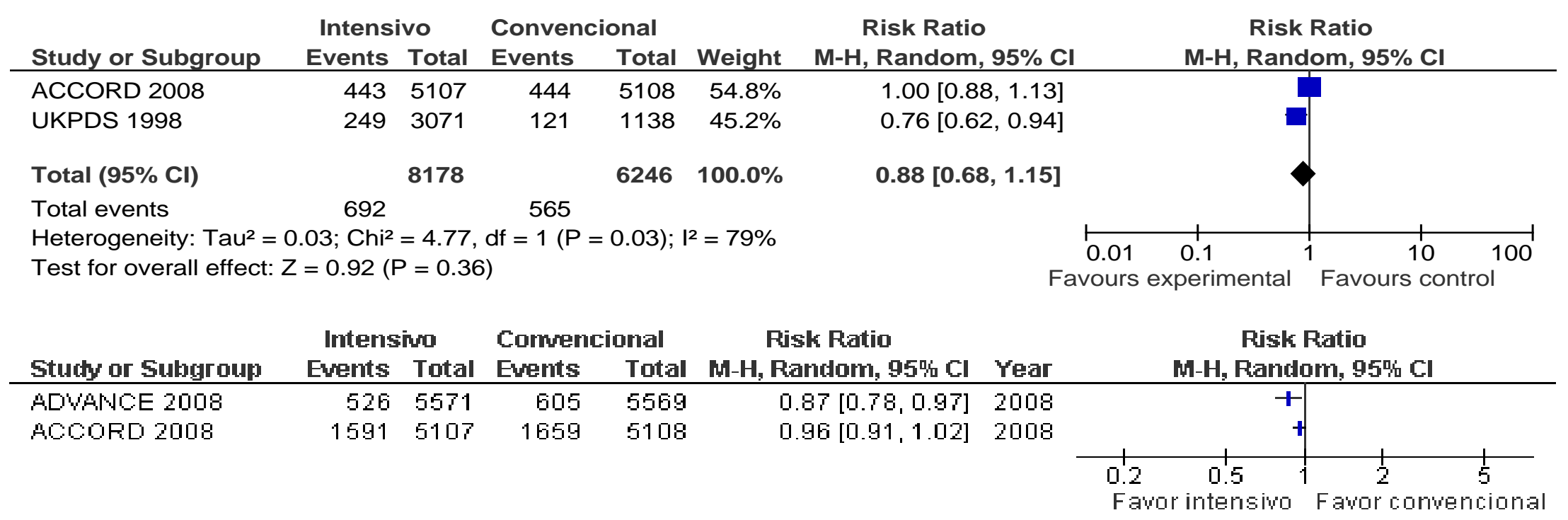

Figura 14 - Controle intensivo versus convencional da glicemia sobre desfecho combinado microvascular em pacientes com DMII. 
Intensivo Comencional

Risk Ratio

Risk Ratio

\begin{tabular}{|c|c|c|c|c|c|c|c|c|}
\hline Stucty or Subgroup & Events & Total & Events & Total & Weight & M-H, Random, 95\% $\mathrm{Cl}$ & Year & M-H, Random, 95\% Cl \\
\hline \multicolumn{9}{|c|}{ 1.16.1 Episódio menor } \\
\hline Steno-2 2003 & 42 & 80 & 39 & 80 & $47.8 \%$ & $1.08[0.79,1.46]$ & 2003 & \\
\hline $\begin{array}{l}\text { ACCORD } 2008 \\
\text { Subtotal }(95 \% \text { Cl) }\end{array}$ & 830 & $\begin{array}{l}5128 \\
5208\end{array}$ & 261 & $\begin{array}{l}5123 \\
5203\end{array}$ & $\begin{array}{r}52.2 \% \\
100.0 \%\end{array}$ & $\begin{array}{r}3.18[2.78,3.63] \\
1.87[0.63,5.51]\end{array}$ & 2008 & \\
\hline \multicolumn{9}{|c|}{$\begin{array}{l}\text { Heterogeneity: } \text { Tau }^{2}=0.60 ; \mathrm{Chi}^{2}=41.98, \mathrm{df}=1(\mathrm{P}=0.00001) ;\left.\right|^{2}=98 \% \\
\text { Test for overall effect: } Z=1.13(\mathrm{P}=0.26)\end{array}$} \\
\hline \multicolumn{9}{|l|}{ 1.16.2 Episódio maior } \\
\hline VACSDM 1995 & 5 & 75 & 2 & 78 & $5.9 \%$ & $2.60[0.52,12.99]$ & 1995 & \\
\hline UKPDS 1998 & 36 & 3071 & 8 & 1138 & $14.6 \%$ & $1.67[0.78,3.58]$ & 1998 & \\
\hline Steno-2 2003 & 5 & 80 & 12 & 80 & $11.2 \%$ & $0.42[0.15,1.13]$ & 2003 & \\
\hline ADVANCE 2008 & 150 & 5571 & 81 & 5569 & $23.2 \%$ & $1.85[1.42,2.42]$ & 2008 & 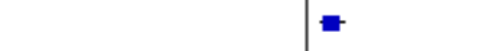 \\
\hline ACCORD 2008 & 538 & 5128 & 179 & 5123 & $24.4 \%$ & $3.00[2.55,3.54]$ & 2008 & - \\
\hline $\begin{array}{l}\text { VADT } 2009 \\
\text { Subtotal (95\% Cl) }\end{array}$ & 76 & $\begin{array}{r}892 \\
14817\end{array}$ & 28 & $\begin{array}{r}899 \\
12887\end{array}$ & $\begin{array}{r}20.6 \% \\
100.0 \%\end{array}$ & $\begin{array}{l}2.74[1.79,4.18] \\
1.97[1.33,2.92]\end{array}$ & 2009 & \\
\hline \multicolumn{9}{|c|}{$\begin{array}{l}\text { Heterogeneity: } \operatorname{Tau}^{2}=0.14 ; \mathrm{Chi}^{2}=23.26, \mathrm{df}=5(\mathrm{P}=0.0003) ; \mathrm{I}^{2}=79 \% \\
\text { Test for overall effect: } Z=3.40(\mathrm{P}=0.0007)\end{array}$} \\
\hline \multicolumn{9}{|c|}{ 1.16.3 Total de eventos hipoglicemia } \\
\hline UKPDS 1998 & 453 & 3071 & 114 & 1138 & $33.3 \%$ & $1.47[1.21,1.79]$ & 1998 & $\square$ \\
\hline Steno-2 2003 & 47 & 80 & 51 & 80 & $32.3 \%$ & $0.92[0.72,1.18]$ & 2003 & 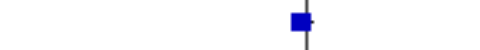 \\
\hline $\begin{array}{l}\text { ACCORD } 2008 \\
\text { Subtotal }(95 \% \mathrm{Cl})\end{array}$ & 1368 & $\begin{array}{l}5128 \\
8279\end{array}$ & 440 & $\begin{array}{l}5123 \\
6341\end{array}$ & $\begin{array}{r}34.4 \% \\
100.0 \%\end{array}$ & $\begin{array}{l}3.11[2.81,3.43] \\
\mathbf{1 . 6 3}[0.77, \mathbf{3 . 4 3}]\end{array}$ & 2008 & \\
\hline \multicolumn{9}{|c|}{$\begin{array}{l}\text { Total events } \quad 1868 \quad 605 \\
\text { Heterogeneity: } \text { Tau }^{2}=0.42 ; \mathrm{Chi}^{2}=110.07, \mathrm{df}=2(\mathrm{P}=0.00001) ; \mathrm{I}^{2}=98 \% \\
\text { Test for overall effect: } Z=1.28(\mathrm{P}=0.20)\end{array}$} \\
\hline
\end{tabular}

Figura 15 - Controle intensivo versus convencional da glicemia sobre hipoglicemia em pacientes com DMII. 


\subsubsection{Análises de Sensibilidade}

Foram realizadas análises de sensibilidade para subgrupos que continham características clínicas julgadas como potenciais fontes de heterogeneidade entre os estudos, a saber:

- Subgrupo 1) estudos que não incluíram pacientes com doença cardiovascular (DCV) prévia ou com população < 30\% dos pacientes com DCV prévia (UKPDS, Kumamoto e Steno-2) versus subgrupo de estudos com população > $30 \%$ de pacientes com DCV prévia (ACCORD, ADVANCE, VADT e VACSDM);

- subgrupo 2: estudos que tiveram pacientes com média de HbA1c final de seguimento no grupo intensivo $<7.0 \%$ (ACCORD, ADVANCE ) versus subgrupo de estudos que tiveram pacientes com média de $\mathrm{HbA} 1 \mathrm{c}$ final de seguimento no grupo intensivo $\geq 7.0 \%$ (Steno-2, VADT, VACSDM ; UKPDS);

- subgrupo 3: estudos que incluíram pacientes com média de idade < 60 anos (UKPDS, Kumamoto e Steno-2) versus subgrupo de estudos que incluíram pacientes com média de idade $\geq 60$ anos (ACCORD, ADVANCE, VADT e VACSDM);

- subgrupo 4: Estudo que incluiu pacientes recém diagnosticados com diabetes melito tipo II - UKPDS - versus estudos que incluíram pacientes com média de seguimento > 5,5 anos (ACCORD, ADVANCE, Steno-2, VADT, VACSDM e Kumamoto);

- subgrupo 5: estudos que utilizaram principalmente rosiglitazona no tratamento intensivo (ACCORD e VADT) versus estudos que não utilizaram principalmente rosiglitazona no tratamento intensivo (ADVANCE, VACSDM, Steno-2, Kumamoto, UKPDS) .

Para os desfechos mortalidade cardiovascular e a mortalidade total, que tiveram heterogeneidade moderada (respectivamente, $\mathrm{I}^{2}=42 \%$ e $\mathrm{I}^{2}=53 \%$ ), observou-se que o principal responsável pela inconsistência das estimativas de efeito foi o estudo ACCORD, interrompido precocemente por aumentar o risco destes desfechos. Ainda, o estudo VADT, embora não significante, mostrou uma tendência também ao aumento do 
risco. Ambos os estudos utilizaram a tiazolidinediona rosiglitazona como principal medicamento no grupo intensivo, que foi retirada do mercado pela agência regulatória da Europa (EMEA) e mantida nos EUA apenas em situações clínicas específicas, devido ao aumento no risco de eventos cardiovasculares. Assim, excluindo estes dois estudos da análise (análise de subgrupo 5), apesar de não se alterar a magnitude da estimativa de efeito, ou seja, continuar não demonstrando diferenças entre os tratamentos no risco de mortalidade total e mortalidade cardiovascular, a heterogeneidade cai para zero $\left(\mathrm{I}^{2}=0 \%\right)$. Por outro lado, a análise dos dados destes dois estudos que utilizaram rosiglitazona como tratamento principal no grupo intensivo demonstrou aumento no risco de mortalidade total [RR 1.20 IC95\%(1.04-1.40)] e aumento no risco de mortalidade por causas cardiovascular [RR 1.38 IC95\%( 1.101.73)] com heterogeneidade nula $\left(\mathrm{I}^{2}=0 \%\right)$ e sem perda da significância para redução de risco relativo de IAM não-fatal. Ainda relacionado à mortalidade total e cardiovascular, a heterogeneidade é nula quando avaliamos estes desfechos no subgrupo 1 de estudos que incluíram $<30 \%$ de pacientes com doenças cardiovasculares prévias $\left(\mathrm{I}^{2}=0 \%\right)$, subgrupo 2 de estudos que tiveram HbA1c final de seguimento no grupo intensivo > $7.0 \%$ e subgrupo 3 de estudos de pacientes com idade < 60 anos, também sem alterar a estimativa de efeito da meta-análise

A heterogeneidade do desfecho IAM não-fatal foi moderada $\left(\mathrm{I}^{2}=34 \%\right)$. Ela pôde ser explicada $\left(\mathrm{I}^{2}=0 \%\right)$ no subgrupo de estudos que incluíram pacientes com idade $\geq 60$ anos e no subgrupo de estudos com > 30\% dos pacientes com doenças cardiovasculares prévias, sem, contudo, alterar a estimativa de efeito, ou seja, demonstrarem reduções de risco significantes até maiores que a meta-análise principal, de $24 \%$ de IAM não-fatal em ambos os subgrupos.

Para desfechos relacionados às retinopatias, tivemos heterogeneidade moderada no risco de incidência $\left(\mathrm{I}^{2}=51 \%\right)$. Embora a meta-análise principal não tenha demonstrado diferenças entre o tratamento intensivo e tratamento convencional para este desfecho, a heterogeneidade passou a leve, sem alteração da estimativa de efeito, no subgrupo de estudos que incluíram > 30\% dos pacientes com doenças cardiovasculares prévias $\left(\mathrm{I}^{2}=10 \%\right)$ e no subgrupo de estudos que incluíram pacientes com idade $\geq 60$ anos $\left(\mathrm{I}^{2}=10 \%\right)$. A heterogeneidade alta relacionada ao desfecho fotocoagulação retinal $\left(\mathrm{I}^{2}=73 \%\right)$ não pôde ser explicada por nenhuma análise de subgrupo, apesar da metaanálise não demonstrar diferenças entre os tratamentos. Vale ressaltar que apenas dois 
estudos reportaram dados para este desfecho, o estudo UKPDS e o estudo VADT. Analisando o resultado pelo subgrupo 4 (recém diagnosticados versus anos de doença), o estudo UKPDS encontrou com significância estatística uma redução de risco relativo de $27 \%$ no grupo tratamento intensivo comparado com o grupo convencional. Contudo, o estudo VADT não encontrou diferenças entre os tratamentos.

Para desfechos relacionados à nefropatias, a heterogeneidade alta $\left(\mathrm{I}^{2}=71 \%\right)$ para incidência passou a moderada nos subgrupos idade $<60$ anos, estudos com pacientes sem doenças cardiovasculares prévia e estudos com > 30\% de pacientes com doenças cardiovascular prévia. A heterogeneidade alta da incidência de microalbuminuria $\left(\mathrm{I}^{2}=79 \%\right)$ foi justificada apenas pelo subgrupo de estudos com pacientes de idade $\geq 60$ anos.

Em alguns casos, as análises de sensibilidade ocasionaram a perda da significância estatística do risco relativo para alguns eventos antes significantes, por conta da separação dos estudos e prejuízo do tamanho de amostra, números de eventos e poder para responder a questão. Também é importante recordar que nem todos os estudos reportaram dados para todos os desfechos analisados.

\subsubsection{Qualidade da Evidência}

A qualidade da evidência foi avaliada para os seguintes desfechos:

Desfechos Macrovasculares: mortalidade total, mortalidade cardiovascular, IAM não fatal, AVC não fatal e amputação de membros

Desfechos microvasculares: progressão de retinopatia, neuropatia periférica, nefropatias (incidência, progressão)

Hipoglicemia: episódio maior.

A tabela 8 apresenta os resultados. As notas de rodapé justificam o decréscimo de graduação da qualidade e fornecem a interpretação dos resultados.

As evidências foram graduadas considerando a análise da qualidade metodológica dos estudos individuais e os parâmetros de avaliação conjunta dos artigos: precisão, evidência direta, consistência dos resultados e viés de publicação 
Nenhuma das estimativas de efeito que tiveram a qualidade da evidência avaliada foi considerada "muito baixa".

A maioria das estimativas de efeito das meta-análises foi considerada de qualidade moderada, principalmente devido à imprecisão das estimativas encontradas nos estudos individuais, que variavam mais de $25 \%$. Neste caso incluem-se os desfechos mortalidade total, infarto agudo do miocárdio não-fatal e episódio menor de hipoglicemia.

Para o desfecho mortalidade cardiovascular e AVC não fatal, a meta-análise foi classificada como baixa, pois, além da imprecisão entre os estudos, os achados dos estudos individuais não foram unanimes em favorecer um único esquema de tratamento da glicemia. Assim, para o desfecho mortalidade cardiovascular, o estudo ACCORD demonstrou aumento do risco para o braço de tratamento intensivo. Para o desfecho AVC não-fatal, os intervalos de confiança dos estudos individuais não se sobrepuseram totalmente. Em ambos os casos, a heterogeneidade entre os estudos foi moderada para alta. Desta forma, a graduação foi rebaixada também no quesito "inconsistência".

Para os desfechos neuropatia periférica e progressão da retinopatia a qualidade da evidência foi classificada como "moderada" e o rebaixamento da graduação foi devido ao quesito "evidência direta", já que estes desfechos foram avaliados por desfechos substitutos e com medidas diferentes de avaliação, como escalas modificadas e métodos diferentes para acessarem os desfechos. 
Tabela 8 - Qualidade da evidência - Análises no GRADEprofiler

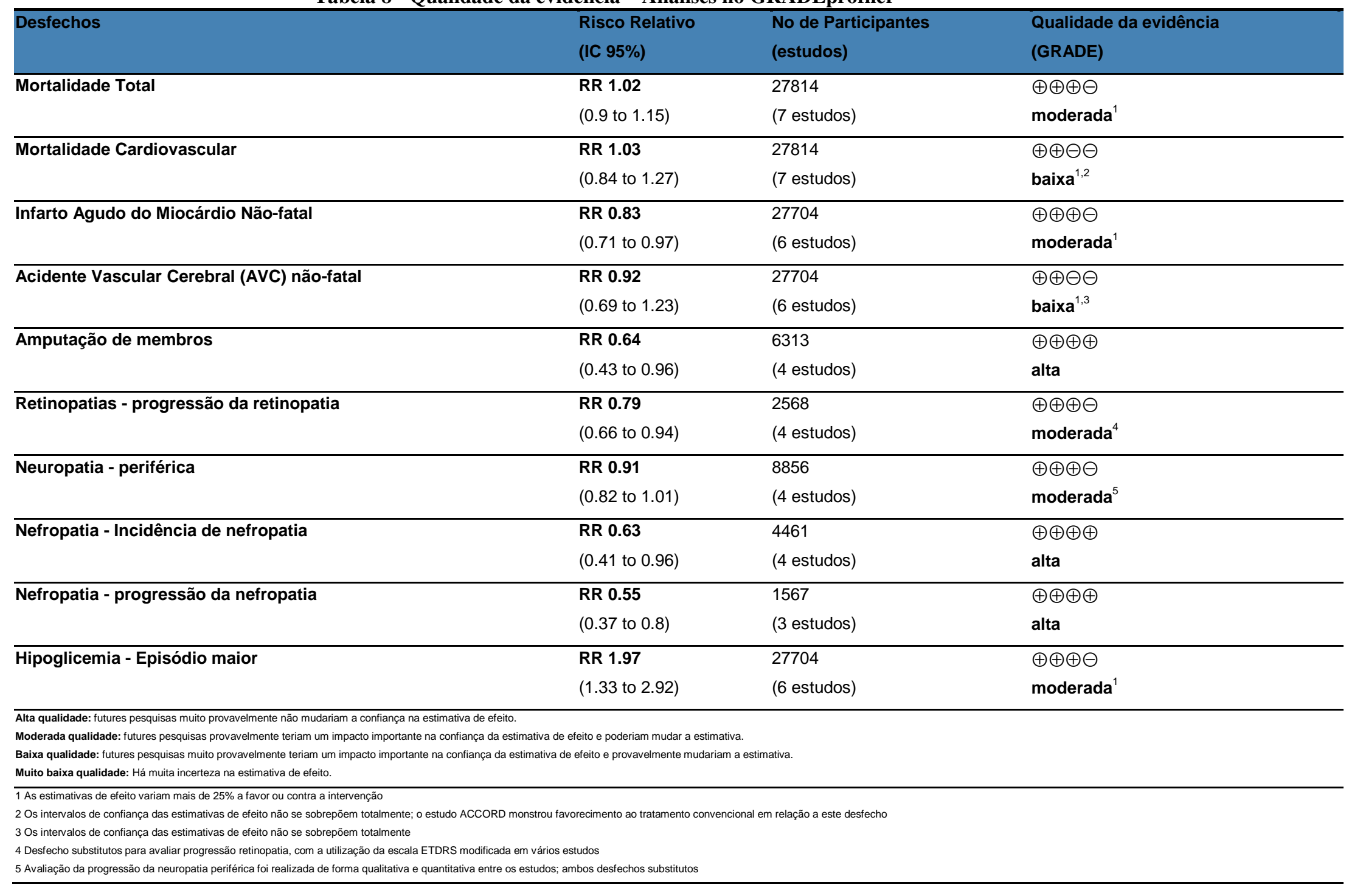




\section{DISCUSSÃO}

A presente revisão sistemática com meta-análise avaliou desfechos microvasculares, macrovasculares, mortalidade total e episódios de hipoglicemia em, no máximo, sete estudos que foram considerados elegíveis pelos nossos critérios.

Em relação aos eventos macrovasculares, o tratamento intensivo de glicose sanguínea reduziu significantemente em $17 \%$ o risco de infarto agudo do miocárdio não-fatal e em $36 \%$ o risco do evento "amputação de membros". Entretanto, o tratamento intensivo não afetou significantemente a mortalidade total e a mortalidade cardiovascular e não foi significativo para a redução de acidente vascular cerebral não fatal.

Quanto aos eventos microvasculares, o tratamento intensivo reduziu significantemente em $21 \%$ o risco de progressão da retinopatia, porém não se demonstrou eficaz na redução de nenhum outro desfecho de retinopatia avaliado, bem como na redução de desfechos relacionados com deterioração visual.

Em relação às neuropatias, o tratamento intensivo demonstrou uma redução significante de risco de $6 \%$ de neuropatia periférica, porém foi incapaz de demonstrar benefícios em relação à neuropatia autonômica, muito provavelmente por apenas ter sido relatado dados deste desfecho em 2 estudos.

O tratamento intensivo do controle da glicemia teve maior impacto na incidência de eventos relacionados à função renal. Ele reduziu significantemente a incidência de nefropatias em $35 \%$, a progressão em $45 \%$ e a microalbuminuria em $22 \%$. O benefício sobre diálise não foi significativo, provavelmente devido ao baixo número de eventos, apesar de demonstrar uma tendência benéfica do tratamento intensivo.

Por fim, o tratamento intensivo significantemente dobrou o risco de eventos maiores de hipoglicemia, mas esta significância não foi demonstrada na avaliação de episódios menores.

Nossa revisão sistemática tem pontos fortes e algumas limitações. Como pontos fortes, temos a elaboração da estratégia de busca, que foi bastante sensível, com pouca probabilidade de não termos identificado alguma evidência relevante. Ainda, as principais bases de dados foram pesquisadas, bem como fontes de evidência não publicada e busca manual de evidência. Todos os procedimentos da realização da 
revisão sistemática foram guiados por diretrizes e literatura específicas para este tipo de estudo, contemplando todas as características metodológicas necessárias à condução adequada da revisão. A elaboração das fichas clínicas de extração dos dados teve assessoria de clínicos e epidemiologistas, permitindo a compilação de informações relevantes, inerentes à patologia.

A revisão sistemática também apresentou algumas limitações. Houve muita heterogeneidade clínica entre os estudos. Neste sentido, o UKPDS foi um estudo que incluiu pacientes recém diagnosticados com diabetes melito tipo II e nos demais os pacientes tinham, pelo menos, 5,5 anos de história natural de doença, alcançando a média de até 11,5 anos no estudo VADT. Ainda, à exceção do estudo Kumamoto e UKPDS que não incluíram pacientes com doenças cardiovasculares prévias e o estudo Steno-2 que incluiu menos que 30\% dos pacientes com doença cardiovascular prévia, os demais estudos possuíam pelo menos $30 \%$ do total de pacientes incluídos com doenças cardiovasculares prévias. Outra fonte de heterogeneidade clínica é a inclusão de pacientes adultos nos estudos Steno-2, UKPDS e Kumamoto e inclusão de pacientes com faixa etária maior nos estudos ACCORD, ADVANCE VACSDM e VADT.

As fontes de heterogeneidade clínica implicam em diferentes prognósticos para a população envolvida, de modo que os achados podem ser divergentes. Assim, uma população mais velha tem maior probabilidade de apresentar maior número de comorbidades que uma população mais jovem, de modo que a evolução de sua doença tende a ser pior. Ainda, uma população que foi recém diagnosticada com Diabetes melito e que, desde o início têm seus índices glicêmicos controlados adequadamente por um protocolo de pesquisa clínica, se beneficiará muito mais que uma população que tenha anos ou décadas de doença descompensada ou mal controlada e que só então passa a ser seguido adequadamente. $\mathrm{Na}$ mesma linha de raciocínio, populações que incluam pacientes com doenças cardiovasculares prévias também tendem a ter prognósticos diferentes de populações sem histórico de doença.

Ainda, para alguns desfechos observou-se uma heterogeneidade estatística de moderada a alta, que reflete a heterogeneidade clínica dos estudos e características específicas de cada protocolo de estudo, como diferentes meios de acesso aos desfechos, por exemplo, a utilização de escalas modificadas ETDRS para avaliação de retinopatias, definições diferentes para incidência de nefropatia e neuropatias, etc. 
Por último, não se pode desconsiderar que os protocolos de tratamento, tanto de controle intensivo, como de controle convencional, também podem ter interferido na estimativa dos resultados. Observou-se que na maioria das vezes o importante era atingir o alvo glicêmico e manter significante a diferença nos parâmetros utilizados para avaliação da diferença de intensidade entre os braços do estudo (HbA1c ou glicemia de jejum), independente da classe, dose e quantidade de medicamento utilizado. Para isso, cada estudo usou diferentes combinações de dieta, sulfonilureas, tiazolidinedionas, metformina e insulinas. Apenas o estudo UKPDS priorizou o controle intensivo utilizando um esquema monoterapêutico.

$\mathrm{Na}$ tentativa de justificar a heterogeneidade dos resultados, foram realizadas análises de subgrupo. De fato, os resultados sugerem que as características de base dos pacientes, os protocolos clínicos e as medidas de desfecho podem interferir nas estimativas de efeito geradas pelas meta-análises.

Nossos achados foram similares aos resultados das duas únicas meta-análises prévias $(144 ; 145)$, nos desfechos em comum reportados , apesar de algumas diferenças relevantes. Entre elas, destacam-se: 1) Ray et al. (2010) (146) incluíram 5 estudos, sendo que o ProActive (147) não era elegível nem para os próprios critérios de sua revisão, já que não objetivava dois níveis de intensidade de controle glicêmico e sim a comparação de esquemas de tratamento medicamentoso. Este estudo foi incluído porque se alcançou uma diferença estatística nos níveis de HbA1c por conta dos protocolos de tratamento sugeridos, mas não se tratava do objetivo inicial do estudo e, portanto, não foi incluído em nossas análises. 2) Kelly et al. (2010) (148) incluíram cinco estudos, porém consideraram o estudo UKPDS 33 e o UKPDS 34 como dois estudos individuais, quando a presente revisão e a revisão de Ray et al. (2010) reportaram os resultados como um único dado. 3) As duas meta-análises cometeram erros na interpretação de texto em relação ao estudo UKPDS. Os dados reportados no estudo UKPDS 34 (149) provêm da mesma coorte inicial de pacientes do estudo UKPDS 33 (150), porém são dados exclusivos de pacientes obesos, que tinham o diferencial de tomarem metformina. No grupo do tratamento intensivo, 411 pacientes obesos foram incluídos. No grupo controle, 342 pacientes eram obesos e tomavam metformina. Entretanto,o grupo controle (tratamento convencional de pacientes obesos) não era uma coorte exclusiva como a do tratamento intensivo e os dados destes pacientes já haviam sido reportados juntamente com os dados dos pacientes não obesos do estudo UKPDS33. Assim, não se 
deveria utilizar como denominador $1480(1138+342)$ pacientes, como ambas as revisões fizeram, e sim 1138 pacientes no grupo convencional de controle de glicemia.

A presente revisão sistemática também diferiu das revisões prévias em relação aos desfechos analisados. Nenhuma das duas reportou desfechos microvasculares nem avaliaram o risco de amputação de membros. Ainda, Kelly et al. (2010) utilizaram os dados de desfecho combinado para Acidente Vascular Cerebral (AVC), que inclui eventos fatais e não-fatais, quando nós só consideramos os eventos não-fatais.

Com quase 28.000 pacientes incluídos em sete estudos, provavelmente temos poder suficiente para detectar pequenos, porém clinicamente importantes efeitos no controle intensivo de glicemia em desfechos macro e microvasculares, além de, aparentemente demonstrar nulidade em relação à mortalidade total e por causas cardiovasculares.

Finalmente, deve-se dar importância aos resultados relacionados aos eventos de hipoglicemia que acompanham os achados. A meta-análise mostrou o dobro do risco de incidência de episódios maiores e este achado deve ser levado em conta para aplicação dos resultados na prática clínica. Hipoglicemia é um evento adverso comum das medicações hipoglicemiantes, que resulta em mal prognóstico, reduz a aderência às medicações por medo da recorrência do evento, aumenta o risco de demência, hospitalização e internações de emergência, reduz a qualidade de vida e aumenta a probabilidade de morte (162). 


\section{CONCLUSÕES}

As análises e resultados nos permitem concluir que não há evidências que permitam indicar um nível de intensidade glicêmica tão restrito quanto uma hemoglobina glicada próxima aos níveis de normalidade, como os alcançados pelos estudos ADVANCE e ACCORD. Se o paciente responder a um tratamento prontamente, sem o uso de uma poli farmácia em doses máximas, parece não haver problemas. Entretanto, se for necessária aq utilização de diferentes classes de agentes hipoglicemiantes, em pacientes mais idosos, com doenças cardiovasculares prévias, anos de história natural de doença não comprovadamente controlada adequadamente, parece não ser indicado. Provavelmente uma HbA1c $<7.0 \%$, já utilizada na prática clínica por diversas diretrizes, já evidencia benefícios microvasculares importantes, podendo ou não agregar benefícios macrovasculares ao longo do tempo.

Parece imprudente utilizar os dados das meta-análises para sugerir atualizações de diretrizes, visando alvos glicêmicos mais conservadores que os preconizados atualmente, dado o perfil de pacientes incluídos nos estudos analisados. Expô-los ao aumento de risco de mortalidade e o dobro do risco de incidência de episódios severos de hipoglicemia parece não sobrepor os potencias benefícios do controle intensivo de glicemia. 


\section{REFERÊNCIAS*}

(1) World Health Organization.Diabettes mellitus [homepage on the inyernet]Available from: www.who.int 07 / jul/2009.

(2) Wild S, Roglic G, Green A, Sicree R, King H. Global prevalence of diabetes: estimates for the year 2000 and projections for 2030. Diabetes Care. 2004 May;27(5):1047-53.

(3) American Diabetes Association. Diabetes mellitus [homepage on the internet]Available from: www.diabetes.org 07/ jul/20009.

(4) World Health Organization. Chronic Diseases [homepage on the internet]Available from: www.who.int 07/ jul/2009.

(5) Wild S, Roglic G, Green A, Sicree R, King H. Global prevalence of diabetes: estimates for the year 2000 and projections for 2030. Diabetes Care. 2004 May;27(5):1047-53.

(6) Resnick HE, Shorr RI, Kuller L, Franse L, Harris TB. Prevalence and clinical implications of American Diabetes Association-defined diabetes and other categories of glucose dysregulation in older adults: the health, aging and body composition study. J Clin Epidemiol. 2001 Sep;54(9):869-76.

(7) Haffner SM, Lehto S, Ronnemaa T, Pyorala K, Laakso M. Mortality from coronary heart disease in subjects with type 2 diabetes and in nondiabetic subjects with and without prior myocardial infarction. N Engl J Med. 1998 Jul 23;339(4):229-34.

(8) Malmberg K, Yusuf S, Gerstein HC, Brown J, Zhao F, Hunt D, et al. Impact of diabetes on long-term prognosis in patients with unstable angina and non-Qwave myocardial infarction: results of the OASIS (Organization to Assess Strategies for Ischemic Syndromes) Registry. Circulation. 2000 Aug 29;102(9):1014-9.

*De acordo com International Committee of Medical Journal Editors. Uniform requirements for manuscripts submitted to Biomedical Journal:sample references. Available from https://www.icmje.org [2007 May 22] 
(9) Herlitz J, Karlson BW, Lindqvist J, Sjolin M. Rate and mode of death during five years of follow-up among patients with acute chest pain with and without a history of diabetes mellitus. Diabet Med. 1998 Apr;15(4):308-14.

(10) Newman AB, Siscovick DS, Manolio TA, Polak J, Fried LP, Borhani NO, et al. Ankle-arm index as a marker of atherosclerosis in the Cardiovascular Health Study. Cardiovascular Heart Study (CHS) Collaborative Research Group. Circulation. 1993 Sep;88(3):837-45.

(11) Hiatt WR, Hoag S, Hamman RF. Effect of diagnostic criteria on the prevalence of peripheral arterial disease. The San Luis Valley Diabetes Study. Circulation. 1995 Mar 1;91(5):1472-9.

(12) Jude EB, Oyibo SO, Chalmers N, Boulton AJ. Peripheral arterial disease in diabetic and nondiabetic patients: a comparison of severity and outcome. Diabetes Care. 2001 Aug;24(8):1433-7.

(13) Uusitupa MI, Niskanen LK, Siitonen O, Voutilainen E, Pyorala K. 5-year incidence of atherosclerotic vascular disease in relation to general risk factors, insulin level, and abnormalities in lipoprotein composition in non-insulindependent diabetic and nondiabetic subjects. Circulation. 1990 Jul;82(1):27-36.

(14) Kannel WB, McGee DL. Update on some epidemiologic features of intermittent claudication: the Framingham Study. J Am Geriatr Soc. 1985 Jan;33(1):13-8.

(15) Folsom AR, Rasmussen ML, Chambless LE, Howard G, Cooper LS, Schmidt MI, et al. Prospective associations of fasting insulin, body fat distribution, and diabetes with risk of ischemic stroke. The Atherosclerosis Risk in Communities (ARIC) Study Investigators. Diabetes Care. 1999 Jul;22(7):1077-83.

(16) Jamrozik K, Broadhurst RJ, Forbes S, Hankey GJ, Anderson CS. Predictors of death and vascular events in the elderly : the Perth Community Stroke Study. Stroke. 2000 Apr;31(4):863-8.

(17) Stamler J, Vaccaro O, Neaton JD, Wentworth D. Diabetes, other risk factors, and 12-yr cardiovascular mortality for men screened in the Multiple Risk Factor Intervention Trial. Diabetes Care. 1993 Feb;16(2):434-44. 
(18) Luchsinger JA, Tang MX, Stern Y, Shea S, Mayeux R. Diabetes mellitus and risk of Alzheimer's disease and dementia with stroke in a multiethnic cohort. Am J Epidemiol. 2001 Oct 1;154(7):635-41.

(19) Hankey GJ, Jamrozik K, Broadhurst RJ, Forbes S, Burvill PW, Anderson CS, et al. Long-term risk of first recurrent stroke in the Perth Community Stroke Study. Stroke.1998 Dec;29(12):2491-500.

(20) Tuomilehto J, Rastenyte D, Jousilahti P, Sarti C, Vartiainen E. Diabetes mellitus as a risk factor for death from stroke. Prospective study of the middle-aged Finnish population. Stroke. 1996 Feb;27(2):210-5.

(21) Hajer GR, van Haeften TW, Visseren FL. Adipose tissue dysfunction in obesity, diabetes, and vascular diseases. Eur Heart. J 2008 Dec;29(24):2959-71.

(22) Shanik MH, Xu Y, Skrha J, Dankner R, Zick Y, Roth J. Insulin resistance and hyperinsulinemia: is hyperinsulinemia the cart or the horse? Diabetes Care. 2008 Feb;31 (Suppl 2):S262-S268.

(23) Thirone AC, Huang C, Klip A. Tissue-specific roles of IRS proteins in insulin signaling and glucose transport. Trends Endocrinol Metab. 2006 Mar;17(2):728.

(24) Wahren J, Ekberg K. Splanchnic regulation of glucose production. Annu Rev Nutr. 2007;27:329-45.

(25) Duncan RE, Ahmadian M, Jaworski K, Sarkadi-Nagy E, Sul HS. Regulation of lipolysis in adipocytes. Annu Rev Nutr. 2007;27:79-101.

(26) Morino K, Petersen KF, Shulman GI. Molecular mechanisms of insulin resistance in humans and their potential links with mitochondrial dysfunction. Diabetes. 2006 Dec;55 (Suppl 2):S9-S15.

(27) Zierath JR, Wallberg-Henriksson H. From receptor to effector: insulin signal transduction in skeletal muscle from type II diabetic patients. Ann N Y Acad Sci. 2002 Jun;967:120-34.

(28) Hamilton MT, Hamilton DG, Zderic TW. Role of low energy expenditure and sitting in obesity, metabolic syndrome, type 2 diabetes, and cardiovascular disease. Diabetes. 2007 Nov;56(11):2655-67. 
(29) Horowitz JF, Klein S. Whole body and abdominal lipolytic sensitivity to epinephrine is suppressed in upper body obese women. Am J Physiol Endocrinol Metab. 2000 Jun;278(6):E1144-E1152.

(30) Klein S, Luu K, Gasic S, Green A. Effect of weight loss on whole body and cellular lipid metabolism in severely obese humans. Am J Physiol. 1996 May;270(5 Pt 1):E739-E745.

(31) Stumvoll M, Goldstein BJ, van Haeften TW. Type 2 diabetes: principles of pathogenesis and therapy. Lancet. 2005 Apr 9;365(9467):1333-46.

(32) Beck-Nielsen H, Groop LC. Metabolic and genetic characterization of prediabetic states. Sequence of events leading to non-insulin-dependent diabetes mellitus. J Clin Invest. 1994 Nov;94(5):1714-21.

(33) Karin M, Shaulian E. AP-1: linking hydrogen peroxide and oxidative stress to the control of cell proliferation and death. IUBMB Life. 2001 Jul;52(1-2):17-24.

(34) Kanda Y, Shimoda M, Tawaramoto K, Hamamoto S, Tatsumi F, Kawasaki F, et al. Molecular analysis of db gene-related pancreatic beta cell dysfunction; evidence for a compensatory mechanism inhibiting development of diabetes in the db gene heterozygote. Endocr J. 2009;56(8):997-1008.

(35) Liu L, Zhang Y, Chen N, Shi X, Tsang B, Yu YH. Upregulation of myocellular DGAT1 augments triglyceride synthesis in skeletal muscle and protects against fat-induced insulin resistance. J Clin Invest. 2007 Jun;117(6):1679-89.

(36) Karin M, Takahashi T, Kapahi P, Delhase M, Chen Y, Makris C, et al. Oxidative stress and gene expression: the AP-1 and NF-kappaB connections. Biofactors. 2001;15(2-4):87-9.

(37) Hosogai N, Fukuhara A, Oshima K, Miyata Y, Tanaka S, Segawa K, et al. Adipose tissue hypoxia in obesity and its impact on adipocytokine dysregulation. Diabetes. 2007 Apr;56(4):901-11.

(38) Wang B, Wood IS, Trayhurn P. Dysregulation of the expression and secretion of inflammation-related adipokines by hypoxia in human adipocytes. Pflugers Arch. 2007 Dec;455(3):479-92.

(39) Rodriguez A, Catalan V, Gomez-Ambrosi J, Fruhbeck G. Visceral and subcutaneous adiposity: are both potential therapeutic targets for tackling the metabolic syndrome? Curr Pharm. Des 2007;13(21):2169-75. 
(40) Beckman JA, Creager MA, Libby P. Diabetes and atherosclerosis: epidemiology, pathophysiology, and management. JAMA. 2002 May 15;287(19):2570-81.

(41) Cines DB, Pollak ES, Buck CA, Loscalzo J, Zimmerman GA, McEver RP, et al. Endothelial cells in physiology and in the pathophysiology of vascular disorders. Blood. 1998 May 15;91(10):3527-61.

(42) Stehouwer CD, Gall MA, Twisk JW, Knudsen E, Emeis JJ, Parving HH. Increased urinary albumin excretion, endothelial dysfunction, and chronic lowgrade inflammation in type 2 diabetes: progressive, interrelated, and independently associated with risk of death. Diabetes. 2002 Apr;51(4):1157-65.

(43) Williams SB, Cusco JA, Roddy MA, Johnstone MT, Creager MA. Impaired nitric oxide-mediated vasodilation in patients with non-insulin-dependent diabetes mellitus. J Am Coll Cardiol. 1996 Mar 1;27(3):567-74.

(44) Verma S, Anderson TJ. The ten most commonly asked questions about endothelial function in cardiology. Cardiol Rev. 2001 Sep;9(5):250-2.

(45) Sarkar R, Meinberg EG, Stanley JC, Gordon D, Webb RC. Nitric oxide reversibly inhibits the migration of cultured vascular smooth muscle cells. Circ Res. 1996 Feb;78(2):225-30.

(46) Forstermann U, Closs EI, Pollock JS, Nakane M, Schwarz P, Gath I, et al. Nitric oxide synthase isozymes. Characterization, purification, molecular cloning, and functions. Hypertension. 1994 Jun;23(6 Pt 2):1121-31.

(47) Cosentino F, Hishikawa K, Katusic ZS, Luscher TF. High glucose increases nitric oxide synthase expression and superoxide anion generation in human aortic endothelial cells. Circulation. 1997 Jul 1;96(1):25-8.

(48) Nathan DM, Lachin J, Cleary P, Orchard T, Brillon DJ, Backlund JY, et al. Intensive diabetes therapy and carotid intima-media thickness in type 1 diabetes mellitus. N Engl J Med. 2003 Jun 5;348(23):2294-303.

(49) Milstien S, Katusic Z. Oxidation of tetrahydrobiopterin by peroxynitrite: implications for vascular endothelial function. Biochem Biophys Res Commun. 1999 Oct 5;263(3):681-4.

(50) Inoguchi T, Li P, Umeda F, Yu HY, Kakimoto M, Imamura M, et al. High glucose level and free fatty acid stimulate reactive oxygen species production 
through protein kinase $\mathrm{C}$--dependent activation of $\mathrm{NAD}(\mathrm{P}) \mathrm{H}$ oxidase in cultured vascular cells. Diabetes. 2000 Nov;49(11):1939-45.

(51) Hopfner RL, Gopalakrishnan V. Endothelin: emerging role in diabetic vascular complications. Diabetologia .1999 Dec;42(12):1383-94.

(52) Tesfamariam B, Brown ML, Deykin D, Cohen RA. Elevated glucose promotes generation of endothelium-derived vasoconstrictor prostanoids in rabbit aorta. $\mathrm{J}$ Clin Invest. 1990 Mar;85(3):929-32.

(53) Engeli S, Bohnke J, Gorzelniak K, Janke J, Schling P, Bader M, et al. Weight loss and the renin-angiotensin-aldosterone system. Hypertension. 2005 Mar;45(3):356-62.

(54) Furuhashi M, Ura N, Higashiura K, Murakami H, Tanaka M, Moniwa N, et al. Blockade of the renin-angiotensin system increases adiponectin concentrations in patients with essential hypertension. Hypertension. 2003 Jul;42(1):76-81.

(55) Schmidt AM, Stern D. Atherosclerosis and diabetes: the RAGE connection. Curr Atheroscler. Rep 2000 Sep;2(5):430-6.

(56) Zeiher AM, Fisslthaler B, Schray-Utz B, Busse R. Nitric oxide modulates the expression of monocyte chemoattractant protein 1 in cultured human endothelial cells. Circ Res. 1995 Jun;76(6):980-6.

(57) Dichtl W, Nilsson L, Goncalves I, Ares MP, Banfi C, Calara F, et al. Very lowdensity lipoprotein activates nuclear factor-kappaB in endothelial cells. Circ Res. 1999 May 14;84(9):1085-94.

(58) Hussain MJ, Peakman M, Gallati H, Lo SS, Hawa M, Viberti GC, et al. Elevated serum levels of macrophage-derived cytokines precede and accompany the onset of IDDM. Diabetologia. 1996 Jan;39(1):60-9.

(59) Fukumoto H, Naito Z, Asano G, Aramaki T. Immunohistochemical and morphometric evaluations of coronary atherosclerotic plaques associated with myocardial infarction and diabetes mellitus. J Atheroscler Thromb. 1998;5(1):29-35.

(60) Taguchi S, Oinuma T, Yamada T. A comparative study of cultured smooth muscle cell proliferation and injury, utilizing glycated low density lipoproteins with slight oxidation, auto-oxidation, or extensive oxidation. J Atheroscler Thromb. 2000;7(3):132-7. 
(61) Vinik AI, Erbas T, Park TS, Nolan R, Pittenger GL. Platelet dysfunction in type 2 diabetes. Diabetes Care. 2001 Aug;24(8):1476-85.

(62) Inoguchi T, Li P, Umeda F, Yu HY, Kakimoto M, Imamura M, et al. High glucose level and free fatty acid stimulate reactive oxygen species production through protein kinase $\mathrm{C}$--dependent activation of $\mathrm{NAD}(\mathrm{P}) \mathrm{H}$ oxidase in cultured vascular cells. Diabetes. 2000 Nov;49(11):1939-45.

(63) Zou M, Yesilkaya A, Ullrich V. Peroxynitrite inactivates prostacyclin synthase by heme-thiolate-catalyzed tyrosine nitration. Drug Metab Rev. 1999 May;31(2):343-9.

(64) Carr ME. Diabetes mellitus: a hypercoagulable state. J Diabetes Complications. 2001 Jan;15(1):44-54.

(65) Ceriello A, Giugliano D, Quatraro A, Marchi E, Barbanti M, Lefebvre P. Evidence for a hyperglycaemia-dependent decrease of antithrombin III-thrombin complex formation in humans. Diabetologia. 1990 Mar;33(3):163-7.

(66) Ceriello A, Giacomello R, Stel G, Motz E, Taboga C, Tonutti L, et al. Hyperglycemia-induced thrombin formation in diabetes. The possible role of oxidative stress. Diabetes. 1995 Aug;44(8):924-8.

(67) Vinik AI, Erbas T, Park TS, Nolan R, Pittenger GL. Platelet dysfunction in type 2 diabetes. Diabetes Care. 2001 Aug;24(8):1476-85.

(68) Intensive blood-glucose control with sulphonylureas or insulin compared with conventional treatment and risk of complications in patients with type 2 diabetes (UKPDS 33). UK Prospective Diabetes Study (UKPDS) Group. Lancet. 1998 Sep 12;352(9131):837-53.

(69) Effect of intensive blood-glucose control with metformin on complications in overweight patients with type 2 diabetes (UKPDS 34). UK Prospective Diabetes Study (UKPDS) Group. Lancet .1998 Sep 12;352(9131):854-65.

(70) Gerstein HC, Miller ME, Byington RP, Goff DC, Jr., Bigger JT, Buse JB, et al. Effects of intensive glucose lowering in type 2 diabetes. N Engl J Med. 2008 Jun $12 ; 358(24): 2545-59$.

(71) Patel A, MacMahon S, Chalmers J, Neal B, Billot L, Woodward M, et al. Intensive blood glucose control and vascular outcomes in patients with type 2 diabetes. N Engl J Med. 2008 Jun 12;358(24):2560-72. 
(72) Effect of intensive blood-glucose control with metformin on complications in overweight patients with type 2 diabetes (UKPDS 34). UK Prospective Diabetes Study (UKPDS) Group. Lancet. 1998 Sep 12;352(9131):854-65.

(73) Intensive blood-glucose control with sulphonylureas or insulin compared with conventional treatment and risk of complications in patients with type 2 diabetes (UKPDS 33). UK Prospective Diabetes Study (UKPDS) Group. Lancet. 1998 Sep 12;352(9131):837-53.

(74) Duckworth W, Abraira C, Moritz T, Reda D, Emanuele N, Reaven PD, et al. Glucose control and vascular complications in veterans with type 2 diabetes. $\mathrm{N}$ Engl J Med. 2009 Jan 8;360(2):129-39.

(75) Shichiri M, Kishikawa H, Ohkubo Y, Wake N. Long-term results of the Kumamoto Study on optimal diabetes control in type 2 diabetic patients. Diabetes Care. 2000 Apr;23 (Suppl 2):B21-B29.

(76) Gerstein HC, Miller ME, Byington RP, Goff DC, Jr., Bigger JT, Buse JB, et al. Effects of intensive glucose lowering in type 2 diabetes. N Engl J Med. 2008 Jun $12 ; 358(24): 2545-59$.

(77) Kelly TN, Bazzano LA, Fonseca VA, Thethi TK, Reynolds K, He J. Systematic review: glucose control and cardiovascular disease in type 2 diabetes. Ann Intern Med. 2009 Sep 15;151(6):394-403.

(78) Ray KK, Seshasai SR, Wijesuriya S, Sivakumaran R, Nethercott S, Preiss D, et al. Effect of intensive control of glucose on cardiovascular outcomes and death in patients with diabetes mellitus: a meta-analysis of randomised controlled trials. Lancet. 2009 May 23;373(9677):1765-72.

(79) Robinson KA, Dickersin K. Development of a highly sensitive search strategy for the retrieval of reports of controlled trials using PubMed. Int J Epidemiol. 2002 Feb;31(1):150-3.

(80) Robinson KA, Dickersin K. Development of a highly sensitive search strategy for the retrieval of reports of controlled trials using PubMed. Int J Epidemiol. 2002 Feb;31(1):150-3.

(81) Review Maneger version 5.0. Review Manager [home page on the internet] Available from: http://www.cc-ims.net/revman.10/ maio/2009. 
(82) Higgins JP, Thompson SG. Quantifying heterogeneity in a meta-analysis. Stat Med. 2002 Jun 15;21(11):1539-58.

(83) Nagy V. [Advanced credit: patient enrolling and therapy initiation in the ADVANCE trial]. Orv Hetil. 2007 Sep 30;148(39):1839-42.

(84) Pospisilova Y. [A study of the United Kingdom Prospective Diabetes Study and its results]. Vnitr Lek. 2000 Oct;46(10):709-14.

(85) Kawamori R, Kamada T. [Diabetes mellitus and its complications in Japan. The determination of glycemic threshold for the regression or prevention of diabetic microangiopathies, and insulin injection regimen to establish strict glycemic control in NIDDM]. Nippon Naika Gakkai Zasshi. 1991 Sep 10;80(9):1436-41.

(86) Yang JM, Guo XH, Yu X. [Long-term intensive glycemic and lipid control ameliorates the carotid intima medial thickness in type 2 diabetes mellitus]. Beijing Da Xue Xue Bao. 2007 Dec 18;39(6):649-52.

(87) Chalmers J. [ADVANCE study: objectives, design and current status]. Drugs. 2003;63 Spec No 1:39-44.

(88) Scheen AJ, Estrella F. [Clinical trial of the month. The STENO-2 study: a plea for global and intensive management of the type 2 diabetic patient]. Rev Med Liege. 2003 Feb;58(2):109-11.

(89) Gaede PH, Jepsen PV, Larsen JN, Jensen GV, Parving HH, Pedersen OB. [The Steno-2 study. Intensive multifactorial intervention reduces the occurrence of cardiovascular disease in patients with type 2 diabetes]. Ugeskr Laeger. 2003 Jun 23;165(26):2658-61.

(90) Lapina I, Filatov DN, Mareev VI, Narusov OI, Bolotina MG, Shestakova MV, et al. [Effect of strict glycemic control on clinical state and course of the disease in patients with chronic heart failure and type II diabetes mellitus. Results of the REMBO "rational effective multicomponent therapy in the struggle against diabetes mellitus in patients with congestive heart failure" study]. Kardiologiia. 2008;48(9):17-27.

(91) Gerstein HC, Miller ME, Byington RP, Goff DC, Jr., Bigger JT, Buse JB, et al. Effects of intensive glucose lowering in type 2 diabetes. N Engl J Med. 2008 Jun $12 ; 358(24): 2545-59$. 
(92) Buse JB, Bigger JT, Byington RP, Cooper LS, Cushman WC, Friedewald WT, et al. Action to Control Cardiovascular Risk in Diabetes (ACCORD) trial: design and methods. Am J Cardiol. 2007 Jun 18;99(12A):21i-33i.

(93) Chew EY, Ambrosius WT, Howard LT, Greven CM, Johnson S, Danis RP, et al. Rationale, design, and methods of the Action to Control Cardiovascular Risk in Diabetes Eye Study (ACCORD-EYE). Am J Cardiol. 2007 Jun 18;99(12A):103i-11i.

(94) Gerstein HC, Riddle MC, Kendall DM, Cohen RM, Goland R, Feinglos MN, et al. Glycemia treatment strategies in the Action to Control Cardiovascular Risk in Diabetes (ACCORD) trial. Am J Cardiol. 2007 Jun 18;99(12A):34i-43i.

(95) Patel A, MacMahon S, Chalmers J, Neal B, Billot L, Woodward M, et al. Intensive blood glucose control and vascular outcomes in patients with type 2 diabetes. N Engl J Med. 2008 Jun 12;358(24):2560-72.

(96) Rationale and design of the ADVANCE study: a randomised trial of blood pressure lowering and intensive glucose control in high-risk individuals with type 2 diabetes mellitus. Action in Diabetes and Vascular Disease: PreterAx and DiamicroN Modified-Release Controlled Evaluation. J Hypertens Suppl. 2001 Nov;19(4):S21-S28.

(97) ADVANCE--Action in Diabetes and Vascular Disease: patient recruitment and characteristics of the study population at baseline. Diabet Med. 2005 Jul;22(7):882-8.

(98) Study rationale and design of ADVANCE: action in diabetes and vascular disease--preterax and diamicron MR controlled evaluation. Diabetologia. 2001 Sep;44(9):1118-20.

(99) Chalmers J. [ADVANCE study: objectives, design and current status]. Drugs. 2003;63 Spec No 1:39-44.

(100) Chalmers J, Perkovic V, Joshi R, Patel A. ADVANCE: breaking new ground in type 2 diabetes. J Hypertens Suppl. 2006 Aug;24(5):S22-S28.

(101) Perkovic V, Joshi R, Patel A, Bompoint S, Chalmers J. ADVANCE: lessons from the run-in phase of a large study in type 2 diabetes. Blood Press. 2006;15(6):340-6. 
(102) Chalmers J, Kengne AP, Joshi R, Perkovic V, Patel A. New insights from ADVANCE. J Hypertens Suppl. 2007 Jun;25(1):S23-S30.

(103) Patel A, Chalmers J, Poulter N. ADVANCE: action in diabetes and vascular disease. J Hum Hypertens. 2005 Jun;19 (Suppl 1):S27-S32.

(104) Intensive blood-glucose control with sulphonylureas or insulin compared with conventional treatment and risk of complications in patients with type 2 diabetes (UKPDS 33). UK Prospective Diabetes Study (UKPDS) Group. Lancet. 1998 Sep 12;352(9131):837-53.

(105) Effect of intensive blood-glucose control with metformin on complications in overweight patients with type 2 diabetes (UKPDS 34). UK Prospective Diabetes Study (UKPDS) Group. Lancet. 1998 Sep 12;352(9131):854-65.

(106) Holman RR, Paul SK, Bethel MA, Matthews DR, Neil HA. 10-year follow-up of intensive glucose control in type 2 diabetes. N Engl J Med. 2008 Oct 9;359(15):1577-89.

(107) UK Prospective Diabetes Study (UKPDS). VIII. Study design, progress and performance. Diabetologia. 1991 Dec;34(12):877-90.

(108) United Kingdom Prospective Diabetes Study (UKPDS). 13: Relative efficacy of randomly allocated diet, sulphonylurea, insulin, or metformin in patients with newly diagnosed non-insulin dependent diabetes followed for three years. BMJ. 1995 Jan 14;310(6972):83-8.

(109) U.K. prospective diabetes study 16. Overview of 6 years' therapy of type II diabetes: a progressive disease. U.K. Prospective Diabetes Study Group. Diabetes. 1995 Nov;44(11):1249-58.

(110) Turner R, Cull C, Holman R. United Kingdom Prospective Diabetes Study 17: a 9-year update of a randomized, controlled trial on the effect of improved metabolic control on complications in non-insulin-dependent diabetes mellitus. Ann Intern Med. 1996 Jan 1;124(1 Pt 2):136-45.

(111) Turner RC, Millns H, Neil HA, Stratton IM, Manley SE, Matthews DR, et al. Risk factors for coronary artery disease in non-insulin dependent diabetes mellitus: United Kingdom Prospective Diabetes Study (UKPDS: 23). BMJ. 1998 Mar 14;316(7134):823-8. 
(112) Clarke P, Gray A, Adler A, Stevens R, Raikou M, Cull C, et al. Costeffectiveness analysis of intensive blood-glucose control with metformin in overweight patients with type II diabetes (UKPDS No. 51). Diabetologia. 2001 Mar;44(3):298-304.

(113) Wright A, Burden AC, Paisey RB, Cull CA, Holman RR. Sulfonylurea inadequacy: efficacy of addition of insulin over 6 years in patients with type 2 diabetes in the U.K. Prospective Diabetes Study (UKPDS 57). Diabetes Care. 2002 Feb;25(2):330-6.

(114) Wright AD, Cull CA, Macleod KM, Holman RR. Hypoglycemia in Type 2 diabetic patients randomized to and maintained on monotherapy with diet, sulfonylurea, metformin, or insulin for 6 years from diagnosis: UKPDS73. J Diabetes Complications. 2006 Nov;20(6):395-401.

(115) Clarke PM, Gray AM, Briggs A, Stevens RJ, Matthews DR, Holman RR. Costutility analyses of intensive blood glucose and tight blood pressure control in type 2 diabetes (UKPDS 72). Diabetologia. 2005 May;48(5):868-77.

(116) Nasr CE, Hoogwerf BJ, Faiman C, Reddy SS. United Kingdom Prospective Diabetes Study (UKPDS). Effects of glucose and blood pressure control on complications of type 2 diabetes mellitus. Cleve Clin J Med. 1999 Apr;66(4):247-53.

(117) Abraira C, Emanuele N, Colwell J, Henderson W, Comstock J, Levin S, et al. Glycemic control and complications in type II diabetes. Design of a feasibility trial. VA CS Group (CSDM). Diabetes Care. 1992 Nov;15(11):1560-71.

(118) Abraira C, Colwell JA, Nuttall FQ, Sawin CT, Nagel NJ, Comstock JP, et al. Veterans Affairs Cooperative Study on glycemic control and complications in type II diabetes (VA CSDM). Results of the feasibility trial. Veterans Affairs Cooperative Study in Type II Diabetes. Diabetes Care. 1995 Aug;18(8):1113-23.

(119) Abraira C, Colwell J, Nuttall F, Sawin CT, Henderson W, Comstock JP, et al. Cardiovascular events and correlates in the Veterans Affairs Diabetes Feasibility Trial. Veterans Affairs Cooperative Study on Glycemic Control and Complications in Type II Diabetes. Arch Intern Med. 1997 Jan 27;157(2):181-8.

(120) Abraira C, Henderson WG, Colwell JA, Nuttall FQ, Comstock JP, Emanuele $\mathrm{NV}$, et al. Response to intensive therapy steps and to glipizide dose in combination with insulin in type 2 diabetes. VA feasibility study on glycemic control and complications (VA CSDM). Diabetes Care. 1998 Apr;21(4):574-9. 
(121) Agrawal L, Emanuele NV, Abraira C, Henderson WG, Levin SR, Sawin CT, et al. Ethnic differences in the glycemic response to exogenous insulin treatment in the Veterans Affairs Cooperative Study in Type 2 Diabetes Mellitus (VA CSDM). Diabetes Care. 1998 Apr;21(4):510-5.

(122) Azad N, Emanuele NV, Abraira C, Henderson WG, Colwell J, Levin SR, et al. The effects of intensive glycemic control on neuropathy in the VA cooperative study on type II diabetes mellitus (VA CSDM). J Diabetes Complications. 1999 Sep;13(5-6):307-13.

(123) Colwell JA. The feasibility of intensive insulin management in non-insulindependent diabetes mellitus. Implications of the Veterans Affairs Cooperative Study on Glycemic Control and Complications in NIDDM. Ann Intern Med. 1996 Jan 1;124(1 Pt 2):131-5.

(124) Emanuele N, Klein R, Abraira C, Colwell J, Comstock J, Henderson WG, et al. Evaluations of retinopathy in the VA Cooperative Study on Glycemic Control and Complications in Type II Diabetes (VA CSDM). A feasibility study. Diabetes Care. 1996 Dec;19(12):1375-81.

(125) Emanuele N, Azad N, Abraira C, Henderson W, Colwell J, Levin S, et al. Effect of intensive glycemic control on fibrinogen, lipids, and lipoproteins: Veterans Affairs Cooperative Study in Type II Diabetes Mellitus. Arch Intern Med. 1998 Dec 7;158(22):2485-90.

(126) Levin SR, Coburn JW, Abraira C, Henderson WG, Colwell JA, Emanuele NV, et al. Effect of intensive glycemic control on microalbuminuria in type 2 diabetes. Veterans Affairs Cooperative Study on Glycemic Control and Complications in Type 2 Diabetes Feasibility Trial Investigators. Diabetes Care. 2000 Oct;23(10):1478-85.

(127) Pitale S, Kernan-Schroeder D, Emanuele N, Sawin C, Sacks J, Abraira C. Health-related quality of life in the VA Feasibility Study on glycemic control and complications in type 2 diabetes mellitus. J Diabetes Complications. 2005 Jul;19(4):207-11.

(128) Pitale SU, Abraira C, Emanuele NV, McCarren M, Henderson WG, Pacold I, et al. Two years of intensive glycemic control and left ventricular function in the Veterans Affairs Cooperative Study in Type 2 Diabetes Mellitus (VA CSDM). Diabetes Care. 2000 Sep;23(9):1316-20.

(129) Abraira C, Duckworth W, McCarren M, Emanuele N, Arca D, Reda D, et al. Design of the cooperative study on glycemic control and complications in 
diabetes mellitus type 2: Veterans Affairs Diabetes Trial. J Diabetes Complications. 2003 Nov;17(6):314-22.

(130) Abraira C, Duckworth WC, Moritz T. Glycaemic separation and risk factor control in the Veterans Affairs Diabetes Trial: an interim report. Diabetes Obes Metab. 2009 Feb;11(2):150-6.

(131) Duckworth W, Abraira C, Moritz T, Reda D, Emanuele N, Reaven PD, et al. Glucose control and vascular complications in veterans with type 2 diabetes. $\mathrm{N}$ Engl J Med. 2009 Jan 8;360(2):129-39.

(132) Gaede P, Vedel P, Parving HH, Pedersen O. Intensified multifactorial intervention in patients with type 2 diabetes mellitus and microalbuminuria: the Steno type 2 randomised study. Lancet. 1999 Feb 20;353(9153):617-22.

(133) Vaag AA. Glycemic control and prevention of microvascular and macrovascular disease in the Steno 2 study. Endocr Pract. 2006 Jan;12 Suppl 1:89-92.

(134) Gaede P, Vedel P, Larsen N, Jensen GV, Parving HH, Pedersen O. Multifactorial intervention and cardiovascular disease in patients with type 2 diabetes. N Engl J Med. 2003 Jan 30;348(5):383-93.

(135) Gaede PH, Jepsen PV, Larsen JN, Jensen GV, Parving HH, Pedersen OB. [The Steno-2 study. Intensive multifactorial intervention reduces the occurrence of cardiovascular disease in patients with type 2 diabetes]. Ugeskr Laeger. 2003 Jun 23;165(26):2658-61.

(136) Ohkubo Y, Kishikawa H, Araki E, Miyata T, Isami S, Motoyoshi S, et al. Intensive insulin therapy prevents the progression of diabetic microvascular complications in Japanese patients with non-insulin-dependent diabetes mellitus: a randomized prospective 6-year study. Diabetes Res Clin Pract. 1995 May;28(2):103-17.

(137) Shichiri M, Kishikawa H, Ohkubo Y, Wake N. Long-term results of the Kumamoto Study on optimal diabetes control in type 2 diabetic patients. Diabetes Care .2000 Apr;23 Suppl 2:B21-B29.

(138) Wake N, Hisashige A, Katayama T, Kishikawa H, Ohkubo Y, Sakai M, et al. Cost-effectiveness of intensive insulin therapy for type 2 diabetes: a 10-year follow-up of the Kumamoto study. Diabetes Res Clin Pract. 2000 Jun;48(3):20110. 
(139) Gerstein HC, Miller ME, Byington RP, Goff DC, Jr., Bigger JT, Buse JB, et al. Effects of intensive glucose lowering in type 2 diabetes. N Engl J Med. 2008 Jun $12 ; 358(24): 2545-59$.

(140) Gerstein HC, Miller ME, Byington RP, Goff DC, Jr., Bigger JT, Buse JB, et al. Effects of intensive glucose lowering in type 2 diabetes. N Engl J Med. 2008 Jun $12 ; 358(24): 2545-59$.

(141) Gerstein HC, Miller ME, Byington RP, Goff DC, Jr., Bigger JT, Buse JB, et al. Effects of intensive glucose lowering in type 2 diabetes. N Engl J Med. 2008 Jun $12 ; 358(24): 2545-59$.

(142) Gaede P, Vedel P, Larsen N, Jensen GV, Parving HH, Pedersen O.

Multifactorial intervention and cardiovascular disease in patients with type 2 diabetes. N Engl J Med. 2003 Jan 30;348(5):383-93.

(143) Intensive blood-glucose control with sulphonylureas or insulin compared with conventional treatment and risk of complications in patients with type 2 diabetes (UKPDS 33). UK Prospective Diabetes Study (UKPDS) Group. Lancet. 1998 Sep 12;352(9131):837-53.

(144) Ray KK, Seshasai SR, Wijesuriya S, Sivakumaran R, Nethercott S, Preiss D, et al. Effect of intensive control of glucose on cardiovascular outcomes and death in patients with diabetes mellitus: a meta-analysis of randomised controlled trials. Lancet. 2009 May 23;373(9677):1765-72.

(145) Kelly TN, Bazzano LA, Fonseca VA, Thethi TK, Reynolds K, He J. Systematic review: glucose control and cardiovascular disease in type 2 diabetes. Ann Intern Med. 2009 Sep 15;151(6):394-403.

(146) Ray KK, Seshasai SR, Wijesuriya S, Sivakumaran R, Nethercott S, Preiss D, et al. Effect of intensive control of glucose on cardiovascular outcomes and death in patients with diabetes mellitus: a meta-analysis of randomised controlled trials. Lancet. 2009 May 23;373(9677):1765-72.

(147) Dormandy JA, Charbonnel B, Eckland DJ, Erdmann E, Massi-Benedetti M, Moules IK, et al. Secondary prevention of macrovascular events in patients with type 2 diabetes in the PROactive Study (PROspective pioglitAzone Clinical Trial In macroVascular Events): a randomised controlled trial. Lancet. 2005 Oct 8;366(9493):1279-89. 
(148) Kelly TN, Bazzano LA, Fonseca VA, Thethi TK, Reynolds K, He J. Systematic review: glucose control and cardiovascular disease in type 2 diabetes. Ann Intern Med. 2009 Sep 15;151(6):394-403.

(149) Effect of intensive blood-glucose control with metformin on complications in overweight patients with type 2 diabetes (UKPDS 34). UK Prospective Diabetes Study (UKPDS) Group. Lancet. 1998 Sep 12;352(9131):854-65.

(150) Intensive blood-glucose control with sulphonylureas or insulin compared with conventional treatment and risk of complications in patients with type 2 diabetes (UKPDS 33). UK Prospective Diabetes Study (UKPDS) Group. Lancet. 1998 Sep 12;352(9131):837-53.

(151) Schulz KF, Chalmers I, Hayes RJ, Altman DG. Empirical evidence of bias. Dimensions of methodological quality associated with estimates of treatment effects in controlled trials. JAMA. 1995 Feb 1;273(5):408-12.

(152) Gotzsche PC. Reference bias in reports of drug trials. Br Med J. (Clin Res Ed) 1987 Sep 12;295(6599):654-6.

(153) Ravnskov U. Cholesterol lowering trials in coronary heart disease: frequency of citation and outcome. BMJ. 1992 Jul 4;305(6844):15-9.

(154) Richardson WS, Wilson MC, Nishikawa J, Hayward RS. The well-built clinical question: a key to evidence-based decisions. ACP J Club. 1995 Nov;123(3):A12-A13.

(155) Dickersin K, Scherer R, Lefebvre C. Identifying relevant studies for systematic reviews. BMJ. 1994 Nov 12;309(6964):1286-91.

(156) Smith BJ, Darzins PJ, Quinn M, Heller RF. Modern methods of searching the medical literature. Med J Aust. 1992 Nov 2;157(9):603-11.

(157) Dickersin K, Scherer R, Lefebvre C. Identifying relevant studies for systematic reviews. BMJ. 1994 Nov 12;309(6964):1286-91.

(158) Robinson KA, Dickersin K. Development of a highly sensitive search strategy for the retrieval of reports of controlled trials using PubMed. Int J Epidemiol. 2002 Feb;31(1):150-3. 
(159) Buehler AM, Suzumura EA, Berwanger O, Oliveira JB.. Como Avaliar Criticamente um Ensaio Clínico de Alocação Aleatória em Terapia Intensiva? Rev Bras Ter Intensiva. 2009 Apr;21(2):219-25.

(160) Schulz KF, Grimes DA. Sample size slippages in randomised trials: exclusions and the lost and wayward. Lancet. 2002 Mar 2;359(9308):781-5.

(161) Lewis S, Clarke M. Forest plots: trying to see the wood and the trees. BMJ. 2001 Jun 16;322(7300):1479-80.

(162) Effect of intensive blood-glucose control with metformin on complications in overweight patients with type 2 diabetes (UKPDS 34). UK Prospective Diabetes Study (UKPDS) Group. Lancet. 1998 Sep 12;352(9131):854-65.

(163) Intensive blood-glucose control with sulphonylureas or insulin compared with conventional treatment and risk of complications in patients with type 2 diabetes (UKPDS 33). UK Prospective Diabetes Study (UKPDS) Group. Lancet. 1998 Sep 12;352(9131):837-53.

(164) Higgins JP, Thompson SG. Quantifying heterogeneity in a meta-analysis. Stat Med. 2002 Jun 15;21(11):1539-58.

(165) Higgins JP, Thompson SG, Deeks JJ, Altman DG. Measuring inconsistency in meta-analyses. BMJ. 2003 Sep 6;327(7414):557-60.

(166) Higgins JP, Thompson SG. Quantifying heterogeneity in a meta-analysis. Stat Med. 2002 Jun 15;21(11):1539-58.

(167) Robinson KA, Dickersin K. Development of a highly sensitive search strategy for the retrieval of reports of controlled trials using PubMed. Int J Epidemiol. 2002 Feb;31(1):150-3.

(168) Review Maneger version 5.0. Review Manager [homepage on the internet] Available from http://www.cc-ims.net/revman.15/jul/2007.

(169) Jadad AR, Cook DJ, Browman GP. A guide to interpreting discordant systematic reviews. CMAJ. 1997 May 15;156(10):1411-6.

(170) Bailar JC, III. The promise and problems of meta-analysis. N Engl J Med. 1997 Aug 21;337(8):559-61. 
(171) Intensive blood-glucose control with sulphonylureas or insulin compared with conventional treatment and risk of complications in patients with type 2 diabetes (UKPDS 33). UK Prospective Diabetes Study (UKPDS) Group. Lancet. 1998 Sep 12;352(9131):837-53. 


\section{APÊNDICE A - METODOLOGIA DAS REVISÕES SISTEMÁTICAS E META-ANÁLISES}

\subsection{Definição}

Revisões sistemáticas são revisões de literatura científica que têm por objetivo identificar todos os estudos já realizados no meio, publicados ou não, pelo mundo, sobre um determinado assunto de interesse, utilizando-se uma metodologia sistemática de busca, que visa eliminar vieses e erros aleatórios. A partir dos resultados dos estudos incluídos na revisão sistemática, pode-se ou não realizar uma meta-análise, que é uma análise estatística dos resultados dos estudos independentes, com a finalidade de se produzir uma única estimativa de efeito para o desfecho.

Apesar das revisões sistemáticas estarem no topo da hierarquia das evidências, esta metodologia não isenta as análises de possíveis vieses. Viés de publicação, estratégia de busca inadequada, além de vieses introduzidos por conta de problemas metodológicos, podem comprometer as medidas de efeito e devem ser levadas em conta na análise crítica do estudo (151).

\subsection{Diferenças entre revisões sistemáticas e revisões narrativas}

As revisões narrativas possuem inúmeras desvantagens que as revisões sistemáticas conseguem resolver. Primeiramente, as revisões narrativas são subjetivas e susceptíveis a erros e vieses. Muitas vezes possuem informações sem especificação de fonte e sem análise crítica da mesma. Ainda, os estudos realizados que são inseridos como referências podem ter seus resultados contraditórios ou sem conclusões definitivas. Quando uma conduta clínica não está estabelecida por diretrizes, as opiniões de especialistas são bastante divergentes. Em revisões narrativas, este ponto de vista específico do autor geralmente é inserido na redação da revisão e pode ocorrer uma seleção das referências que serão incluídas para fortalecerem e confirmarem sua opinião sobre o tema (152). Quando as evidências são sistematicamente acessadas, a revisão promove uma visão mais objetiva, que ajuda a resolver uma incerteza clínica diante de todas as evidências disponíveis sobre o tema, possibilitando a generalização dos achados e estimativas mais precisas das medidas de efeito (153). Ainda, as revisões 
sistemáticas são importantes, pois identificam questões que ainda precisam ser resolvidas em estudos posteriores.

\subsection{Princípios e Procedimentos para Revisões Sistemáticas}

Uma revisão sistemática se parece muito com a elaboração de um estudo clínico, com algumas peculiaridades. Os principais pontos serão discutidos a seguir:

\subsubsection{Elaboração da Questão de Revisão}

Assim como nos estudos clínicos que definem sua questão de pesquisa, a questão da revisão sistemática também deve estar bem definida, de preferência obedecendo ao esquema PICO (154), que é um acrônimo cujas letras significam (do inglês):

P - População: deve estar bem definida, por exemplo, pacientes portadores de diabetes melito tipo II.

I - Intervenção: Todo ensaio clínico randomizado possui uma intervenção que se deseja investigar. Esta intervenção pode ser um medicamento, um novo produto para a saúde, um novo procedimento ou técnica cirúrgica. Quando realizamos uma revisão sistemática, esta intervenção também tem que estar definida.

C - Controle: Qualquer intervenção investigada precisa ser comparada com um controle, que pode ser um tratamento padrão já estabelecido em diretrizes ou um controle por placebo. Este parâmetro também deve estar definido na questão de pesquisa

O - Outcome: Palavra em inglês que significa desfecho. Na presente revisão sistemática estes desfechos são os eventos macrovasculares e microvasculares.

\subsubsection{Definição dos Critérios de Elegibilidade}

Os critérios de elegibilidade complementam a questão de pesquisa estruturada. Definem-se a priori os critérios de inclusão e exclusão da revisão, baseados em quais tipos de estudo serão selecionados, condições de interesse do paciente, período mínimo de seguimento dos estudos, métodos para diagnóstico e critérios adequados para a busca, e depois se define a estratégia de busca. 
Estes critérios compõem a ficha clínica padronizada que auxilia na triagem dos artigos recuperados pela estratégia de busca

\subsubsection{Base de dados para busca e identificação dos potenciais estudos incluídos}

A estratégia de busca para identificação dos estudos relevantes deve ser cuidadosamente elaborada e é um dos pontos principais de uma revisão sistemática. É necessário definir termos apropriados para a busca, que garantam a recuperação dos potenciais artigos elegíveis de forma eficaz, a fim de reunirmos a totalidade da evidência disponível (155).

O conhecimento dos mecanismos de busca nas várias bases de dados se faz necessário, já que diferem bastante entre si. É importante que se busque nas principais bases de dados disponíveis, já que os estudos não necessariamente se sobrepõem nas várias bases de dados científicos. Por exemplo, a sobreposição de trabalho publicados na maior base de dados MEDLINE e em outra não menos importante, EMBASE, é de apenas 34\% (156). O MEDLINE é uma base americana de dados e o EMBASE arquiva bastante trabalhos publicados em jornais europeus.

As bases de dados informatizadas utilizam-se de um processo chamado indexação para catalogar os artigos. Cada base de dados tem uma lista própria de periódicos que cataloga e alguns destes fazem parte de mais de uma base de dados. Cada artigo destes periódicos é lido por técnicos e suas informações principais são transcritas para a base de dados - autores, título, resumo, instituição, revista, ano de publicação, volume e número da página.

Uma parte dos artigos apresenta também o resumo. Estes dados são próprios do autor e da revista em que o artigo foi publicado, não tendo o indexador controle sobre eles. Estas partes de cada artigo indexado constituem o chamado vocabulário nãocontrolado.

A estas informações próprias de cada artigo, o técnico responsável por sua indexação adiciona outras próprias da base de dados. Destas informações, a de maior importância constitui o chamado thesaurus. Um thesaurus consiste de uma palavrachave, que é um descritor de assunto. O thesaurus do MEDLINE chamase MeSH 
(Medical Subject Headings) e é adotado por diversas bases de dados em medicina e biologia. No EMBASE, este thesaurus é o EMTREE tool.

Cada descritor de assunto tem uma definição e engloba várias sinonímias e termos relacionados do termo clínico em um “princípio de árvore”. Um descritor mais abrangente está colocado nos ramos mais grossos da árvore e à medida que eles ficam mais precisos, vão se distanciando do tronco até que atinja uma definição bastante específica. Esta noção é importante, pois existem meios de se procurar apenas pelo descritor mais abrangente e incluir todos os "ramos" dele, utilizando um recurso chamado "explodir" (explode, em inglês).

Ainda, não se devem usar limites ou restrições na busca, como seleção de linguagem (todas as línguas devem ser procuradas), períodos de tempo, status de publicação (devemos procurar por estudos concluídos, em andamento e não publicados, resumos trabalhos apresentados em congresso), etc. Restrições podem comprometer a busca sistemática de toda a evidência disponível, gerando um viés de publicação e comprometendo as estimativas de efeito dos achados.

Outras estratégias para a busca das evidências são contatar especialistas da área, indústrias farmacêuticas e outros canais informais de informação, que podem ser fontes importantes de estudos não publicados ou em andamento; analisar as referências citadas nos principais artigos incluídos, a fim de identificar se há algum estudo potencialmente elegível que não esteja em sua base de dados; e realizar a busca manual, feita em publicações regionais não indexadas, anais de congressos, teses e dissertações, registros de ensaios clínicos randomizados que estarão em andamento entre outras, e não se constitui como fonte obrigatória para o revisor (157).

Existem várias estratégias disponíveis para acessar ensaios clínicos randomizados. Elas utilizam a combinação de termos e operadores boleados, de modo a filtrarem apenas os ensaios clínicos randomizados realizados em seres humanos, excluindo a pesquisa animal. A utilizada na presente revisão é o filtro ultra-sensível validado para ensaios clínicos randomizados da Cochrane (158).

\subsubsection{Seleção dos estudos, acesso a qualidade metodológica e extração de dados}


Decisões sobre inclusão ou exclusão de estudos individuais geralmente envolvem algum grau de subjetividade. Para minimizar os possíveis equívocos obtidos na triagem dos estudos, a seleção dos artigos que preenchem os critérios de elegibilidade é realizada por dois revisores independentes, onde as discordâncias são discutidas e resolvidas por consenso ou com a ajuda de um terceiro revisor.

Ensaios clínicos randomizados provêm a melhor evidência de eficácia a cerca de uma intervenção médica, mas não estão imunes a vieses, embora eliminem a grande maioria dos encontrados em estudos observacionais. Assim, é recomendável avaliarmos a qualidade metodológica de todos os estudos incluídos na revisão, no que diz respeito às características metodológicas inerentes aos ensaios clínicos randomizados. Esta avaliação deve fazer parte da apresentação dos resultados de uma meta-análise, para auxiliar os leitores na análise critica da revisão. Quando a informação acerca desta qualidade metodológica do estudo não esta disponível no artigo original, os autores deste trabalho devem ser contatados a fim de responderem as solicitações.

As principais qualidades metodológicas de um ensaio clínico podem ser resumidas pelos princípios metodológicos descritos a seguir (159):

Randomização: deve ser gerada por uma técnica adequada. Para a randomização ser válida é necessário que cada paciente elegível tenha chance igual de ser alocado para cada um dos grupos do estudo e não pode haver influências dos investigadores, equipe e pacientes. Para tanto, é fundamental que os investigadores não sejam capazes de prever a alocação dos próximos pacientes, para evitar que ele selecione um paciente com pior prognóstico para o tratamento ativo, por exemplo. É por essa razão que alocar o tratamento conforme o número do prontuário, data de nascimento ou dia da semana não são métodos válidos de randomização. A lista de alocação aleatória geralmente é gerada utilizando softwares apropriados. Outros métodos também considerados válidos são utilização de tabela de números aleatórios, ou mesmo uso de dado ou moeda, e a utilização de envelopes lacrados contendo o código de tratamento.

Alocação sigilosa: É o ato de manter a lista de randomização sob sigilo, ou seja, os investigadores devem primeiro incluir o paciente no estudo e só após o tratamento (experimental ou controle) é definido. A alocação sigilosa representa o critério metodológico mais importante em um ensaio clínico randomizado. O método mais efetivo para garantir alocação sigilosa é utilizando a randomização central, em que os 
investigadores cadastram o paciente no estudo via internet ou telefone, e após isto é que recebem a alocação do paciente.

Esquema de cegamento (conhecido por "duplo-cego"): O cegamento ocorre conjuntamente com a randomização e representa o desconhecimento de todos envolvidos na pesquisa (participantes do estudo, investigadores, equipe médica, estatístico) quanto à alocação dos pacientes a um grupo ou a outro. Assim, o estudo não será influenciado por alterações de conduta por parte da equipe médica ou do paciente (efeito Hawthorne). O cegamento previne vieses em vários estágios da pesquisa, mas nem sempre ele é possível de ser aplicado. Não se pode ser cego quanto à avaliação de um novo procedimento cirúrgico, por exemplo.

Princípio metodológico de análise por Intenção de Tratar: É uma metodologia que, na análise primária, inclui e analisa os dados de todos os pacientes do estudo no braço para o qual eles foram originalmente alocados, independente se eles completaram todos os procedimentos estabelecidos no protocolo ou não. É um princípio que permite analisar os resultados de acordo com o tratamento designado e não de acordo com o tratamento recebido. Assim, os fatores prognósticos, sabidos ou não, serão, na média, distribuídos igualmente entre os grupos e todos os dados dos pacientes recrutados serão analisados, independentemente do paciente ter sido seguido até o final do estudo. Se os dados de pacientes que não foram complacentes forem excluídos, podemos comprometer o efeito da randomização, já que estes pacientes podem ter fatores prognósticos piores e características mais graves, que acarretarão em desbalanço entre o grupo intervenção e controle em relação as suas características de base.

Seguimento dos pacientes randomizados: Idealmente, todos os pacientes incluídos no estudo devem ser avaliados na sua conclusão final. Quando existe um número significante de pacientes que não se conhece nenhuma informação sobre desfechos, e esta perda não necessariamente está balanceada entre os braços do estudo, o benefício da randomização é comprometido, já que estes pacientes frequientemente têm prognósticos diferentes do que aqueles onde o seguimento foi adequadamente realizado (160).

Quanto à extração dos dados de interesse dos ensaios clínicos selecionados, utiliza-se uma ficha clínica padronizada. Também são dois revisores independentes que 
extraem as informações, que depois são comparadas e as divergências resolvidas por consenso ou por um terceiro revisor.

\subsubsection{Padronização das medidas de desfecho e apresentação dos resultados}

Os resultados individuais devem ser expressos em formato padronizado que permitam comparações entre os estudos. Se um desfecho é binário (doença versus nãodoença, morte versus sobrevivência), então o risco relativo (RR) ou o odds ratio (OR) geralmente é calculado. Medidas absolutas como redução absoluta de risco ou número necessário para tratar (NNT) são mais úteis para a aplicação clínica dos resultados. Quando os desfechos são contínuos e as medidas são realizadas na mesma escala, a diferença das médias entre o grupo tratamento e o grupo controle é utilizada, com seus respectivos desvios-padrão.

Os resultados de um estudo clínico podem ser apresentados segundo uma tabela 2 × 2 :

\begin{tabular}{|c|c|c|c|c|}
\hline \multirow{5}{*}{$\underline{\text { EXPOSIÇÃO }}$} & \multicolumn{3}{|c|}{ DESFECHO } & \multirow[b]{2}{*}{ TOTAL } \\
\hline & & Sim & Não & \\
\hline & Sim & $\mathrm{a}$ & b & $a+b$ \\
\hline & Não & $\mathrm{c}$ & $\mathrm{d}$ & $c+d$ \\
\hline & & $a+c$ & $b+d$ & \\
\hline
\end{tabular}

Assim, o cálculo das principais medidas de efeito pode ser obtido conforme:

Risco Absoluto (RA): É a probabilidade de desenvolver o desfecho em cada grupo. É matematicamente representado por $\mathrm{a} /(\mathrm{a}+\mathrm{b})$ e $\mathrm{c} /(\mathrm{c}+\mathrm{d})$

Redução Absoluta de risco (RAR): é a diferença de risco absoluto entre o grupo controle e entre o grupo tratado. É matematicamente representado por

RAR $=c /(c+d)-a /(a+b)$. Embora a Redução de Risco Relativo (descrito abaixo) seja o parâmetro mais utilizado para a apresentação dos resultados, a RAR é a medida que tem maior importância clínica, pois é ela quem avalia a eficácia absoluta da intervenção. 
Risco relativo (RR): é o risco de eventos entre pacientes no grupo tratado, relativo ao risco nos pacientes do grupo controle, ou seja, $R R=[a /(a+b)] /[c /(c+d)]$. Essa medida nos informa a proporção do risco original que ainda está presente quando os pacientes recebem o tratamento experimental.

Redução de risco relativo (RRR): É uma estimativa da proporção do risco basal que é removido pelo tratamento experimental. Pode ser calculado de duas maneiras: RRR= 1- RR ou RRR = RRA/RA (no grupo controle).

A RRR normalmente tem preferência ao RR na apresentação dos resultados.

Odds ratio (OR): $(\mathrm{a} / \mathrm{b}) /(\mathrm{c} / \mathrm{d})=\mathrm{ad} / \mathrm{bc}$. O odds ratio é uma razão de probabilidades que um evento particular vai ocorrer com a probabilidade que este evento não vai ocorrer e é qualquer número entre zero e infinito

Número Necessário para Tratar (NNT): é a medida utilizada para avaliar a significância clínica. É matematicamente representada pelo inverso da redução absoluta de risco.

\section{$\mathrm{NNT}=1 /$ RAR}

Expressa o número de pacientes que devem ser tratados por um período de tempo para obter um evento favorável (em caso de tratamento) ou para prevenir um evento desfavorável (em caso de profilaxia). Por exemplo, se uma droga tem um NNT igual a cinco, em relação ao evento morte, significa que cinco pacientes devem ser tratados com ela para que uma morte adicional seja evitada.

Nas revisões sistemáticas com meta-análise, os resultados globais e de cada estudo incluído são geralmente apresentados graficamente. A maneira mais usual é apresentar seus resultados com seus respectivos intervalos de confiança em um gráfico chamado de "forest plot", uma forma de apresentação que mostra as estimativas de efeito e intervalos de confiança dos estudos individuais e da meta-análise. Cada estudo é representado por um quadrado preto e uma linha horizontal que corresponde ao ponto estimado e o intervalo de confiança de $95 \%$ do risco relativo/odds ratio. O intervalo de confiança contém o verdadeiro valor da estimativa em $95 \%$ das vezes, ou seja, se ensaios similares fossem realizados 100 vezes, em 95 das vezes o resultado encontrado estaria dentro dos valores do intervalo. A linha sólida vertical do forest plot de valor 1.0 (RR ou OR) significa que o tratamento não tem efeito algum. Se o intervalo de confiança incluir o valor 1 , então a diferença de efeito do grupo tratamento e controle 
não é estatisticamente significante em níveis convencionais, ou seja, valores de $\mathrm{p}>$ 0.05. Estudos que concentram o quadrado preto a esquerda da linha vertical indicam resultados a favor da intervenção e os estudos que concentram seus quadrados pretos a direita da linha vertical indicam resultados a favor do grupo controle, ou seja, contrárias a intervenção. A área do quadrado preto reflete o peso de cada estudo na meta-análise. A meta-análise, ou seja, a combinação de todas os resultados individuais, é representada por um diamante preto (ao invés do quadrado), respeitando as mesmas convenções adotadas no forest plot para os resultados individuais dos estudos (161).

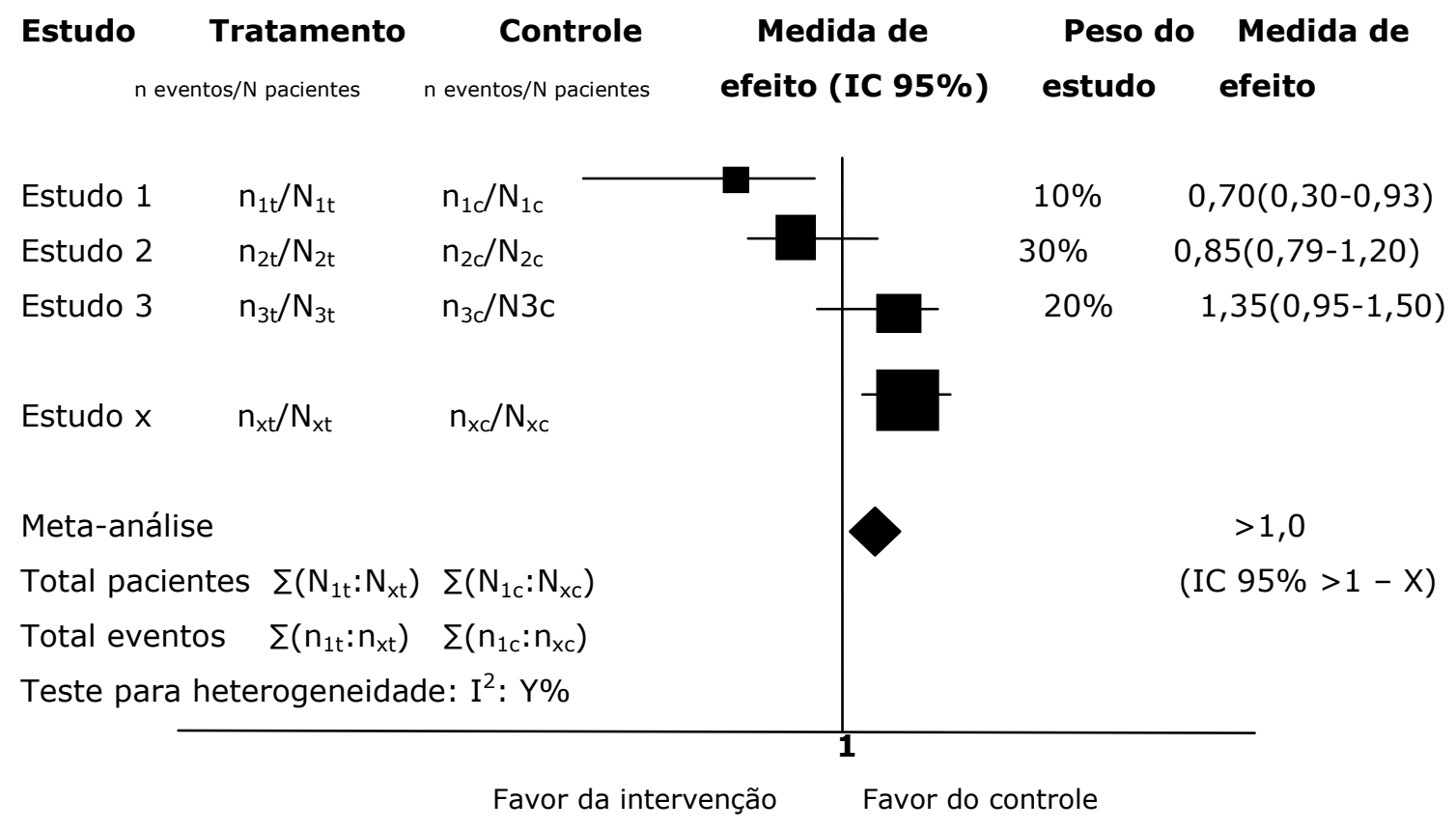

Figura 16 - Esquema de apresentação de uma meta-análise, utilizando o Forest plot

\subsubsection{Heterogeneidade entre os resultados dos estudos}

Mesmo incluindo-se estudos que preencham critérios de elegibilidade bem estabelecidos, os resultados fornecidos podem diferir muito entre eles. Diversas são as variáveis que contribuem para esta heterogeneidade entre os estudos, como definições de desfecho, tamanho de amostra, tempo de seguimento. Uma simples inspeção no Forest plot é bastante informativa, porém são desejáveis testes estatísticos que quantifiquem esta heterogeneidade. Testes estatísticos para heterogeneidade avaliam o quanto os resultados provenientes de estudos individuais refletem a estimativa única do 
efeito (meta-análise). Vários são os métodos estatísticos para avaliação da heterogeneidade entre os estudos. Para fins da presente meta-análise, utilizaremos o $\mathrm{I}^{2}$ de Higgs (162-164). Este teste utiliza o teste Qui-quadrado (Q) considerando os graus de liberdade (df), através da fórmula $\mathrm{I}^{2}=(\mathrm{Q}-\mathrm{df} / \mathrm{Q}) \mathrm{X} 100 \%$. Esta equação descreve a proporção da variabilidade entre os estudos atribuível à heterogeneidade (ou seja, descontando a variabilidade esperada somente pelo acaso). $\mathrm{O}$ valor de $\mathrm{I}^{2}$ depende da magnitude e direção do efeito e força da evidência para heterogeneidade (valor do teste de Chi-quadrado ou intervalo de confiança para $\left.\mathrm{I}^{2}\right)(165)$. Para interpretação desta porcentagem, considera-se baixa heterogeneidade para valores de $\mathrm{I} 2 \leq 25 \%$ e alta para $\mathrm{I} 2 \geq 75 \%$ (166).

\subsubsection{Métodos para estimar o efeito combinado dos estudos elegíveis}

Para combinar dados de diferentes estudos, deve-se levar em consideração alguns aspectos. Agrupar dados de diferentes estudos com amostras pequenas e tratá-los como um grande e único estudo pode levar a perda do efeito de randomização e introduzir viéses e fatores de confusão. A unidade do estudo deve ser sempre preservada e os resultados devem ser somados individualmente. Ainda, o simples cálculo das médias aritméticas pode ser inapropriado. Os resultados de estudos pequenos são mais susceptíveis a erros aleatórios do que estudos com maior número de pacientes incluídos e, portanto, deve ser dado menos peso para estes estudos menores no cálculo da estimativa do resultado final. As técnicas adequadas para combinarem os estudos seguem o princípio geral de combinar os efeitos de cada estudo ponderando-os de acordo com medidas associadas à robustez da informação de cada estudo, por exemplo, utilizando o inverso da variância.

A meta-análise pode ser calculada por inúmeros programas estatísticos ou pelo programa Review Manager $(167,168)$, que é um programa utilizado como padrão para preparar e atualizar revisões sistemáticas que são publicadas pela Cochrane Collaboration. Este programa estrutura a revisão, de modo a orientar o autor a cumprir todas as etapas relevantes para a elaboração de uma revisão sistemática. Neste sentido, auxilia na definição da questão de pesquisa, estrutura a redação do texto, permite a construção de tabelas que mostram as características dos estudos e as comparações, além de permitir adicionar os dados dos estudos e realizar as meta-análises. 


\subsubsection{Avaliação da qualidade da Evidência}

A qualidade da evidência indica até que ponto pode-se ter certeza de que uma estimativa do efeito é correta.

Para qualificar a evidência gerada por uma meta-análise para cada desfecho considerado, pode-se recorrer a várias ferramentas de classificação.

O GRADEprofiler é um programa que permite qualificar a evidência considerando 4 elementos chave: limitações no desenho do estudo, consistência entre os achados nos estudos individuais incluídos, evidência direta dos estudos incluídos (até que ponto população, intervenção ou desfecho são similares ao desfecho analisado) e precisão dos achados nos estudos individuais (se as estimativas de efeito variam mais de $25 \%$ entre os estudos).

Caso a evidência gerada não tenha o comprometimento de nenhum dos elementos-chave utilizados para a graduação da evidência, a meta-análise será considerada como de "Alta" qualidade. Para cada limitante, decresce um ou dois níveis, dependendo da gravidade da característica, podendo decair o grau da evidência para "moderado", "baixo" ou "muito baixo", com as seguintes interpretações:

Alta: futuras pesquisas muito provavelmente não mudariam a medida de efeito

Moderada: futuras pesquisas provavelmente teriam um impacto grande na estimativa de efeito, podendo alterá-la.

Baixa: futuras pesquisas muito provavelmente mudariam a estimativa de efeito

Muito baixa: A estimativa de efeito é muito incerta.

\subsubsection{Limitações das Revisões Sistemáticas}

A qualidade dos estudos elegíveis para a revisão é um ponto crucial para análise do resultado final da meta-análise. Se os estudos não foram conduzidos de forma adequada e tiverem pouca qualidade metodológica, seguramente o resultado final de uma meta-análise estará comprometido. Além disto, diferenças inerentes à condução dos estudos individualmente também devem ser consideradas e são sempre fontes de viéses: as características individuais dos pacientes no momento de início do estudo (viés de seleção), seguimento desigual entre os braços do tratamento sobre avaliação (viés de performance), avaliação dos desfechos de interesse (Viés de detecção) e viés devido às exclusões de pacientes depois que eles foram alocados para os grupos de investigação. 
São por todos estes fatores que a avaliação da qualidade metodológica dos estudos incluídos na meta-análise é tão importante e deve ser avaliado para análise crítica dos resultados de uma meta-análise (169). A avaliação da heterogeneidade, obtido por diferentes métodos estatísticos, também oferece uma boa ferramenta para avaliarmos se estamos sintetizando a informação de estudos similares.

Outro ponto a ser discutidos é a ausência da totalidade das evidências disponíveis. Quando se limitam as buscas das evidências por língua ou período, e, quando a estratégia de busca não possui uma sensibilidade adequada, podem-se excluir estudos que contribuiriam para a somatória dos efeitos. Estudos em andamento ou não publicados, bem como estudos com resultados negativos, devem ser acessados, quer em anais de congresso, consultas com especialistas da área, dissertações de mestrado, doutorado, indústrias farmacêuticas ou busca manual em referencias de estudos previamente incluídos (170). 


\section{APÊNDICE B - ESTRATÉGIA DETALHADA DE BUSCA}

As seguintes estratégias e seus respectivos resultados parciais foram obtidos nas bases de dados:

\section{1 - PUBMED/MEDLINE:}

\section{Bloco 1 - tipo de paciente/patologia e desfechos -}

Em relação à definição dos desfechos, não existem termos Mesh para as palavras microvasculares e macrovasculares. Entretanto, ao utilizar o termo Mesh genérico, em inglês, "Diabetes mellitus", nota-se que o mesmo engloba hierarquicamente (segundo o modelo de árvore) outro termo Mesh denominado de "Diabetes Complications", definido conforme tradução: "Condição ou processo patológico associado com a doença diabetes mellitus. Devido ao prejuízo no controle dos níveis de glicose sanguínea em pacientes diabéticos, processos patológicos desenvolvem em inúmeros tecidos e órgãos incluindo olhos, rins, vasos sanguíneos e tecido nervoso". Desta maneira, asseguramos que os desfechos de interesse da revisão foram incluídos na busca.

Ainda, além do termo Mesh "Diabetes mellitus", incluímos a busca de um termo Mesh mais específico "Diabetes mellitus type 2" e somamos o resultado das duas buscas individuais utilizando o operador booleano "OR". Vale ressaltar que, sempre que disponível, somou-se ao termo Mesh principal todos os Entry terms, que nada mais são que sinônimos do termo Mesh principal, descritos dentro da definição do termo e que aumentam a sensibilidade da busca.

Assim, ficamos com os seguintes resultado para o Bloco 1:

\#1 - Search "Diabetes Mellitus"[Mesh] 235188 artigos (não continha entry terms)

$\longrightarrow$ todos os entry terms presentes \#2 - Search "Diabetes Mellitus, Type 2"[Mesh]or (Diabetes Mellitus, Ketosis-Resistant) or(Diabetes Mellitus, Ketosis Resistant )or(Ketosis-Resistant Diabetes Mellitus)or(Diabetes Mellitus, Maturity-Onset)or( Diabetes Mellitus, Maturity Onset) or (Diabetes Mellitus, Non Insulin Dependent )or(Diabetes Mellitus, Non-InsulinDependent )or(Non-Insulin-Dependent Diabetes Mellitus)or( Type 2 Diabetes Mellitus)or( Diabetes Mellitus, Slow-Onset)or( Diabetes Mellitus, Slow Onset)or( 
Slow-Onset Diabetes Mellitus)or( Diabetes Mellitus, Stable)or(Stable Diabetes Mellitus )or(Diabetes Mellitus, Type II)or(Maturity-Onset Diabetes Mellitus)or( Maturity Onset Diabetes Mellitus)or(MODY)or(NIDDM)or(Diabetes Mellitus, Adult-Onset)or(AdultOnset Diabetes Mellitus)or( Diabetes Mellitus, Adult Onset)or( Diabetes Mellitus, Noninsulin Dependent) 75669 artigos

Somando estes termos Mesh (utilizando o operador booleano OR), ficamos com \#3 = \#1 OR \#2 241203 artigos

\section{Bloco 2 - Intervenção}

As palavras definidas para caracterizarem a intervenção foram a soma de glicemia, que tem como Mesh o termo "blood glucose" (mais seus "entry terms") e os agentes hipoglicemiantes, que tem como Mesh o termo "Hypoglycemic Agents" (mais seus "entry terms").

Assim, ficamos com os seguintes resultado para o Bloco 2:

\#4 - Search "Blood Glucose"[Mesh] or (Blood Sugar) or ( Sugar, Blood) or (Glucose, Blood) 167800 artigos

\#5 - Search "Hypoglycemic Agents"[Mesh] or (Agents, Hypoglycemic) or (Hypoglycemics) or (Hypoglycemic Drugs) or (Drugs, Hypoglycemic) or (Antidiabetics) or ( Antidiabetic Drugs) or ( Drugs, Antidiabetic) or ( Antidiabetic Agents) or (Agents, Antidiabetic) 161152 artigos

\#6 - \#4 OR \#5 268382 artigos

\section{Bloco 3 - Ensaios Clínicos Randomizados}

Conforme comentado anteriormente, utilizamos uma estratégia para ensaios clínicos randomizados já validada pela Chocrane, denominado de filtro ultra-sensível para ensaios clínicos randomizados, que exclui pesquisas realizadas em animais, conforme a combinação:

\#7 (randomized controlled trial [pt] OR controlled clinical trial [pt] OR randomized controlled trials $[\mathrm{mh}]$ OR random allocation $[\mathrm{mh}]$ OR double-blind method [mh] OR single-blind method [mh] OR clinical trial [pt] OR clinical trials[mh] OR ("clinical trial" $[\mathrm{tw}])$ OR ((singl*[tw] OR doubl*[tw] OR trebl*[tw] OR tripl*[tw]) AND 
(mask*[tw] OR blind*[tw])) OR (placebos [mh] OR placebo* [tw] OR random [tw] OR research design [mh:noexp] OR comparative study [pt] OR"Evaluation Studies as Topic"[Mesh] OR follow-up studies [mh] OR prospective studies [mh] OR control* [tw] OR prospective* [tw] OR volunteer* [tw]) NOT (animals [mh] NOT humans $[\mathrm{mh}])$ 3919835 artigos

\section{Bloco 4 - Adjetivos que caracterizam o nível intensivo de controle glicêmico:}

Tight OR intensive OR Strict, que não possuem termo Mesh.

\#8 - Tight OR intensive OR Strict 196290 artigos

Com estes resultados parciais disponíveis por soma nos blocos, faltava combinálos de forma a obtermos a intersecção entre eles, ou seja, que um artigo contivesse todas estas características dos blocos, para que pudesse ser específico para nossa questão de pesquisa.

Assim, a intersecção entre o resultado do bloco 1 , resultado do bloco 2 , bloco 3 e bloco 4 foi:

\#9 - \#3 AND \#6 AND \#7 AND \#8

2675 artigos

\section{2 - COCHRANE LIBRARY}

Basicamente, esta base de dados utiliza os mesmos termos indexadores Mesh e procedimentos que o PubMed/MEDLINE. Assim, as mesmas considerações descritas acima se aplicam para esta base de dados, à exceção que as definições desta base não possuem Entry Terms (sinônimos do Mesh term).

A Cochrane é uma base de dados especializada em revisões sistemáticas. Entretanto, além de selecionar referências extraídas principalmente do Medline e Embase, incluí outras fontes de documentos publicados e de resultados não publicados. Não inclui texto completo, apenas a referência bibliográfica e, na maioria dos casos, os resumos.

A peculiaridade é que em "busca avançada", devemos restringir a busca para ensaios clínicos randomizados clicando em "Cochrane Central Register of Controlled Trials (Clinical Trials)", pois o flitro para ensaios clínicos randomizados já esta embutido na base. 
Assim, encontramos os seguintes resultados

Bloco 1:

\#1 search MeSH descriptor Diabetes Mellitus explode all trees 10762

\#2 search MeSH descriptor Diabetes Mellitus, Type 2 explode all trees 5249

Bloco 2:

\#3 search MeSH descriptor Blood Glucose explode all trees 8031

\#4 search MeSH descriptor Hypoglycemic Agents explode all trees 8068

Bloco 3:

Não precisa descrever a estratégia de busca de ensaios clínicos randomizados. Basta restringir a busca, conforme descrito acima.

Combinações:

\#5 search (intensive) or (strict) or (tight) 17806

\#6 (\#3 OR \#4) 11189

\#7 (\#1 OR \#2) 10762

\#8 (\#5 AND \#6 AND \#7) 423

\section{3 - ISI OF KNOWLEDGE:}

Esta base de dados, além de incluir periódicos de alto impacto, inclui jornais de acesso livre e referências dos chamados "conference proceedings" que são conferências, eventos, congressos, onde trabalhos em andamento ou ainda não publicados são apresentados, permitindo o conhecimento e contato com os autores, a fim de obtermos a totalizada de informação disponível.

Entretanto, esta estratégia de busca adotada diferiu das demais bases de dados. Elegeu-se o estudo referência do assunto investigado, onde, provavelmente, qualquer trabalho semelhante o citará como referência na discussão dos resultados. Na presente revisão, este trabalho é o UKPDS 33(171) : "Intensive blood-glucose control with sulphonylureas or insulin compared with conventional treatment and risk of complications in patients with type 2 diabetes"

Depois, selecionaram-se todas as referências que citaram este primeiro artigo até a data da busca na base WEB OF KNOWLEDGE (16/04/2009). Essas referências que citaram o artigo prévio totalizaram 4875 artigos. 
Entretanto, estas referências não incluem somente os ensaios clínicos randomizados. Deve-se comandar a seleção apenas deste tipo de estudo, de modo que assim obtivemos 1277 artigos.

\section{4- EMBASE:}

A estratégia de busca seguiu o mesmo raciocínio que nas bases PubMed/MEDLINE e Cochrane, com algumas peculiaridades. O termo indexador desta base é o EMTREE term e alguns diferem dos Mesh term utilizados nas outras bases.

Para seleção de ensaios clínicos randomizados, ao contrário do PubMed/MEDLINE e Cochrane, não existe um filtro já validado, de modo que tivemos que testar várias estratégias, até obtermos uma mais sensível. A busca foi realizada a partir da data de inauguração da base (1974) até a data da ocasião da busca (Abril de 2009) e totalizou 1846 artigos, conforme detalhamento:

\# 1- 'diabetes mellitus'/exp 256,040

\# 2-'non insulin dependent diabetes mellitus'/exp AND [embase]/lim AND [1974$2009] / p y$ 58,517

\#3-'antidiabetic agent'/exp AND [embase]/lim AND [1974-2009]/py 178,380

\# 4-'glucose blood level'/exp AND [embase]/lim AND [1974-2009]/py 65,495

\# 5-intensive OR tight OR strict AND [embase]/lim AND [1974-2009]/py 185,413

\#6-'randomized controlled trial'/exp AND [embase]/lim AND [1974-2009]/py_ 145,127 \#7-'controlled study'/exp AND [embase]/lim AND [1974-2009]/py $2,875,706$

\# 8- 'randomization'/exp AND [embase]/lim AND [1974-2009]/py 26,716

\# 9- 'double blind procedure'/exp AND [embase]/lim AND [1974-2009]/py 74,372

\# 10- 'single blind procedure'/exp AND [embase]/lim AND [1974-2009]/py 8,108

\# 11- 'clinical trial'/exp AND [embase]/lim AND [19742009]/py 520,287

\# 12- 'crossover procedure'/exp AND [embase]/lim AND [1974-2009]/py 21,207

\# 13- 'evaluation and follow up'/exp AND [embase]/lim AND [1974-2009]/py_535,126 \# 14- 'prospective study'/exp AND [embase]/lim AND [1974-2009]/py 81,429

\# 15- 'placebo'/exp AND [embase]/lim AND [1974-2009]/py 137,411

\# 16- 'comparative study'/exp AND [embase]/lim AND [1974-2009]/py 374,088

Seleção de estudos em animais: 
\# 17- 'animal'/exp AND [embase]/lim AND [1974-2009]/py 118,358

\# 18- 'nonhuman'/exp AND [embase]/lim AND [1974-2009]/py 3,209,574

\# 19- 'human'/exp AND [embase]/lim AND [1974-2009]/py 6,610,686

\#20- \#17 OR \#18

$3,229,681$

\#21- \#20 NOT \#19

$2,699,099$

\#22- \#6 OR \#7 OR \#8 OR \#9 OR \#10 OR \#11 OR \#12 OR \#13 OR \#14 OR \#15 OR \#16 $3,698,052$

\#23- \#22 NOT \#21 $2,525,627$

\#24- \#1 OR \#2 256,040

\#25- \#3 OR \#4 211,974

\#26- \#24 AND \#25 89,971

\#27- \#26 AND \#5 3,818

\#28- \#27 AND \#23 1846

\section{4 - BUSCA MANUAL:}

Todos os artigos finalmente elegíveis para a revisão sistemática tiveram suas referências bibliográficas analisadas, a fim de detectarmos possíveis artigos elegíveis não incluídos em nossa estratégia de busca. Foram encontrados 7 referências elegíveis para a presente revisão, a maioria derivada de estudos maiores já incluídos, e que somaram no resultado final de artigos incluídos. 


\section{APÊNDICE C - FORMULÁRIO DE AVALIAÇÃO DE ELEGIBILIDADE}

\section{Revisor:}

( ) Anna Maria Buehler

( ) Alexandre Biasi Cavalcanti

( ) Hélio Penna Guimarães

( ) Diogo Bugano Diniz Gomes

( ) Lígia Nasi Laranjeira

( ) Eliana Santucci

( ) Antônio Cláudio de Oliveira

( ) Bruno Kioshi

( ) Ana Denise Zazula

Sobrenome do autor (Se a autoria pertencer a um grupo de Pesquisa, entrar com o primeiro nome significativo do grupo)

Nome do jornal (abreviação comumente utilizada, nome no PubMed ou nome completo do jornal)

Ano de Publicação Volume

$\mathbf{N}^{\circ}$ da $1^{\circ}$ página do artigo

$N^{\circ}$ do artigo na base do "RefMan"

Critérios de Elegibilidade

a. É um Ensaio Clínico Randomizado (ECR)?

$$
\text { Sim }
$$

descrição/desconhecido 
b. O estudo inclui pacientes portadores de Diabetes Mellitus tipo II (ou NIDDM) ou ambas populações (portadores de Diabetes Mellitus tipo II (ou NIDDM) e potadores de Diabetes Mellitus tipo I (ou IDDM) ?

$\square \operatorname{Sim}$

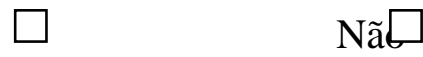

Sem

descrição/desconhecido

c. O Estudo tem ao menos dois braços objetivando dois níveis de intensidade diferentes de controle glicêmico?
$\square \operatorname{Sim}$
Não
Sem descrição/desconhecido

d. O Período de tratamento e seguimento foi de, pelo menos, 1 ano?
$\operatorname{Sim}$
Não
Sem descrição/desconhecido

Nós incluiremos em nossa revisão apenas estudos que são considerados elegíveis pelas instruções de elegibilidade do presente documento, isto é, caso todas as respostas para as questões a até d forem "sim". Caso as respostas para alguma das questões não esteja clara no texto, contataremos os autores para esclarecimentos.

Nós incluiremos ensaios clínicos randomizados (ECR) que tenham ao menos dois níveis de intensidades diferentes de controle glicêmico, independente dos protocolos de tratamento e independentes do números de agentes hipoglicemiantes/insulina administrados em cada braço. Os ECR serão elegíveis independente de seu status de publicação, lingua, tamanho de amostra, tempo de seguimento (desde que maior que 1 ano) e avaliação de seus desfechos.

Importante: favor NÃO EXCLUIR um ECR por não avaliar desfechos da revisão. Neste caso contataremos os autores para tentarmos adquirir informações pertinentes, principalmente mortalidade. Se o ECR preencher os critérios de elegibilidade mas achar que trata-se de uma publicação duplicada ou um subestudo NÃO EXCLUIR este ECR. Excluirmos posteriormente quando tivermos certeza que original foi incluído. 


\section{APÊNDICE D - FORMULÁRIO DE EXTRAÇÃO DE DADOS}

\section{META-ANÁLISE DE CONTROLE GLICÊMICO INTENSIVO VERSUS CONTROLE GLICÊMICO PADRÃO EM PACIENTES PORTADORES DE DIABETES MELLITUS}

Revisor:

( ) Anna Maria Buehler

( ) Alexandre Biasi Cavalcanti

( ) Hélio Penna Guimarães

( ) Ana Denise Zazula

( ) Lígia Nasi Laranjeira

Sobrenome do autor (Se a autoria pertencer a um grupo de Pesquisa, entrar com o primeiro nome significativo do grupo)

Nome do jornal (abreviação comumente utilizada, nome no PubMed ou nome completo do jornal)

Ano de Publicação Volume

$\mathbf{N}^{\circ}$ da $1^{\circ}$ página do artigo

$N^{\circ}$ do artigo na base do "RefMan"

\section{MULTIPLICIDADE DE PUBLICAÇÃO.}

Esta é a única publicação dos resultados do estudo ou tem outras possíveis publicações reportando resultados do mesmo estudo (mesmo se o estudo $\mathrm{N}$ é diferente, ou um subgrupo ou os autores não são os mesmos): 
Observação: Após identificarmos grupos de publicações possivelmente múltiplas, confirmaremos esta multiplicidade e confirmaremos os dados em dúvida com os autores. Listaremos as publicações originadas do mesmo estudo e utilizaremos os dados da publicação mais completa.

\section{QUALIDADE METODOLÓGICA}

\section{a. Allocation concealment}

( ) Adequate - Randomization method described that would not allow investigator/participant to know or influence intervention group before eligible participant entered in the study. Examples are: allocation involving a central independent unit, on-site locked computer, identically appearing numbered drug bottles or containers prepared by an independent pharmacist or investigator, or sealed envelopes.

( ) Unclear - Randomization stated but no information on method used is available.

( ) Inadequate - Method of randomization used such as alternate medical record numbers or unsealed envelopes; any information in the study that indicated that investigators or participants could influence intervention group.

\section{b. Blinding of investigators:}
( ) Yes
( ) No
( ) Not stated

( ) Unclear or inadequate - if the trial was described as double blind, but the method of blinding was not described or is not compatible with blinding

\section{c. Blinding of participants:}
( ) Yes
( ) No
( ) Not stated

( ) Unclear or inadequate - if the trial was described as double blind, but the method of blinding was not described or is not compatible with blinding

\section{d. Blinding of outcome assessors (adjudicators):}
( ) Yes
( ) No
( ) Not stated

( ) Unclear or inadequate - if the trial was described as double blind, but the method of blinding was not described or is not compatible with blinding

\section{e. Blinding of data analysis:}



( ) Yes
( ) No
( ) Not stated

( ) Unclear or inadequate - if the trial was described as double blind, but the method of blinding was not described or is not compatible with blinding

\section{f. Intention-to-treat analysis*:}

( ) Yes - Confirmation on study assessment that the number of participants randomized and the number analyzed are identical; except for patients lost to follow-up or who withdrew consent for study participation

( ) No - Confirmation on study assessment that patients who were randomized were not included in the analysis, because they did not receive the study intervention, were not included because of protocol violation or any other reason.

( ) Not stated.

* Obs.: Our evaluation should be independent of authors' claim of ITT analysis, i.e., a study may be considered by us as analyzed according to ITT principle even if there is no such statement as long as we confirm that on study assessment. The opposite is also true, a study is reported as being ITT but we may consider it not to be ITT depending on our evaluation. 


\section{SEGUIMENTO:}

a. Tempo total de seguimento (meses):

\begin{tabular}{|c|c|c|}
\hline & Grupo Intensivo & Grupo Convencional \\
\hline $\begin{array}{l}\text { Seguimento: } \\
\text { media ( ) mediana ( ) }\end{array}$ & 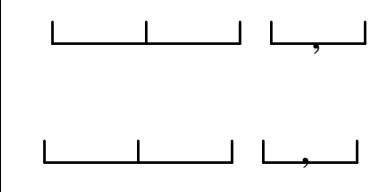 & 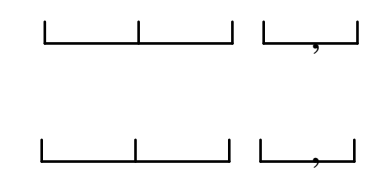 \\
\hline $\begin{array}{l}\text { Seguimento: } \\
\text { Desvio-padrão ( ) } \\
\text { Interval interquartil ( ) }\end{array}$ & \pm & \pm \\
\hline
\end{tabular}

b. Número de pacientes randomizados e perdas de seguimento:

\begin{tabular}{|l|l|l|}
\hline $\begin{array}{l}\text { Número de pacientes } \\
\text { randomizados }\end{array}$ & Grupo Intensivo & Grupo Padrão \\
\hline $\begin{array}{l}\text { Número } \\
\text { perda de seguimento ou } \\
\text { excluídos }\end{array}$ & & \\
\hline
\end{tabular}

\section{CARACTERÍSTICAS DE BASE DOS PACIENTES:}

OBS: Para as informações não disponíveis, favor preencher "NR" nos respectivos campos.

\begin{tabular}{|c|c|c|}
\hline & $\begin{array}{l}\text { GRUPO } \\
\text { INTENSIVO }\end{array}$ & GRUPO PADRÃO \\
\hline $\begin{array}{l}\text { Idade: } \\
\text { ( ) } \text { )media }\end{array}$ & 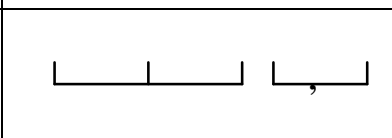 & $\downarrow \downarrow$ \\
\hline ( ) mediana & 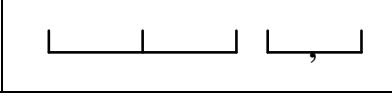 & $\downarrow$ \\
\hline
\end{tabular}




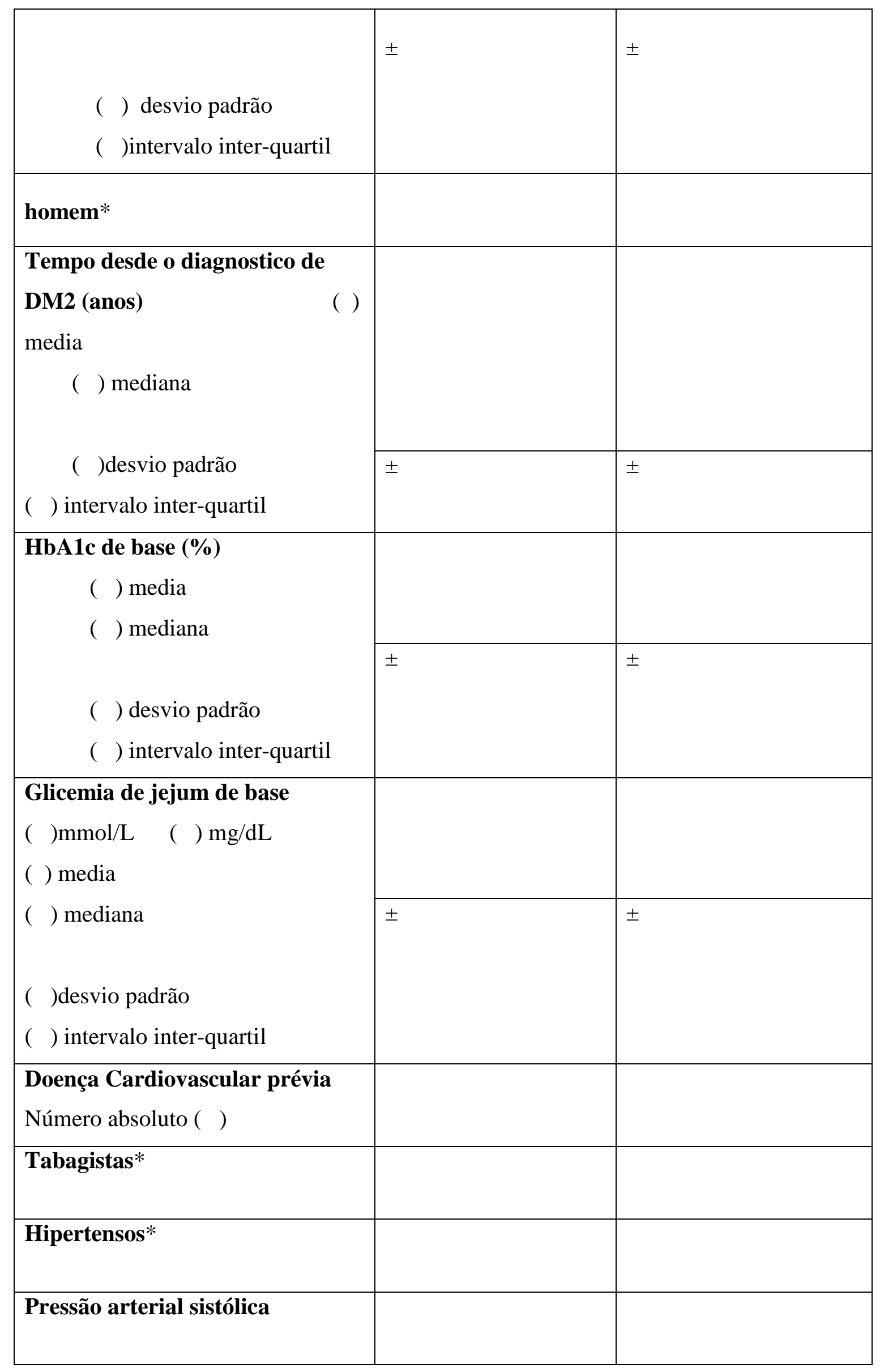




\begin{tabular}{|l|l|l|}
\hline $\begin{array}{l}\text { média } \\
\text { desvio padrão }\end{array}$ & \pm & \pm \\
\hline Dislipidêmicos* & \\
\hline $\begin{array}{l}\text { LDL ( }) \mathrm{mg} / \mathrm{dL} \mathrm{(}) \mathrm{mmol} / \mathrm{L} \\
\text { média } \\
\text { Desvio padrão }\end{array}$ & \pm & \\
\hline $\begin{array}{l}\text { IMC }\left(\mathrm{Kg} / \mathrm{m}^{2}\right) \\
\text { média }\end{array}$ & & \pm \\
Desvio padrão & \pm & \pm \\
\hline
\end{tabular}

$* \mathrm{~N}^{\circ}$ de pacientes, não porcentagem.

\section{PROTOCOLOS DE INTERVENÇÃO:}

\section{CONTROLE INTENSIVO}

A) (FARMACO)TERAPIA NO CONTROLE INTENSIVO:

Definir a intervenção principal do estudo, se aplicável:

a) Hipoglicemiante (s) oral (is) não especificados

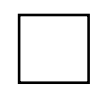

Numerar as intervenções de 1 a $n$ 
Tipo: Número de paciente: Total: Dose

total/dia:

Glipizida

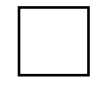

Gliclazida

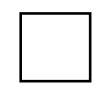

b) Secretagogos: - gliburida

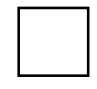
Sulfanilureas

Glimepirida

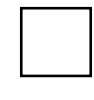

Glibenclamida
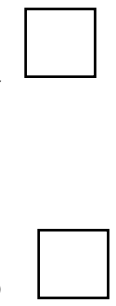

Repaglinida

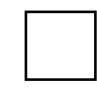

$\underline{\text { Meglitinidas }}$

Nateglinida

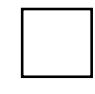

Não especificado $\square$

c) Biguanidas: Metformina $\square$ 
d) Inibidores da

$\alpha$-glicosidase: acarbose

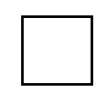

Miglitol

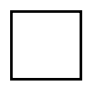

Não especificado

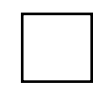

e) Thiazolidinedionas: rosiglitazona

$$
\text { pioglitazona }
$$

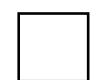

Não especificado

f) Análogo do GLP-1 (incretinas): exenatida

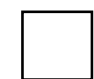

Sitagliptina

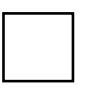

\section{Insulina Tipo}

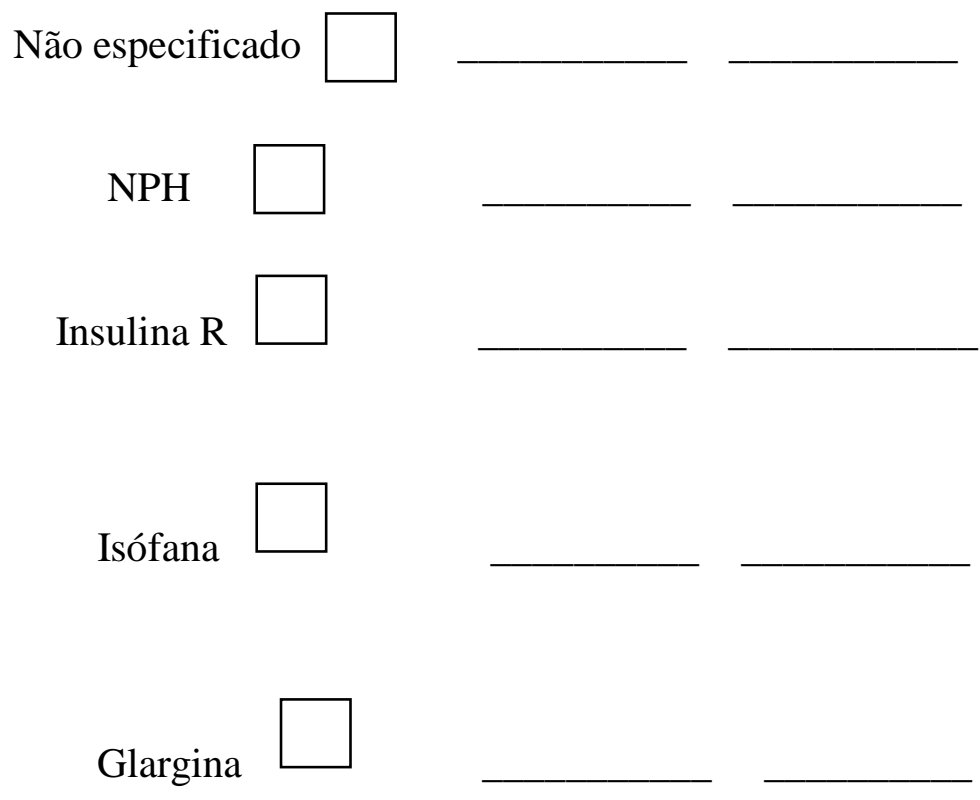


g) Insulinoterapia

detemir

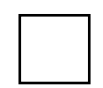

Lispro $\square$

Aspart $\square$

Não especificado

h) Atividade física:

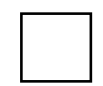

Frequência (x/semana)

duração (min)

intensidade (Int, mod, leve)

Não especificado

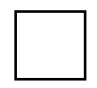

Restrição calórica

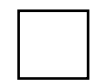

i) Dieta:

Restrição lipídica

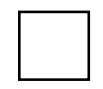

Não especificado

\section{CONTROLE PADRÃO:}

Definir o controle convencional principal do estudo: 
a) Hipoglicemiante (s) oral (is) especificados

\section{Numerar as intervenções de 1 a $n$}

Tipo: Número de paciente: Total: Dose

total/dia:
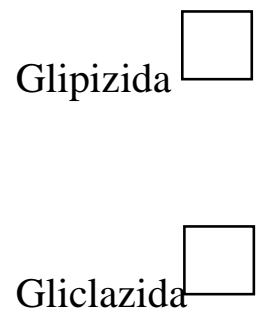

b) Secretagogos:
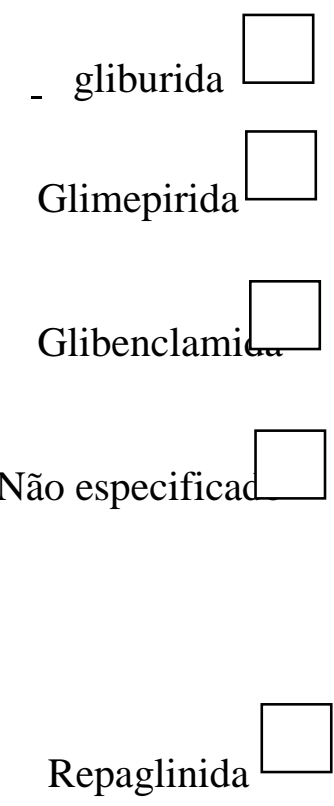

$\underline{\text { Meglitinidas }}$

Nateglinida

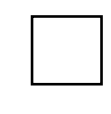

Não especificado 
c) Biguanidas: Metformina

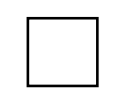

d) Inibidores da $\alpha$-glicosidase: acarbose

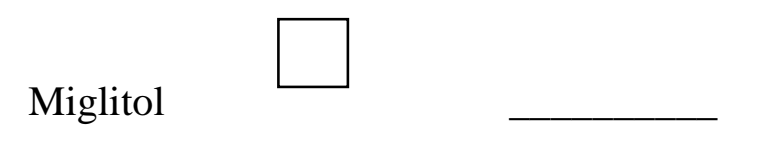

Não especificado $\square$

e) Thiazolidinedionas:

rosiglitazona

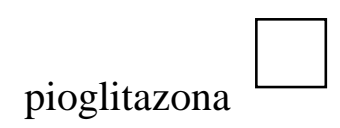

Não especificado $\square$

f) Análogo do GLP-1 (incretinas):

Sitagliptina

Insulina Tipo: Número de paciente: Total: Dose total/dia:

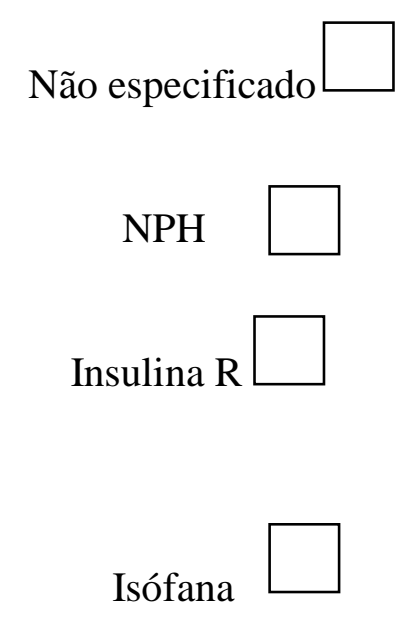




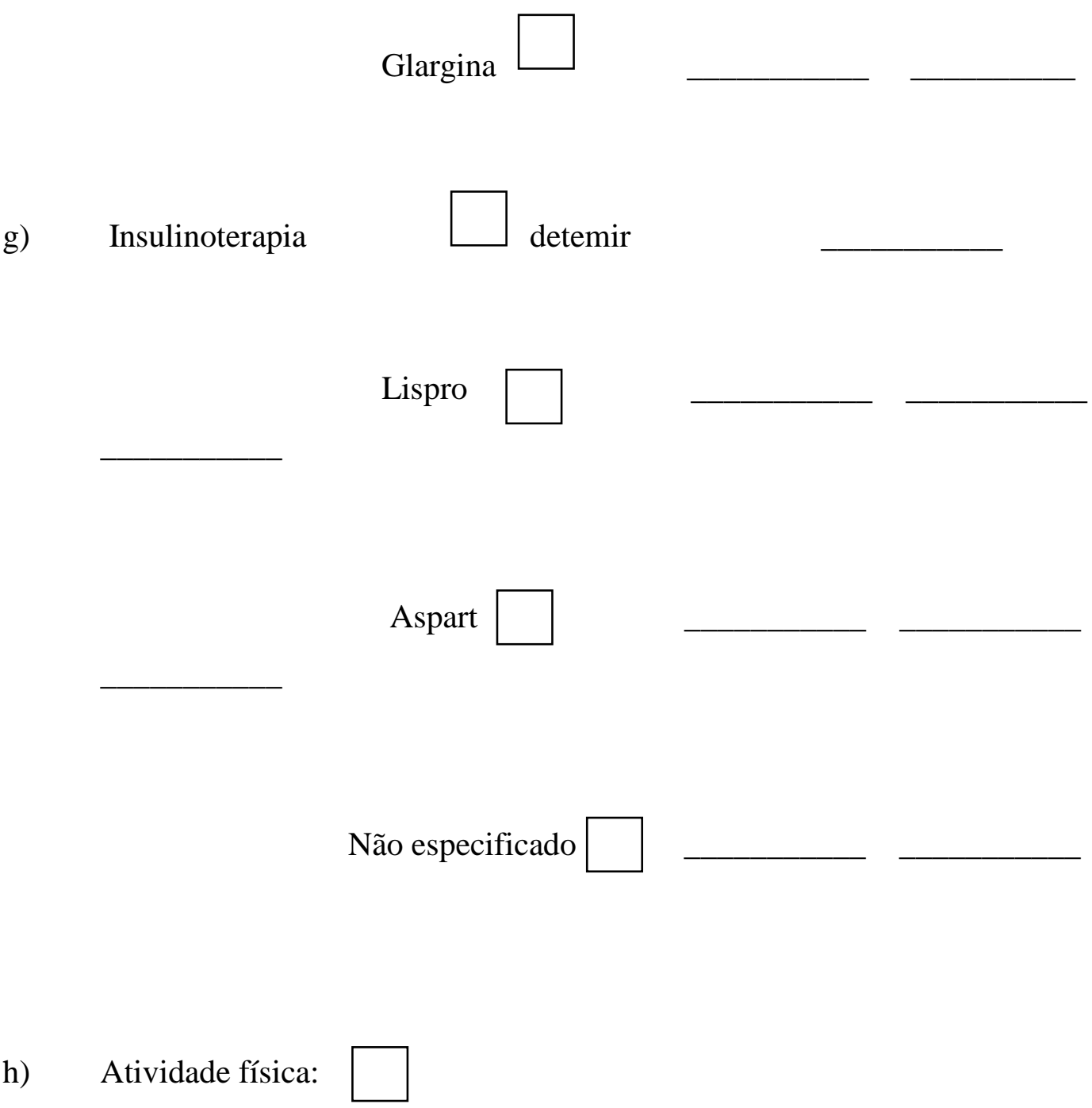

Frequência (x/semana)

duração (min)

intensidade (Int, mod, leve)

Não especit

Restrição calórica

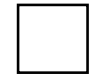

i) Dieta:

Restrição lipídica $\square$

Não especificado 
j) Placebo de:

Especificar:

6. DESFECHOS DO ESTUDO (estudo original - numerar e descrever o(s) primário(s), secundário(s) ou terciário(s):

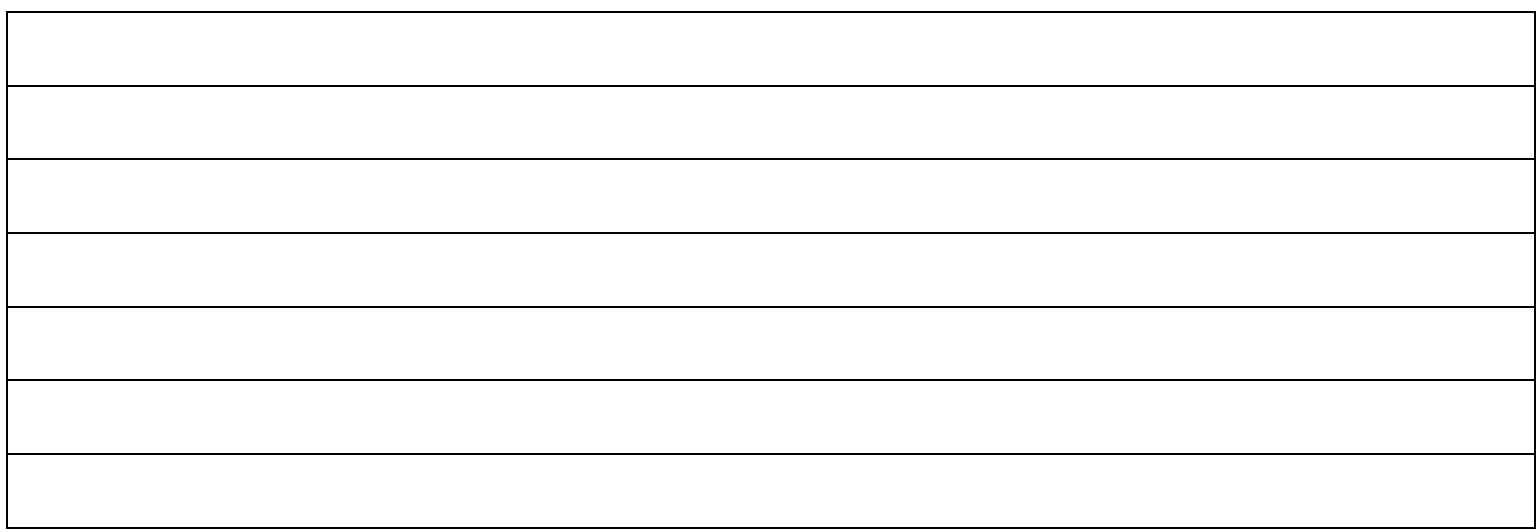

7. RESULTADOS:

a) $\mathrm{HbA1C}$ seguimento:

OBS: Caso a medida tenha sido observada em mais de um período do total do seguimento, favor registrar em que momento e seus respectivos valores. Se só existir uma observação no tempo total de seguimento, favor inserir "NA" (não se aplica) na segunda coluna do grupo intensivo e padrão.

\begin{tabular}{|l|l|l|l|l|}
\hline & \multicolumn{2}{|c|}{ Grupo Intensivo } & \multicolumn{2}{|c|}{ Grupo Padrão } \\
\hline $\begin{array}{l}\text { Período do } \\
\text { Seguimento (meses) }\end{array}$ & & & & \\
\hline
\end{tabular}




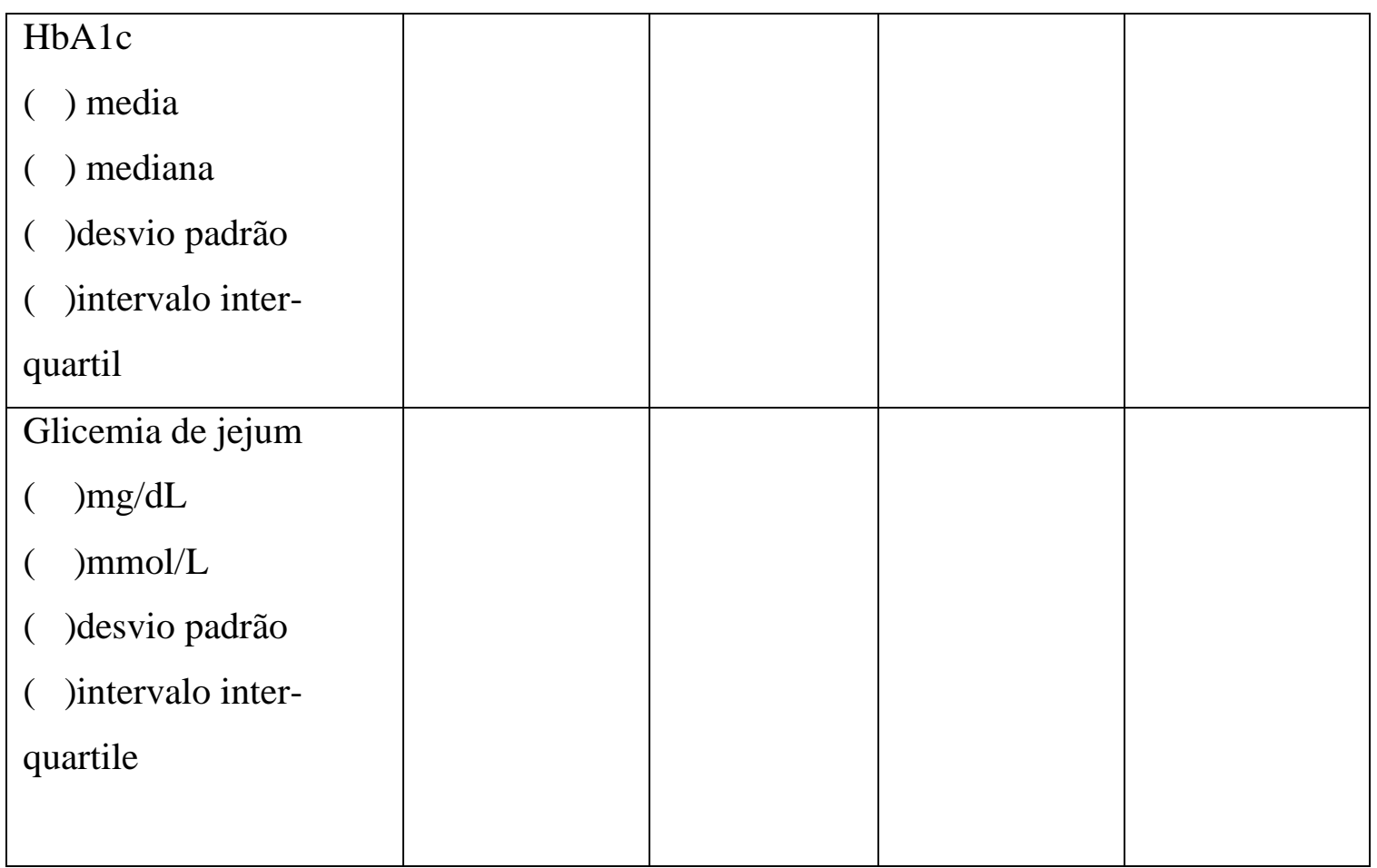

b) RETINOPATIA

Definição no estudo: (numerar)

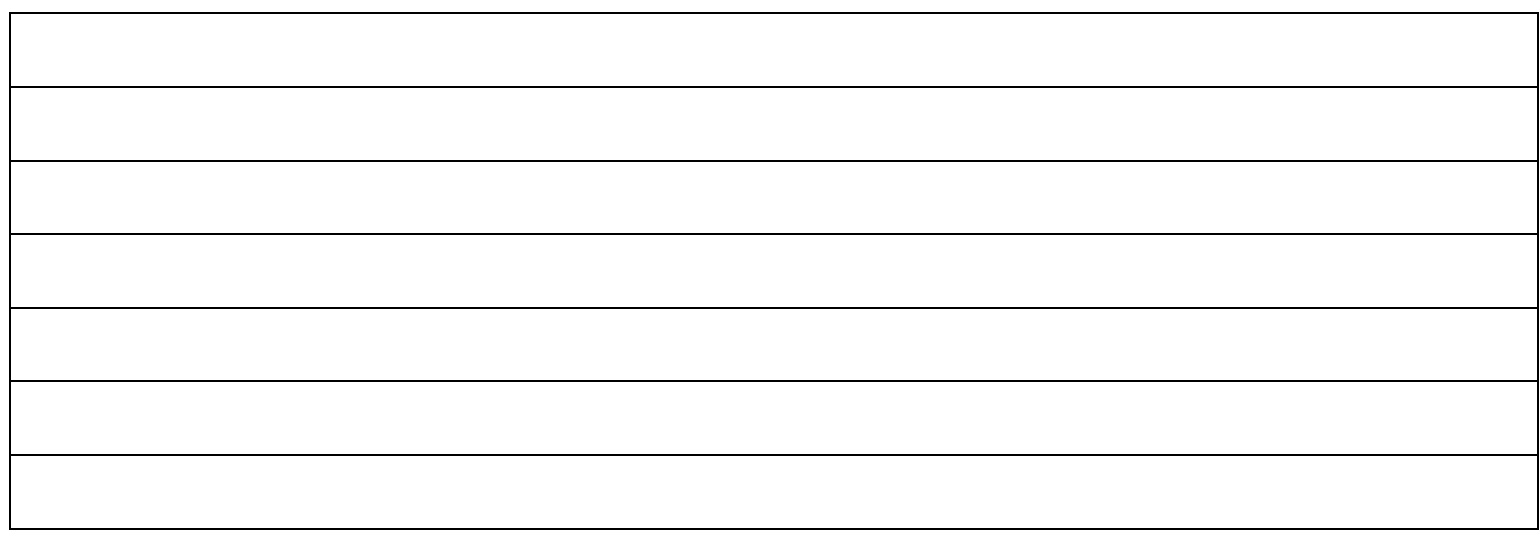

Período máximo de observação do evento (meses)

Períodos em que o evento foi observado

(time points) - meses

OBS: Caso o evento tenha sido observado em mais de um período do total do seguimento, favor inseri-los em "time point" na tabela abaixo. Se só existir a 
observação do evento em um período do tempo total de seguimento, favor inserir "NA" (não se aplica) nas demais colunas (2, 3 e 4$)$.

Results :( absolute number of events/total of participants in the group)

\begin{tabular}{|l|c|c|c|c|}
\hline Definição número: & & & & \\
\hline Time Point (meses) & & & & \\
\hline Intensive & $/$ & $/$ & $/$ & $/$ \\
\hline Control & $/$ & $/$ & $/$ & $/$ \\
\hline
\end{tabular}

c) DETERIORIZAÇÃO VISUAL:

\section{Definição no estudo:}

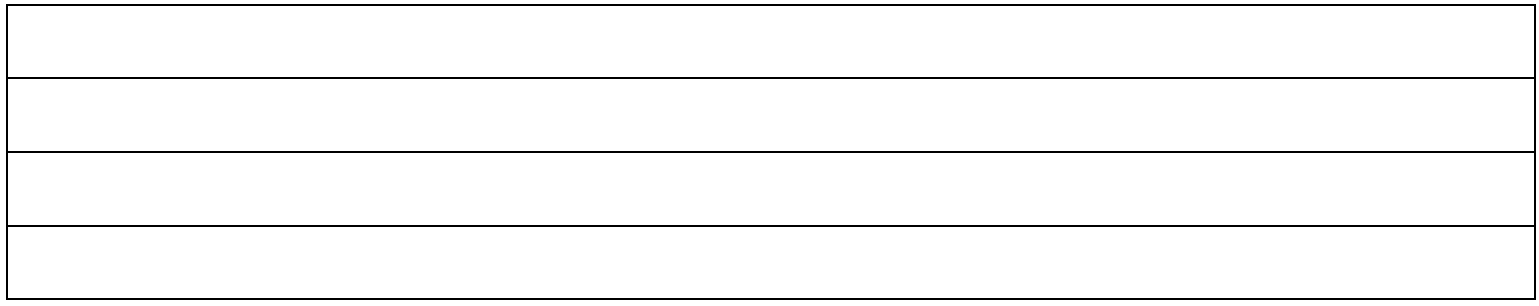

Período máximo de observação do evento (meses)

Períodos em que o evento foi observado

(time points) - meses

OBS: Caso o evento tenha sido observado em mais de um período do total do seguimento, favor inseri-los em "time point" na tabela abaixo. Se só existir a observação

do evento em um período do tempo total de seguimento, favor inserir "NA" (não se aplica) nas demais colunas ( 2, 3 e 4).

Results :( absolute number of events/total of participants in the group)

Definição número:

\begin{tabular}{|l|l|}
\hline & \\
\hline
\end{tabular}




\begin{tabular}{|l|c|c|c|c|}
\hline Time Point (meses) & & & & \\
\hline Intensive & $/$ & $/$ & $/$ & $/$ \\
\hline Control & $/$ & $/$ & $/$ & $/$ \\
\hline
\end{tabular}

d) NEFROPATIA:

Definição no estudo: (numerar e descrever)

\begin{tabular}{|l|}
\hline \\
\hline \\
\hline \\
\hline \\
\hline \\
\hline
\end{tabular}

Período máximo de observação do evento (meses)

Períodos em que o evento foi observado

(time points) - meses

OBS: Caso o evento tenha sido observado em mais de um período do total do seguimento, favor inseri-los em "time point" na tabela abaixo. Se só existir a observação do evento em um período do tempo total, favor inserir NA (não se aplica) nas demais colunas $(2,3$, e 4$)$.

Results: (absolute number of events/total of participants in the group)

\begin{tabular}{|l|c|c|c|c|}
\hline Definição número: & & & & \\
\hline Time Point (meses) & & & & \\
\hline Intensive & $/$ & $/$ & $/$ & $/$ \\
\hline Control & $/$ & $/$ & $/$ & $/$ \\
\hline
\end{tabular}


e) NEUROPATIA

Definição no estudo: (numerar e descrever)

\begin{tabular}{|l|}
\hline \\
\hline \\
\hline \\
\hline \\
\hline \\
\hline
\end{tabular}

Período máximo de observação do evento (meses)

Períodos em que o evento foi observado

(time points) - meses

OBS: Caso o evento tenha sido observado em mais de um período do total do seguimento, favor inseri-los em "time point" na tabela abaixo. Se só existir a observação do evento em um período do tempo total, favor inserir NA (não se aplica) nas demais colunas $(2,3$, e 4).

Results: (absolute number of events/total of participants in the group)

\begin{tabular}{|l|c|c|c|c|}
\hline Definição número: & & & & \\
\hline Time Point (meses) & & & & \\
\hline Intensive & $/$ & $/$ & $/$ & $/$ \\
\hline Control & $/$ & $/$ & $/$ & $/$ \\
\hline
\end{tabular}

f) INFARTO AGUDO DO MIOCÁRDIO (IAM) NÃO-FATAL: 
Definição no estudo:

\begin{tabular}{|l|}
\hline \\
\hline \\
\hline \\
\hline \\
\hline \\
\hline
\end{tabular}

Período máximo de observação do evento (meses)

Períodos em que o evento foi observado

(time points) - meses

OBS: Caso o evento tenha sido observado em mais de um período do total do seguimento, favor inseri-los em "time point" na tabela abaixo. Se só existir a observação do evento em um período do tempo total, favor inserir NA (não se aplica) nas demais colunas $(2,3$, e 4).

Results: (absolute number of events/total of participants in the group)

\begin{tabular}{|l|c|c|c|c|}
\hline Definição número: & & & & \\
\hline Time Point (meses) & & & & \\
\hline Intensive & $/$ & $/$ & $/$ & $/$ \\
\hline Control & $/$ & $/$ & $/$ & $/$ \\
\hline
\end{tabular}

g) ACIDENTE VASCULAR CEREBRAL (AVC) NÃO-FATAL:

\section{Definição no estudo:}




\begin{tabular}{|l|}
\hline \\
\hline \\
\hline \\
\hline \\
\hline
\end{tabular}

Período máximo de observação do evento (meses)

Períodos em que o evento foi observado

(time points) - meses

OBS: Caso o evento tenha sido observado em mais de um período do total do seguimento, favor inseri-los em "time point" na tabela abaixo. Se só existir a observação do evento em um período do tempo total, favor inserir NA (não se aplica) nas demais colunas $(2,3$, e 4$)$.

Results: (absolute number of events/total of participants in the group)

\begin{tabular}{|l|c|c|c|c|}
\hline Definição número: & & & & \\
\hline Time Point (meses) & & & & \\
\hline Intensive & $/$ & $/$ & $/$ & $/$ \\
\hline Control & $/$ & $/$ & $/$ & $/$ \\
\hline
\end{tabular}

h) AMPUTAÇÃO DE MEMBROS:

Definição no estudo: 
Período máximo de observação do evento (meses)

Períodos em que o evento foi observado

(time points) - meses

OBS: Caso o evento tenha sido observado em mais de um período do total do seguimento, favor inseri-los em "time point" na tabela abaixo. Se só existir a observação do evento em um período do tempo total, favor inserir NA (não se aplica) nas demais colunas $(2,3$, e 4).

Results: (absolute number of events/total of participants in the group)

\begin{tabular}{|l|c|c|c|c|}
\hline Definição número: & & & & \\
\hline Time Point (meses) & & & & \\
\hline Intensive & $/$ & $/$ & $/$ & $/$ \\
\hline Control & $/$ & $/$ & $/$ & $/$ \\
\hline
\end{tabular}

i) MORTE CARDIOVASCULAR:

Inclui as segintes situações clínicas:

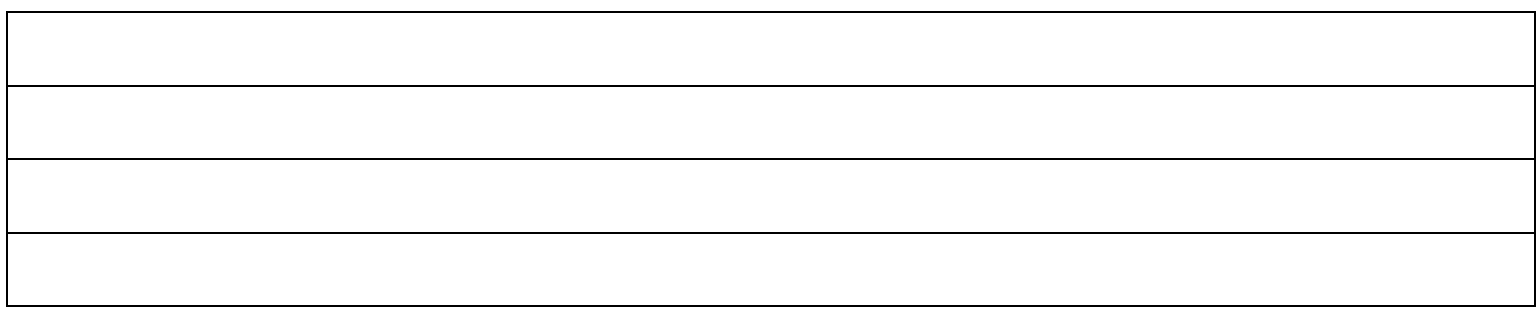

Período máximo de observação do evento (meses)

Períodos em que o evento foi observado

(time points) - meses 
OBS: Caso o evento tenha sido observado em mais de um período do total do seguimento, favor inseri-los em "time point" na tabela abaixo. Se só existir a observação do evento em um período do tempo total, favor inserir NA (não se aplica) nas demais colunas $(2,3$, e 4).

Results: (absolute number of events/total of participants in the group)

\begin{tabular}{|l|c|c|c|c|}
\hline Definição número: & & & & \\
\hline Time Point (meses) & & & & \\
\hline Intensive & $/$ & $/$ & $/$ & $/$ \\
\hline Control & $/$ & $/$ & $/$ & $/$ \\
\hline
\end{tabular}

\section{j) MORTALIDADE TOTAL:}

Período máximo de observação do evento (meses)

Períodos em que o evento foi observado

(time points) - meses

OBS: Caso o evento tenha sido observado em mais de um período do total do seguimento, favor inseri-los em "time point" na tabela abaixo. Se só existir a observação do evento em um período do tempo total, favor inserir NA (não se aplica) nas demais colunas $(2,3$, e 4).

Results: (absolute number of events/total of participants in the group)

\begin{tabular}{|l|c|c|c|c|}
\hline Definição número: & & & & \\
\hline Time Point (meses) & & & & \\
\hline Intensive & $/$ & $/$ & $/$ & $/$ \\
\hline Control & $/$ & $/$ & $/$ & $/$ \\
\hline
\end{tabular}


k) DESFECHO COMBINADO MICROVASCULAR

RETINOPATIA ( )

NEFROPATIA ( )

NEUROPATIA:（ )

OUTROS: ( ) especificar

Definições no estudo:

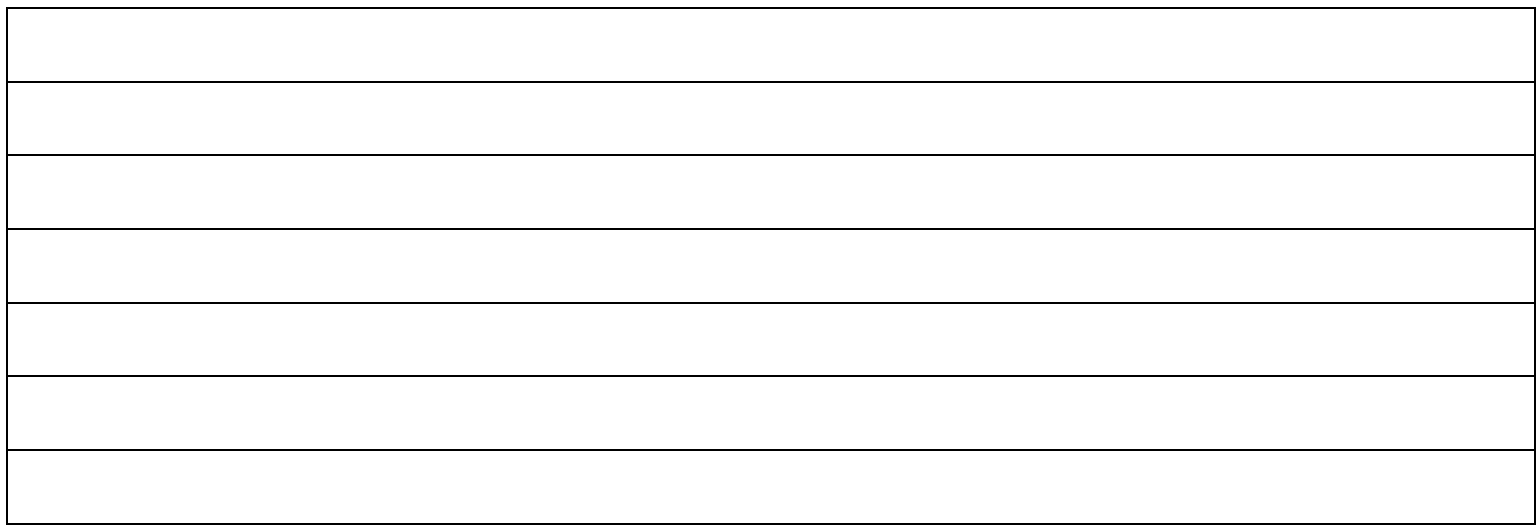

Período máximo de observação do evento (meses)

Períodos em que o evento foi observado

(time points) - meses

OBS: Caso o evento tenha sido observado em mais de um período do total do seguimento, favor inseri-los em "time point" na tabela abaixo. Se só existir a observação do evento em um período do tempo total, favor inserir NA (não se aplica) nas demais colunas $(2,3$, e 4$)$.

Results: (absolute number of events/total of participants in the group) 


\begin{tabular}{|l|c|c|c|c|}
\hline Definição número: & & & & \\
\hline Time Point (meses) & & & & \\
\hline Intensive & $/$ & $/$ & $/$ & $/$ \\
\hline Control & $/$ & $/$ & $/$ & $/$ \\
\hline
\end{tabular}

\section{I) DESFECHO COMBINADO MACROVASCULAR}

IAM não fatal ( )

AVC não fatal ( )

MORTE CARDIOVASCULAR ( )

OUTROS: ( ) especificar:

\section{Definição no estudo:}

\begin{tabular}{|l|}
\hline \\
\hline \\
\hline \\
\hline \\
\hline \\
\hline
\end{tabular}

Período máximo de observação do evento (meses)

Períodos em que o evento foi observado

(time points) - meses 
OBS: Caso o evento tenha sido observado em mais de um período do total do seguimento, favor inseri-los em "time point" na tabela abaixo. Se só existir a observação do evento em um período do tempo total, favor inserir NA (não se aplica) nas demais colunas $(2,3$, e 4$)$.

Results: (absolute number of events/total of participants in the group)

\begin{tabular}{|l|c|c|c|c|}
\hline & \multicolumn{3}{|l|}{ Results at each time point } \\
\hline Time Point (meses) & & & & \\
\hline Intensive & $/$ & $/$ & $/$ & $/$ \\
\hline Control & $/$ & $/$ & $/$ & $/$ \\
\hline
\end{tabular}

m) HIPOGLICEMIA:

\section{Definição no estudo:}

\begin{tabular}{|l|c|c|c|c|}
\hline Definição número: & & & & \\
\hline Time Point (meses) & & & & \\
\hline Intensive & $/$ & $/$ & $/$ & $/$ \\
\hline Control & $/$ & $/$ & $/$ & $/$ \\
\hline
\end{tabular}

Período máximo de observação do evento (meses)

Períodos em que o evento foi observado 
(time points) - meses

OBS: Caso o evento tenha sido observado em mais de um período do total do seguimento, favor inseri-los em "time point" na tabela abaixo. Se só existir a observação do evento em um período do tempo total, favor inserir NA (não se aplica) nas demais colunas $(2,3, \mathrm{e} 4)$.

Results: (absolute number of events/total of participants in the group)

\begin{tabular}{|l|c|c|c|c|}
\hline Definição número: & & & & \\
\hline Time Point (meses) & & & & \\
\hline Intensive & $/$ & $/$ & $/$ & $/$ \\
\hline Control & $/$ & $/$ & $/$ & $/$ \\
\hline
\end{tabular}




\section{APÊNDICE E - PLANILHA DE CONTROLE DE REFERÊNCIAS E AVALIAÇÃO DA ELEGIBILIDADE}

\begin{tabular}{|c|c|c|c|c|c|}
\hline $\begin{array}{l}\text { ID } \\
\text { REFMAN }\end{array}$ & AUTOR(ES) & TíTULO & REVISOR & PARECER & MOTIVO \\
\hline $\begin{array}{l}\text { Ref ID: } \\
1750\end{array}$ & & $\begin{array}{l}\text { Older diabetics: } \\
\text { Intensive therapy is } \\
\text { safe and effective. } \\
\text { Geriatrics } \\
1993 ; 48(8): 21-2 \text {. }\end{array}$ & Anna/Ligia & NE & 1 \\
\hline $\begin{array}{l}\text { Ref ID: } \\
2093\end{array}$ & & $\begin{array}{l}\text { Risk of long-term } \\
\text { complications of } \\
\text { diabetes mellitus } \\
\text { reduced by tight } \\
\text { blood sugar control. } \\
\text { Drug Ther Bull } \\
1994 \text { May } \\
19 ; 32(5): 40 .\end{array}$ & Anna / Bruno & NE & 1 \\
\hline $\begin{array}{l}\text { Ref ID: } \\
3005\end{array}$ & & $\begin{array}{l}\text { Intensive therapy } \\
\text { and progression to } \\
\text { clinical albuminuria } \\
\text { in patients with } \\
\text { insulin dependent } \\
\text { diabetes mellitus } \\
\text { and } \\
\text { microalbuminuria. } \\
\text { Microalbuminuria } \\
\text { Collaborative Study } \\
\text { Group, United } \\
\text { Kingdom. BMJ } \\
1995 ; 311: 973-7 .\end{array}$ & $\begin{array}{l}\text { Ana Denise / } \\
\text { Diogo }\end{array}$ & $\mathrm{NE}$ & 2 \\
\hline $\begin{array}{l}\text { Ref ID: } \\
3017\end{array}$ & & $\begin{array}{l}\text { U.K. prospective } \\
\text { diabetes study } 16 . \\
\text { Overview of } 6 \\
\text { years' therapy of } \\
\text { type II diabetes: a } \\
\text { progressive } \\
\text { disease.U.K. } \\
\text { Prospective } \\
\text { Diabetes Study } \\
\text { Group. Diabetes } \\
\text { 1995;44:1249-58. }\end{array}$ & $\begin{array}{l}\text { Ana Denise / } \\
\text { Diogo }\end{array}$ & $\mathrm{E}$ & \\
\hline Ref ID: & & Journal of & Anna/Ligia & $E$ & mesma \\
\hline
\end{tabular}




\begin{tabular}{|c|c|c|c|c|c|}
\hline Ref ID: 7 & & $\begin{array}{l}\text { hypertension } \\
\text { Supplement : } \\
\text { official journal of the } \\
\text { International } \\
\text { Society of } \\
\text { Hypertension } \\
\text { 2001;19:S21- } \\
\text { S28.Rationale and } \\
\text { design of the } \\
\text { ADVANCE study: a } \\
\text { randomised trial of } \\
\text { blood pressure } \\
\text { lowering and } \\
\text { intensive glucose } \\
\text { control in high-risk } \\
\text { individuals with type } \\
2 \text { diabetes mellitus. } \\
\text { Action in Diabetes } \\
\text { and Vascular } \\
\text { Disease: PreterAx } \\
\text { and DiamicroN } \\
\text { Modified-Release } \\
\text { Controlled } \\
\text { Evaluation } \\
\text { Effects of intensive } \\
\text { lowering in type 2. } \\
\text { Aust J Pharm } \\
2009 ; 90(1066): 76- \\
7 .\end{array}$ & \begin{tabular}{|l} 
não confere ref \\
nat
\end{tabular} & & $\begin{array}{l}\text { publicaçã } \\
\text { o que ID } \\
6906 \\
\\
\\
\\
\text { pelo } \\
\text { título, } \\
\text { refere-se } \\
\text { ao paper } \\
\text { principal } \\
\text { do } \\
\text { ACCORD } \\
\text { Ref ID } \\
2686 \\
\end{array}$ \\
\hline $\begin{array}{c}\text { Ref ID: } \\
2686\end{array}$ & $\begin{array}{l}\text {-Action-to- } \\
\text { Control- } \\
\text { Cardiovascul } \\
\text { ar-Risk-in- } \\
\text { Diabetes- } \\
\text { Study-Group, } \\
\text { Gerstein HC, } \\
\text { Miller ME, } \\
\text { Byington RP, } \\
\text { Goff DC, } \\
\text { Bigger JT, et } \\
\text { al. }\end{array}$ & $\begin{array}{l}\text { Effects of intensive } \\
\text { glucose lowering in } \\
\text { type } 2 \text { diabetes. } \\
\text { The New England } \\
\text { journal of medicine } \\
2008 ; 358: 2545-59 \text {. }\end{array}$ & Anna / Eliana & & $\begin{array}{l}\text { mesma } \\
\text { publicaçã } \\
\text { o que ID } \\
146\end{array}$ \\
\hline $\begin{array}{c}\text { Ref ID: } \\
2770\end{array}$ & $\begin{array}{l}\text {-ADVANCE- } \\
\text { Collaborative- } \\
\text { Group. }\end{array}$ & $\begin{array}{l}\text { ADVANCE--Action } \\
\text { in Diabetes and } \\
\text { Vascular Disease: } \\
\text { patient recruitment } \\
\text { and characteristics } \\
\text { of the study } \\
\text { population at } \\
\text { baseline. Diabetic } \\
\text { medicine : a journal } \\
\text { of the British } \\
\text { Diabetic } \\
\text { Association } \\
2005 ; 22: 882-8 .\end{array}$ & 更 & $\mathrm{E}$ & \\
\hline
\end{tabular}




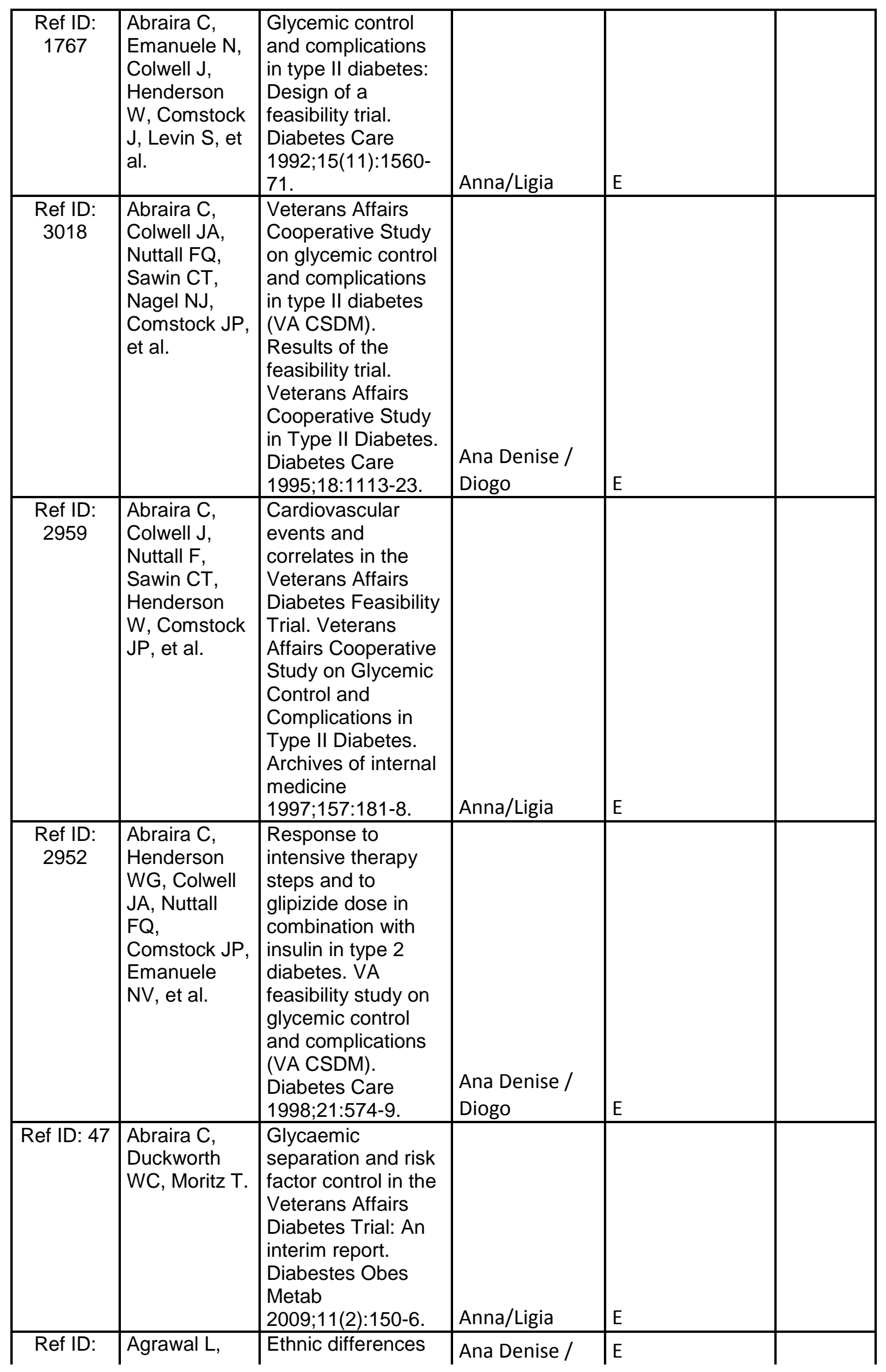




\begin{tabular}{|c|c|c|c|c|c|}
\hline $\begin{array}{c}\text { Ref ID: } \\
6419\end{array}$ & $\begin{array}{l}\text { Emanuele } \\
\text { NV, Abraira } \\
\text { C, Henderson } \\
\text { WG, Levin } \\
\text { SR, Sawin } \\
\text { CT, et al. } \\
\\
\\
\text { Al-Ozairi E, } \\
\text { Sibal L, Home } \\
\text { P. }\end{array}$ & $\begin{array}{l}\text { in the glycemic } \\
\text { response to } \\
\text { exogenous insulin } \\
\text { treatment in the } \\
\text { Veterans Affairs } \\
\text { Cooperative Study } \\
\text { in Type 2 Diabetes } \\
\text { Mellitus (VA } \\
\text { CSDM). Diabetes } \\
\text { Care 1998;21:510- } \\
\text { 5. } \\
\text { Counterpoint: A } \\
\text { Diabetes Outcome } \\
\text { Progression Trial } \\
\text { (ADOPT): Good for } \\
\text { sulfonylureas? } \\
\text { Diabetes Care } \\
\text { 2007;30(6):1677- } \\
\text { 80. }\end{array}$ & Anna / Diogo & NE & 1 \\
\hline $\begin{array}{c}\text { Ref ID: } \\
3181\end{array}$ & Andre P. & $\begin{array}{l}\text { [lmpact of intensive } \\
\text { blood glucose } \\
\text { control with } \\
\text { hypoglycemic } \\
\text { sulfamides, } \\
\text { metformin or insulin } \\
\text { on complications of } \\
\text { non-insulin } \\
\text { dependent } \\
\text { diabetes]. Rev } \\
\text { Epidemiol Sante } \\
\text { Publique 1999 } \\
\text { Mar;47(1):93-5. }\end{array}$ & Anna / Bruno & NE & 1 \\
\hline $\begin{array}{l}\text { Ref ID: } \\
2934\end{array}$ & $\begin{array}{l}\text { Azad N, } \\
\text { Emanuele } \\
\text { NV, Abraira } \\
\text { C, Henderson } \\
\text { WG, Colwell } \\
\text { J, Levin SR, } \\
\text { et al. }\end{array}$ & $\begin{array}{l}\text { The effects of } \\
\text { intensive glycemic } \\
\text { control on } \\
\text { neuropathy in the } \\
\text { VA cooperative } \\
\text { study on type II } \\
\text { diabetes mellitus } \\
\text { (VA CSDM). } \\
\text { Journal of diabetes } \\
\text { and its } \\
\text { complications } \\
\text { 1999;13:307-13. }\end{array}$ & Anna / Bruno & $\mathrm{E}$ & \\
\hline $\begin{array}{l}\text { Ref ID: } \\
7037\end{array}$ & $\begin{array}{l}\text { Bagg W, Ferri } \\
\text { C, Desideri G, } \\
\text { Gamble G, } \\
\text { Ockelford P, } \\
\text { Braatvedt } \\
\text { GD. }\end{array}$ & $\begin{array}{l}\text { The influences of } \\
\text { obesity and } \\
\text { glycemic control on } \\
\text { endothelial } \\
\text { activation in } \\
\text { patients with type } 2 \\
\text { diabetes. J Clin } \\
\text { Endocrinol Metab } \\
2001 ; 86(11): 5491- \\
7 . \\
\end{array}$ & \begin{tabular}{|l} 
Ana Denise / \\
Diogo
\end{tabular} & $\mathrm{NE}$ & 4 \\
\hline $\begin{array}{l}\text { Ref ID: } \\
3093\end{array}$ & $\begin{array}{l}\text { Barbosa J, } \\
\text { Johnson S. }\end{array}$ & $\begin{array}{l}\text { Severe } \\
\text { hypoglycemia } \\
\text { during maximized } \\
\text { insulin treatment of } \\
\text { diabetes in a }\end{array}$ & Anna/Ligia & NE & 1 \\
\hline
\end{tabular}




\begin{tabular}{|c|c|c|c|c|c|}
\hline $\begin{array}{l}\text { Ref ID: } \\
2830\end{array}$ & $\begin{array}{l}\text { Becker A, } \\
\text { van-der-Does } \\
\text { FE, van H, V, } \\
\text { Heine RJ, } \\
\text { Bouter LM, } \\
\text { Stehouwer } \\
\text { CD. }\end{array}$ & $\begin{array}{l}\text { randomized clinical } \\
\text { trial. Diabetes Care } \\
\text { 1983;6:62-3. } \\
\\
\text { Improvement of } \\
\text { glycaemic control in } \\
\text { type } 2 \text { diabetes: } \\
\text { favourable changes } \\
\text { in blood pressure, } \\
\text { total cholesterol } \\
\text { and triglycerides, } \\
\text { but not in HDL } \\
\text { cholesterol, } \\
\text { fibrinogen, Von } \\
\text { Willebrand factor } \\
\text { and (pro)insulin. } \\
\text { The Netherlands } \\
\text { journal of medicine } \\
\text { 2003;61:129-36. }\end{array}$ & Anna / Ligia & $\mathrm{E}$ & \\
\hline $\begin{array}{l}\text { Ref ID: } \\
6745\end{array}$ & $\begin{array}{l}\text { Bell DSH, } \\
\text { Ovalle F. }\end{array}$ & $\begin{array}{l}\text { Long-term } \\
\text { glycaemic efficacy } \\
\text { and weight changes } \\
\text { associated with } \\
\text { thiazolidinediones } \\
\text { when added at an } \\
\text { advanced stage of } \\
\text { type } 2 \text { diabetes. } \\
\text { Diabetes Obesity \& } \\
\text { Metabolism } \\
2006 ; 8(1): 110-5 .\end{array}$ & $\begin{array}{l}\text { Ana Denise / } \\
\text { Diogo }\end{array}$ & NE & 1 \\
\hline $\begin{array}{l}\text { Ref ID: } \\
3316\end{array}$ & $\begin{array}{l}\text { Buse JB, } \\
\text { Bigger JT, } \\
\text { Byington RP, } \\
\text { Cooper LS, } \\
\text { Cushman } \\
\text { WC, } \\
\text { Friedewald } \\
\text { WT, et al. } \\
\end{array}$ & $\begin{array}{l}\text { Action to Control } \\
\text { Cardiovascular Risk } \\
\text { in Diabetes } \\
\text { (ACCORD) trial: } \\
\text { design and } \\
\text { methods. Am J } \\
\text { Cardiol 2007 Jun } \\
\text { 18;99(12A):21i-33i. }\end{array}$ & Anna/Ligia & $\mathrm{E}$ & \\
\hline $\begin{array}{l}\text { Ref ID: } \\
6342\end{array}$ & $\begin{array}{l}\text { Camacho P, } \\
\text { Pitale S, } \\
\text { Abraira C. }\end{array}$ & \begin{tabular}{|l} 
Beneficial and \\
detrimental effects \\
of intensive \\
glycaemic control, \\
with emphasis on \\
type 2 diabetes \\
mellitus. Drugs \& \\
Aging \\
$2000 ; 17(6): 463-76$.
\end{tabular} & Anna / Diogo & NE & 1 \\
\hline $\begin{array}{c}\text { Ref ID: } \\
1398\end{array}$ & Campbell IW. & $\begin{array}{l}\text { Need for intensive, } \\
\text { early glycaemic } \\
\text { control in patients } \\
\text { with type } 2 \\
\text { diabetes. Br J } \\
\text { Cardiol } \\
2000 ; 7(10): 625-31 . \\
\end{array}$ & Anna / & NE & 1 \\
\hline Ref ID: & Chalmers J, & Study rationale and & Ana Denise / & $E$ & \\
\hline
\end{tabular}




\begin{tabular}{|c|c|c|c|c|c|}
\hline 1344 & $\begin{array}{l}\text { Cooper M, } \\
\text { Ferrannini E, } \\
\text { Glasziou P, } \\
\text { Grobbee D, } \\
\text { Hamet P, et } \\
\text { al. }\end{array}$ & $\begin{array}{l}\text { design of } \\
\text { ADVANCE: Action } \\
\text { in diabetes and } \\
\text { vascular disease - } \\
\text { Preterax and } \\
\text { diamicron MR } \\
\text { controlled } \\
\text { evaluation. } \\
\text { Diabetologia } \\
2001 ; 44(9): 1118- \\
20 .\end{array}$ & Diogo & & \\
\hline $\begin{array}{l}\text { Ref ID: } \\
6906\end{array}$ & $\begin{array}{l}\text { Chalmers J, } \\
\text { MacMahon S, } \\
\text { Cooper M, } \\
\text { Glasziou P, } \\
\text { Harrap S, } \\
\text { Neal B, et al. }\end{array}$ & $\begin{array}{l}\text { Rationale and } \\
\text { design of the } \\
\text { ADVANCE study: a } \\
\text { randomised trial of } \\
\text { blood pressure } \\
\text { lowering and } \\
\text { intensive glucose } \\
\text { control in high-risk } \\
\text { individuals with type } \\
2 \text { diabetes mellitus. } \\
\text { J Hypertens } \\
\text { 2001;19:S21-S28. }\end{array}$ & Anna / Bruno & E & \\
\hline $\begin{array}{l}\text { Ref ID: } \\
6246\end{array}$ & Chalmers J. & $\begin{array}{l}\text { ADVANCE study: } \\
\text { Objectives, design } \\
\text { and current status. } \\
\text { Drugs } 2003 \text { spec } \\
N^{\circ} 139-44 .\end{array}$ & Anna / Bruno & E & \\
\hline $\begin{array}{l}\text { Ref ID: } \\
6247\end{array}$ & \begin{tabular}{|l|} 
Chalmers J, \\
Perkovic V, \\
Joshi R, Patel \\
A.
\end{tabular} & $\begin{array}{l}\text { ADVANCE: } \\
\text { breaking new } \\
\text { ground in type } 2 \\
\text { diabetes. J } \\
\text { Hypertens } \\
2006 ; 24: S 22-S 28 .\end{array}$ & $\begin{array}{l}\text { Ana Denise / } \\
\text { Diogo }\end{array}$ & E & \\
\hline $\begin{array}{l}\text { Ref ID: } \\
3369\end{array}$ & $\begin{array}{l}\text { Chalmers J, } \\
\text { Kengne AP, } \\
\text { Joshi R, } \\
\text { Perkovic V, } \\
\text { Patel A. } \\
\end{array}$ & $\begin{array}{l}\text { New insights from } \\
\text { ADVANCE. J } \\
\text { Hypertens Suppl } \\
2007 \\
\text { Jun;25(1):S23-S30. }\end{array}$ & Anna / Bruno & E & \\
\hline $\begin{array}{l}\text { Ref ID: } \\
388\end{array}$ & $\begin{array}{l}\text { Chew EY, } \\
\text { Ambrosius } \\
\text { WT, Howard } \\
\text { LT, Greven } \\
\text { CM, Johnson } \\
\text { S, Danis RP, } \\
\text { et al. }\end{array}$ & $\begin{array}{l}\text { Rationale, Design, } \\
\text { and Methods of the } \\
\text { Action to Control } \\
\text { Cardiovascular Risk } \\
\text { in Diabetes Eye } \\
\text { Study (ACCORD- } \\
\text { EYE). Am J Cardiol } \\
\text { 2007;99(12 } \\
\text { SUPPL.):S103- } \\
\text { S111. } \\
\end{array}$ & Anna/Ligia & $E$ & \\
\hline $\begin{array}{l}\text { Ref ID: } \\
6410\end{array}$ & $\begin{array}{l}\text { Clarke P, } \\
\text { Gray A, Adler } \\
\text { A, Stevens R, } \\
\text { Raikou M, } \\
\text { Cull C, et al. }\end{array}$ & $\begin{array}{l}\text { Cost-effectiveness } \\
\text { analysis of } \\
\text { intensive blood- } \\
\text { glucose control with } \\
\text { metformin in } \\
\text { overweight patients } \\
\text { with Type II } \\
\text { diabetes (UKPDS } \\
\text { No. 51). }\end{array}$ & Anna / Diogo & $E$ & \\
\hline
\end{tabular}




\begin{tabular}{|c|c|c|c|c|c|}
\hline & & $\begin{array}{l}\text { Diabetologia } \\
2001 ; 44(3): 298- \\
304 .\end{array}$ & & & \\
\hline $\begin{array}{l}\text { Ref ID: } \\
6414\end{array}$ & $\begin{array}{l}\text { Clarke PM, } \\
\text { Gray AM, } \\
\text { Briggs A, } \\
\text { Stevens RJ, } \\
\text { Matthews DR, } \\
\text { Holman RR, } \\
\text { et al. }\end{array}$ & $\begin{array}{l}\text { Cost-utility analyses } \\
\text { of intensive blood } \\
\text { glucose and tight } \\
\text { blood pressure } \\
\text { control in type } 2 \\
\text { diabetes (UKPDS } \\
\text { 72). Diabetologia } \\
\text { 2005;48(5):868-77. }\end{array}$ & $\begin{array}{l}\text { Ana Denise / } \\
\text { Diogo }\end{array}$ & $E$ & \\
\hline $\begin{array}{l}\text { Ref ID: } \\
2990\end{array}$ & Colwell JA. & \begin{tabular}{|l|} 
The feasibility of \\
intensive insulin \\
management in \\
non-insulin- \\
dependent diabetes \\
mellitus. \\
Implications of the \\
Veterans Affairs \\
Cooperative Study \\
on Glycemic \\
Control and \\
Complications in \\
NIDDM. Annals of \\
internal medicine \\
1996;124:131-5. \\
\end{tabular} & $\begin{array}{l}\text { Ana Denise / } \\
\text { Diogo }\end{array}$ & $E$ & \\
\hline $\begin{array}{l}\text { Ref ID: } \\
6641\end{array}$ & $\begin{array}{l}\text { Dasgupta K, } \\
\text { Grover SA, } \\
\text { Da Costa D, } \\
\text { Lowensteyn I, } \\
\text { Yale JF, } \\
\text { Rahme E. }\end{array}$ & $\begin{array}{l}\text { Impact of modified } \\
\text { glucose target and } \\
\text { exercise } \\
\text { interventions on } \\
\text { vascular risk } \\
\text { factors. Diabetes } \\
\text { Res Clin Pract } \\
2006 ; 72(1): 53-60 .\end{array}$ & Anna / Diogo & $\mathrm{NE}$ & 4 \\
\hline $\begin{array}{l}\text { Ref ID: } \\
6918\end{array}$ & $\begin{array}{l}\text { Davis TME, } \\
\text { Cull CA, } \\
\text { Holman RR, } \\
\text { Grp UKP. }\end{array}$ & \begin{tabular}{|l|} 
Relationship \\
between ethnicity \\
and glycemic \\
control, lipid \\
profiles, and blood \\
pressure during the \\
first 9 years of type \\
2 diabetes - UK \\
prospective \\
diabetes study \\
(UKPDS 55). \\
Diabetes Care \\
$2001 ; 24(7): 1167-$ \\
74. \\
\end{tabular} & Anna / Diogo & $\mathrm{E}$ & \\
\hline $\begin{array}{c}\text { Ref ID: } \\
3068\end{array}$ & \begin{tabular}{|l|} 
Ditzel J, \\
Clemmensen \\
NK.
\end{tabular} & \begin{tabular}{|l|} 
[A comparative \\
study of intensive \\
conventional insulin \\
treatment and a \\
multiple insulin- \\
injection regimen \\
with NovoPen]. \\
Ugeskrift for laeger \\
$1987 ; 149: 1335-8$.
\end{tabular} & Anna / Bruno & $\mathrm{NE}$ & 2 \\
\hline
\end{tabular}




\begin{tabular}{|c|c|c|c|c|c|}
\hline $\begin{array}{l}\text { Ref ID: } \\
561\end{array}$ & $\begin{array}{l}\text { Dormandy } \\
\text { JA, } \\
\text { Charbonnel } \\
\text { B, Eckland } \\
\text { DJA, } \\
\text { Erdmann E, } \\
\text { Massi- } \\
\text { Benedetti M, } \\
\text { Kmoules IK, } \\
\text { et al. }\end{array}$ & \begin{tabular}{|l} 
Secondary \\
prevention of \\
macrovascular \\
events in patients \\
with type 2 diabetes \\
in the PROactive \\
Study \\
(PROspective \\
pioglitAzone \\
Clinical Trial In \\
macroVascular \\
Events): a \\
randomised \\
controlled trial. \\
Lancet \\
2005;366(9493):12 \\
$79-89$. \\
\end{tabular} & Anna / Diogo & NE & 3 \\
\hline $\begin{array}{l}\text { Ref ID: } \\
3525\end{array}$ & \begin{tabular}{|l|} 
Duckworth W, \\
Abraira C, \\
Moritz T, \\
Reda D, \\
Emanuele N, \\
Reaven PD, \\
et al. \\
\end{tabular} & $\begin{array}{l}\text { Glucose control and } \\
\text { vascular } \\
\text { complications in } \\
\text { veterans with type } 2 \\
\text { diabetes. N Engl J } \\
\text { Med 2009 Jan } \\
\text { 8;360(2):129-39. } \\
\end{array}$ & Anna / Eliana & $E$ & \\
\hline $\begin{array}{l}\text { Ref ID: } \\
6591\end{array}$ & $\begin{array}{l}\text { Duckworth } \\
\text { WC, } \\
\text { McCarren M, } \\
\text { Abraira C. }\end{array}$ & $\begin{array}{l}\text { Glucose control and } \\
\text { cardiovascular } \\
\text { complications: The } \\
\text { VA Diabetes Trial. } \\
\text { Diabetes Care } \\
2001 ; 24(5): 942-5 .\end{array}$ & Anna / Diago & NE & 1 \\
\hline $\begin{array}{l}\text { Ref ID: } \\
1584\end{array}$ & $\begin{array}{l}\text { Emanuele N, } \\
\text { Klein R, } \\
\text { Abraira C, } \\
\text { Colwell J, } \\
\text { Comstock J, } \\
\text { Henderson } \\
\text { WG, et al. }\end{array}$ & \begin{tabular}{|l|} 
Evaluations of \\
retinopathy in the \\
VA Cooperative \\
Study on glycemic \\
control and \\
complications in \\
type II diabetes (VA \\
CSDM): A feasibility \\
study. Diabetes \\
Care \\
$1996 ; 19(12): 1375-$ \\
81.
\end{tabular} & Anna / Diogo & E & \\
\hline $\begin{array}{l}\text { Ref ID: } \\
2942\end{array}$ & \begin{tabular}{|l|} 
Emanuele N, \\
Azad N, \\
Abraira C, \\
Henderson \\
W, Colwell J, \\
Levin S, et al.
\end{tabular} & $\begin{array}{l}\text { Effect of intensive } \\
\text { glycemic control on } \\
\text { fibrinogen, lipids, } \\
\text { and lipoproteins: } \\
\text { Veterans Affairs } \\
\text { Cooperative Study } \\
\text { in Type II Diabetes } \\
\text { Mellitus. Archives of } \\
\text { internal medicine } \\
\text { 1998;158:2485-90. } \\
\end{array}$ & $\begin{array}{l}\text { Ana Denise / } \\
\text { Diogo }\end{array}$ & $\mathrm{E}$ & \\
\hline $\begin{array}{l}\text { Ref ID: } \\
146\end{array}$ & \begin{tabular}{|l|} 
Friedewald \\
WT, Buse JB, \\
Bigger JT, \\
Byington RP, \\
Cushman \\
WC, Gerstein \\
HC, et al.
\end{tabular} & $\begin{array}{l}\text { Effects of intensive } \\
\text { glucose lowering in } \\
\text { type } 2 \text { diabetes. } \\
\text { New Engl J Med } \\
2008 ; 358(24): 2545- \\
59 .\end{array}$ & Anna / Diogo & E & \\
\hline
\end{tabular}




\begin{tabular}{|c|c|c|c|c|c|}
\hline $\begin{array}{l}\text { Ref ID: } \\
6711\end{array}$ & $\begin{array}{l}\text { Gaede P, } \\
\text { Vedel P, } \\
\text { Parving HH, } \\
\text { Pedersen O. }\end{array}$ & \begin{tabular}{|l} 
Intensified \\
multifactorial \\
intervention in \\
patients with type 2 \\
diabetes mellitus \\
and \\
microalbuminuria: \\
the Steno type 2 \\
randomised study. \\
Lancet \\
1999;353(9153):61 \\
$7-22$.
\end{tabular} & $\begin{array}{l}\text { Ana Denise / } \\
\text { Diogo }\end{array}$ & $E$ & \\
\hline $\begin{array}{l}\text { Ref ID: } \\
6598\end{array}$ & $\begin{array}{l}\text { Gerstein HC, } \\
\text { Riddle MC, } \\
\text { Kendall DM, } \\
\text { Cohen RM, } \\
\text { Goland R, } \\
\text { Feinglos MN, } \\
\text { et al. }\end{array}$ & $\begin{array}{l}\text { Glycemia treatment } \\
\text { strategies in the } \\
\text { action to control } \\
\text { cardiovascular risk } \\
\text { in diabetes } \\
\text { (ACCORD) trial. } \\
\text { Am J Cardiol } \\
2007 ; 99(12 \mathrm{~A}): 34 \mathrm{I}- \\
43 \mathrm{I} . \\
\end{array}$ & $\begin{array}{l}\text { Ana Denise / } \\
\text { Diogo }\end{array}$ & $E$ & \\
\hline $\begin{array}{l}\text { Ref ID: } \\
3670\end{array}$ & $\begin{array}{l}\text { Gerstein HC, } \\
\text { Miller ME, } \\
\text { Byington RP, } \\
\text { Goff DC, Jr., } \\
\text { Bigger JT, } \\
\text { Buse JB, et } \\
\text { al. } \\
\end{array}$ & \begin{tabular}{|l|} 
Effects of intensive \\
glucose lowering in \\
type 2 diabetes. N \\
Engl J Med 2008 \\
Jun \\
$12 ; 358(24): 2545-$ \\
59.
\end{tabular} & $\begin{array}{l}\text { duplicado com } \\
\text { outro autor }\end{array}$ & & \\
\hline $\begin{array}{c}\text { Ref ID: } \\
1761\end{array}$ & \begin{tabular}{|l} 
Giorda C, \\
Priasca G, \\
Zerbola S, \\
Mason MG, \\
Pagano G.
\end{tabular} & $\begin{array}{l}\text { Effects of tight } \\
\text { glycaemic control } \\
\text { by artificial } \\
\text { pancreas on the } \\
\text { haemodialysis } \\
\text { session of diabetic } \\
\text { uraemic patients. } \\
\text { Eur J Intern Med } \\
1993 ; 4(3): 201-6 .\end{array}$ & não confere ref & & \\
\hline $\begin{array}{l}\text { Ref ID: } \\
2456\end{array}$ & \begin{tabular}{|l|} 
Haire-Joshu \\
D, Flavin K, \\
Santiago JV.
\end{tabular} & $\begin{array}{l}\text { Diabetes: } \\
\text { controlling the } \\
\text { insulin balance. } \\
\text { Intensive } \\
\text { conventional insulin } \\
\text { therapy. Am J Nurs } \\
1986 \\
\text { Nov;86(11):1251-5. }\end{array}$ & Anna/Ligia & NE & 1 \\
\hline $\begin{array}{l}\text { Ref ID: } \\
6388\end{array}$ & $\begin{array}{l}\text { Hanefeld M, } \\
\text { Goke B. }\end{array}$ & $\begin{array}{l}\text { Combining } \\
\text { pioglitazone with a } \\
\text { sulphonylurea or } \\
\text { metformin in the } \\
\text { management of } \\
\text { type } 2 \text { diabetes. } \\
\text { Experimental and } \\
\text { Clinical } \\
\text { Endocrinology \& } \\
\text { Diabetes } \\
2000 ; 108: S 256- \\
\text { S266. }\end{array}$ & Anna / Bruno & $\mathrm{NE}$ & 1 \\
\hline Ref ID: & Hasche $\mathrm{H}$, & Effects of acarbose & Anna / Bruno & NE & 3 \\
\hline
\end{tabular}




\begin{tabular}{|c|c|c|c|c|c|}
\hline $\begin{array}{l}\text { Ref ID: } \\
2566\end{array}$ & $\begin{array}{l}\text { Mertes G, } \\
\text { Bruns C, } \\
\text { Englert R, } \\
\text { Genthner P, } \\
\text { Heim D, et al. } \\
\\
\text { Hollander P. }\end{array}$ & $\begin{array}{l}\text { treatment in Type } 2 \\
\text { diabetic patients } \\
\text { under dietary } \\
\text { training: A } \\
\text { multicentre, double- } \\
\text { blind, placebo- } \\
\text { controlled, 2-year } \\
\text { study. Diabetes } \\
\text { Nutrition \& } \\
\text { Metabolism } \\
\text { 1999;12(4):277-85. } \\
\text { The case for tight } \\
\text { control in diabetes. } \\
\text { Postgrad Med } 1984 \\
\text { Mar;75(4):80-7. }\end{array}$ & Anna / Ligia & NE & 1 \\
\hline $\begin{array}{l}\text { Ref ID: } \\
2676\end{array}$ & $\begin{array}{l}\text { Holman RR, } \\
\text { Paul SK, } \\
\text { Bethel MA, } \\
\text { Matthews DR, } \\
\text { Neil HA. }\end{array}$ & $\begin{array}{l}\text { 10-year follow-up of } \\
\text { intensive glucose } \\
\text { control in type } 2 \\
\text { diabetes. The New } \\
\text { England journal of } \\
\text { medicine } \\
\text { 2008;359:1577-89. }\end{array}$ & Anna / Eliana & E & \\
\hline $\begin{array}{l}\text { Ref ID: } \\
6935\end{array}$ & $\begin{array}{l}\text { Home PD, } \\
\text { Pocock SJ, } \\
\text { Beck-Nielsen } \\
\text { H, Gomis R, } \\
\text { Hanefeld M, } \\
\text { Jones NP, et } \\
\text { al. }\end{array}$ & $\begin{array}{l}\text { Rosiglitazone } \\
\text { evaluated for } \\
\text { cardiovascular } \\
\text { outcomes - An } \\
\text { interim analysis. } \\
\text { New Engl J Med } \\
\text { 2007;357(1):28-38. }\end{array}$ & Anna / Eliana & NE & 3 \\
\hline $\begin{array}{l}\text { Ref ID: } \\
6939\end{array}$ & $\begin{array}{l}\text { Home PD, } \\
\text { Jones NP, } \\
\text { Pocock SJ, } \\
\text { Beck-Nielsen } \\
\text { H, Gomis R, } \\
\text { Hanefeld M, } \\
\text { et al. }\end{array}$ & $\begin{array}{l}\text { Rosiglitazone } \\
\text { RECORD study: } \\
\text { glucose control } \\
\text { outcomes at } 18 \\
\text { months. Diabet } \\
\text { Med } \\
2007 ; 24(6): 626-34 . \\
\end{array}$ & Anna / Diogo & $\mathrm{NE}$ & 3 \\
\hline Ref ID: 87 & Howard PA. & $\begin{array}{l}\text { Does intensive } \\
\text { glycemic control } \\
\text { reduce } \\
\text { cardiovascular } \\
\text { complications in } \\
\text { type } 2 \text { diabetes? } \\
\text { Hosp Pharm } \\
2008 ; 43(9): 705-8 . \\
\end{array}$ & $\begin{array}{l}\text { Ana Denise / } \\
\text { Diogo }\end{array}$ & NE & 1 \\
\hline $\begin{array}{c}\text { Ref ID: } \\
3893\end{array}$ & $\begin{array}{l}\text { Jarnert C, } \\
\text { Landstedt- } \\
\text { Hallin L, } \\
\text { Malmberg K, } \\
\text { Melcher A, } \\
\text { Ohrvik J, } \\
\text { Persson H, et } \\
\text { al. }\end{array}$ & $\begin{array}{l}\text { A randomized trial } \\
\text { of the impact of } \\
\text { strict glycaemic } \\
\text { control on } \\
\text { myocardial diastolic } \\
\text { function and } \\
\text { perfusion reserve: a } \\
\text { report from the } \\
\text { DADD (Diabetes } \\
\text { mellitus And } \\
\text { Diastolic } \\
\text { Dysfunction) study. } \\
\text { Eur J Heart Fail } \\
2009 \text { Jan;11(1):39- } \\
47 .\end{array}$ & Anna/Ligia & NE & 3 \\
\hline
\end{tabular}




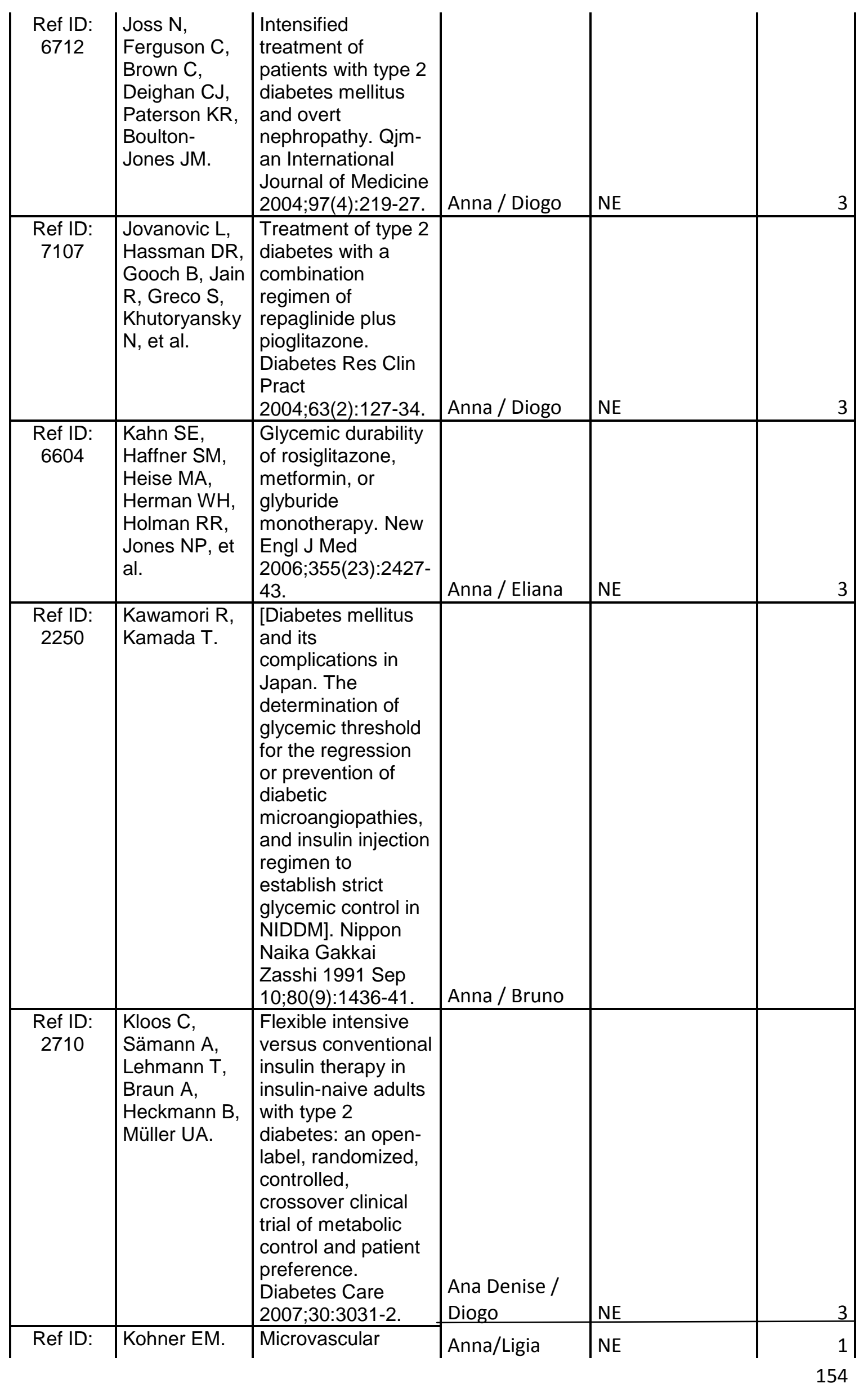




\begin{tabular}{|c|c|c|c|c|c|}
\hline $\begin{array}{c}3999 \\
\\
\text { Ref ID: } \\
2555\end{array}$ & $\begin{array}{l}\text { Kornfeld J. } \\
\text { Diabetes. }\end{array}$ & $\begin{array}{l}\text { disease: what does } \\
\text { the UKPDS tell us } \\
\text { about diabetic } \\
\text { retinopathy? Diabet } \\
\text { Med 2008 Aug;25 } \\
\text { Suppl 2:20-4. } \\
\text { Can tight glycemic } \\
\text { control stem the } \\
\text { tide of } \\
\text { complications? Med } \\
\text { World News 1984 } \\
\text { Aug 13;25(15):43-9, } \\
52 \text {. } \\
\end{array}$ & Anna / Bruno & NE & 1 \\
\hline $\begin{array}{l}\text { Ref ID: } \\
4050\end{array}$ & $\begin{array}{l}\text { Lapina I, } \\
\text { Filatov DN, } \\
\text { Mareev VI, } \\
\text { Narusov OI, } \\
\text { Bolotina MG, } \\
\text { Shestakova } \\
\text { MV, et al. }\end{array}$ & $\begin{array}{l}\text { [Effect of strict } \\
\text { glycemic control on } \\
\text { clinical state and } \\
\text { course of the } \\
\text { disease in patients } \\
\text { with chronic heart } \\
\text { failure and type II } \\
\text { diabetes mellitus. } \\
\text { Results of the } \\
\text { REMBO "rational } \\
\text { effective } \\
\text { multicomponent } \\
\text { therapy in the } \\
\text { struggle against } \\
\text { diabetes mellitus in } \\
\text { patients with } \\
\text { congestive heart } \\
\text { failure" study]. } \\
\text { Kardiologiia } \\
\text { 2008;48b(9):17-27. }\end{array}$ & Anna / Bruno & E & \\
\hline $\begin{array}{l}\text { Ref ID: } \\
2898\end{array}$ & $\begin{array}{l}\text { Levin SR, } \\
\text { Coburn JW, } \\
\text { Abraira C, } \\
\text { Henderson } \\
\text { WG, Colwell } \\
\text { JA, Emanuele } \\
\text { NV, et al. }\end{array}$ & $\begin{array}{l}\text { Effect of intensive } \\
\text { glycemic control on } \\
\text { microalbuminuria in } \\
\text { type } 2 \text { diabetes. } \\
\text { Veterans Affairs } \\
\text { Cooperative Study } \\
\text { on Glycemic } \\
\text { Control and } \\
\text { Complications in } \\
\text { Type } 2 \text { Diabetes } \\
\text { Feasibility Trial } \\
\text { Investigators. } \\
\text { Diabetes Care } \\
\text { 2000;23:1478-85. }\end{array}$ & $\begin{array}{l}\text { Ana Denise / } \\
\text { Diogo }\end{array}$ & E & \\
\hline $\begin{array}{l}\text { Ref ID: } \\
2984\end{array}$ & $\begin{array}{l}\text { Linn T, Ortac } \\
\text { K, Laube H, } \\
\text { Federlin K. }\end{array}$ & $\begin{array}{l}\text { Intensive therapy } \\
\text { in adult insulin- } \\
\text { dependent diabetes } \\
\text { mellitus is } \\
\text { associated with } \\
\text { improved insulin } \\
\text { sensitivity and } \\
\text { reserve: a } \\
\text { randomized, } \\
\text { controlled, } \\
\text { prospective study } \\
\text { over } 5 \text { years in }\end{array}$ & Anna / Diogo & NE & 2 \\
\hline
\end{tabular}




\begin{tabular}{|c|c|c|c|c|c|}
\hline $\begin{array}{l}\text { Ref ID: } \\
5241\end{array}$ & $\begin{array}{l}\text { Magee MF, } \\
\text { Isley WL, } \\
\text { Investigators } \\
\text { BDT. }\end{array}$ & \begin{tabular}{|l|} 
newly diagnosed \\
patients. \\
Metabolism: clinical \\
and experimental \\
1996;45:1508-13. \\
Rationale, design, \\
and methods for \\
glycemic control in \\
the Bypass \\
Angioplasty \\
Revascularization \\
Investigation 2 \\
Diabetes (BARI 2D) \\
trial. Am J Cardiol \\
2006;97(12A):20G- \\
30G. \\
\end{tabular} & Anna / Diogo & NE & 3 \\
\hline $\begin{array}{l}\text { Ref ID: } \\
6608\end{array}$ & $\begin{array}{l}\text { Malmberg K, } \\
\text { Norhammar } \\
\text { A, Wedel H, } \\
\text { Ryden L. }\end{array}$ & $\begin{array}{l}\text { Glycometabolic } \\
\text { state at admission: } \\
\text { Important risk } \\
\text { marker of mortality } \\
\text { in conventionally } \\
\text { treated patients } \\
\text { with diabetes } \\
\text { mellitus and acute } \\
\text { myocardial } \\
\text { infarction - Long- } \\
\text { term results from } \\
\text { the Diabetes and } \\
\text { Insulin-Glucose } \\
\text { Infusion in Acute } \\
\text { Myocardial } \\
\text { Infarction (DIGAMI) } \\
\text { study. Circulation } \\
\text { 1999;99(20):2626- } \\
\text { 32. }\end{array}$ & Anna / Ligia & $\mathrm{NE}$ & 3 \\
\hline $\begin{array}{l}\text { Ref ID: } \\
6643\end{array}$ & mer Diabet A. & $\begin{array}{l}\text { Implications at the } \\
\text { Diabetes Control } \\
\text { and Complications } \\
\text { Trial. Diabetes Care } \\
\text { 2000;23:S24-S26. }\end{array}$ & Anna/Ligia & NE & 1 \\
\hline $\begin{array}{l}\text { Ref ID: } \\
2774\end{array}$ & $\begin{array}{l}\text { Ménard J, } \\
\text { Payette H, } \\
\text { Baillargeon } \\
\text { JP, Maheux } \\
\text { P, Lepage S, } \\
\text { Tessier D, et } \\
\text { al. }\end{array}$ & $\begin{array}{l}\text { Efficacy of intensive } \\
\text { multitherapy for } \\
\text { patients with type } 2 \\
\text { diabetes mellitus: a } \\
\text { randomized } \\
\text { controlled trial. } \\
\text { CMAJ : Canadian } \\
\text { Medical Association } \\
\text { journal = journal de } \\
\text { l'Association } \\
\text { medicale } \\
\text { canadienne } \\
2005 ; 173: 1457-66 .\end{array}$ & $\begin{array}{l}\text { Ana Denise / } \\
\text { Diogo }\end{array}$ & E & \\
\hline $\begin{array}{l}\text { Ref ID: } \\
4255\end{array}$ & $\begin{array}{l}\text { Montanya E, } \\
\text { Fernandez- } \\
\text { Castaner M, } \\
\text { Soler J. }\end{array}$ & $\begin{array}{l}\text { Improved } \\
\text { metabolic control } \\
\text { preserved beta-cell } \\
\text { function two years } \\
\text { after diagnosis of } \\
\text { insulin-dependent }\end{array}$ & Anna / Ligia & NE & 2 \\
\hline
\end{tabular}




\begin{tabular}{|c|c|c|c|c|c|}
\hline $\begin{array}{c}\text { Ref ID: } \\
309\end{array}$ & $\begin{array}{l}\text { Nagy V. } \\
\text { Advanced } \\
\text { credit: }\end{array}$ & $\begin{array}{l}\text { diabetes mellitus. } \\
\text { Diabetes Metab } \\
1997 \\
\text { Sep;23(4):314-9. } \\
\text { Patient enrolling } \\
\text { and therapy } \\
\text { initiation in the } \\
\text { ADVANCE trial. } \\
\text { Orvosi Hetil } \\
2007 ; 148(39): 1839- \\
42 .\end{array}$ & Anna / Bruno & $E$ & \\
\hline $\begin{array}{c}\text { Ref ID: } \\
4299\end{array}$ & \begin{tabular}{|l} 
Nasr CE, \\
Hoogwerf BJ, \\
Faiman C, \\
Reddy SS. \\
United \\
Kingdom \\
Prospective \\
Diabetes \\
Study \\
(UKPDS). \\
\end{tabular} & $\begin{array}{l}\text { Effects of glucose } \\
\text { and blood pressure } \\
\text { control on } \\
\text { complications of } \\
\text { type } 2 \text { diabetes } \\
\text { mellitus. Cleve Clin } \\
\text { J Med 1999 } \\
\text { Apr;66(4):247-53. }\end{array}$ & Anna / Bruno & $\mathrm{E}$ & \\
\hline $\begin{array}{c}\text { Ref ID: } \\
4312\end{array}$ & Nicollerat JA. & \begin{tabular}{|l|} 
Implications of the \\
United Kingdom \\
Prospective \\
Diabetes Study \\
(UKPDS) results on \\
patient \\
management. \\
Diabetes Educ \\
2000 Nov;26 \\
Suppl:8-10. \\
\end{tabular} & Anna / Bruno & NE & 1 \\
\hline Ref ID: 14 & $\begin{array}{l}\text { O'Sullivan } \\
\text { EP, Dinneen } \\
\text { SF. }\end{array}$ & $\begin{array}{l}\text { Benefits of early } \\
\text { intensive glucose } \\
\text { control to prevent } \\
\text { diabetes } \\
\text { complications were } \\
\text { sustained for up to } \\
10 \text { years. Evid - } \\
\text { Based Med } \\
2009 ; 14(1): 9+10 . \\
\end{array}$ & Anna / Bruno & NE & 1 \\
\hline $\begin{array}{c}\text { Ref ID: } \\
3003\end{array}$ & $\begin{array}{l}\text { Ohkubo Y, } \\
\text { Kishikawa H, } \\
\text { Araki E, } \\
\text { Miyata T, } \\
\text { Isami S, } \\
\text { Motoyoshi S, } \\
\text { et al. }\end{array}$ & $\begin{array}{l}\text { Intensive insulin } \\
\text { therapy prevents } \\
\text { the progression of } \\
\text { diabetic } \\
\text { microvascular } \\
\text { complications in } \\
\text { Japanese patients } \\
\text { with non-insulin- } \\
\text { dependent diabetes } \\
\text { mellitus: a } \\
\text { randomized } \\
\text { prospective 6-year } \\
\text { study. Diabetes } \\
\text { research and } \\
\text { clinical practice } \\
\text { 1995;28:103-17. }\end{array}$ & Anna/Ligia & $\mathrm{E}$ & \\
\hline Ref ID: & Paisey RB, & Five year results of & Anna/Ligia & NE & 1 \\
\hline
\end{tabular}




\begin{tabular}{|c|c|c|c|c|c|}
\hline $\begin{array}{l}\text { Ref ID: } \\
4371\end{array}$ & \begin{tabular}{|l|} 
Frost J, \\
Harvey P, \\
Paisey A, \\
Bower L, \\
Paisey RM, et \\
al. \\
Parashar A. \\
\end{tabular} & $\begin{array}{l}\text { a prospective very } \\
\text { low calorie diet or } \\
\text { conventional weight } \\
\text { loss programme in } \\
\text { type } 2 \text { diabetes. J } \\
\text { Hum Nutr Diet } 2002 \\
\text { Apr;15(2):121-7. } \\
\text { Intensive glucose } \\
\text { control in type } 2 \\
\text { diabetes. N Engl J } \\
\text { Med 2008 Oct } \\
\text { 2;359(14):1520-1. } \\
\end{array}$ & Anna / Eliana & $\mathrm{NE}$ & 1 \\
\hline $\begin{array}{l}\text { Ref ID: } \\
1719\end{array}$ & $\begin{array}{l}\text { Patel A, } \\
\text { Chalmers J, } \\
\text { Poulter N. }\end{array}$ & $\begin{array}{l}\text { ADVANCE: action } \\
\text { in diabetes and } \\
\text { vascular disease.J } \\
\text { Hum Hypertens } \\
2005 \text { p. S27-S32. }\end{array}$ & Anna / Ligia & $E$ & \\
\hline $\begin{array}{l}\text { Ref ID: } \\
5641\end{array}$ & \begin{tabular}{|l|} 
Patel A, \\
MacMahon S, \\
Chalmers J, \\
Neal B, \\
Woodward M, \\
Billot L, et al.
\end{tabular} & $\begin{array}{l}\text { Effects of a fixed } \\
\text { combination of } \\
\text { perindopril and } \\
\text { indapamide on } \\
\text { macrovascular and } \\
\text { microvascular } \\
\text { outcomes in } \\
\text { patients with type } 2 \\
\text { diabetes mellitus } \\
\text { (the ADVANCE } \\
\text { trial): a randomised } \\
\text { controlled trial. } \\
\text { Lancet } \\
2007 ; 370(9590): 82 \\
9-40 . \\
\end{array}$ & \multirow[t]{2}{*}{ Anna / Eliana } & \multirow[t]{2}{*}{$\mathrm{NE}$} & \multirow[t]{2}{*}{3} \\
\hline $\begin{array}{l}\text { Ref ID: } \\
256\end{array}$ & \begin{tabular}{|l|} 
Patel A, \\
Montori VM, \\
Malaga G.
\end{tabular} & $\begin{array}{l}\text { Intensive glucose } \\
\text { control did not } \\
\text { prevent important } \\
\text { complications in } \\
\text { type } 2 \text { diabetes. } \\
\text { Evid -Based Med } \\
2008 ; 13(6): 168-9 . \\
\end{array}$ & & & \\
\hline $\begin{array}{l}\text { Ref ID: } \\
4377\end{array}$ & $\begin{array}{l}\text { Patel A, } \\
\text { MacMahon S, } \\
\text { Chalmers J, } \\
\text { Neal B, Billot } \\
\text { L, Woodward } \\
\text { M, et al. }\end{array}$ & $\begin{array}{l}\text { Intensive blood } \\
\text { glucose control and } \\
\text { vascular outcomes } \\
\text { in patients with type } \\
2 \text { diabetes. N Engl } \\
\text { J Med } 2008 \text { Jun } \\
12 ; 358(24): 2560- \\
72 .\end{array}$ & Anna / Eliana & $E$ & \\
\hline $\begin{array}{l}\text { Ref ID: } \\
4386\end{array}$ & $\begin{array}{l}\text { Pendergrass } \\
\text { M. }\end{array}$ & $\begin{array}{l}\text { Does intensive } \\
\text { glycemic control } \\
\text { improve } \\
\text { cardiovascular } \\
\text { outcomes? Nat Clin } \\
\text { Pract Endocrinol } \\
\text { Metab 2008 } \\
\text { Oct;4(10):529. } \\
\end{array}$ & Anna/Ligia & $\mathrm{NE}$ & 1 \\
\hline Ref ID: & Perkovic V, & ADVANCE: lessons & Anna/Ligia & $E$ & \\
\hline
\end{tabular}




\begin{tabular}{|c|c|c|c|c|c|}
\hline $\begin{array}{l}\text { Ref ID: } \\
4398\end{array}$ & $\begin{array}{l}\text { Joshi R, Patel } \\
\text { A, Bompoint } \\
\text { S, Chalmers } \\
\text { J. } \\
\\
\text { Petrie JR. }\end{array}$ & \begin{tabular}{|l} 
from the run-in \\
phase of a large \\
study in type 2 \\
diabetes. Blood \\
Press \\
$2006 ; 15(6): 340-6$. \\
Follow-up of \\
intensive glucose \\
control in type 2 \\
diabetes. N Engl J \\
Med 2009 Jan \\
22;360(4):416-7. \\
\end{tabular} & Anna / Eliana & NE & 1 \\
\hline $\begin{array}{l}\text { Ref ID: } \\
2776\end{array}$ & $\begin{array}{l}\text { Pitale S, } \\
\text { Kernan SD, } \\
\text { Emanuele N, } \\
\text { Sawin C, } \\
\text { Sacks J, } \\
\text { Abraira C, et } \\
\text { al. }\end{array}$ & $\begin{array}{l}\text { Health-related } \\
\text { quality of life in the } \\
\text { VA Feasibility Study } \\
\text { on glycemic control } \\
\text { and complications } \\
\text { in type } 2 \text { diabetes } \\
\text { mellitus. Journal of } \\
\text { diabetes and its } \\
\text { complications } \\
2005 ; 19: 207-11 .\end{array}$ & Anna/Ligia & $E$ & \\
\hline $\begin{array}{l}\text { Ref ID: } \\
2913\end{array}$ & $\begin{array}{l}\text { Pitale SU, } \\
\text { Abraira C, } \\
\text { Emanuele } \\
\text { NV, } \\
\text { McCarren M, } \\
\text { Henderson } \\
\text { WG, Pacold I, } \\
\text { et al. }\end{array}$ & $\begin{array}{l}\text { Two years of } \\
\text { intensive glycemic } \\
\text { control and left } \\
\text { ventricular function } \\
\text { in the Veterans } \\
\text { Affairs Cooperative } \\
\text { Study in Type } 2 \\
\text { Diabetes Mellitus } \\
\text { (VA CSDM). } \\
\text { Diabetes Care } \\
\text { 2000;23:1316-20. }\end{array}$ & $\begin{array}{l}\text { Ana Denise / } \\
\text { Diogo }\end{array}$ & $E$ & \\
\hline $\begin{array}{l}\text { Ref ID: } \\
4430\end{array}$ & Pospisilova Y. & $\begin{array}{l}\text { A study of the } \\
\text { United Kingdom } \\
\text { Prospective } \\
\text { Diabetes Study and } \\
\text { its results]. Vnitr } \\
\text { Lek 2000 } \\
\text { Oct;46(10):709-14. } \\
\end{array}$ & Anna / Bruno & $E$ & \\
\hline $\begin{array}{l}\text { Ref ID: } \\
4440\end{array}$ & \begin{tabular}{|l} 
Preiser JC, \\
Brunkhorst F.
\end{tabular} & \begin{tabular}{|l|} 
Tight glucose \\
control and \\
hypoglycemia. Crit \\
Care Med 2008 \\
Apr;36(4):1391-2. \\
\end{tabular} & Anna / Eliana & NE & 1 \\
\hline $\begin{array}{c}\text { Ref ID: } \\
4471\end{array}$ & Reaven GM. & $\begin{array}{l}\text { Intensive blood } \\
\text { pressure/glucose } \\
\text { control in type } 2 \\
\text { diabetes: why is it } \\
\text { so difficult to } \\
\text { decrease coronary } \\
\text { heart disease? J } \\
\text { Hum Hypertens } \\
\text { 1999 Apr;13 Suppl } \\
\text { 2:S19-S23. } \\
\end{array}$ & Anna/Ligia & NE & 1 \\
\hline Ref ID: & Reichard P, & Intensified & Anna/Ligia & NE & 2 \\
\hline
\end{tabular}




\begin{tabular}{|c|c|c|c|c|c|}
\hline $\begin{array}{l} \\
\text { Ref ID: } \\
4488\end{array}$ & $\begin{array}{l}\text { Berglund B, } \\
\text { Britz A, Cars } \\
\text { I, Nilsson BY, } \\
\text { Rosenqvist U. } \\
\\
\text { Reyes EP. }\end{array}$ & $\begin{array}{l}\text { conventional insulin } \\
\text { treatment retards } \\
\text { the microvascular } \\
\text { complications of } \\
\text { insulin-dependent } \\
\text { diabetes mellitus } \\
\text { (IDDM): The } \\
\text { Stockholm Diabetes } \\
\text { Intervention Study } \\
\text { (SDIS) after } 5 \\
\text { years. J Intern Med } \\
\text { (GBR) } \\
1991 ; 230(2): 101-8 . \\
\text { Tighter glycemic } \\
\text { control saves lives, } \\
\text { reduces costs. Nurs } \\
\text { Manage 2007 } \\
\text { Apr;38(4):51, 70- } \\
51,71 .\end{array}$ & Anna / Diogo & NE & 1 \\
\hline $\begin{array}{c}\text { Ref ID: } \\
4530\end{array}$ & Ross PS. & $\begin{array}{l}\text { Intensive diabetes } \\
\text { treatment and } \\
\text { cardiovascular } \\
\text { disease. N Engl J } \\
\text { Med 2006 Apr } \\
20 ; 354(16): 1751-2 .\end{array}$ & Anna / Eliana & NE & 1 \\
\hline $\begin{array}{c}\text { Ref ID: } \\
4545\end{array}$ & $\begin{array}{l}\text { Ryden M, } \\
\text { Freyschuss } \\
\text { B. }\end{array}$ & $\begin{array}{l}\text { [Intensive glucose } \\
\text { control in type } 2 \\
\text { diabetes. The } \\
\text { benefit greater than } \\
\text { the risks?]. } \\
\text { Lakartidningen } \\
2008 \text { Oct } \\
15 ; 105(42): 2910-1 .\end{array}$ & Anna / Bruno & NE & 1 \\
\hline $\begin{array}{c}\text { Ref ID: } \\
4588\end{array}$ & $\begin{array}{l}\text { Scheen AJ, } \\
\text { Radermecker } \\
\text { RP, Philips } \\
\text { JC. }\end{array}$ & $\begin{array}{l}\text { [Effects of intensive } \\
\text { insulin therapy after } \\
\text { an acute } \\
\text { myocardial } \\
\text { infarction in patients } \\
\text { with type } 2 \\
\text { diabetes: results of } \\
\text { the DIGAMI-2 trial]. } \\
\text { Rev Med Liege } \\
2004 \\
\text { Sep;59(9):534-9. }\end{array}$ & Anna / Ligia & NE & 3 \\
\hline $\begin{array}{c}\text { Ref ID: } \\
4600\end{array}$ & \begin{tabular}{|l} 
Schiel R, \\
Muller UA.
\end{tabular} & $\begin{array}{l}\text { Intensive or } \\
\text { conventional insulin } \\
\text { therapy in type } 2 \\
\text { diabetic patients? A } \\
\text { population-based } \\
\text { study on metabolic } \\
\text { control and quality } \\
\text { of life (The JEVIN- } \\
\text { trial). Exp Clin } \\
\text { Endocrinol } \\
\text { Diabetes } \\
1999 ; 107(8): 506- \\
11 .\end{array}$ & Anna / Bruno & NE & 1 \\
\hline Ref ID: 76 & Sherman FT. & Tight blood glucose & Anna/Ligia & NE & 1 \\
\hline
\end{tabular}




\begin{tabular}{|c|c|c|c|c|c|}
\hline $\begin{array}{c}\text { Ref ID: } \\
6746\end{array}$ & $\begin{array}{l}\text { Shichiri M, } \\
\text { Kishikawa H, } \\
\text { Ohkubo Y, } \\
\text { Wake N. }\end{array}$ & \begin{tabular}{|l|} 
control (3). \\
Geriatrics \\
$2008 ; 63(10): 3$. \\
Long-term results of \\
the Kumamoto \\
Study on optimal \\
diabetes control in \\
type 2 diabetic \\
patients. Diabetes \\
Care 2000 Apr 23 \\
suppl 2 Barcelona, \\
Spain p. B21-B29.
\end{tabular} & Anna / Diogo & E & \\
\hline $\begin{array}{c}\text { Ref ID: } \\
4710\end{array}$ & Suarez Jl. & $\begin{array}{l}\text { Pro: Tight control of } \\
\text { blood glucose in the } \\
\text { brain-injured patient } \\
\text { is important and } \\
\text { desirable. J } \\
\text { Neurosurg } \\
\text { Anesthesiol } 2009 \\
\text { Jan;21(1):52-4. }\end{array}$ & Anna / Bruno & NE & 1 \\
\hline $\begin{array}{c}\text { Ref ID: } \\
4735\end{array}$ & Tambascia M. & $\begin{array}{l}\text { [Does the strict } \\
\text { blood glucose } \\
\text { control worsen } \\
\text { cardiovascular risk } \\
\text { in type } 2 \text { diabetes } \\
\text { ?]. Rev Assoc Med } \\
\text { Bras 2008 } \\
\text { Jan;54(1):1. }\end{array}$ & Anna / Eliana & NE & 1 \\
\hline $\begin{array}{c}\text { Ref ID: } \\
4763\end{array}$ & Tobey TA. & $\begin{array}{l}\text { Intensive glucose } \\
\text { control in type } 2 \\
\text { diabetes. N Engl J } \\
\text { Med 2008 Oct } \\
\text { 2;359(14):1520-1. }\end{array}$ & Anna / Eliana & NE & 1 \\
\hline $\begin{array}{c}\text { Ref ID: } \\
6387\end{array}$ & $\begin{array}{l}\text { Tosi F, } \\
\text { Muggeo M, } \\
\text { Brun E, } \\
\text { Spiazzi G, } \\
\text { Perobelli L, } \\
\text { Zanolin E, et } \\
\text { al. }\end{array}$ & $\begin{array}{l}\text { Combination } \\
\text { treatment with } \\
\text { metformin and } \\
\text { glibenclamide } \\
\text { versus single-drug } \\
\text { therapies in type } 2 \\
\text { diabetes mellitus: A } \\
\text { randomized, } \\
\text { double-blind, } \\
\text { comparative study. } \\
\text { Metabolism-Clinical } \\
\text { and Experimental } \\
\text { 2003;52(7):862-7. }\end{array}$ & Anna/Ligia & NE & 3 \\
\hline $\begin{array}{c}\text { Ref ID: } \\
6612\end{array}$ & $\begin{array}{l}\text { Trento M, } \\
\text { Passera P, } \\
\text { Tomalino M, } \\
\text { Bajardi M, } \\
\text { Pomero F, } \\
\text { Allione A, et } \\
\text { al. }\end{array}$ & $\begin{array}{l}\text { Group visits } \\
\text { improve metabolic } \\
\text { control in type } 2 \\
\text { diabetes - A 2-year } \\
\text { follow-up. Diabetes } \\
\text { Care } \\
2001 ; 24(6): 995- \\
1000 .\end{array}$ & Anna / Bruno & NE & 3 \\
\hline
\end{tabular}




\begin{tabular}{|c|c|c|c|c|c|}
\hline $\begin{array}{l}\text { Ref ID: } \\
2991\end{array}$ & $\begin{array}{l}\text { Turner R, Cull } \\
\text { C, Holman R. }\end{array}$ & $\begin{array}{l}\text { United Kingdom } \\
\text { Prospective } \\
\text { Diabetes Study 17: } \\
\text { a 9-year update of } \\
\text { a randomized, } \\
\text { controlled trial on } \\
\text { the effect of } \\
\text { improved metabolic } \\
\text { control on } \\
\text { complications in } \\
\text { non-insulin- } \\
\text { dependent diabetes } \\
\text { mellitus. Annals of } \\
\text { internal medicine } \\
\text { 1996;124:136-45. }\end{array}$ & \multirow[t]{2}{*}{ Anna / Eliana } & \multirow[t]{2}{*}{ E } & \\
\hline $\begin{array}{l}\text { Ref ID: } \\
1496\end{array}$ & Turner R. & $\begin{array}{l}\text { Intensive blood } \\
\text { glucose control } \\
\text { reduced type } 2 \\
\text { diabetes mellitus- } \\
\text { related end points: } \\
\text { Commentary. Evid - } \\
\text { Based Med } \\
\text { 1999;4(1):10-1. } \\
\end{array}$ & & & 1 \\
\hline $\begin{array}{l}\text { Ref ID: } \\
1803\end{array}$ & \begin{tabular}{|l} 
Turner RC, \\
Holman RR, \\
Mathews DR, \\
Oakes SF, \\
Bassett PA, \\
Stratton IM, et \\
al.
\end{tabular} & $\begin{array}{l}\text { UK Prospective } \\
\text { Diabetes Study } \\
\text { (UKPDS). VIII. } \\
\text { Study design, } \\
\text { progress and } \\
\text { performance. } \\
\text { Diabetologia } \\
1991 ; 34(12): 877- \\
90 . \\
\end{array}$ & $\begin{array}{l}\text { Ana Denise / } \\
\text { Diogo }\end{array}$ & $E$ & \\
\hline $\begin{array}{l}\text { Ref ID: } \\
1522\end{array}$ & $\begin{array}{l}\text { Turner RC, } \\
\text { Holman RR, } \\
\text { Cull CA, } \\
\text { Stratton IM, } \\
\text { Matthews DR, } \\
\text { Frighi V, et al. }\end{array}$ & $\begin{array}{l}\text { Intensive blood- } \\
\text { glucose control with } \\
\text { sulphonylureas or } \\
\text { insulin compared } \\
\text { with conventional } \\
\text { treatment and risk } \\
\text { of complications in } \\
\text { patients with type } 2 \\
\text { diabetes (UKPDS } \\
\text { 33). Lancet } \\
\text { 1998;352(9131):83 } \\
\text { 7-53. }\end{array}$ & Anna / Eliana & E & \\
\hline $\begin{array}{l}\text { Ref ID: } \\
6495\end{array}$ & $\begin{array}{l}\text { Turner RC, } \\
\text { Holman RR, } \\
\text { Stratton IM, } \\
\text { Cull CA, } \\
\text { Matthews DR, } \\
\text { Manley SE, et } \\
\text { al. }\end{array}$ & $\begin{array}{l}\text { Effect of intensive } \\
\text { blood-glucose } \\
\text { control with } \\
\text { metformin on } \\
\text { complications in } \\
\text { overweight patients } \\
\text { with type } 2 \text { diabetes } \\
\text { (UKPDS 34). } \\
\text { Lancet } \\
\text { 1998;352(9131):85 } \\
\text { 4-65. } \\
\end{array}$ & Anna / Eliana & $E$ & \\
\hline Ref ID: & Vaag AA. & Glycemic control & Anna / Bruno & E & \\
\hline
\end{tabular}




\begin{tabular}{|c|c|c|c|c|c|}
\hline $\begin{array}{c}4788 \\
\text { Ref ID: } \\
6806\end{array}$ & Vaaler S. & $\begin{array}{l}\text { and prevention of } \\
\text { microvascular and } \\
\text { macrovascular } \\
\text { disease in the } \\
\text { Steno } 2 \text { study. } \\
\text { Endocr Pract } 2006 \\
\text { Jan;12 Suppl 1:89- } \\
92 . \\
\text { Optimal glycemic } \\
\text { control in type } 2 \\
\text { diabetic patients - } \\
\text { Does including } \\
\text { insulin treatment } \\
\text { mean a better } \\
\text { outcome?Diabetes } \\
\text { Care. 2000 Apr;23 } \\
\text { Suppl 2:B30-4 } \\
\end{array}$ & Anna / Diogo & NE & 1 \\
\hline $\begin{array}{l}\text { Ref ID: } \\
4796\end{array}$ & Van den BG. & $\begin{array}{l}\text { Insulin vs. strict } \\
\text { blood glucose } \\
\text { control to achieve a } \\
\text { survival benefit } \\
\text { after AMI? Eur } \\
\text { Heart J 2005 } \\
\text { Apr;26(7):639-41. } \\
\end{array}$ & Anna / Diogo & $\mathrm{NE}$ & 1 \\
\hline $\begin{array}{l}\text { Ref ID: } \\
4797\end{array}$ & Van den BG. & $\begin{array}{l}\text { Does tight blood } \\
\text { glucose control } \\
\text { during cardiac } \\
\text { surgery improve } \\
\text { patient outcome? } \\
\text { Ann Intern Med } \\
2007 \text { Feb } \\
20 ; 146(4): 307-8 . \\
\end{array}$ & Anna / Diogo & NE & 1 \\
\hline $\begin{array}{l}\text { Ref ID: } \\
1508\end{array}$ & $\begin{array}{l}\text { Van Der Does } \\
\text { FEE, De } \\
\text { Neeling JND, } \\
\text { Snoek FJ, } \\
\text { Grootenhuis } \\
\text { PA, Kostense } \\
\text { PJ, Bouter } \\
\text { LM, et al. }\end{array}$ & $\begin{array}{l}\text { Randomized study } \\
\text { of two different } \\
\text { target levels of } \\
\text { glycemic control } \\
\text { within the } \\
\text { acceptable range in } \\
\text { type } 2 \text { diabetes: } \\
\text { Effects on well- } \\
\text { being at } 1 \text { year. } \\
\text { Diabetes Care } \\
\text { 1998;21(12):2085- } \\
93 \text {. }\end{array}$ & $\begin{array}{l}\text { Ana Denise / } \\
\text { Diogo }\end{array}$ & E & \\
\hline $\begin{array}{l}\text { Ref ID: } \\
4811\end{array}$ & Viberti G. & $\begin{array}{l}\text { [The need for strict } \\
\text { control of } \\
\text { cardiovascular risk } \\
\text { factors in type } 2 \\
\text { diabetic patients]. } \\
\text { Presse Med } 2002 \\
\text { Oct;31 Spec No } \\
\text { 2:S5-S8. }\end{array}$ & Anna / Ligia & NE & 1 \\
\hline $\begin{array}{l}\text { Ref ID: } \\
4814\end{array}$ & $\begin{array}{l}\text { Vijan S, Hofer } \\
\text { TP, Hayward } \\
\text { RA. }\end{array}$ & $\begin{array}{l}\text { Estimated benefits } \\
\text { of glycemic control } \\
\text { in microvascular } \\
\text { complications in } \\
\text { type } 2 \text { diabetes. } \\
\text { Ann Intern Med } \\
1997 \text { Nov }\end{array}$ & Anna / Eliana & NE & 1 \\
\hline
\end{tabular}




\begin{tabular}{|c|c|c|c|c|c|}
\hline $\begin{array}{l}\text { Ref ID: } \\
6412\end{array}$ & $\begin{array}{l}\text { Wake N, } \\
\text { Hisashige A, } \\
\text { Katayama T, } \\
\text { Kishikawa H, } \\
\text { Ohkubo Y, } \\
\text { Sakai M, et } \\
\text { al. }\end{array}$ & $\begin{array}{l}\text { 1;127(9):788-95. } \\
\text { Cost-effectiveness } \\
\text { of intensive insulin } \\
\text { therapy for type } 2 \\
\text { diabetes: a 10-year } \\
\text { follow-up of the } \\
\text { Kumamoto study. } \\
\text { Diabetes Res Clin } \\
\text { Pract } \\
2000 ; 48(3): 201-10 . \\
\end{array}$ & Anna / Eliana & $\mathrm{E}$ & \\
\hline $\begin{array}{c}\text { Ref ID: } \\
2526\end{array}$ & Ward JD. & $\begin{array}{l}\text { The role of strict } \\
\text { control of blood } \\
\text { glucose and nerve } \\
\text { function. Clin } \\
\text { Physiol 1985;5 } \\
\text { Suppl 5:85-9. } \\
\end{array}$ & ratos/humano & NE & \\
\hline $\begin{array}{c}\text { Ref ID: } \\
671\end{array}$ & $\begin{array}{l}\text { Weissman } \\
\text { AJ. }\end{array}$ & $\begin{array}{l}\text { Intensive diabetes } \\
\text { treatment and } \\
\text { cardiovascular } \\
\text { disease [8]. New } \\
\text { Engl J Med } \\
\text { 2006;354(16):1751. }\end{array}$ & Anna / Eliana & $\mathrm{NE}$ & 1 \\
\hline $\begin{array}{l}\text { Ref ID: } \\
6983\end{array}$ & $\begin{array}{l}\text { Wright A, } \\
\text { Burden ACF, } \\
\text { Paisey RB, } \\
\text { Cull CA, } \\
\text { Holman RR, } \\
\text { Grp UKP. }\end{array}$ & $\begin{array}{l}\text { Sulfonylurea } \\
\text { inadequacy - } \\
\text { Efficacy of addition } \\
\text { of insulin over } 6 \\
\text { years in patients } \\
\text { with type } 2 \text { diabetes } \\
\text { in the UK } \\
\text { Prospective } \\
\text { Diabetes Study } \\
\text { (UKPDS 57). } \\
\text { Diabetes Care } \\
\text { 2002;25(2):330-6. } \\
\end{array}$ & Anna / Eliana & $\mathrm{E}$ & \\
\hline $\begin{array}{l}\text { Ref ID: } \\
6313\end{array}$ & $\begin{array}{l}\text { Wright AD, } \\
\text { Cull CA, } \\
\text { Macleod KM, } \\
\text { Holman RR, } \\
\text { Grp U. }\end{array}$ & $\begin{array}{l}\text { Hypoglycemia in } \\
\text { type } 2 \text { diabetic } \\
\text { patients } \\
\text { randomized to and } \\
\text { maintained on } \\
\text { monotherapy with } \\
\text { diet, sulfonylurea, } \\
\text { metformin, or } \\
\text { insulin for } 6 \text { years } \\
\text { from diagnosis: } \\
\text { UKPDS73. J } \\
\text { Diabetes } \\
\text { Complications } \\
2006 ; 20(6): 395- \\
401 . \\
\end{array}$ & Anna / Eliana & $\mathrm{E}$ & \\
\hline $\begin{array}{l}\text { Ref ID: } \\
4907\end{array}$ & $\begin{array}{l}\text { Yang JM, } \\
\text { Guo XH, Yu } \\
\text { X. }\end{array}$ & $\begin{array}{l}\text { [Long-term } \\
\text { intensive glycemic } \\
\text { and lipid control } \\
\text { ameliorates the } \\
\text { carotid intima } \\
\text { medial thickness in } \\
\text { type } 2 \text { diabetes } \\
\text { mellitus]. Beijing Da }\end{array}$ & Anna / Bruno & $\mathrm{E}$ & \\
\hline
\end{tabular}




\begin{tabular}{|c|c|c|c|c|c|}
\hline $\begin{array}{l}\text { Ref ID: } \\
650\end{array}$ & $\begin{array}{l}\text { Yncen M, } \\
\text { Norhammar } \\
\text { A, Hjemdahl } \\
\text { P, Wallen NH. }\end{array}$ & $\begin{array}{l}\text { Xue Xue Bao } 2007 \\
\text { Dec 18;39(6):649- } \\
52 . \\
\\
\text { Effects of improved } \\
\text { metabolic control } \\
\text { on platelet reactivity } \\
\text { in patients with type } \\
2 \text { diabetes mellitus } \\
\text { following coronary } \\
\text { angioplasty. } \\
\text { Diabets Vasc Dis } \\
\text { Res 2006;3(1):52-6. }\end{array}$ & $\begin{array}{l}\text { Ana Denise / } \\
\text { Diogo }\end{array}$ & NE & 4 \\
\hline Ref ID: 2 & $\begin{array}{l}\text { Younis } \mathrm{N}, \\
\text { Soran H, } \\
\text { Hassanein M. }\end{array}$ & $\begin{array}{l}\text { Cardiovascular } \\
\text { disease and } \\
\text { intensive glucose } \\
\text { lowering in type } 2 \\
\text { diabetes. QJM } \\
2009 ; 102(4): 293-6 .\end{array}$ & Anna / Eliana & NE & 1 \\
\hline $\begin{array}{l}\text { Ref ID: } \\
7009\end{array}$ & Yudkin JS. & $\begin{array}{l}\text { The DREAM trial. } \\
\text { Lancet } \\
2006 ; 368(9552): 20 \\
49-50 .\end{array}$ & Anna / Eliana & NE & 1 \\
\hline $\begin{array}{c}\text { Ref ID: } \\
4924\end{array}$ & Yudkin JS. & $\begin{array}{l}\text { Very tight glucose } \\
\text { control: May be } \\
\text { high risk, low } \\
\text { benefit. BMJ } 2008 \\
\text { Mar } \\
29 ; 336(7646): 683 .\end{array}$ & Anna / Eliana & NE & 1 \\
\hline $\begin{array}{l}\text { Ref ID: } \\
4930\end{array}$ & Zarich SW. & $\begin{array}{l}\text { The role of } \\
\text { intensive glycemic } \\
\text { control in the } \\
\text { management of } \\
\text { patients who have } \\
\text { acute myocardial } \\
\text { infarction. Cardiol } \\
\text { Clin } 2005 \\
\text { May;23(2):109-17. }\end{array}$ & Anna / Eliana & NE & 1 \\
\hline $\begin{array}{l}\text { Ref ID: } \\
4936\end{array}$ & $\begin{array}{l}\text { Zhu J, Schott } \\
\text { M, Liu R, Liu } \\
\text { C, Shen B, } \\
\text { Wang Q, et } \\
\text { al. }\end{array}$ & $\begin{array}{l}\text { Intensive glycemic } \\
\text { control lowers } \\
\text { plasma visfatin } \\
\text { levels in patients } \\
\text { with type } 2 \\
\text { diabetes. Horm } \\
\text { Metab Res } 2008 \\
\text { Nov; } 40(11): 801-5 .\end{array}$ & Anna / Bruno & NE & 1 \\
\hline $\begin{array}{l}\text { Ref ID: } \\
4941\end{array}$ & $\begin{array}{l}\text { Zoungas S, } \\
\text { Kerr PG, Lui } \\
\text { M, Teede HJ. }\end{array}$ & $\begin{array}{l}\text { The impact of } \\
\text { glycaemic control } \\
\text { on outcomes in } \\
\text { patients with end- } \\
\text { stage renal disease } \\
\text { and type } 2 \\
\text { diabetes. } \\
\text { Nephrology } \\
\text { (Carlton ) } 2008 \\
\text { Apr;13(2):124-7. } \\
\end{array}$ & Anna / Eliana & NE & 1 \\
\hline
\end{tabular}




\begin{tabular}{|c|c|c|c|c|}
\hline 1 & \begin{tabular}{|l} 
Gaede P, \\
Vedel P, \\
Larsen N, \\
Jensen GV, \\
Parving HH, \\
Pedersen O. \\
\end{tabular} & \begin{tabular}{|l} 
Multifactorial \\
intervention and \\
cardiovascular \\
disease in patients \\
with type 2 \\
diabetes. \\
\end{tabular} & $\begin{array}{l}\text { N Engl J Med. } \\
2003 \text { Jan } \\
30 ; 348(5): 383- \\
93\end{array}$ & $E$ \\
\hline 2 & $\begin{array}{l}\text { Scheen AJ, } \\
\text { Estrella F. }\end{array}$ & $\begin{array}{l}\text { [Clinical trial of the } \\
\text { month. The STENO- } \\
2 \text { study: a plea for } \\
\text { global and } \\
\text { intensive } \\
\text { management of the } \\
\text { type } 2 \text { diabetic } \\
\text { patient] }\end{array}$ & $\begin{array}{l}\text { Rev Med Liege. } \\
2003 \\
\text { Feb;58(2):109- } \\
11 .\end{array}$ & EM FRANCES \\
\hline 3 & \begin{tabular}{|l} 
Gaede PH, \\
Jepsen PV, \\
Larsen JN, \\
Jensen GV, \\
Parving HH, \\
Pedersen OB. \\
\end{tabular} & \begin{tabular}{|l|} 
[The Steno-2 study. \\
Intensive \\
multifactorial \\
intervention \\
reduces the \\
occurrence of \\
cardiovascular \\
disease in patients \\
with type 2 \\
diabetes] \\
\end{tabular} & $\begin{array}{l}\text { Ugeskr Laeger. } \\
2003 \text { Jun } \\
23 ; 165(26): 265 \\
8-61\end{array}$ & $\begin{array}{l} \\
\text { EM } \\
\text { DINAMARQUES }\end{array}$ \\
\hline 4 & $\begin{array}{l}\text { Gaede } P, \\
\text { Beck M, } \\
\text { Vedel P, } \\
\text { Pedersen O. }\end{array}$ & $\begin{array}{l}\text { Limited impact of } \\
\text { lifestyle education } \\
\text { in patients with } \\
\text { Type } 2 \text { diabetes } \\
\text { mellitus and } \\
\text { microalbuminuria: } \\
\text { results from a } \\
\text { randomized } \\
\text { intervention study. }\end{array}$ & $\begin{array}{l}\text { Diabet Med. } \\
2001 \\
\text { Feb;18(2):104- } \\
8 .\end{array}$ & E \\
\hline 5 & $\begin{array}{l}\text { Origin Trial } \\
\text { Investigators, } \\
\text { Gerstein H, } \\
\text { Yusuf S, } \\
\text { Riddle MC, } \\
\text { Ryden L, } \\
\text { Bosch J. }\end{array}$ & \begin{tabular}{|l|} 
Rationale, design, \\
and baseline \\
characteristics for a \\
large international \\
trial of \\
cardiovascular \\
disease prevention \\
in people with \\
dysglycemia: the \\
ORIGIN Trial \\
(Outcome \\
Reduction with an \\
Initial Glargine \\
Intervention).
\end{tabular} & $\begin{array}{l}\text { Am Heart J. } \\
2008 \\
\text { Jan;155(1):26- } \\
32,32 . e 1-6 . \\
\text { Epub 2007 Nov } \\
26\end{array}$ & em andamento \\
\hline
\end{tabular}




\begin{tabular}{|c|c|c|c|c|}
\hline 6 & $\begin{array}{l}\text { C. Abraira et } \\
\text { al. }\end{array}$ & \begin{tabular}{|l} 
Design of the \\
cooperative study \\
on glycemic control \\
and complications \\
in diabetes mellitus \\
type 2 \\
Veterans Affairs \\
Diabetes Trial \\
\end{tabular} & $\begin{array}{l}\text { Journal of } \\
\text { Diabetes and } \\
\text { Its } \\
\text { Complications } \\
17 \text { (2003) 314- } \\
322 \\
\end{array}$ & $E$ \\
\hline 7 & 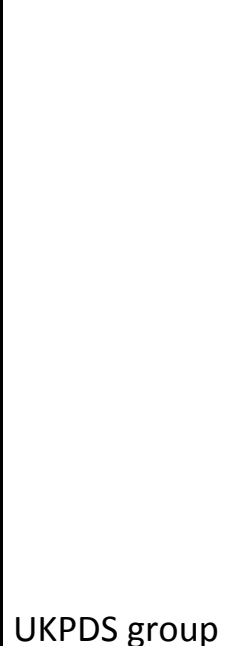 & $\begin{array}{l}\text { United Kingdom } \\
\text { Prospective } \\
\text { Diabetes Study } \\
\text { (UKPDS). 13: } \\
\text { Relative efficacy of } \\
\text { randomly allocated } \\
\text { diet, sulphonylurea, } \\
\text { insulin, or } \\
\text { metformin in } \\
\text { patients with newly } \\
\text { diagnosed non- } \\
\text { insulin dependent } \\
\text { diabetes followed } \\
\text { for three years. }\end{array}$ & $\begin{array}{l}\text { BMJ. } 1995 \text { Jan } \\
14 ; 310(6972): 8 \\
3-8 .\end{array}$ & $E$ \\
\hline
\end{tabular}

\section{LEGENDAS}

NE - não elegível

E - elegível

1 - Não é RTC

2 - Não incluiu DM II

3 - Não objetivou 2 níveis de intensidade

controle glicêmico

4 - Período seguimento inferior 1 ano 


\section{ANEXO A - CORRESPONDÊNCIAS COM AUTORES DOS ENSAIOS CLÍNICOS RANDOMIZADOS}

\section{Correspondência 1:}

De: Anushka Patel [mailto:apatel@ george.org.au]

Enviada em: terça-feira, 18 de agosto de 2009 20:04

Para: Anna Maria Buehler

Assunto: RE: individual events data from ADVANCE study to perform my metaanalyses

Dear Ms Buehler,

Thank you for your email. However, as you probably know, we are collaborating with the investigators of ACCORD, UKPDS and VADT to share data (recent publication in Diabetologia of the CONTROL collaboration) and, unfortunately, I am not in a position to share individual unpublished data presently.

I'm sorry I cannot be more helpful at this time.

Best wishes,

Anushka Patel

From: Anna Maria Buehler [mailto:abuehler@hcor.com.br]

Sent: Wednesday, 19 August 2009 8:36 AM

To: Anushka Patel

Subject: individual events data from ADVANCE study to perform my meta-analyses

Hi, Dr Patel,

First, congratulation for the ADVANCE trial and all the articles that you wrote about it. It's a methodological perfect randomized controlled trial! 
Let me introduce myself: I'm a research at Cardiac Hospital in Sao Paulo - Brazil and I'm doing a systematic review (other, unfortunately!) about intensive glucose control vs standard glucose control and I want to know if is possible that you send me some information regarding ADVANCE trial:

In your sub-group analyses, you use a combined macrovascular and microvascular events. Just for the follow baseline characteristics, do you have the individuals data for macrovascular and microvascular events?

- History of macrovascular disease

- History of microvascular disease

- Glycated hemoglobin

I will realy apreciated If you could send me this informations, because we will analyse the macro and micro events individually.

Many thanks

I'm waiting for your answer.

\section{Correspondência 2}

Hi Anna

Unfortunately I am not the custodian of the ACCORD data which is at the coordinating center in the US. I also can tell you that we are not able to provide any unpublished data until all of the ACCORD papers have been published and there are currently at least 10 in preparation including an update of the effect of glycemic control on outcomes.

Best of Luck

Hertzel C. Gerstein MD MSc FRCPC

HSC 3V38, 1200 Main St W

Hamilton, Ontario, L8N 3Z5 Canada

FAX: $\quad 905-521-4967$

Phone: 905-521-2100, 73371 
From: Anna Maria Buehler [mailto:abuehler@hcor.com.br]

Sent: Thursday, August 20, 2009 10:06 AM

To: Gerstein, Hertzel

Subject: data of ACCORD analyses requiring

\section{Hi, Dr Hertzel}

Let me introduce myself: I'm a (biochemistry) research at Cardiac Hospital in Sao Paulo, Brazil, and I'm doing a systematic review regarding intensive glucose control versus standard glucose control. Unfortunately, just on this year, we have already had 3 (including one that is yours) new systematic review about this clinical situation but, even I started my version since a few mounts, I will finish it.

For my surprise you work at McMaster University. My team work with Dr Deborah Cook (at PROTECT trial) and with Pj Deveraux (at VISION Registry) and others studies/meta-analyses.

At this moment, I will appreciated if you could provide some unpublished ACCORD data: In your subgroup analyses, you not show the number of events in the two groups intensive and standard, separately. I just need the individual data for only this two subgroups:

- Previous cardiovascular event (total number of event 393)

- Glycated hemoglobin at baseline $\leq 8,0 \%$ and $>8,0 \%$ (total number of event 284 and 438 , respectively)

I'm waiting for your answer.

Thanks for considering

\section{Correspondência 3}

De: Yang Jianmei [mailto:jianmeiyang20@yahoo.com]

Enviada em: domingo, 4 de outubro de 2009 07:15 
Para: Anna Maria Buehler

Assunto: [Suspeito SPAM - Re: ENC: data of your study Long-term intensive glycemic and lipid control ameliorates the carotid intima medial thickness in type 2 diabetes mellitus (for a meta-analyses)

Prioridade: Baixa

\section{Hi,Dr Buehler:}

Tnanks for your attenion.

This is on-goiong research, We investigate the microvascular envents and macrovascular events, but it hasn't reach our terminal point, untill now we have not results about microvascular and macrovascular data.

Best regards

Jianmeiyang

The first hospital Beijing University

--- On Tue, 9/29/09, Anna Maria Buehler <abuehler@hcor.com.br> wrote:

From: Anna Maria Buehler <abuehler@hcor.com.br>

Subject: ENC: data of your study Long-term intensive glycemic and lipid control ameliorates the carotid intima medial thickness in type 2 diabetes mellitus (for a metaanalyses)

To: jianmeiyang20@yahoo.com

Date: Tuesday, September 29, 2009, 10:50 PM

Hi, Dr Yang

I'm a research at Cardiac Hospital in São Paulo - Brazil - and I'm doing a systematic review regarding intensive glucose control versus standard glucose control. In my database review, I found your RTC "Long-term intensive glycemic and lipid control ameliorates the carotid intima medial thickness in type 2 diabetes mellitus" that have all of our eligibility criteria, but it doesn't investigate our outcome of interest. We are investigating macrovascular and microvascular events.

In this context, we would like to know if you have any data (and if you could provide 
this data), of the follow events:

- $\quad$ Total mortality

- Cardiovascular mortality

- $\quad$ Nonfatal MI

- $\quad$ Nonfatal stroke

- $\quad$ Nephropathy, retinopathy, neuropathy (any definition of)

- $\quad$ Any subgroup analyses

We will realy appreciated if you coul provide this data (if you have) because there are 2 systematic review published at this year that are incompleted because de research strategy are not ideal. We are trying to do a complete work (we ask to translate your article from Chinese to Portuguese,to acess the elegibility criteria ) and include all the trials that have been done in this context. If you provide this data for us (and if you wish), we can include your name at the authorship of the paper.

I wil waiting for your answer

Many thanks for considering

Anna Buehler

\section{Correspondência 4}

De: Gerstein, Hertzel [mailto:gerstein@mcmaster.ca]

Enviada em: quarta-feira, 7 de outubro de 2009 13:48

Para: Anna Maria Buehler

Assunto: RE: data of ACCORD analyses requiring 
Only the one paper was published so far.

The planned study duration is 6.5 years

Best Regards

Hertzel C. Gerstein MD MSc FRCPC

McMaster University Dept. of Medicine, HSC 3V38

1200 Main Street West

Hamilton, Ontario, L8N 3Z5, Canada

Phone: 905-521-2100, ext 73371

FAX: $905-521-4967$

From: Anna Maria Buehler [mailto:abuehler@hcor.com.br]

Sent: October 7, 2009 12:25 PM

To: Gerstein, Hertzel

Subject: RES: data of ACCORD analyses requiring

Hi, Dr Gerstein, how are you?

And about the ORIGIN study? I get the paper called "Rationale, design, and baseline characteristics for a large international trial of cardiovascular disease prevention in people with dysglycemia: the ORIGIN Trial (Outcome Reduction with an Initial Glargine Intervention)" that is eligible for my systematic review too but I don't find any information about how many years will be the follow up. Could you answer me this question, just to include this information in my research strategy discussion ? Do you have any other publication regarding ORIGIN study that I don't find?

Thanks for considering 
Anna Buehler

PharmD

De: Gerstein, Hertzel [mailto:gerstein@mcmaster.ca]

Enviada em: quinta-feira, 20 de agosto de 2009 13:55

Para: Anna Maria Buehler

Assunto: RE: data of ACCORD analyses requiring

Hi Anna

Unfortunately I am not the custodian of the ACCORD data which is at the coordinating center in the US. I also can tell you that we are not able to provide any unpublished data until all of the ACCORD papers have been published and there are currently at least 10 in preparation including an update of the effect of glycemic control on outcomes.

Best of Luck

Hertzel C. Gerstein MD MSc FRCPC

HSC 3V38, 1200 Main St W

Hamilton, Ontario, L8N $3 Z 5$ Canada

FAX: $\quad 905-521-4967$

Phone: 905-521-2100, 73371

From: Anna Maria Buehler [mailto:abuehler@hcor.com.br]

Sent: Thursday, August 20, 2009 10:06 AM

To: Gerstein, Hertzel

Subject: data of ACCORD analyses requiring

Hi, Dr Hertzel

Let me introduce myself: I'm a (biochemistry) research at Cardiac Hospital in Sao Paulo, Brazil, and I'm doing a systematic review regarding intensive glucose control 
versus standard glucose control. Unfortunately, just on this year, we have already had 3 (including one that is yours) new systematic review about this clinical situation but, even I started my version since a few mounts, I will finish it.

For my surprise you work at McMaster University. My team work with Dr Deborah Cook (at PROTECT trial) and with Pj Deveraux (at VISION Registry) and others studies/meta-analyses.

At this moment, I will appreciated if you could provide some unpublished ACCORD data: In your subgroup analyses, you not show the number of events in the two groups intensive and standard, separately. I just need the individual data for only this two subgroups:

- Previous cardiovascular event (total number of event 393)

- Glycated hemoglobin at baseline $\leq 8,0 \%$ and $>8,0 \%$ (total number of event 284 and 438, respectively)

I'm waiting for your answer.

Thanks for considering

\section{Correspondência 5}

De: Peter Haulund Gæde [mailto:peter.gaede@dadlnet.dk]

Enviada em: quarta-feira, 21 de outubro de 2009 08:35

Para: Anna Maria Buehler

Assunto: SV: data of steno-2 study for systematic reviw

Hi Anna

I will look into things and give you an answer. However in my copy of the 1999 paper there is an increase of $0.2 \%$ in the standard group and a decline of $0.8 \%$ in the table. I will write back soon.

Best regards - Peter

Fra: Anna Maria Buehler [abuehler@hcor.com.br]

Sendt: 21. oktober 2009 14:17 


\section{Til: Peter Haulund Gæde}

Emne: data of steno-2 study for systematic reviw

Hi, Dr Gaede, how are you?

I'm a clinical research at Cardiac Hospital from Sao Paulo - Brazil, and I'm doing a systematic review about intensive glycemic control versus conventional control in DMII patient and your study was eligible for my study. In this context, I identified 2 principal publications: one at Lancet (1999) and other at NEJM (2003) otherwise the outcomes are different.

I need to know something that I can't understand. I will really appreciated if you could help me in the follows:

In the original study (1999) you show a table 4 - changes at the end of study variables. When I analyze the values of $\mathrm{HbA1c}$, how can I interpret this data? The intensive group had a increase in HbA1c about $0.8 \%$ compared to standard group that had a increase of $0.2 \%$ ? (The baseline value were $8.4 \%$ for intensive group and $8,8 \%$ for standard group so the values for the end of study was $9.2 \%$ for intensive group and $9,0 \%$ for standard group?). If this interpretation is correct, how do you explain the graphics in other publication (2003) - Figure 2 - that showed all the time the minor value of HbA1c in intensive group compared with standard group? Or the 0.2 and 0.8 referred to decrease at $\mathrm{HbA1c}$ ? Could you clarify this data for me, please?

The data of withdrew the consent are not the same in the 2 publications (at 1999 publication you show a withdrew consent of 3 patient at intensive group and a withdrew consent of 2 patients at conventional group; at 2003 publication, you show a withdrew consent of 2 patient at conventional group and 1 withdrew consent at intensive group). Could you clarify this data for me, please?

In the 2003 publication, as intention to treat analyses, do you consider a total patient as 78 in conventional group or 63? And at intensive group, do you consider the total patients as 79 at intensive group or 67? Do you have a table with individual data like the table 5 that you show on the steno-2 study (1999)? 
I really need this information to include your study in our systematic review. There are 2 recent systematic review about this issue (both in 2009) but the research strategies was incomplete and your study is not included in these publications.

I'm waiting for your answer as soon as possible.

I really like to say thank you very much for your help.

Best regards

Anna Buehler - PharmD 